COMMERCIAL-SCALE DEMONSTRATION OF THE LIQUID PHASE METHANOL (LPMEOH ${ }^{\top \mathrm{M}}$ ) PROCESS

FINAL REPORT

(Volume 2: Project Performance and Economics) for the period 16 October 1992 - 30 June 2003

Prepared by:

E. C. Heydorn and B. W. Diamond Air Products and Chemicals, Inc.

Allentown, PA

and

R. D. Lilly

Eastman Chemical Company

Kingsport, $T N$

for the

Air Products Liquid Phase Conversion Company, L.P. 7201 Hamilton Blvd.

Allentown, PA 18195-1501

June 2003

Prepared for the United States Department of Energy

National Energy Technology Laboratory

Under Cooperative Agreement No. DE-FC22-92PC 90543

R. M. Kornosky, Contracting Officer's Representative 


\section{DISCLAIMER}

This report was prepared by Air Products \& Chemicals, Inc. and Eastman Chemical Company for the Air Products Liquid Phase Conversion Company, L.P., pursuant to a Cooperative Agreement partially funded by the U.S. Department of Energy, and neither Air Products \& Chemicals, Inc., Eastman Chemical Company, the Air Products Liquid Phase Conversion Company, L.P., nor any of their subcontractors nor the U.S. Department of Energy, nor any person acting on behalf of either:

(A) Makes any warranty or representation, express or implied, with respect to the accuracy, completeness, or usefulness of the information contained in this report, or that the use of any information, apparatus, method, or process disclosed in this report may not infringe privately owned rights; or

(B) Assumes any liabilities with respect to the use of, or for damages resulting from the use of, any information, apparatus, method, or process disclosed in this report.

Reference herein to any specific commercial product, process, or service by trade name, trademark, manufacturer, or otherwise, does not necessarily constitute its endorsement, recommendation, or favoring by the U.S. Department of Energy. The views and opinions of authors expressed herein does not necessarily state or reflect those of the U.S. Department of Energy. 


\begin{abstract}
This project, which was sponsored by the U.S. Department of Energy (DOE) under the Clean Coal Technology Program to demonstrate the production of methanol from coal-derived synthesis gas (syngas), has completed the 69-month operating phase of the program. The purpose of this Final Report for the "Commercial-Scale Demonstration of the Liquid Phase Methanol (LPMEOH ${ }^{\mathrm{TM}}$ ) Process" is to provide the public with details on the performance and economics of the technology. The LPMEOH ${ }^{\mathrm{TM}}$ Demonstration Project was a $\$ 213.7$ million cooperative agreement between the DOE and Air Products Liquid Phase Conversion Company, L.P. (the Partnership). The DOE's cost share was $\$ 92,708,370$ with the remaining funds coming from the Partnership. The LPMEOH ${ }^{\mathrm{TM}}$ demonstration unit is located at the Eastman Chemical Company (Eastman) chemicals-from-coal complex in Kingsport, Tennessee.
\end{abstract}

The technology was the product of a cooperative development effort by Air Products and Chemicals, Inc. (Air Products) and DOE in a program that started in 1981. Developed to enhance electric power generation using integrated gasification combined cycle (IGCC) technology, the LPMEOH ${ }^{\mathrm{TM}}$ Process is ideally suited for directly processing gases produced by modern coal gasifiers. Originally tested at the Alternative Fuels Development Unit (AFDU), a small, DOE-owned process development facility in LaPorte, Texas, the technology provides several improvements essential for the economic coproduction of methanol and electricity directly from gasified coal. This liquid phase process suspends fine catalyst particles in an inert liquid, forming a slurry. The slurry dissipates the heat of the chemical reaction away from the catalyst surface, protecting the catalyst, and allowing the methanol synthesis reaction to proceed at higher rates.

The LPMEOH ${ }^{\mathrm{TM}}$ Demonstration Project accomplished the objectives set out in the Cooperative Agreement with DOE for this Clean Coal Technology project. Overall plant availability (defined as the percentage of time that the LPMEOH ${ }^{\mathrm{TM}}$ demonstration unit was able to operate, with the exclusion of scheduled outages) was $97.5 \%$, and the longest operating run without interruption of any kind was 94 days. Over 103.9 million gallons of methanol was produced; Eastman accepted all of the available methanol for use in the production of methyl acetate, and ultimately cellulose acetate and acetic acid.

The slurry bubble column reactor was successfully scaled from the 10 short tons-per-day (sT/D) LaPorte AFDU to the 260 sT/D or 80,000 gallons-per-day LPMEOH ${ }^{\mathrm{TM}}$ demonstration unit. Over the first 4 years of operation, the catalyst deactivation rate averaged 0.6 to $0.7 \%$ per day, which was higher than the basis for the design of the LPMEOH ${ }^{\mathrm{TM}}$ demonstration unit obtained from the LaPorte AFDU ( $0.4 \%$ per day). Engineering and laboratory efforts focused on the removal of trace contaminants in coal-derived synthesis gas (syngas), and the development of a procedure to activate a full charge of catalyst in the LPMEOH ${ }^{\mathrm{TM}}$ reactor (in-situ activation) followed by temperature programming (the increase of reactor temperature as necessary to maintain the desired methanol production rate) could reduce the capital cost by as much as 10 percent. Over the last 6 months of operation, these improvements demonstrated the potential to reduce the design basis for catalyst deactivation rate by $50 \%$. Because the impact of catalyst cost on the economics of methanol production is significant (reducing the rate of catalyst deactivation to $0.2 \%$ per day can realize a 25 percent reduction in variable cost), this 
performance demonstrated the potential of the $\mathrm{LPMEOH}^{\mathrm{TM}}$ process to meet the targets for catalyst consumption utilizing coal-derived syngas. Over the demonstration period, tests were successfully performed at a variety of conditions anticipated in IGCC/ coproduction applications (catalyst withdrawal and addition to maintain the desired methanol production rate, operation on a carbon monoxide (CO)-rich syngas feed, ramping, and on-off operation).

Methanol from the LPMEOH ${ }^{\mathrm{TM}}$ Demonstration Project was also used to conduct product-use testing to demonstrate how a centrally located clean coal electric power plant with methanol coproduct could provide energy services to local communities. Product-use testing proved that coal-derived methanol, free of sulfur and other impurities, could be used one day as a replacement for petroleum in transportation, a peaking fuel in combustion turbines IGCC power plants, a hydrogen $\left(\mathrm{H}_{2}\right)$ source for small fuel cells, or as a chemical feedstock.

As a secondary objective to the LPMEOH ${ }^{\mathrm{TM}}$ Demonstration Project, design verification testing was completed to evaluate capability of the slurry bubble column reactor to produce dimethyl ether (DME) as a coproduct with methanol using the Liquid Phase Dimethyl Ether (LPDME ${ }^{\mathrm{TM}}$ ) Process. The LPDMETM Process uses a physical mixture of a commercial methanol catalyst and a commercial dehydration catalyst in a single slurry reactor. During a 25-day design verification test at the LaPorte AFDU in 1999, the rate of catalyst deactivation for both the methanol synthesis and dehydration catalysts were slightly higher than the results for the LPMEOH ${ }^{\mathrm{TM}}$ Process from the first 3 weeks of the 4-month proof-of-concept run at the LaPorte AFDU in 1988/89. Follow-up economic analysis showed that attractive economics for DME can likely be achieved at plant sizes approaching 1,100 sT/D. The program participants agreed that additional work on DME should be deferred so that all resources could be directed toward improving the catalyst performance for the $\mathrm{LPMEOH}^{\mathrm{TM}}$ Process during the remaining time within the operating program.

In evaluating the economics for the technology, studies showed that methanol from the LPMEOH $^{\text {TM }}$ Process can be coproduced with IGCC power at less than $\$ 0.50$ per gallon. If the improvement in catalyst performance from the last 6 months of operation can be extrapolated, the variable cost of production of methanol can be reduced by $25 \%$ over the current basis for future plants. Together, IGCC and $\mathrm{LPMEOH}^{\mathrm{TM}}$ technologies will be able to fill local needs for electric power, transportation fuels, and manufactured chemical products. 


\section{ACKNOWLEDGEMENTS}

We would like to acknowledge the contributions made to the project by the following individuals during the operating phase of the project:

Air Products and Chemicals, Inc.

Edward Heydorn

Barry Diamond

VanEric Stein

Bharat Bhatt

Bernard Toseland

Robert Quinn

Xiang-Dong Peng

Fred Lucrezi

The Laboratory and Analytical Teams at Air Products

\section{Eastman Chemical Company}

William Jones

Ronnie Lilly

Barry Street

Travis Smith

Chuck Crawford

Richard Ramsey

The Operations and Maintenance Teams for Plant 29

\section{U.S. Department of Energy}

Robert Kornosky

William O'Dowd

Richard Hargis

Edward Schmetz

John Shen 


\section{POINT OF CONTACT}

Air Products and Chemicals, Inc., is the licensor of the LPMEOH ${ }^{\mathrm{TM}}$ technology. Listed below are two individuals to contact for more information on commercial applications:

Name

Department

Phone No.

E-mail

Robert J. Kirkland

Worldwide Hydrocarbon

$610-481-4866$

kirklarj@apci.com

Equipment - Services

Zoltan S. Pukanecz

Intellectual Asset

610-481-3639 pukanezs@apci.com

Management \& Licensing

Address for both:

Air Products and Chemicals, Inc.

7201 Hamilton Blvd.

Allentown, PA 18195-1501 


\section{TABLE OF CONTENTS}

Abstract
Acknowledgments
Point of Contact
List of Tables
List of Figures
List of Abbreviations
List of Units
Glossary of Terms
Executive Summary

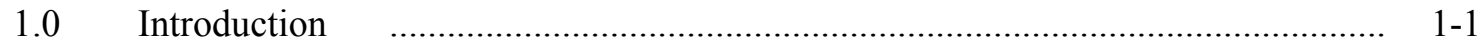

1.1 Purpose of the Project Performance and Economics Report...................... 1-1

$1.2 \quad$ Overview of the Project.................................................................... $1-1$

1.2.1 Background and History of the Project ...................................... $1-1$

1.2.2 Project Organization.......................................................... 1-3

1.2.3 Project Description................................................................ $1-4$

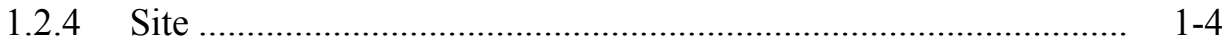

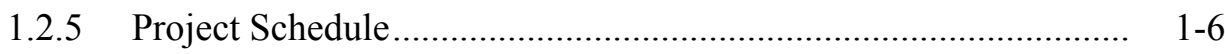

$1.3 \quad$ Objectives of the Project …................................................................. $1-8$

1.3.1 Primary Objective …............................................................ $1-8$

1.3.2 Secondary Objective …...................................................... $1-8$

$1.4 \quad$ Significance of the Project ................................................................. 1-10

$1.5 \quad$ DOE's Role in the Project..................................................................... $1-11$

1.5.1 Clean Coal Technology Program .............................................. 1-11

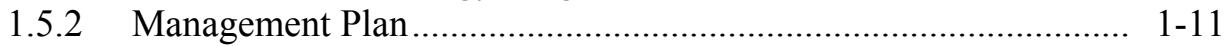

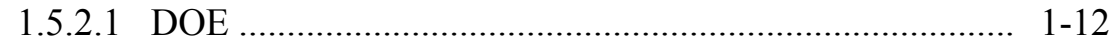

1.5.2.2 The Partnership ............................................................. $1-12$

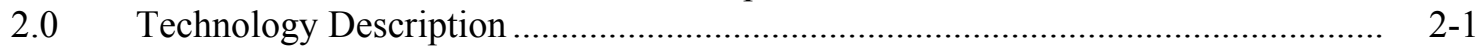

$2.1 \quad$ Description of the Demonstrated Technology......................................... 2-1

$2.2 \quad$ Description of the Demonstration Facility ….......................................... 2-3

$2.3 \quad$ Proprietary Information................................................................... 2-3

$2.4 \quad$ Simplified Process Flow Diagram......................................................... 2-4

$2.5 \quad$ Stream Data ............................................................................... 2-4

2.6 Process and Instrumentation Diagrams ................................................. 2-4

3.0 Update of the Public Design Report................................................................ $3-1$

3.1 Design and Equipment Changes .......................................................... 3-1

3.1.1 Condensed Oil (29G-01) and Oil Makeup (29G-03) Pumps ......... 3-2

3.1.2 Slurry Return Pump (29G-02) ................................................. 3-3

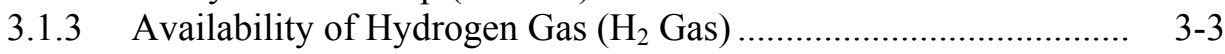

3.1.4 Gas Sparger .................................................................... 3-4

3.2 Demonstration Plant Equipment Cost Update....................................... 3-4

3.3 Demonstration Plant Operating Cost Update .......................................... 3-5

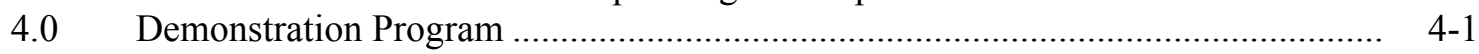

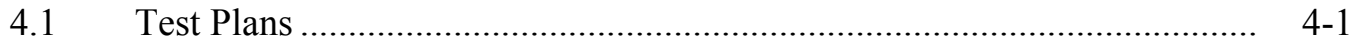

$4.2 \quad$ Operating Procedures .................................................................. $4-2$

4.2.1 Instrumentation and Data Acquisition....................................... 4-8 


\section{TABLE OF CONTENTS (cont'd)}

4.2.2 Test Methods .................................................................. 4-8

4.3 Analysis of Feedstocks, Products and Reagents ..................................... 4-8

4.4 Data Analysis Methodology ................................................................ 4-9

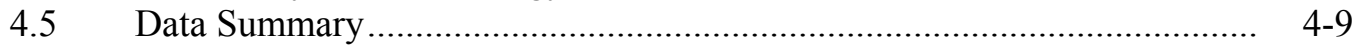

4.6 Operability and Reliability ............................................................. 4-10

4.7 Section 4 Bibliography.................................................................... 4-12

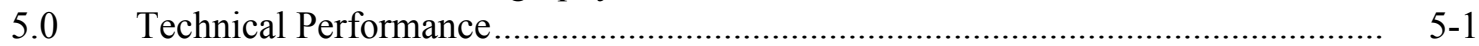

5.1 Catalyst Performance ............................................................................ 5 5

5.1.1 Catalyst Performance: Catalyst Campaign 1 ............................. 5-2

5.1.2 Catalyst Performance: Catalyst Campaign 2 ............................. 5-4

5.1.3 Catalyst Performance: Catalyst Campaign 3 .............................. 5-8

5.1.4 Catalyst Performance: Catalyst Campaign 4 ............................. 5-10

5.1.5 Summary .......................................................................... 5-11

5.2 Identification and Removal of Trace Contaminants in Coal-Derived......... 5-13 Syngas

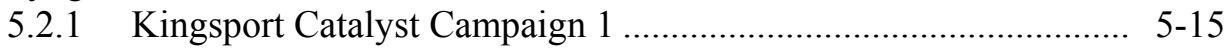

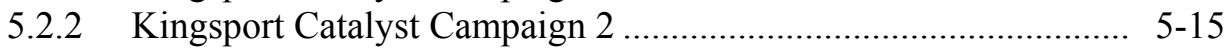

5.2.3 Kingsport Catalyst Campaign 3 ........................................... 5-20

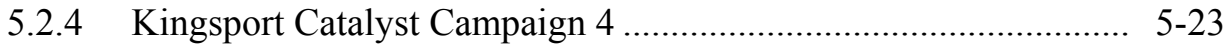

5.2.5 Summary …........................................................ $5-24$

5.3 Gas Sparger Performance ................................................................ $\quad 5-25$

5.3.1 Initial Sparger Design (April - November 1997)......................... 5-25

5.3.2 Second Sparger Design (December 1997 - February 1999) .......... 5-28

5.3.3 Current Sparger Design (March 1999 - Present) ............................ 5-29

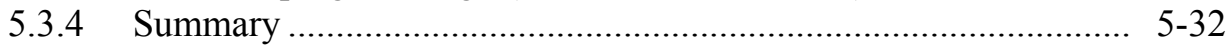

5.4 Process Variable Tests: $\mathrm{H}_{2}: \mathrm{CO}$ Ratio ................................................ 5-33

5.5 Ramping and On/Off Testing ......................................................... 5-35

5.6 In-Situ Activation and Temperature Programming.................................. 5-37

5.6.1 Preparatory Engineering and Laboratory Work ........................... 5-37

5.6.2 In-situ Activation Procedure and Results - August 2001 .............. 5-38

5.6.3 Temperature Programming (August 2001 - March 2002) ............. 5-40

5.6.4 Second In-situ Activation Procedure and Results (June 2002) ...... 5-40

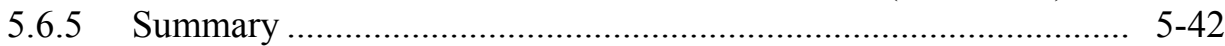

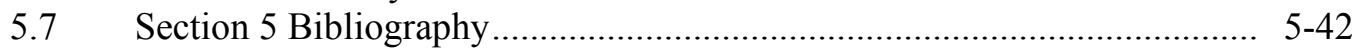

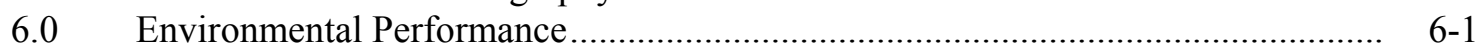

6.1 Introduction ...............................................................

6.2 Waste Streams and Their Disposal..................................................... 6-1

6.2.1 Spent Catalyst Slurry ............................................................ 6-1

6.2.2 10C-30 Catalyst Guard Bed ................................................. 6-3

6.2.3 29C-40 Carbonyl Guard Bed ..................................................... 6-3

6.2.4 Waste Oil......................................................................... 6

6.2.5 Recovered Distillation Liquids............................................. $\quad 6-5$

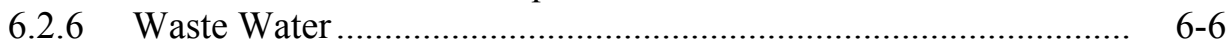

6.3 Potential Environmental Concerns ......................................................... $6-6$

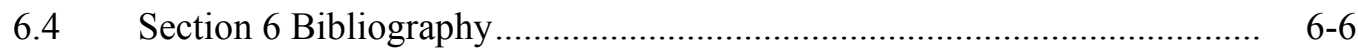




\section{TABLE OF CONTENTS (cont'd)}

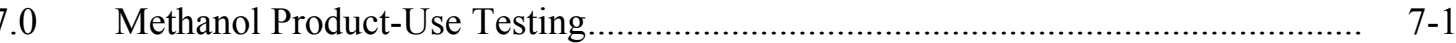

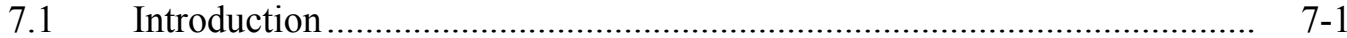

7.2 On-Site Testing of Methanol.................................................................. 7-2

7.3 Off-Site Testing of Methanol ….............................................................

7.3.1 Transportation Systems ............................................................. 7-5

7.3.1.1 Florida Institute of Technology Bus \& Light Vehicles.... 7-5

7.3.1.2 ARCADIS Geraghty \& Miller Flexible Fuel Vehicle...... 7-5

7.3.1.3 West Virginia University Study of Stabilized Methanol

in Transit Bus ..........................................................

7.3.2 Power Generation Systems................................................... 7-8

7.3.2.1 West Virginia University Stationary Gas Turbine .......... 7-8

7.3.2.2 Aircraft Ground Support Equipment.............................. 7-10

7.3.2.3 Low- $\mathrm{NO}_{\mathrm{x}}$ Stationary Microturbine Combustor................ 7-12

7.3.2.4 University of Florida Fuel Cell ...................................... 7-14

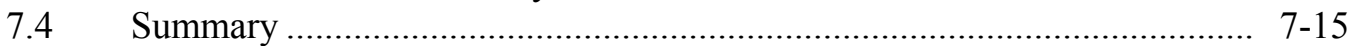

7.5 Section 7 Bibliography .............................................................. 7-16

8.0 Liquid Phase Dimethyl Ether (LPDMETM) Design Verification Testing (DVT).... 8-1

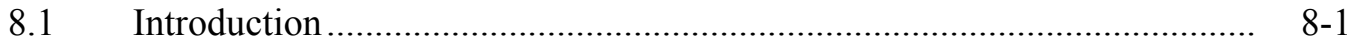

8.2 DME Market Studies.................................................................... 8-2

8.3 DVT Economic Studies.................................................................... 8

$8.4 \quad$ DVT Catalyst Studies..................................................................... 8-3

8.5 1999 LPDMETM Process Design Verification Test Run ........................... 8-4

8.6 DME DVT Conclusions ................................................................. $8-8$

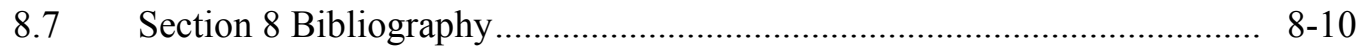

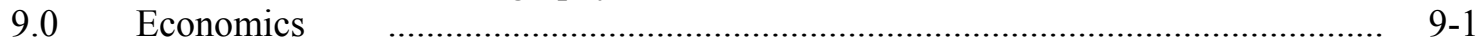

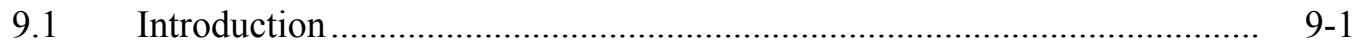

9.2 Estimated Process Capital Costs .............................................................. 9-3

9.3 Projected Operating and Maintenance Costs............................................... 9-5

9.4 Summary of Performance and Economics .................................................. 9-6

9.5 Effect of Variables on Economics.............................................................. 9-6

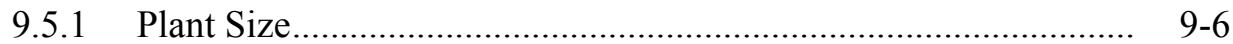

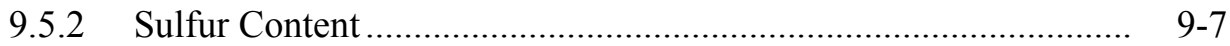

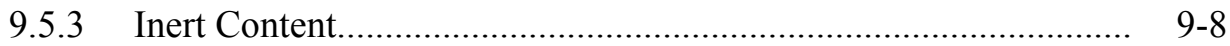

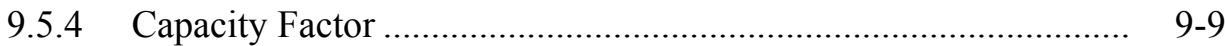

9.6 Section 9 Bibliography............................................................... 9-10

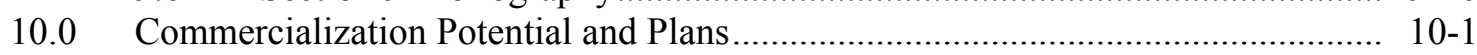

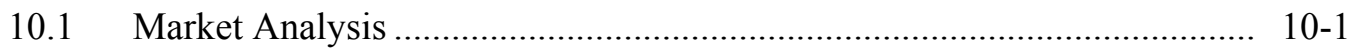

10.1.1 Applicability of the Technology .............................................. 10 10

10.1.2 Market Size and Barriers............................................................. 10-3

10.1.3 Economics Comparison with Competing Technologies ............... 10-4

10.2 Commercialization Plans.............................................................. 10 10

10.3 Section 10 Bibliography .......................................................... 10-6

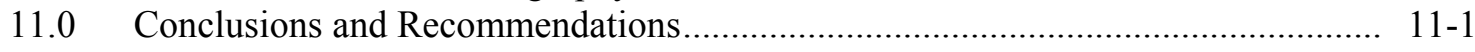

12.0 Other Project Reports and Publications......................................................... 12-1 


\section{APPENDICES}

Appendix A Analytical Measurements for LPMEOH ${ }^{\mathrm{TM}}$ Demonstration Unit Appendix B Sample Material Balances from LPMEOH ${ }^{\mathrm{TM}}$ Demonstration Unit Appendix C Details on Data Analysis Methodology

Appendix D Data Summary Tables 


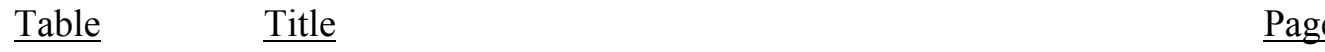

2.5-1 Heat and Material Balance Summary 2-6

3.2-1 Kingsport LPMEOH ${ }^{\mathrm{TM}}$ Demonstration Unit - Update of 3-5

3.3-1 Kingsport LPMEOH 1 Temonstration Unit - Update of

4.1-1 Test Conditions at LPMEOH ${ }^{\mathrm{TM}}$ Demonstration Unit 4-3

4.6-1 LPMEOH ${ }^{\mathrm{TM}}$ Demonstration Unit Availability and Causes of 4-10

5.1-1 Kingsport LPMEOH $\quad$ 5-1

5.2.1-1 Kingsport Catalyst Campaign 1-Elemental Composition of $\quad 5-15$

5.2.2-1 Elemental Analysis Results for Spent Activated Carbon from 5-17

5.2.2-2 Analysis of Fresh and Spent Manganese Dioxide from 29C-40 5-18

Carbonyl Guard Bed (11 August 1999)

5.2.2-3 Analysis of Fresh and Spent Activated Carbon from 29C-40 5-18

5.2.3-1 Analysis of Fresh and Spent $\mathrm{Cu} / \mathrm{C}$ Adsorbent from 29C-40 5-22

5.2.4-1 Kingsport Catalyst Campaign 4 - Elemental Composition of 5-23

5.4-1 Kingsport LPMEOH ${ }^{\mathrm{TM}}$ Process - $\mathrm{H}_{2}$ :CO Ratio Testing 5-34

6.2-1 Spent Catalyst Slurry from LPMEOH ${ }^{\text {TM }}$ Demonstration Unit $\quad 6-2$

6.2-2 10C-30 Catalyst Guard Bed - Adsorbents Used during 6-3

6.2-3 29C-40 Carbonyl Guard Bed - Adsorbents Used during 6-4

Operation of LPMEOH ${ }^{\mathrm{TM}}$ Demonstration Unit

6.2-4 Waste Oil from LPMEOH ${ }^{\mathrm{TM}}$ Demonstration Unit 6-5

6.2-5 Oil Collected in Distillation Equipment from LPMEOH ${ }^{\mathrm{TM}} \quad 6-5$

7.2-1 Refined-Grade Methanol from LPMEOH ${ }^{\text {TM }}$ Demonstration $\quad$ 7-3

7.3-1 Stabilized Methanol Composition - CO-rich Feed Gas $\quad$ 7-4

7.3.1-1 ARCADIS Geraghty \& Miller FFV Fuel Economy Results 7-6

7.3.1-2 ARCADIS Geraghty \& Miller FFV Emissions Results 7-6

7.3.1-3 West Virginia University - Tri-Boro Coach Emissions 7-8

8.6-1 LPDME ${ }^{\mathrm{TM}}$ Goals and Performance Results (Laboratory and 8-9

AFDU)

9.2-1 Estimated Facility Investment Summary for Once-Through $\quad 9-4$

500 sT/D LPMEOH ${ }^{\mathrm{TM}}$ Plant

9.3-1 Projected Operating and Maintenance Costs for Once-Through 9-5 500 sT/D LPMEOHTM Plant

10.1.2-1 Market Forecast for Methanol 10-3

10.1.3-1 Baseload Coproduction, 500 sT/D, Fuel Grade Methanol 10-5 


\section{LIST OF TABLES (cont'd)}

$\begin{array}{lll}\text { A-1 } & \begin{array}{l}\text { Summary of Streams to be Analyzed for Material Balance } \\ \text { Calculations }\end{array} & \text { A-2 } \\ \text { C-1 } & \begin{array}{l}\text { Summary of Data for Typical Material and Energy Balance } \\ \text { and Reactor Performance Assessment }\end{array} & \text { C-2 } \\ \text { D-1 } & \begin{array}{l}\text { Data Summary for Kingsport Catalyst Campaign 1 } \\ \text { D-2 }\end{array} & \text { D-2 } \\ \text { D-3 } & \begin{array}{l}\text { Data Summary for Kingsport Catalyst Campaign 2 } \\ \text { D-4 }\end{array} & \text { D-5 } \\ & \text { Data Summary for Kingsport Catalyst Campaign 3 } & \text { D-26 } \\ \end{array}$


1.2.2-1 $\quad$ LPMEOH $^{\mathrm{TM}}$ Demonstration Project Organization 1-3

1.2.3-1 Integration of Existing Facilities with LPMEOH ${ }^{\mathrm{TM}} \quad 1-5$

1.2.4-1 Photograph of Eastman Chemical Company's $1-6$

1.2.5-1 LPMEOH ${ }^{\text {TM }}$ Demonstration Project Schedule 1-9

1.5.2-1 Kingsport LPMEOH ${ }^{\mathrm{TM}}$ Demonstration Project Operating 1-13

2.1-1 Gas-Phase Methanol Reactors 2-2

2.1-2 $\quad$ LPMEOH $^{\text {TM }}$ Reactor Schematic $\quad 2-2$

2.4-1 $\quad$ LPMEOH $^{\text {TM }}$ Demonstration Unit Simplified Process Flow 2-5

4.1-1 $\quad$ LPMEOH $^{\text {TM }}$ Demonstration Test Plan Schedule of Tests 4-4

5.1.1-1 Kingsport LPMEOH ${ }^{\text {TM }}$ Catalyst Life (Catalyst Campaign 1) 5-2

5.1.2-1 Kingsport LPMEOH ${ }^{\mathrm{TM}}$ Catalyst Life (Catalyst Campaign 2: $\quad$ 5-4 1997-1998)

5.1.2-2 Kingsport LPMEOH ${ }^{\text {TM }}$ Catalyst Life (Catalyst Campaign 2: $\quad$ 5-6 1999)

5.1.2-3 Kingsport LPMEOH ${ }^{\text {TM }}$ Catalyst Life (Catalyst Campaign 2: $\quad$ 5-7 2000-2001)

5.1.3-1 Kingsport LPMEOH ${ }^{\text {TM }}$ Catalyst Life (Catalyst Campaign 3) 5-9

5.1.4-1 Kingsport LPMEOH ${ }^{\mathrm{TM}}$ Catalyst Life (Catalyst Campaign 4) 5-10

5.2-1 Photograph of Alternative Fuels Field Test Unit (AFFTU) 5-14

5.2.2-1 Kingsport Catalyst Campaign 2 - Trace Contaminant 5-16

5.2.2-2 Effect of Arsine Concentration on Methanol Catalyst 5-17

5.2.3-1 Kingsport Catalyst Campaign 3 - Trace Contaminant 5-20

Concentrations on Slurry Samples

5.3.1-1 Sparger Resistance Coefficient - Sparger Design \#1 5-26

(April - November 1997)

5.3.2-1 Sparger Resistance Coefficient - Sparger Design \#2 5-29

(December 1997 - February 1999)

5.3.3-1 Sparger Resistance Coefficient - Sparger Design \#3 5-30

(March 1999 - August 2001)

5.3.3-2 Sparger Resistance Coefficient - Sparger Design \#3 5-31

(August 2001 - June 2002)

5.3.3-3 Sparger Resistance Coefficient - Sparger Design \#3 5-32

(June 2002 - 31 December 2002)

5.5-1 Ramping Study at LPMEOH ${ }^{\mathrm{TM}}$ Demonstration Unit 5-36

(13 June 2000)

5.5-2 Ramping Study at LPMEOH ${ }^{\mathrm{TM}}$ Demonstration Unit 5-36

(13 March 2001)

5.6-1 Reduction Gas Uptake vs. Temperature - In-Situ Catalyst 5-39

Activation (22-24 August 2001) 
Figure

$5.6-2$

7.1-1

7.3.1-1

$8.5-1$

$8.5-3$

$8.6-1$

$9.5-1$

$9.5-2$

9.5-3

$10.1-1$

A-1 $\underline{\text { Title }}$

Reduction Gas Uptake vs. Temperature - In-Situ Catalyst Activation (25-27 June 2002)

Once-through Methanol Coproduction with IGCC Electric Power

West Virginia University Transportable Heavy Duty Emissions Testing Laboratory

West Virginia University Stationary Gas Turbine Emissions Test Results - 1998 Testing

West Virginia University Stationary Gas Turbine Emissions Test Results - 2000 Testing Aircraft Ground Support Equipment Average $\mathrm{NO}_{\mathrm{x}}$ Emissions Reduction with WIF vs. JP-8

\section{Low- $\mathrm{NO}_{\mathrm{x}}$ Microturbine $\mathrm{NO}_{\mathrm{x}}$ Emissions with Stabilized} Methanol vs. Natural Gas

LaPorte Alternative Fuels Development Unit (AFDU)

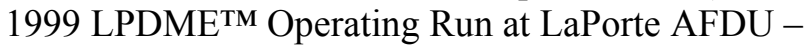
Estimated Catalyst Activity

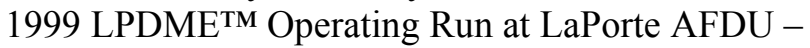
Production Results LPDMETM Process Economics Effect of Methanol Plant Size on Methanol Conversion Cost Effect of Syngas Conversion on Methanol Conversion Cost Effect of Inerts Concentration on Methanol Conversion Cost LPMEOH $^{\text {TM }}$ Process Flow Diagram - Design Options for IGCC Applications

Syngas Sampling Apparatus
Page

$5-41$

$7-1$

$7-7$

$7-9$

$7-10$

$7-12$

7-14

8-5

$8-6$

$8-7$

$8-10$

9-7

9-8

9-9

$10-2$

A-8 


\section{LIST OF ABBREVIATIONS}

\begin{tabular}{|c|c|c|}
\hline AFB & - & Air Force Base \\
\hline AFDU & - & Alternative Fuels Development Unit \\
\hline AFFTU & - & Alternative Fuels Field Test Unit \\
\hline AGSE & - & Aircraft Ground Support Equipment \\
\hline $\mathrm{Al} / \mathrm{P}$ & - & Aluminum to Phosphate \\
\hline Air Products & - & Air Products and Chemicals, Inc. \\
\hline APCI & - & Air Products and Chemicals, Inc. \\
\hline $\mathrm{AsH}_{3}$ & - & Arsine \\
\hline $\mathrm{CO}$ & - & Carbon Monoxide \\
\hline $\mathrm{CO}_{2}$ & - & Carbon Dioxide \\
\hline $\mathrm{COS}$ & - & Carbonyl Sulfide \\
\hline COTR & - & Contracting Officer's Technical Representative \\
\hline $\mathrm{Cu} / \mathrm{C}$ & - & Copper-impregnated Activated Carbon (following reduction of copper oxide) \\
\hline $\mathrm{CuO} / \mathrm{C}$ & - & Copper Oxide-impregnated Activated Carbon \\
\hline DME & - & Dimethyl Ether \\
\hline $\mathrm{DOE}$ & - & United States Department of Energy \\
\hline DVT & - & Design Verification Testing \\
\hline EA & - & Environmental Assessment \\
\hline Eastman & - & Eastman Chemical Company \\
\hline EIV & - & Environmental Information Volume \\
\hline EMP & - & Environmental Monitoring Plan \\
\hline EPA & - & United States Environmental Protection Agency \\
\hline FFV & - & Flexible-Fuel Vehicle \\
\hline FONSI & - & Finding of No Significant Impact \\
\hline $\mathrm{H}_{2}$ & - & Hydrogen \\
\hline $\mathrm{H}_{2} \mathrm{~S}$ & - & Hydrogen Sulfide \\
\hline IGCC & - & Integrated Gasification Combined Cycle \\
\hline ISO & - & International Organization for Standardization \\
\hline LHV & - & Lower Heating Value \\
\hline LPMEOH ${ }^{\mathrm{TM}}$ & - & Liquid Phase Methanol \\
\hline LPDMETM & - & Liquid Phase Dimethyl Ether \\
\hline LPG & - & Liquefied Petroleum Gas \\
\hline $\mathrm{MeOH}$ & - & Methanol \\
\hline MTBE & - & Methyl Tertiary Butyl Ether \\
\hline $\mathrm{N}_{2}$ & - & Nitrogen \\
\hline NEPA & - & National Environmental Policy Act \\
\hline $\mathrm{NO}_{\mathrm{x}}$ & - & Nitrogen Oxides \\
\hline NPDES & - & National Pollutant Discharge Elimination System \\
\hline $\mathrm{O}_{2}$ & - & Oxygen \\
\hline Partnership & - & Air Products Liquid Phase Conversion Company, L.P. \\
\hline PFD & - & Process Flow Diagram(s) \\
\hline PON & - & Program Opportunity Notice \\
\hline Project & - & $\begin{array}{l}\text { Production of Methanol/DME Using the LPMEOH }{ }^{\mathrm{TM}} \text { Process at an } \\
\text { Integrated Coal Gasification Facility }\end{array}$ \\
\hline $\mathrm{P} \& \mathrm{ID}(\mathrm{s})$ & - & Piping and Instrumentation Diagram(s) \\
\hline RCRA & - & Resource and Conservation Recovery Act \\
\hline ROI & - & Return on Investment \\
\hline $\mathrm{SO}_{2}$ & - & Sulfur Dioxide \\
\hline Syngas & - & Synthesis Gas \\
\hline TCLP & - & Toxicity Characteristic Leaching Procedure \\
\hline TPD or $\mathrm{sT} / \mathrm{D}$ & - & Short Ton(s) per Day $(2,000 \mathrm{lbs} /$ ton $)$ \\
\hline UHC & - & Unburned Hydrocarbons \\
\hline
\end{tabular}




\section{LIST OF ABBREVIATIONS (cont'd)}

$\begin{array}{lll}\text { VOC } & - & \text { Volatile Organic Compounds } \\ \text { vol } & - & \text { Volume } \\ \text { vol\% } & - & \text { Volume } \% \\ \text { WIF } & - & \text { Water-in-Fuel } \\ \text { wt } & - & \text { Weight } \\ \text { wt } \% & - & \text { Weight } \% \\ \text { WVU } & - & \text { West Virginia University }\end{array}$




\section{LIST OF UNITS}

\begin{tabular}{|c|c|c|}
\hline Btu & - & British Thermal Units \\
\hline $\mathrm{Btu} / \mathrm{hr}$ & - & British Thermal Units per hour \\
\hline $\mathrm{Btu} / \mathrm{lb}$ & - & British Thermal Units per pound \\
\hline $\mathrm{Btu} / \mathrm{SCF}$ & - & British Thermal Units per standard cubic foot \\
\hline${ }^{\circ} \mathrm{C}$ & - & Degrees Centigrade \\
\hline $\mathrm{Ft}$ & - & Foot \\
\hline${ }^{\circ} \mathrm{F}$ & - & Degrees Fahrenheit \\
\hline $\mathrm{g}$ & - & Grams \\
\hline Gal or gal & - & Gallons \\
\hline gmol & - & Gram-mole \\
\hline gpm & - & Gallons per minute \\
\hline Hp & - & Horsepower \\
\hline $\mathrm{hr}$ & - & Hour \\
\hline KCAL & - & Kilocalories \\
\hline $\mathrm{KSCFH}$ & - & $\begin{array}{l}\text { Acronym for } 1,000 \text { standard cubic feet per hour; for this term, standard } \\
\text { conditions are } 14.7 \text { psia and } 60^{\circ} \mathrm{F}\end{array}$ \\
\hline $\mathrm{kWh}$ & - & Kilowatt-hour \\
\hline 1 & - & Liter \\
\hline $\mathrm{lb}$ & - & Pound \\
\hline lb mole & - & Pound mole \\
\hline lbs & - & Pounds \\
\hline $\mathrm{mg}$ & - & Milligrams \\
\hline mpg & - & Miles per gallon \\
\hline $\mathrm{MM}$ or $\mathrm{mm}$ & - & Million \\
\hline ppbv & - & Parts per billion (volume basis) \\
\hline ppm & - & Parts per million \\
\hline ppmw & - & Parts per million (weight basis) \\
\hline psi & - & Pounds per square inch \\
\hline psia & - & Pounds per square inch (Absolute) \\
\hline psig & - & Pounds per square inch (Gauge) \\
\hline SCF & - & Standard cubic feet $\left(60^{\circ} \mathrm{F}, 14.7\right.$ psia $)$ \\
\hline SCFM & - & Standard cubic feet per minute \\
\hline SCFH & - & Standard cubic feet per hour \\
\hline SCFD & - & Standard cubic feet per day \\
\hline $\mathrm{Sl} / \mathrm{hr}-\mathrm{kg}$ & - & Standard Liter(s) per Hour per Kilogram of Catalyst (oxide basis) \\
\hline$x^{\prime}-y^{\prime \prime}$ & - & $\mathrm{x}$ feet $-\mathrm{y}$ inches \\
\hline
\end{tabular}




\title{
GLOSSARY OF TERMS
}

\author{
Availability $\quad-\quad$ The percentage of time that the LPMEOH ${ }^{\mathrm{TM}}$ demonstration unit was able to operate, with \\ the exclusion of scheduled outages \\ Balanced Gas - $\quad$ A syngas with a composition of hydrogen $\left(\mathrm{H}_{2}\right)$, carbon monoxide $(\mathrm{CO})$, and \\ carbon dioxide $\left(\mathrm{CO}_{2}\right)$ in stoichiometric balance $\left(\left[\mathrm{H}_{2}-\mathrm{CO}_{2}\right] /\left[\mathrm{CO}+\mathrm{CO}_{2}\right]=2.05\right)$ for the \\ production of methanol \\ Carbon Monoxide Gas - A syngas containing primarily carbon monoxide (CO); also called CO Gas \\ Catalyst Activity - the rate at which the catalyst promotes the desired chemical reaction to proceed within \\ the limitations of chemical equilibrium \\ Catalyst Age ( $\eta$-eta) - The ratio of the rate constant at any point in time to the rate constant for a freshly reduced \\ catalyst (as determined in the laboratory autoclave) \\ Catalyst Concentration - Synonym for Slurry Concentration \\ Catalyst Loading - $\quad$ Synonym for Slurry Concentration \\ CO Conversion - $\quad$ The percentage of $\mathrm{CO}$ consumed across the reactor \\ Crude-Grade Methanol - Underflow from rectifier column (29C-20), defined as $80 \mathrm{wt} \%$ minimum purity; \\ requires further distillation in existing Eastman equipment prior to use \\ DOE-NETL - $\quad$ The DOE's National Energy Technology Laboratory (Project Team) \\ DOE-HQ - $\quad$ The DOE's Headquarters - Coal Fuels and Industrial Systems (Project Team) \\ Fresh Feed - $\quad$ Sum of Balanced Gas, $\mathrm{H}_{2}$ Gas, and CO Gas \\ Gas Holdup - $\quad$ - The percentage of reactor volume up to the Gassed Slurry Height which is gas \\ Gassed Slurry \\ Height - $\quad$ Height of gassed slurry in the reactor \\ Hydrogen Gas - $\quad$ A syngas containing an excess of hydrogen $\left(\mathrm{H}_{2}\right)$ over the stoichiometric balance for \\ the production of methanol; also called $\mathrm{H}_{2}$ Gas \\ IGCC/OTM - $\quad$ An IGCC plant with a "Once-Thru Methanol" plant (the LPMEOH ${ }^{\mathrm{TM}}$ Process) added-on \\ Inlet Superficial \\ Velocity \\ The ratio of the actual cubic feet of gas at the reactor inlet (calculated at the reactor \\ temperature and pressure) to the reactor cross-sectional area (excluding the area contribution \\ by the internal heat exchanger); typical units are feet per second \\ $\mathrm{K} \quad$ - $\quad$ Sparger resistance coefficient (term used in calculation of pressure drop) \\ M85 - $\quad$ A fuel blend of 85 volume percent methanol and 15 volume percent unleaded gasoline \\ Methanol Productivity - The gram-moles of methanol produced per hour per kilogram catalyst (on an oxide basis) \\ MW $\quad$ - $\quad$ Molecular weight, pound per pound mole \\ $\rho \quad$ - $\quad$ Density, pounds per cubic foot \\ Project $\quad$ - $\quad$ Production of Methanol/DME Using the LPMEOH ${ }^{\mathrm{TM}}$ Process at an Integrated Coal \\ Gasification Facility \\ Raw Methanol - $\quad$ The sum of Refined-Grade Methanol and Crude-Grade Methanol; represents total methanol \\ which is produced after stabilization \\ Reactor Feed $\quad$ - $\quad$ The sum of Fresh Feed and Recycle Gas \\ Reactor O-T-M \\ Conversion \\ Percentage of energy (on a lower heating value basis) in the Reactor Feed converted to \\ methanol (Once-Through-Methanol basis) \\ Reactor Volumetric \\ Productivity - \\ The quantity of Raw Methanol produced (tons per day) per cubic foot of reactor volume \\ up to the Gassed Slurry Level \\ Recycle Gas - $\quad$ The portion of unreacted syngas effluent from the reactor "recycled" as a feed gas \\ Refined-Grade Methanol - Distilled methanol, defined as $99.8 \mathrm{wt} \%$ minimum purity; used directly in downstream \\ Eastman processes \\ Slurry Concentration - Percentage of weight of slurry (solid plus liquid) which is catalyst (on an oxide basis) \\ Syngas Utilization - $\quad$ Defined as the number of standard cubic feet of Balanced Gas plus CO Gas to the \\ $\mathrm{LPMEOH}^{\mathrm{TM}}$ demonstration unit required to produce one pound of Raw Methanol
}




\section{GLOSSARY OF TERMS (cont'd)}

Synthesis Gas - $\quad$ A gas containing primarily $\mathrm{H}_{2}$ and $\mathrm{CO}$, or mixtures of $\mathrm{H}_{2}$ and $\mathrm{CO}$; intended for "synthesis" in a reactor to form methanol and/or other hydrocarbons (synthesis gas may also contain $\mathrm{CO}_{2}$, water, and other gases)

Temperature

Programming

The increase of reactor temperature as necessary to control the reactor purge flowrate and maintain reactor volumetric productivity

Tie-in(s) The interconnection(s) between the LPMEOH ${ }^{\mathrm{TM}}$ demonstration unit and the Eastman Facility Volumetric flowrate, thousand standard cubic feet per hour 


\section{EXECUTIVE SUMMARY}

This project, which was sponsored by the U.S. Department of Energy (DOE) under the Clean Coal Technology Program to demonstrate the production of methanol from coal-derived synthesis gas (syngas), has completed the 69-month operating phase of the program. The purpose of this Final Report for the "Commercial-Scale Demonstration of the Liquid Phase Methanol (LPMEOH ${ }^{\mathrm{TM}}$ ) Process" is to provide the public with details on the performance and economics of the technology. The LPMEOH ${ }^{\mathrm{TM}}$ Demonstration Project was a $\$ 213.7$ million cooperative agreement between the DOE and Air Products Liquid Phase Conversion Company, L.P. (the Partnership). The DOE's cost share was $\$ 92,708,370$ with the remaining funds coming from the Partnership. The LPMEOH ${ }^{\mathrm{TM}}$ demonstration unit is located at the Eastman Chemical Company (Eastman) chemicals-from-coal complex in Kingsport, Tennessee.

The technology was the product of a cooperative development effort by Air Products and Chemicals, Inc. (Air Products) and DOE in a program that started in 1981. Developed to enhance electric power generation using integrated gasification combined cycle (IGCC) technology, the LPMEOH ${ }^{\mathrm{TM}}$ Process is ideally suited for directly processing gases produced by modern coal gasifiers. Originally tested at the Alternative Fuels Development Unit (AFDU), a small, DOE-owned process development facility in LaPorte, Texas, the technology provides several improvements essential for the economic coproduction of methanol and electricity directly from gasified coal. This liquid phase process suspends fine catalyst particles in an inert liquid, forming a slurry. The slurry dissipates the heat of the chemical reaction away from the catalyst surface, protecting the catalyst, and allowing the methanol synthesis reaction to proceed at higher rates.

The LPMEOH ${ }^{\mathrm{TM}}$ Demonstration Project accomplished the objectives set out in the Cooperative Agreement with DOE for this Clean Coal Technology project. Methanol operation began on 02 April 1997, and startup was completed in two days. Nameplate production of 80,000 gallons per day (260 short tons per day [sT/D]) was achieved within four days, and production rates exceeding $115 \%$ of design were achieved within six days. Overall plant availability (defined as the percentage of time that the $\mathrm{LPMEOH}^{\mathrm{TM}}$ demonstration unit was able to operate, with the exclusion of scheduled outages) was $97.5 \%$, and the longest operating period without interruption of any kind was 94 days. Over 103.9 million gallons of methanol was produced, including a one-month maximum of 2.5 million gallons. Eastman accepted all of the available methanol for use in the production of methyl acetate, and ultimately cellulose acetate and acetic acid.

The slurry bubble column reactor was successfully scaled from the $10 \mathrm{sT} / \mathrm{D}$ LaPorte AFDU to the 260 sT/D LPMEOH ${ }^{\mathrm{TM}}$ demonstration unit. The $\mathrm{LPMEOH}^{\mathrm{TM}}$ reactor did not exhibit any hydrodynamic instability, and the maximum catalyst loading of $151 \%$ of the design value of about 40,000 pounds (corresponding to a slurry concentration of greater than 49 weight \% $[\mathrm{wt} \%])$ was achieved. The gas sparger at the inlet to the $\mathrm{LPMEOH}^{\mathrm{TM}}$ reactor was replaced with two modified units (using the same design principles as the original device), and stable performance was realized when a continuous flush of condensed process oil (in this case, by gravity) was utilized. 
Catalyst performance (as determined by the rate of catalyst deactivation using an in-house kinetic model) improved during the demonstration test period. Initially, deactivation rates of greater than $1 \%$ per day were calculated at the design operating temperature of $250^{\circ} \mathrm{C}$. As a basis of comparison, the calculated deactivation rate from the 4-month proof-of-concept run at the LaPorte AFDU in 1988/89 was $0.4 \%$ per day. (This run was performed on carbon monoxide $[\mathrm{CO}]$-rich syngas derived from natural gas.) The high deactivation rates were attributed to the presence of post-construction debris in the reactor system. During the second catalyst campaign that began in December of 1997, the rate of catalyst deactivation was calculated to be 0.6 to $0.7 \%$ per day at a reactor temperature of $235^{\circ} \mathrm{C}$. The practice of catalyst withdrawal and addition (removing a portion of the spent catalyst from the $\mathrm{LPMEOH}^{\mathrm{TM}}$ reactor and adding fresh catalyst in 2,000 pound batches) to maintain the desired methanol production rate was successfully demonstrated.

In determining the reasons for the higher rate of catalyst deactivation, the presence of certain elements (in particular, arsenic and sulfur) was identified from samples of spent catalyst, spent adsorbent materials from catalyst guard beds, and syngas entering the LPMEOH ${ }^{\mathrm{TM}}$ demonstration unit. A commercially available copper oxide-impregnated activated carbon was identified as having capacity to remove arsenic (in the form of arsine) within an existing catalyst guard bed that was originally designed for removal of metal carbonyls at ambient temperature.

In parallel, laboratory testing was performed to develop a procedure to activate (or reduce) a full charge of methanol synthesis catalyst within the LPMEOH ${ }^{\mathrm{TM}}$ reactor (so-called in-situ activation). The in-situ activation procedure prepared fresh methanol synthesis catalyst for production of methanol by reacting metal oxides (for example, copper oxide) with a reductant such as $\mathrm{CO}$ or hydrogen $\left(\mathrm{H}_{2}\right)$ to produce the base metal plus either carbon dioxide $\left(\mathrm{CO}_{2}\right)$ or water $\left(\mathrm{H}_{2} \mathrm{O}\right)$. During the operating program, this feature was identified as having significant commercial interest, as capital cost savings of about $10 \%$ could be realized by elimination of the separate processing equipment for the catalyst withdrawal/addition procedure. Also, operating the LPMEOH ${ }^{\mathrm{TM}}$ reactor at low temperatures at the outset and slowly increasing temperature with time to maintain a constant production of methanol (called temperature programming) was believed to have the potential to extend the life of the methanol synthesis catalyst. Following the first in-situ activation of methanol synthesis catalyst in August of 2001 (during which initial performance of the catalyst was about $70 \%$ of the value expected from the laboratory testing), the concept of temperature programming was demonstrated (temperature was gradually raised from $216^{\circ} \mathrm{C}$ to $250^{\circ} \mathrm{C}$ in order to maintain the desired methanol production rate). Following changes to the storage conditions of the catalyst slurry prior to reduction, the in-situ activation procedure was successfully practiced in June of 2002, resulting in the catalyst meeting the initial performance targets.

During the final six months of operation under the demonstration test plan, the average rate of catalyst deactivation was calculated to be $0.17 \%$ per day, which was $1 / 2$ of the design basis for the $\mathrm{LPMEOH}^{\mathrm{TM}}$ demonstration unit. The reactor was maintained at a constant low temperature of $215^{\circ} \mathrm{C}$ during this period, and the adsorbent used in the catalyst guard bed within the $\mathrm{LPMEOH}^{\mathrm{TM}}$ demonstration unit (copper oxide-impregnated activated carbon) was replaced with fresh material after 3 months of operation (including a novel thermal treatment that was applied after two months to extend the useful life of the adsorbent). Because the impact of catalyst cost 
on the economics of methanol production is significant (reducing the rate of catalyst deactivation by up to $1 / 2$ of the current basis can realize a 25 percent reduction in variable cost), this performance demonstrated the potential of the $\mathrm{LPMEOH}^{\mathrm{TM}}$ process to meet the targets for catalyst consumption utilizing coal-derived syngas.

Although the host site for the LPMEOHTM demonstration unit was a chemical production facility, testing was able to be performed to simulate the performance of the LPMEOH ${ }^{\mathrm{TM}}$ Process in an IGCC power plant. A total of 78 days of testing at a variety of $\mathrm{H}_{2}: \mathrm{CO}$ ratios were performed to evaluate the effect of syngas compositions expected from coal-based IGCC units on the performance of the LPMEOH ${ }^{\mathrm{TM}}$ Process. All of the results met the expectations for methanol production rate based upon earlier studies in the laboratory. Catalyst performance for the $\mathrm{LPMEOH}^{\mathrm{TM}}$ reactor with lower $\mathrm{H}_{2}$ : $\mathrm{CO}$ ratios were not significantly impacted based on the calculated rate of catalyst deactivation. On/off and ramping studies were also completed, and the $\mathrm{LPMEOH}^{\mathrm{TM}}$ demonstration unit was capable of meeting the ramping requirements for an IGCC system by achieving the goal of a minimum 5\% change in design flow per minute. Tests of the ability of the $\mathrm{LPMEOH}^{\mathrm{TM}}$ reactor to operate in a load-following environment were also successful.

Stabilized (degassed) methanol produced from CO-rich syngas in the LPMEOH ${ }^{\mathrm{TM}}$ Process can have less than $1 \mathrm{wt} \% \mathrm{H}_{2} \mathrm{O}$, and has the potential to be used directly in transportation and power generation applications. The cost of distillation from stabilized methanol to chemical-grade purity has been estimated to be $\$ 0.02$ to $\$ 0.04$ per gallon. Stabilized methanol from the LPMEOH $^{\mathrm{TM}}$ Demonstration Project was made available to seven test locations to study the feasibility of its use these systems. Successful demonstration of the use of stabilized methanol in these applications can enhance the flexibility of and revenue from IGCC plants. In bus and flexible fuel vehicle (FFV) trials, stabilized methanol provided the same environmental benefits as chemical-grade methanol with no penalty on performance or fuel economy. Tests in a gas turbine and a diesel generator showed that levels of nitrogen oxides $\left(\mathrm{NO}_{\mathrm{x}}\right)$ in the exhaust air were lowered when stabilized methanol or methanol emulsions are used instead of conventional oil fuels. As with chemical-grade methanol, lubrication additives will likely be required when stabilized methanol is fed to a gas turbine. Testing of stabilized methanol as the source of $\mathrm{H}_{2}$ to a phosphoric acid fuel cell has shown that conventional steam reforming catalysts are not compatible with the trace mineral oil present in the stabilized methanol; when auto-thermal reforming or partial oxidation reforming are used, the stabilized methanol would possibly be acceptable as a fuel. Methanol from the LPMEOH ${ }^{\mathrm{TM}}$ Process that is purified to chemical-grade specifications should be suitable for use in this application. Product-use testing proved that coalderived methanol, free of sulfur and other impurities, could be used one day as a replacement for petroleum in transportation, a peaking fuel in combustion turbines IGCC power plants, a source of $\mathrm{H}_{2}$ for small fuel cells, or as a chemical feedstock.

As a secondary objective to the LPMEOH ${ }^{\mathrm{TM}}$ Demonstration Project, design verification testing was completed to evaluate capability of the slurry bubble column reactor to produce dimethyl ether (DME) as a coproduct with methanol using the Liquid Phase Dimethyl Ether (LPDME ${ }^{\text {TM})}$ Process. The LPDMETM Process uses a physical mixture of a commercial methanol catalyst and a commercial dehydration catalyst in a single slurry reactor. In addition to its current uses, DME has potential applications as a chemical building block. Also, since the physical properties of 
DME are similar to those of liquefied petroleum gas (LPG), it has been speculated that DME could be used in large-scale power production, in home heating, in replacement of LPG for automobiles, and as a diesel fuel substitute or combustion supplement. Economic targets on the production cost of DME from the LPDMETM Process were established, and a 25-day design verification test was performed at the LaPorte AFDU in 1999. The rate of catalyst deactivation for both the methanol synthesis and dehydration catalysts was calculated to be $0.7 \%$ per day, which was a large improvement over the $4 \%$ per day rate of deactivation which was calculated from autoclave studies prior to the initial test of the LPDMETM Process at the LaPorte AFDU in 1991; these results were slightly higher than the results $\left(0.5 \%\right.$ per day) for the LPMEOH ${ }^{\mathrm{TM}}$ Process from the first 3 weeks of the 4-month proof-of-concept run at the LaPorte AFDU in $1988 / 89$. Follow-up economic analysis showed that the target DME cost of $\$ 7$ to $\$ 8$ per MMBtu (equivalent to costs for LPG in China) can likely be achieved at plant sizes approaching 1,100 sT/D. The program participants agreed that additional work on DME should be deferred so that all resources could be directed toward improving the catalyst performance for the LPMEOHTM Process during the remaining time within the operating program.

In evaluating the economics for the technology, parametric studies were also performed to determine the production cost of methanol from the LPMEOH ${ }^{\mathrm{TM}}$ Process in an IGCC power plant. The process can be designed to operate in a continuous, baseload manner, converting syngas from oversized gasifiers or from a spare gasifier. The process can also be designed to operate only during periods of off-peak electric power demand to consume a portion of the excess syngas and allow the electricity output from the combined-cycle power unit to be reduced. In this latter circumstance, the gasifiers continue to operate at full baseload capacity, so the IGCC facility's major capital asset is fully utilized. In either baseload or cycling operation, partial conversion of between $20 \%$ and $40 \%$ of the volume of $\mathrm{H}_{2}$ and $\mathrm{CO}$ in the IGCC power plant's syngas is optimal on an economic basis, and conversion of up to $50 \%$ is feasible. Methanol conversion costs of about $\$ 0.15$ per gallon were determined for a coal-based IGCC plant using the once-through configuration; when the cost of syngas is added, the price of methanol is less than $\$ 0.50$ per gallon. As the economics for IGCC systems improve, the economics for coproduction of methanol will continue to look attractive in local markets when compared with methanol that is produced in off-shore locations from natural gas. 


\subsection{INTRODUCTION}

\subsection{PURPOSE OF THE PROJECT PERFORMANCE AND ECONOMICS REPORT}

The purpose of the Project Performance and Economics Report for the "Commercial-Scale Demonstration of the Liquid Phase Methanol (LPMEOH ${ }^{\mathrm{TM}}$ ) Process" project is to consolidate for public use all relevant nonproprietary information on the project, other than that already included in the Public Design Report (Final Report - Volume 1).

The scope of the report is limited to nonproprietary information. Therefore, although its content is insufficient to provide a complete tool for designing a $\mathrm{LPMEOH}^{\mathrm{TM}}$ unit, it will serve as a reference for the design considerations involved in developing a commercial-scale facility.

\subsection{OVERVIEW OF THE PROJECT}

\subsubsection{Background and History of the Project}

The purpose of this project was to demonstrate the commercial viability of the $\mathrm{LPMEOH}^{\mathrm{TM}}$ Process using coal-derived synthesis gas (syngas). This project was conducted pursuant to the U.S. Department of Energy (DOE) Clean Coal Technology Program.

The United States needs future sources of alternative liquid fuels. With domestic oil production declining and imports increasing, the potential of producing affordable liquid fuels from nonpetroleum sources could one day prove both strategically and economically important. The LPMEOH $^{\mathrm{TM}}$ Process offers an extremely attractive route to supplementing our liquid fuel supplies with methanol made from the abundant coal reserves of the United States.

Methanol also has a broad range of commercial applications. It can be substituted for or blended with gasoline to power vehicles. It is an excellent fuel for the rapid-start combustion turbines used by utilities to meet peak electricity demands. It contains no sulfur and has exceptionally low nitrogen oxide $\left(\mathrm{NO}_{\mathrm{x}}\right)$ characteristics when burned. Methanol may be an economical source of hydrogen $\left(\mathrm{H}_{2}\right)$ for fuel cells. It can also be used as a chemical feedstock.

Air Products and Chemicals, Inc. (Air Products) and Eastman Chemical Company (Eastman) entered into a partnership known as Air Products Liquid Phase Conversion Company, L.P. (the Partnership). The Partnership and the DOE participated in the Clean Coal Technology Program demonstration of $\mathrm{LPMEOH}^{\mathrm{TM}}$ technology. The Partnership designed, built, owned, and operated a nominal 80,000 gallons-per-day (260 short tons-per-day [sT/D]) LPMEOH ${ }^{\mathrm{TM}}$ demonstration unit at Eastman's chemicals-from-coal complex in Kingsport, Tennessee. The program objectives were to demonstrate the scaleup and operability of the LPMEOH ${ }^{\mathrm{TM}}$ Process under various coal-based syngas feed compositions and to gain operating experience for future syngas conversion projects.

The technology is the product of a cooperative development effort by Air Products and DOE in a program that started in 1981. Developed to enhance electric power generation using integrated gasification combined cycle (IGCC) technology, the LPMEOH ${ }^{\mathrm{TM}}$ Process is ideally suited for 
directly processing gases produced by modern day coal gasifiers. Originally tested at the Alternative Fuels Development Unit (AFDU), a small, DOE-owned experimental unit in LaPorte, Texas, the technology offers significant potential, compared to conventional gas-phase methanol production technologies, to reduce electric power generation costs at coal-based IGCC facilities with the coproduction of chemical feedstocks and alternative liquid fuels. The domestically developed LPMEOH ${ }^{\mathrm{TM}}$ technology can use domestic coal reserves to produce clean, storable, liquid fuels and chemical feedstocks. Eventual commercialization of the LPMEOH $^{\text {TM }}$ Process would provide chemical feedstock and electric power cost savings, lower sulfur dioxide $\left(\mathrm{SO}_{2}\right)$ and $\mathrm{NO}_{\mathrm{x}}$ emissions, and could reduce the use of imported liquid fuels.

The LPMEOH ${ }^{\mathrm{TM}}$ technology could someday be used as an adjunct to an IGCC power plant - one of the cleanest and most efficient of the 21 st century power generating options. When the IGCC power plant is not generating electricity at its full capacity, excess syngas can be diverted to make methanol in a fast ramping LPMEOH ${ }^{\mathrm{TM}}$ plant. The methanol could be stored on-site and used in peaking turbines or sold as a commercial fuel or a chemical feedstock. In this configuration, the cost of making methanol from coal is likely to be competitive with stand alone natural gas-to-methanol facilities. A discussion of the process options and economics is provided in Section 9 of this report.

The LPMEOH ${ }^{\mathrm{TM}}$ demonstration unit was integrated with Eastman's chemicals-from-coal complex, accepting syngas and converting it to methanol, for use as a chemical feedstock within the Eastman facility. A portion of the methanol product was evaluated as a zero sulfur, low- $\mathrm{NO}_{\mathrm{x}}$ combustion fuel for testing in stationary power applications and mobile transportation use (buses, flexible-fuel vehicles [FFV's], etc.).

These fuel-use tests provided a basis for the comparison of the product methanol with conventionally accepted fuels with regard to emission levels and economic viability. The program goal of demonstrating methanol as a fuel can lead to the potential for greater use of oxygenated fuels, which burn cleaner than conventional fuels, thereby reducing air emissions from mobile (e.g., buses and vanpools) and stationary (e.g., engines, turbines, and fuel cells) sources.

The DOE, under the Clean Coal Technology Program, provided cost-shared financial assistance for the design, construction, and operation of the commercial-scale LPMEOH ${ }^{\mathrm{TM}}$ demonstration unit by The Partnership. Air Products designed and constructed the LPMEOH ${ }^{\mathrm{TM}}$ demonstration unit and Eastman operated it. The demonstration unit is a nominal 260 ton-per-day (or 80,000 gallon per day) unit situated on a 0.6 acre plot within the existing Eastman chemicals-from-coal complex in Kingsport, Tennessee.

The Eastman coal gasification facility has operated commercially since 1983. Eastman currently both produces and purchases methanol for use at the site. At this site, it was possible to perform studies that demonstrate the unique load-following flexibility of the LPMEOH ${ }^{\mathrm{TM}}$ demonstration unit for application to coal-based IGCC electric power generation facilities.

This project has also completed design verification testing (DVT), including laboratory- and pilot-scale research and market verification studies, to evaluate whether to include a 
demonstration of the production of dimethyl ether (DME) as a mixed coproduct with methanol. DME has several commercial uses. In a storable blend with methanol, the mixture can be used as a peaking fuel in gasification-based electric power generating facilities, or as a diesel engine fuel. Blends of methanol and DME can be used as chemical feedstocks for synthesizing chemicals, including new oxygenated fuel additives.

\subsubsection{Project Organization}

As noted above, Air Products and Eastman formed the Partnership to execute the LPMEOH ${ }^{\mathrm{TM}}$ Demonstration Project. The Partnership subcontracted with Air Products to provide the overall management of the project, and to act as the primary interface with DOE. As subcontractor to the Partnership, Air Products provided the engineering design, procurement, construction, and commissioning of the $\mathrm{LPMEOH}^{\mathrm{TM}}$ demonstration unit, and provided the technical and engineering supervision needed to conduct the operational testing program required as part of the project. As subcontractor to Air Products, Eastman was responsible for operation of the $\mathrm{LPMEOH}^{\mathrm{TM}}$ demonstration unit, and for the interconnection and supply of syngas, utilities, product storage, and other needed services. Air Products also issued subcontracts for and managed the projects within the off-site testing of methanol from the LPMEOH ${ }^{\mathrm{TM}}$ Process. These roles and responsibilities are summarized in Figure 1.2.2-1.

Figure 1.2.2-1

\section{LPMEOH $^{\text {TM }}$ Demonstration Project Organization}

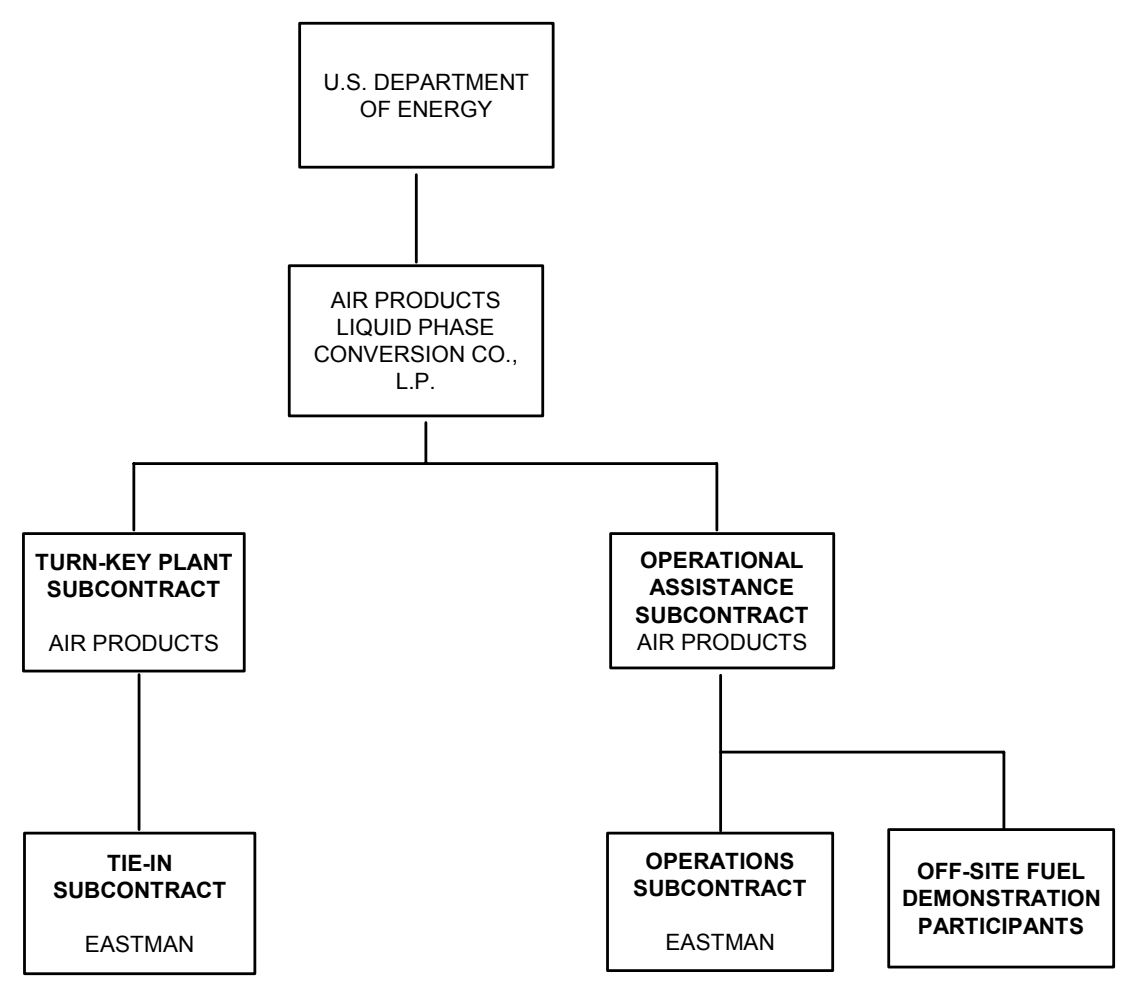




\subsubsection{Project Description}

Air Products developed the two technologies that were demonstrated at various engineering scales during this demonstration project with the financial support of the DOE. The LPMEOH ${ }^{\mathrm{TM}}$ Process uses a slurry bubble column reactor to convert coal-derived syngas to methanol. Because of its superior heat management, the process can directly utilize the carbon monoxide (CO)-rich syngas characteristic of the gasification of coal, petroleum coke, residual oil, wastes, or other hydrocarbon feedstock. When added to a high-efficiency IGCC power plant, the LPMEOH $^{\mathrm{TM}}$ Process converts a portion of the CO-rich syngas produced by the gasifier to methanol, and the unconverted gas is used to fuel the gas turbine combined-cycle power plant. The LPMEOH ${ }^{\mathrm{TM}}$ Process can also be applied to the conversion of syngas derived from natural gas. A block diagram showing the integration of the $\mathrm{LPMEOH}^{\mathrm{TM}}$ demonstration unit within the Eastman chemicals-from-coal complex is provided in Figure 1.2.3-1.

The Liquid Phase Dimethyl Ether (LPDMETM) Process uses a physical mixture of a commercial methanol catalyst and a commercial dehydration catalyst in a single slurry reactor to coproduce DME with methanol. This process provides high syngas conversion, efficient heat transfer, and directly converts a variety of syngas compositions.

\subsubsection{Site}

The demonstration unit, which occupies an area of 0.6 acre, is integrated into the existing 4,000acre Eastman chemicals-from-complex located in Kingsport, Tennessee. The Eastman complex employs approximately 8,600 people. In 1983, Eastman constructed a coal gasification facility utilizing Texaco technology. The syngas generated by this gasification facility is used to produce carbon monoxide and methanol. Both of these products are used to produce methyl acetate and ultimately cellulose acetate and acetic acid. The availability of this highly reliable coal gasification facility was the major factor in selecting this location for the LPMEOH ${ }^{\mathrm{TM}}$ demonstration unit. An aerial photograph of Eastman's chemicals-from-coal complex is provided in Figure 1.2.4-1.

Three different feed gas streams $\left(\mathrm{H}_{2}\right.$ Gas, $\mathrm{CO}$ Gas, and the primary syngas feed known as Balanced Gas) are available from existing operations to the $\mathrm{LPMEOH}^{\mathrm{TM}}$ demonstration unit, thus providing the range of coal-derived syngas ratios $\left(\mathrm{H}_{2}\right.$ to $\left.\mathrm{CO}\right)$ needed to meet the technical objectives of the demonstration project. 
Figure 1.2.3-1

Integration of Existing Facilities with LPMEOH ${ }^{\mathrm{TM}}$ Demonstration Unit

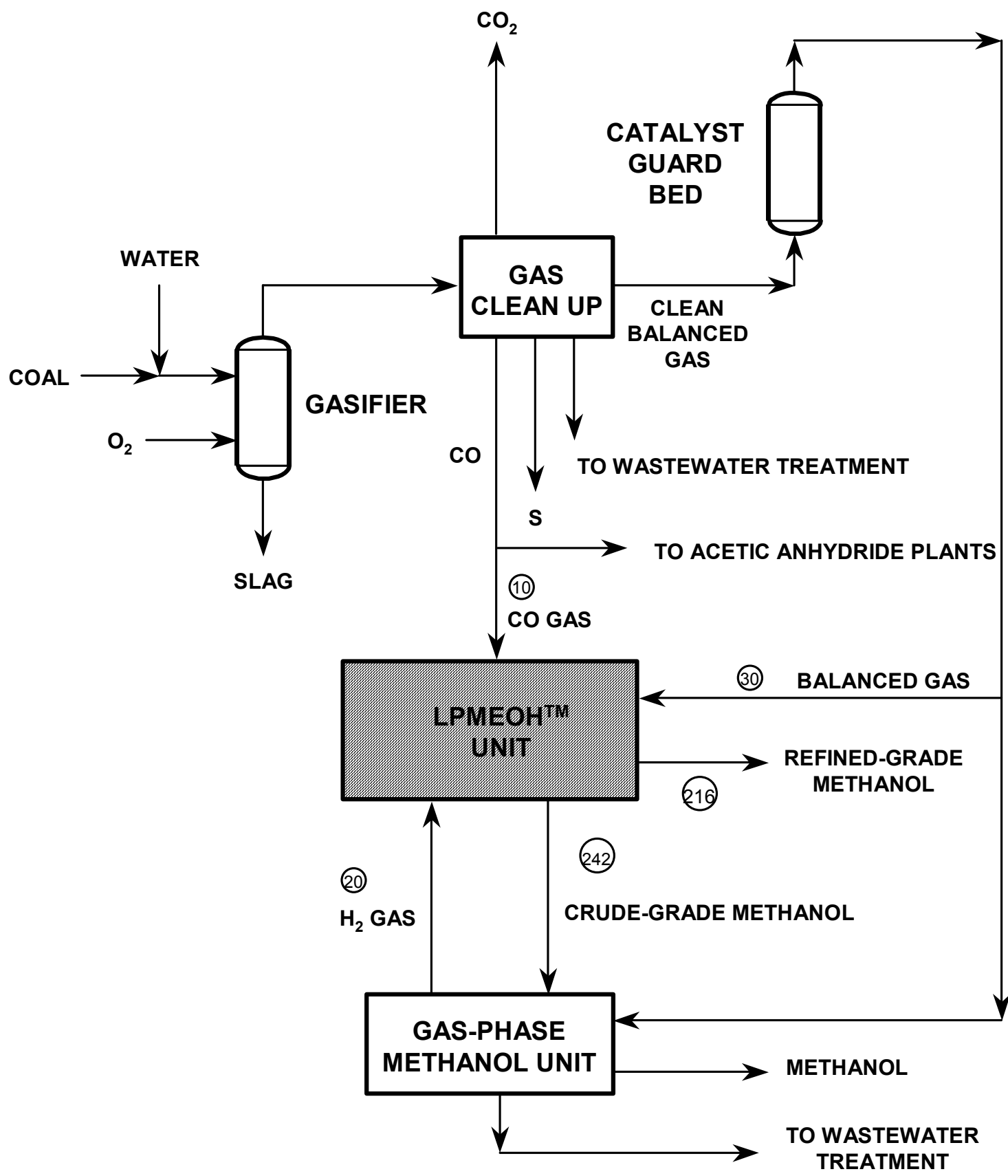

NEW

EXISTING FACILITIES

Note: Material Balance Points correspond to Stream Numbers on Table 2.5-1. 


\section{Figure 1.2.4-1 \\ Photograph of Eastman Chemical Company's Chemicals-from-Coal Complex}

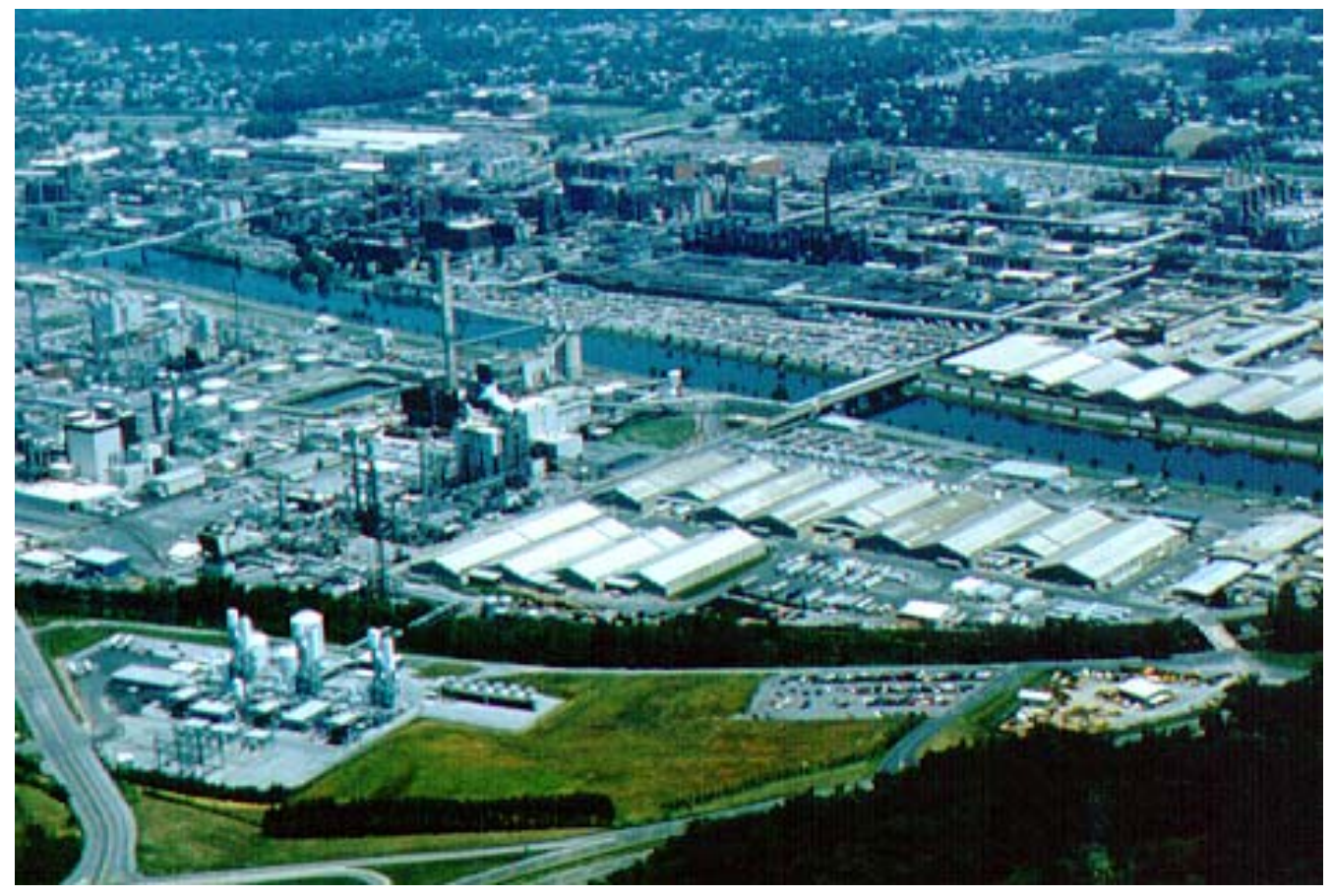

\subsubsection{Project Schedule}

The project was divided into the following three phases:
Design
Construction
Operation

The design phase included all of the engineering needed to construct the demonstration unit. This activity started in October of 1993 and was completed in early 1996. The construction phase started in October of 1995 and included the fabrication of the equipment and the field construction tasks (foundations, steel erection, etc.). The demonstration unit was commissioned in March of 1997. The startup was extremely smooth, as demonstrated by the rapid progression from first introduction of syngas (02 April 1997) to stable operation at design conditions (06 April 1997) to a test at $115 \%$ of the design production rate of methanol (10 April 1997). The startup also proceeded without injury or environmental incidents.

Based upon the original timetable for the project, the four-year demonstration test period was scheduled to be completed on 31 March 2001, with project close-out to be concluded by 31 December 2001. However, operational issues were encountered with the gas sparger within the LPMEOH $^{\mathrm{TM}}$ reactor and with the impact of trace contaminants present in the coal-derived syngas on the long-term performance and life of the methanol synthesis catalyst. Additional information on these items is provided in Section 3.1 of this report. The time required to study 
and develop solutions to these technical challenges adversely impacted the ability to execute the Demonstration Test Plan according to the original schedule.

During the project execution, an update on the economics of the coproduction of methanol with electric power via the LPMEOH ${ }^{\mathrm{TM}}$ Process was performed. During these studies, modes of operation that had not been anticipated during the development of the original Demonstration Test Plan were identified. One example was the development of a procedure to activate the methanol synthesis catalyst within the LPMEOH ${ }^{\mathrm{TM}}$ reactor by using syngas which is diluted with nitrogen $\left(\mathrm{N}_{2}\right)$ (known as in-situ activation). If the separate processing equipment to activate catalyst on a batch-wise basis could be eliminated, a capital cost savings of about $10 \%$ would be realized. Also, operating the $\mathrm{LPMEOH}^{\mathrm{TM}}$ reactor at low temperatures at the outset and slowly increasing temperature with time to maintain a constant production of methanol can extend the life of the methanol synthesis catalyst.

Based upon these results, Air Products, on behalf of the Partnership, requested a 15-month nocost time extension on 25 February 2000. This extension was necessary to complete some of the key tests which were originally defined in the September 1996 Demonstration Test Plan, and to allow the opportunity to perform the new tests of significant commercial interest. The extension was approved by DOE on 24 April 2000 and accepted by Air Products on behalf of the Partnership on 08 May 2000. Air Products submitted the first draft for the update to the Demonstration Test Plan on 15 May 2000; the final version was approved by DOE on 15 February 2001.

Over the next year, significant progress was made toward achieving the objectives for operation of the LPMEOH ${ }^{\mathrm{TM}}$ demonstration unit during the 15 -month period of extended operation. A new commercially available adsorbent material was charged into the catalyst guard bed within the LPMEOH ${ }^{\mathrm{TM}}$ demonstration unit, pretreated to remove oxygen $\left(\mathrm{O}_{2}\right)$, and brought on stream; initial results for the removal of arsenic from the Balanced Gas feed met performance expectations. Tests on operation in load-following and on-off modes, which are expected to occur in an IGCC complex where both methanol and electric power are produced, were successfully completed. Additional test campaigns on CO-rich syngas were performed. In August of 2001, the first test of the in-situ activation procedure was performed. Initial catalyst performance was less than the value expected from experiments in the laboratory.

Based upon this continued progress, Air Products, on behalf of the Partnership, requested an inscope technical redirection of funds on 01 February 2002. Pending results from a laboratory assessment, the Partnership was considering a recommendation to DOE that a second attempt to perform the in-situ catalyst activation procedure may be warranted. Based upon the redirection of the available project funds and the time necessary to complete the laboratory studies, implement changes, perform the in-situ activation, and assess the results, it was expected that demonstration operations could be supported through December of 2002. Project closeout activities would be completed by the project end date of 31 March 2003 (the project was extended to 30 June 2003 to allow for completion of all technical reports). DOE approved this in-scope technical redirection on 08 March 2002. Based upon this redirection, the list and schedule of tests within the Demonstration Test Plan was updated; these changes are discussed in Section 4.1. As detailed in Section 5.6.4, the performance following the second in-situ 
activation of catalyst matched the performance expected with properly activated catalyst from the laboratory autoclave.

The operating phase for the LPMEOH ${ }^{\mathrm{TM}}$ Demonstration Project was concluded on 31 December 2002. The final schedule, including activities associated with Design Verification Testing (DVT) of DME and the off-site fuel use testing program for stabilized methanol, is provided in Figure 1.2.5-1.

\subsection{OBJECTIVES OF THE PROJECT}

\subsubsection{Primary Objective}

The LPMEOH ${ }^{\mathrm{TM}}$ Process technology is expected to be commercialized as part of an IGCC electric power generation system. Therefore, the project incorporates the commercially important aspects of the operation of the LPMEOH ${ }^{\mathrm{TM}}$ Process which would enhance IGCC power generation. These include the following:

- The coproduction of electric power and of high value liquid transportation fuels and/or chemical feedstocks from coal. This coproduction requires that the partial conversion of syngas to storable liquid products be demonstrated.

- Using an energy load-following operating concept which allows conversion of off-peak energy, at attendant low value, into peak energy commanding a higher value. The loadfollowing concept makes use of gasifier capacity that is under utilized during low-demand periods by using the LPMEOH ${ }^{\mathrm{TM}}$ Process to convert the excess syngas to a storable liquid fuel for use in electric power generation during the peak energy periods. This operating concept requires that on/off and electrical load following capabilities be demonstrated.

During operation, the instrumentation system allowed for the collection of engineering data, analysis, and reporting which was done by technical personnel. Typical reporting included onstream factors, material and energy balances, reactor and equipment performance, comparison with laboratory and AFDU results, conversion efficiencies, and catalyst activity. The resulting database will be used to quantitatively evaluate the LPMEOH ${ }^{\text {TM }}$ Process technology compared to other commercially available methanol synthesis process technologies.

\subsubsection{Secondary Objective}

A secondary objective of the project was to demonstrate the production of DME as a mixed coproduct with methanol.

Subject to successful DVT, the Partnership proposed to enhance the project by including the demonstration of the slurry reactor's capability to produce DME as a mixed coproduct with methanol. DVT was required to address issues such as catalyst activity and stability and to provide data for engineering design and demonstration decision making. 


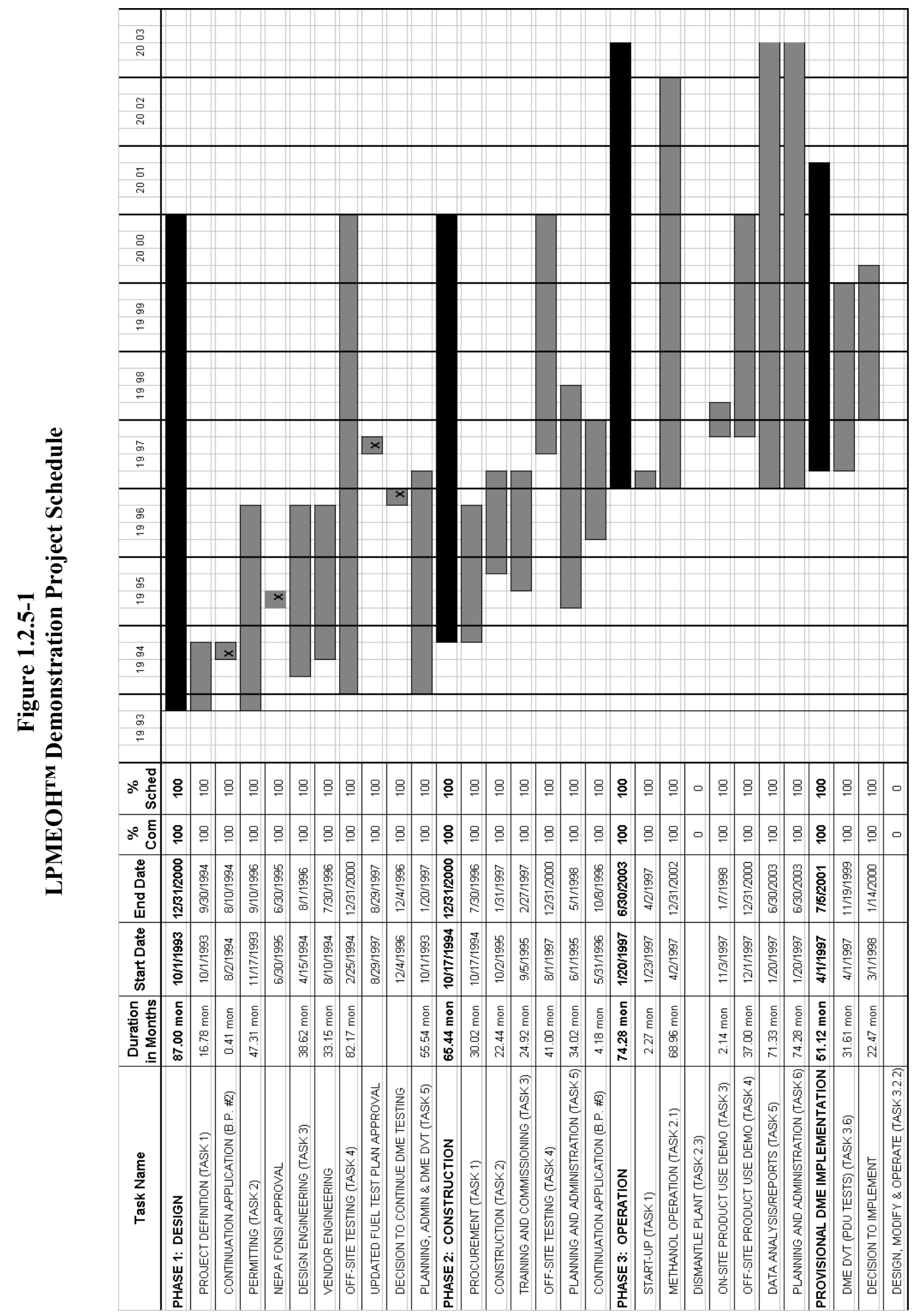

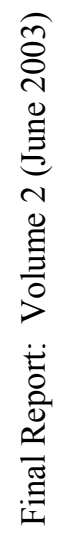




\subsection{SIGNIFICANCE OF THE PROJECT}

This project demonstrated the commercial viability of Air Products' LPMEOH ${ }^{\text {TM }}$ Process using coal-derived syngas, a mixture of $\mathrm{H}_{2}$ and $\mathrm{CO}$. The DOE's purpose for the demonstration project was to help fulfill the goals and objectives of the Clean Coal Technology Program by demonstrating the potential of a more efficient, liquid-phase reaction process as a preferred alternative to gas-phase reactions for methanol production.

The United States needs future sources of alternative liquid fuels. With domestic oil production declining and imports increasing, the potential of producing affordable liquid fuels from nonpetroleum sources could one day prove both strategically and economically important. The LPMEOH $^{\text {TM }}$ Process offers an extremely attractive route to supplementing liquid fuel supplies with methanol made from abundant coal reserves in the United States.

Methanol has a broad range of commercial applications. It can be substituted for or blended with gasoline to power vehicles. It is an excellent fuel for the rapid-start combustion turbines used by utilities to meet peak electricity demands. It contains no sulfur and has exceptionally low $\mathrm{NO}_{\mathrm{x}}$ characteristics when burned. It is also used as a chemical feedstock.

The technology that has now completed the demonstration operations phase is ideally suited as an adjunct to a coal-based IGCC power plant - one of the cleanest and most efficient of the 21 st century power generating options. When the power plant is not generating at its full capacity, excess syngas can be diverted to make methanol. The methanol could be stored on-site and used in peaking turbines or sold as a commercial fuel or chemical feedstock. In this configuration, the cost of making methanol from coal is likely to be competitive with stand-alone natural gas-tomethanol facilities.

The project objectives were to demonstrate the scaleup and operability of the LPMEOH ${ }^{\mathrm{TM}}$ Process under various coal-based feed gas compositions and to gain operating experience for future syngas conversion projects. DVT was also performed to evaluate the potential demonstration of the production of DME from syngas as a mixed coproduct with methanol.

The LPMEOH ${ }^{\mathrm{TM}}$ Process offers significant potential to economically produce methanol (using a technology developed in the United States over conventional technologies) and to reduce electric power generation costs with the production of alternative liquid fuels. The domestically developed LPMEOH ${ }^{\mathrm{TM}}$ technology can utilize the abundant coal reserves of the United States to

produce clean, storable, liquid fuels and chemical feedstocks. Eventual commercialization of the LPMEOH $^{\text {TM }}$ Process in IGCC power plants would provide low priced chemical feedstocks and fuel leading to electric power generation cost savings, lower $\mathrm{SO}_{2}$ and $\mathrm{NO}_{\mathrm{x}}$ emissions, and the reduced use of imported liquid fuels. 


\subsection{DOE'S ROLE IN THE PROJECT}

\subsubsection{Clean Coal Technology Program}

The DOE's Clean Coal Technology Program has been implemented through five competitive solicitations. Congress set the basic goals for the program and for each solicitation in the enabling legislation and accompanying report language. DOE subsequently translated the guidance into performance-oriented solicitations. For each solicitation, evaluation criteria were defined and weighted to reflect specific congressional guidance and the current program objectives. This process enabled industry to set the technical agenda by allowing companies to propose their own technologies as qualifying projects. This had the significant benefit of attracting higher levels of private-sector cost-sharing and increasing the likelihood of realizing commercialization objectives.

An important attribute to the solicitation approach used to implement the program was the use of multiple solicitations spread over a number of years. Allowing time between solicitations made it possible to adjust program objectives. At the end of each solicitation, Congress provided the flexibility as needed to effectively implement the program.

Each solicitation was issued as a Program Opportunity Notice (PON). Proposals for demonstration projects consistent with the objectives of each PON were submitted to DOE by a specific deadline. DOE evaluated the proposals and announced those projects selected for negotiation.

The objective of the Round III was to solicit cost-shared clean coal technology projects to demonstrate innovative, energy-efficient technologies capable of being commercialized in the 1990's. These technologies were to be capable of (1) achieving significant reductions in emissions of $\mathrm{SO}_{2}$ and/or $\mathrm{NO}_{\mathrm{x}}$ from existing facilities to minimize environmental impacts, such as transboundary and interstate pollution, and/or (2) providing for future energy needs in an environmentally acceptable manner. DOE received 48 proposals and selected 13 projects as best furthering the goals and objectives of the PON.

The LPMEOH ${ }^{\mathrm{TM}}$ Demonstration Project was selected in December of 1989 under Round III of the Clean Coal Technology Program.

\subsubsection{Management Plan}

The DOE entered into a Cooperative Agreement with Air Products and Chemicals, Inc., which was later novated to the Partnership (between Air Products and Eastman) to conduct the project. The DOE monitored the project through the Contracting Officer and the Contracting Officer's Technical Representative (COTR). The Partnership managed the project through an Air Products Program Manager, who was assisted by a team of technical and managerial personnel from Air Products and from Eastman. 
The organizational chart for the design and construction phases is included in the Public Design Report (Final Report - Volume 1). The organizational chart for the operating phase is shown in Figure 1.5.2-1.

\subsubsection{DOE}

The DOE was responsible for monitoring all aspects of the project and for granting or denying approvals required by the Cooperative Agreement. The DOE Contracting Officer was the authorized representative of the DOE for all matters related to the Cooperative Agreement.

The DOE Contracting Officer appointed a COTR, who was the authorized representative for all technical matters and had the authority to issue "Technical Advice." The COTR also approved those reports, plans, and technical information required under the Cooperative Agreement. The DOE COTR did not have the authority to issue any technical advice that assigned additional work outside the Statement of Work, increased or decreased the total estimated cost or time required for performance of the Cooperative Agreement, changed any of the terms, conditions, or specifications of the Agreement, or interfered with The Partnership's right to perform the terms and conditions of the Agreement. All Technical Advice was issued in writing by the DOE COTR.

\subsubsection{The Partnership}

The Air Products Program Manager coordinated the overall project and was responsible for all communication with the DOE and for interfacing with the DOE COTR.

The Air Products Program Manager was the primary focal point for this project having responsibility and authority for direction of the project subsequent to the signing of the Cooperative Agreement. The Air Products Program Manager was the principal representative between the Partnership and the DOE.

The Program Manager's responsibilities encompassed both technical and fiscal considerations, including the following:

- Overall technical coordination of the program

- Monitoring of program cost

- Monitoring of program planning

- Monitoring of program schedule

- Commitment of resources to optimize performance under the Cooperative Agreement

- Reporting requirements

- Final review of all contract deliverables

Throughout the course of this project, reports dealing with technical, cost, and environmental aspects of the project were prepared by the Partnership and provided to DOE. 
Figure 1.5.2-1

Kingsport LPMEOH ${ }^{\mathrm{TM}}$ Demonstration Project

Operating Phase Organization Chart

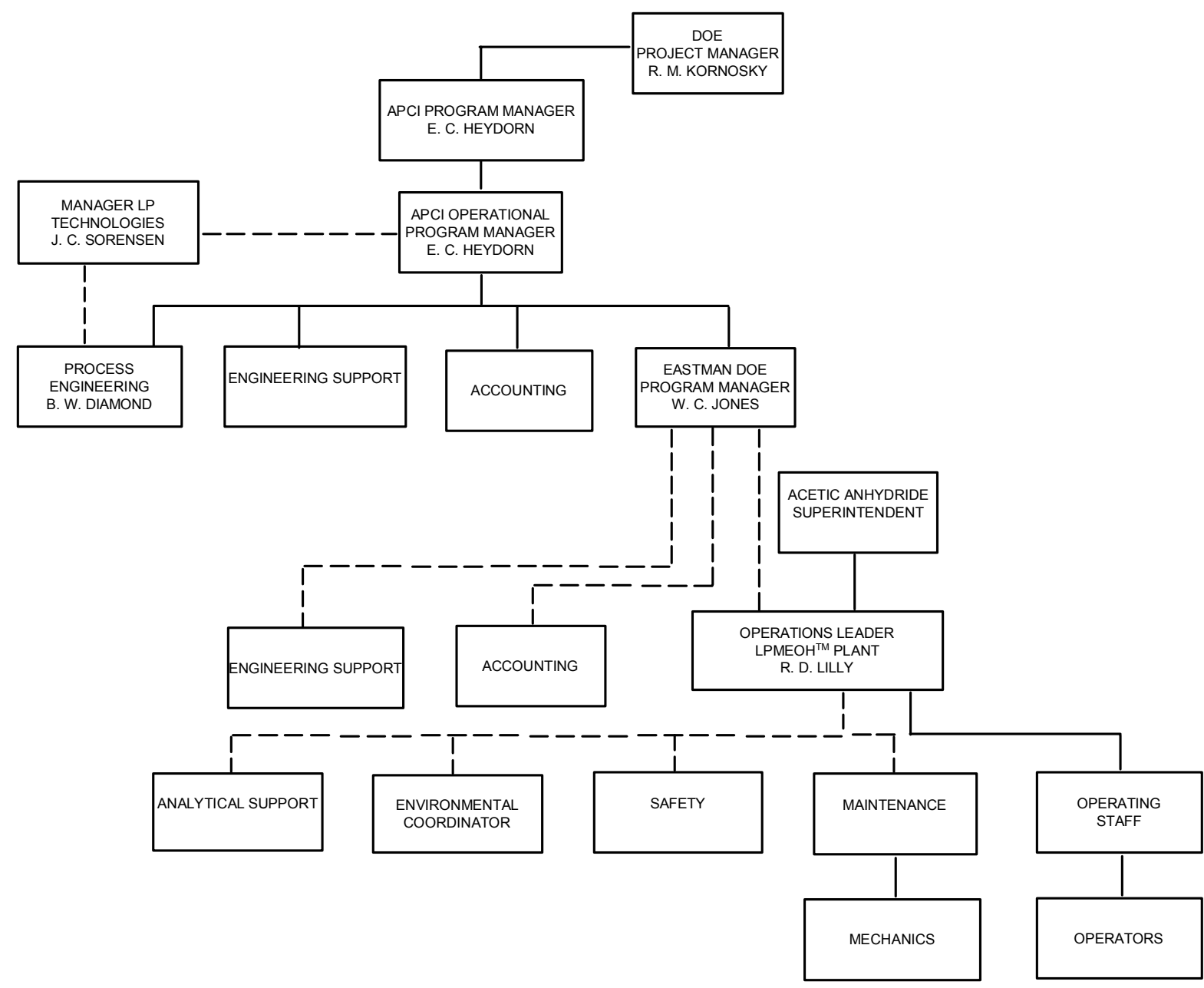




\subsection{TECHNOLOGY DESCRIPTION}

\subsection{DESCRIPTION OF THE DEMONSTRATED TECHNOLOGY}

Methanol is a versatile commodity chemical with applications ranging from fuels to feedstocks for higher valued chemicals such as methyl methacrylate and methyl tertiary-butyl ether (MTBE, an octane booster). Many applications have evolved for methanol as a fuel including methanol as a gasoline extender, the methanol to gasoline process, methanol as a feedstock to fuel cell systems, and IGCC technology for the coproduction of methanol and electricity.

The LPMEOH ${ }^{\mathrm{TM}}$ Process represents a major departure from traditional gas-phase routes to methanol in the method of removing the heat of reaction. The reactions of $\mathrm{H}_{2}$ and $\mathrm{CO}$ and carbon dioxide $\left(\mathrm{CO}_{2}\right)$ to form methanol are highly exothermic.

$$
\begin{gathered}
\mathrm{CO}+2 \mathrm{H}_{2} \longrightarrow \mathrm{CH}_{3} \mathrm{OH}+21.7 \mathrm{KCAL} / \mathrm{gmol} \\
\mathrm{CO}_{2}+3 \mathrm{H}_{2} \longrightarrow \mathrm{CH}_{3} \mathrm{OH}+\mathrm{H}_{2} \mathrm{O}+12.8 \mathrm{KCAL} / \mathrm{gmol} \\
\text { TYPICAL REACTION CONDITIONS: } \\
1,000 \text { psig } \\
440^{\circ}-520^{\circ} \mathrm{F}
\end{gathered}
$$

One of the most difficult design problems of the methanol synthesis process is removing the heat of reaction while maintaining precise temperature control to achieve optimum catalyst life and reaction rate. Catalyst life is seriously reduced by excessive temperatures.

Reactor schematics for conventional gas-phase reactors are shown in Figure 2.1-1. The catalyst is in the form of pellets. In these conventional gas-phase reactors, either cool unreacted gas is injected at stages in the catalyst bed, or internal cooling surfaces are used to provide temperature control. These schemes, however, were developed for diluted syngas which yields low conversion per pass. The LPMEOH ${ }^{\mathrm{TM}}$ Process (Figure 2.1-2) uses fine catalyst particles entrained in an inert hydrocarbon liquid, usually a mineral oil. The mineral oil acts as a temperature moderator and a heat removal medium, transferring the heat of reaction from the catalyst surface via the liquid slurry to boiling water in an internal tubular heat exchanger. As a result of this capability to remove heat and maintain a constant, highly uniform temperature through the entire length of the reactor, the slurry reactor can achieve much higher syngas conversion per pass than its gas-phase counterparts.

In addition, the LPMEOH ${ }^{\mathrm{TM}}$ Process is particularly well suited to coal-derived syngas which is rich in CO. These capabilities make the LPMEOH ${ }^{\mathrm{TM}}$ Process a potentially lower-cost conversion route to methanol, especially when methanol coproduction is added to a coal-based IGCC power plant. For a modest increase in complexity of an IGCC power plant, the methanol coproduction scheme produces a storable liquid fuel in parallel with electric power production, providing a significant turndown and peak-load capability for the IGCC power plant. 
Figure 2.1-1

Gas-Phase Methanol Reactors

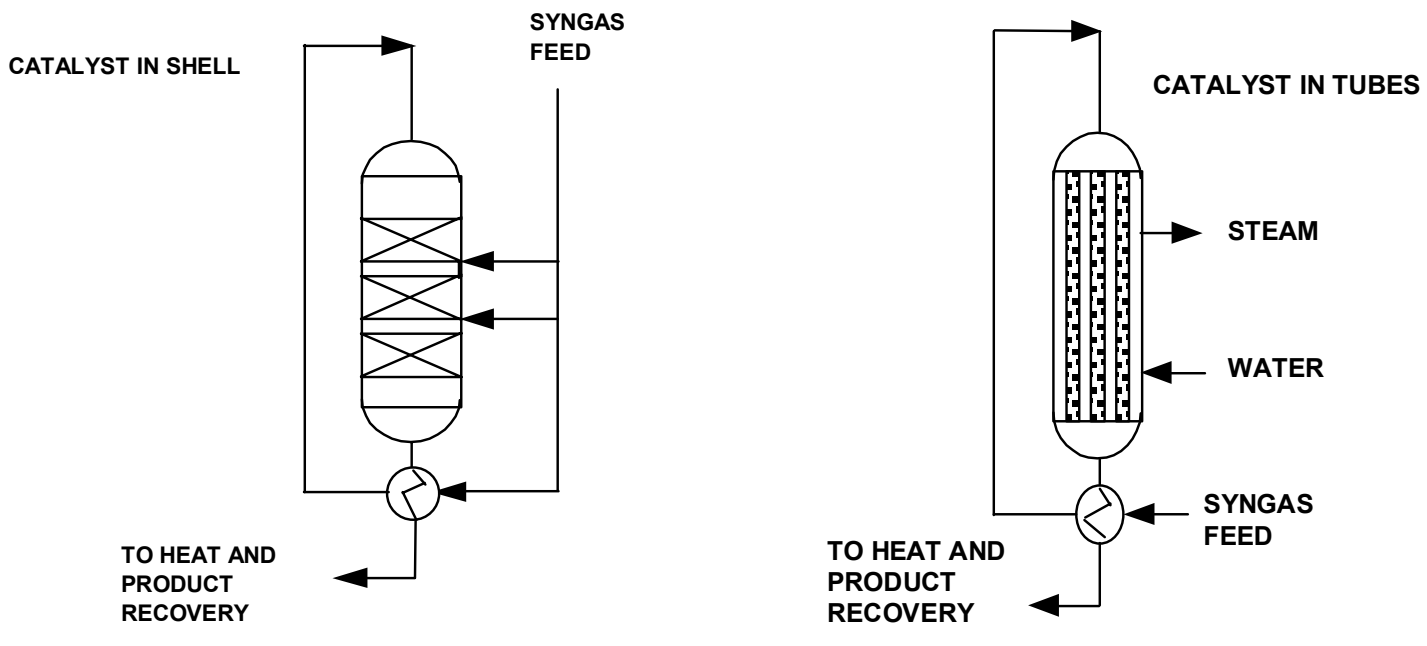

Figure 2.1-2

LPMEOH $^{\text {TM }}$ Reactor Schematic

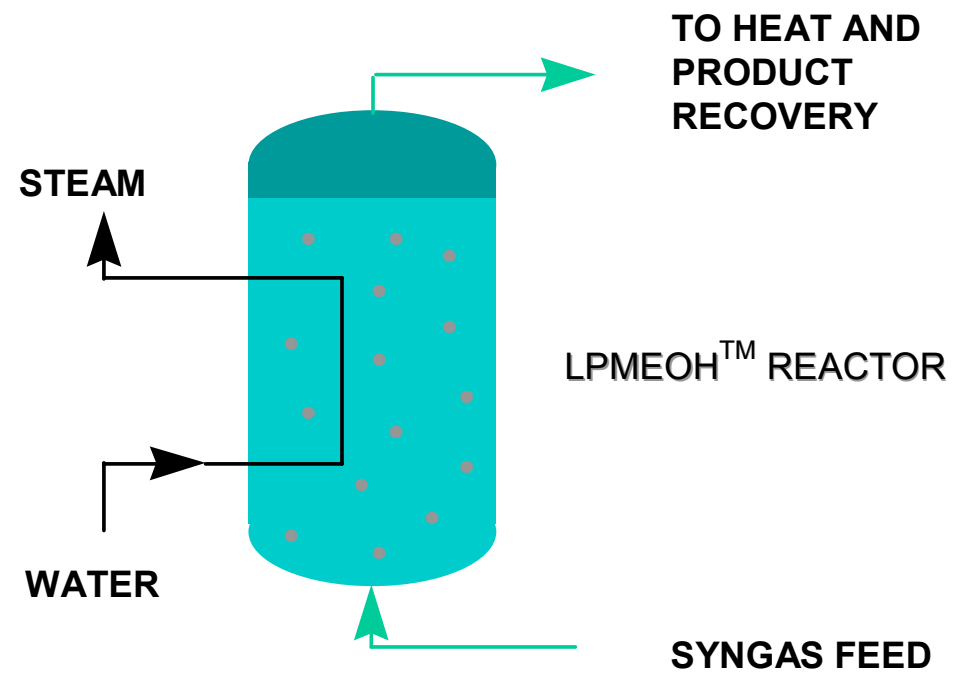

Information on the application of the LPMEOH ${ }^{\mathrm{TM}}$ Process to the IGCC power plant is provided in Section 9 of this report. 


\subsection{DESCRIPTION OF THE DEMONSTRATION FACILITY}

The reactor used in the $\mathrm{LPMEOH}^{\mathrm{TM}}$ Process is unlike conventional gas-phase reactors that use fixed beds of catalyst pellets and largely depend upon recycle diluent gas to both dilute the $\mathrm{CO}$ concentration and control the temperature rise caused by the heat of reaction. The LPMEOH ${ }^{\mathrm{TM}}$ reactor is a slurry reactor with small, powder-size catalyst particles suspended in inert mineral oil. The syngas bubbles up through the slurry where the $\mathrm{H}_{2}$ and $\mathrm{CO}$ dissolve in the oil and diffuse to the catalyst surface where the methanol reaction occurs. The product methanol diffuses out of the slurry and exits as a vapor with the unreacted syngas. The inert oil acts as a heat sink and permits isothermal operation. The net heat of reaction is removed via an internal heat exchanger which produces steam. Unlike gas-phase reactors that limit per-pass conversion of syngas to methanol to accommodate the reaction exotherm, the LPMEOH ${ }^{\mathrm{TM}}$ reactor maintains isothermal operation. The methanol vapor leaves the reactor and is condensed to a liquid, sent to distillation columns for removal of higher alcohols, water $\left(\mathrm{H}_{2} \mathrm{O}\right)$, and other impurities, and is then stored in lot tanks for sampling prior to being sent to Eastman's methanol storage. A portion of the unreacted syngas is sent back to the reactor with the recycle compressor, improving cycle efficiency. The methanol is used for downstream feedstocks and for off-site fuel-use testing.

Unlike gas-phase reactors, the $\mathrm{LPMEOH}{ }^{\mathrm{TM}}$ reactor is tolerant to CO-rich gas. Shift and $\mathrm{CO}_{2}$ removal are not required. Low $\mathrm{H}_{2}$-to-CO ratios are acceptable as is any $\mathrm{CO}_{2}$ content. Finally, in contrast to the gas-phase reactor in which the catalyst is sensitive to flow variations and changes from steady-state, the $\mathrm{LPMEOH}^{\mathrm{TM}}$ reactor is eminently suited for load-following and on/off operation in electrical generating applications.

The LPMEOH ${ }^{\mathrm{TM}}$ demonstration unit is integrated with Eastman's coal gasification facility and inserted in parallel with an existing gas-phase methanol unit.

No new equipment items were added to the $\mathrm{LPMEOH}^{\mathrm{TM}}$ demonstration unit during the operating phase; however, a different design for the pump used to add fresh mineral oil to the process was installed to replace the pumps from the original design. Also, Air Products developed two alternative designs for the gas sparger within the $\mathrm{LPMEOH}^{\mathrm{TM}}$ reactor, the last of which has been in service since March of 1999. The adsorbent material in the catalyst guard bed within the $\mathrm{LPMEOH}^{\mathrm{TM}}$ demonstration unit was also changed to remove arsine in addition to metal carbonyls, and changes were made to the piping and instrumentation system around this catalyst guard bed to allow for the new adsorbent to be pretreated prior to use in the process. Details on the changes can be found in Section 3.0 of this report.

\subsection{PROPRIETARY INFORMATION}

As noted in Section 1.1, the scope of this report is limited to nonproprietary information. Therefore, although its content is insufficient to provide a complete tool for designing a $\mathrm{LPMEOH}^{\mathrm{TM}}$ unit, it will serve as a reference for the design considerations involved in developing a commercial-scale facility. 


\subsection{SIMPLIFIED PROCESS FLOW DIAGRAM}

The LPMEOH ${ }^{\mathrm{TM}}$ demonstration unit consists of five main process sections: Feed Gas Purification, Compression, Reactor Loop and Catalyst Reduction, Distillation, and Storage and Miscellaneous. The Feed Gas Purification area includes the feed gas supply tie-ins and a catalyst guard bed. The Compression area contains the recycle gas compressor and associated systems. The Reactor Loop and Catalyst Reduction area includes the reactor with its associated equipment and the slurry handling equipment and utility oil skid associated with catalyst preparation. The Distillation area includes two distillation columns and heat exchangers. The Storage and Miscellaneous area comprises oil storage and other process components. A detailed description of these sections is provided in Section 4.3 of the Public Design Report (Final Report - Volume 1). A block diagram for the LPMEOH ${ }^{\mathrm{TM}}$ demonstration unit is provided in Figure 2.4-1. A glossary of syngas terminology is provided in the beginning of this document.

\subsection{STREAM DATA}

Table 2.5-1 shows the material balance for the points shown on Figures 1.2.3-1 and 2.4-1.

\subsection{PROCESS AND INSTRUMENTATION DIAGRAMS}

A set of Process and Instrumentation Diagrams (P\&ID's) can be found in Appendix A of the Public Design Report (Final Report - Volume 1). 
Figure 2.4-1

LPMEOH $^{\text {TM }}$ Demonstration Unit Simplified Process Flow Diagram

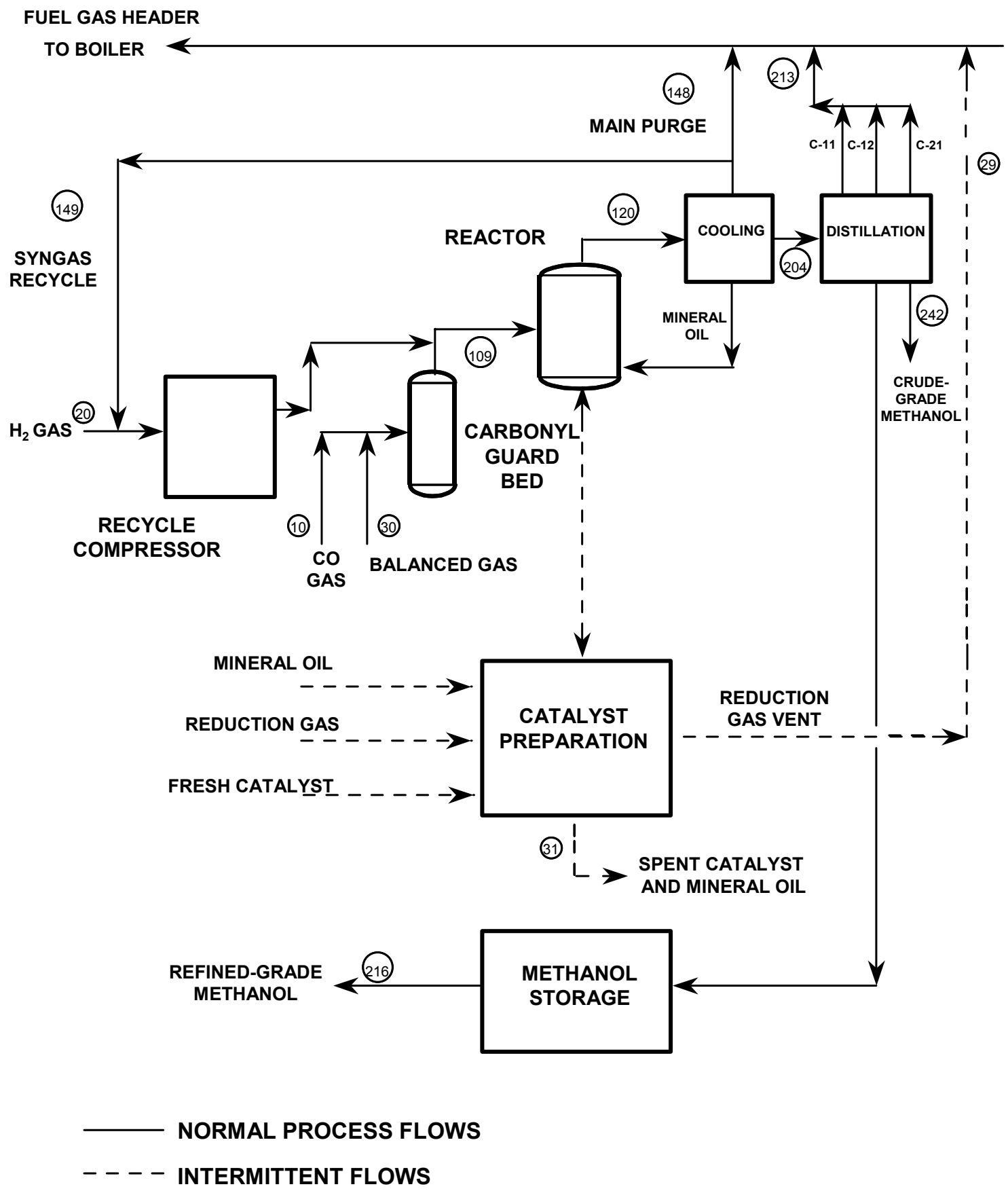

Note: Material Balance Points correspond to Stream Numbers on Table 2.5-1. 
Table 2.5-1

Heat and Material Balance Summary

\begin{tabular}{|c|c|c|c|c|c|c|c|c|}
\hline CASE: & \multicolumn{3}{|c|}{ L:\ kingsprt $\backslash \mathrm{hmb} \backslash 1 \mathrm{feb} 95 \backslash$ design } & & & & & \\
\hline Stream No. & & 10 & 109 & 120 & 148 & 149 & 20 & 204 \\
\hline Press & PSI & 875.0 & 785.0 & 735.0 & 722.0 & 722.0 & 765.0 & 85.0 \\
\hline Temp & C & 37.8 & 169.5 & 121.1 & 40.5 & 40.5 & 37.8 & 40.1 \\
\hline Temp & $\mathrm{F}$ & 100.0 & 337.1 & 249.9 & 105.0 & 105.0 & 100.0 & 104.2 \\
\hline \multicolumn{9}{|l|}{ Lb mol/hr } \\
\hline $\mathrm{H} 2$ & & 2.636 & 4402.484 & 2967.899 & 252.163 & 2712.126 & 77.996 & 3.610 \\
\hline $\mathrm{CO}$ & & 127.846 & 1818.957 & 1121.754 & 95.167 & 1023.566 & 11.594 & 3.021 \\
\hline N2 & & 1.318 & 293.947 & 294.054 & 24.922 & 268.047 & 12.648 & 1.084 \\
\hline $\mathrm{CO} 2$ & & 0.000 & 654.744 & 635.137 & 51.831 & 557.470 & 3.162 & 25.836 \\
\hline MEOH & & 0.000 & 42.496 & 744.457 & 3.952 & 42.504 & 0.000 & 698.001 \\
\hline DME & & 0.000 & 3.790 & 5.057 & 0.353 & 3.796 & 0.000 & 0.909 \\
\hline $\mathrm{H} 2 \mathrm{O}$ & & 0.000 & 0.448 & 21.642 & 0.042 & 0.448 & 0.000 & 21.152 \\
\hline ETOH & & 0.000 & 0.016 & 0.447 & 0.002 & 0.016 & 0.000 & 0.429 \\
\hline $\mathrm{C} 3 \mathrm{OH}$ & & 0.000 & 0.001 & 0.065 & 0.000 & 0.001 & 0.000 & 0.063 \\
\hline $\mathrm{C} 4 \mathrm{OH}$ & & 0.000 & 0.000 & 0.026 & 0.000 & 0.000 & 0.000 & 0.026 \\
\hline$\sqrt{\mathrm{IBOH}}$ & & 0.000 & 0.001 & 0.087 & 0.000 & 0.001 & 0.000 & 0.086 \\
\hline $\mathrm{C} 5 \mathrm{OH}$ & & 0.000 & 0.000 & 0.018 & 0.000 & 0.000 & 0.000 & 0.018 \\
\hline MEAC & & 0.000 & 0.065 & 0.242 & 0.006 & 0.065 & 0.000 & 0.171 \\
\hline MEFM & & 0.000 & 1.256 & 2.790 & 0.117 & 1.259 & 0.000 & 1.415 \\
\hline C1 & & 0.000 & 12.228 & 13.449 & 1.137 & 12.234 & 0.000 & 0.077 \\
\hline $\mathrm{C} 2$ & & 0.000 & 3.549 & 3.982 & 0.331 & 3.557 & 0.000 & 0.095 \\
\hline C3 & & 0.000 & 1.007 & 1.171 & 0.094 & 1.010 & 0.000 & 0.067 \\
\hline OIL & & 0.000 & 0.000 & 0.032 & 0.000 & 0.000 & 0.000 & 0.032 \\
\hline Total molar flow & & 131.8 & 7235.0 & 5812.3 & 430.1 & 4626.1 & 105.4 & 756.1 \\
\hline Total mass flow & $\mathrm{lb} / \mathrm{hr}$ & 3,623 & 98,846 & 98,686 & 6,337 & 68,154 & 975 & 24,195 \\
\hline Enthalpy & MMBtu/hr & -6.083 & -188.288 & -221.879 & -13.674 & -147.071 & -1.066 & -79.011 \\
\hline & & & & & & & & \\
\hline \multicolumn{9}{|l|}{ mol\% } \\
\hline $\mathrm{H} 2$ & & 2.000 & 60.850 & 51.062 & 58.627 & 58.627 & 74.000 & 0.477 \\
\hline $\mathrm{CO}$ & & 97.000 & 25.141 & 19.300 & 22.126 & 22.126 & 11.000 & 0.400 \\
\hline N2 & & 1.000 & 4.063 & 5.059 & 5.794 & 5.794 & 12.000 & 0.143 \\
\hline $\mathrm{CO} 2$ & & 0.000 & 9.050 & 10.927 & 12.051 & 12.051 & 3.000 & 3.417 \\
\hline MEOH & & 0.000 & 0.587 & 12.808 & 0.919 & 0.919 & 0.000 & 92.317 \\
\hline DME & & 0.000 & 0.052 & 0.087 & 0.082 & 0.082 & 0.000 & 0.120 \\
\hline $\mathrm{H} 2 \mathrm{O}$ & & 0.000 & 0.006 & 0.372 & 0.010 & 0.010 & 0.000 & 2.797 \\
\hline ETOH & & 0.000 & 0.000 & 0.008 & 0.000 & 0.000 & 0.000 & 0.057 \\
\hline $\mathrm{C} 3 \mathrm{OH}$ & & 0.000 & 0.000 & 0.001 & 0.000 & 0.000 & 0.000 & 0.008 \\
\hline $\mathrm{C} 4 \mathrm{OH}$ & & 0.000 & 0.000 & 0.000 & 0.000 & 0.000 & 0.000 & 0.003 \\
\hline IBOH & & 0.000 & 0.000 & 0.001 & 0.000 & 0.000 & 0.000 & 0.011 \\
\hline $\mathrm{C} 5 \mathrm{OH}$ & & 0.000 & 0.000 & 0.000 & 0.000 & 0.000 & 0.000 & 0.002 \\
\hline MEAC & & 0.000 & 0.001 & 0.004 & 0.001 & 0.001 & 0.000 & 0.023 \\
\hline MEFM & & 0.000 & 0.017 & 0.048 & 0.027 & 0.027 & 0.000 & 0.187 \\
\hline C1 & & 0.000 & 0.169 & 0.231 & 0.264 & 0.264 & 0.000 & 0.010 \\
\hline C2 & & 0.000 & 0.049 & 0.069 & 0.077 & 0.077 & 0.000 & 0.013 \\
\hline C3 & & 0.000 & 0.014 & 0.020 & 0.022 & 0.022 & 0.000 & 0.009 \\
\hline OIL & & 0.000 & 0.000 & 0.001 & 0.000 & 0.000 & 0.000 & 0.004 \\
\hline Total & & 100 & 100 & 100 & 100 & 100 & 100 & 100 \\
\hline & & & & & & & & \\
\hline Vapor Fraction & & 1.000 & 1.000 & 1.000 & 1.000 & 1.000 & 1.000 & 0.025 \\
\hline Liquid Fraction & & 0.000 & 0.000 & 0.000 & 0.000 & 0.000 & 0.000 & 0.975 \\
\hline Mol. Wt. Mix & & 27.490 & 13.662 & 16.979 & 14.733 & 14.733 & 9.255 & 32.000 \\
\hline Mol. Wt. Vapor & & 27.490 & 13.662 & 16.979 & 14.733 & 14.733 & 9.255 & 32.286 \\
\hline Mol. Wt. Liquid & & & & & & & & 31.992 \\
\hline \begin{tabular}{|l} 
Density \\
\end{tabular} & LB/ CUFT & 4.092 & 1.206 & 1.621 & 1.701 & 1.701 & 1.114 & 13.386 \\
\hline Vapor Density & LB/ CUFT & 4.092 & 1.206 & 1.621 & 1.701 & 1.701 & 1.114 & 0.461 \\
\hline Liquid Density & LB/ CUFT & & & & & & & 48.981 \\
\hline & & & & & & & & \\
\hline
\end{tabular}


Table 2.5-1

Heat and Material Balance Summary (cont'd)

\begin{tabular}{|c|c|c|c|c|c|}
\hline CASE: & \multicolumn{3}{|c|}{ L:\king sprt $\backslash \mathrm{hmb} \backslash 1 \mathrm{fe} b 95 \backslash$ design } & & \\
\hline Stream No. & & 213 & 216 & 242 & 30 \\
\hline Press & PSI & & 40.0 & 80.0 & 790.0 \\
\hline Temp & C & & 40.7 & 100.8 & 37.8 \\
\hline Temp & $\mathrm{F}$ & & 105.3 & 213.4 & 100.0 \\
\hline \multicolumn{6}{|l|}{ Lb mol/hr } \\
\hline $\mathrm{H} 2$ & & 3.610 & 0.000 & 0.000 & 1608.013 \\
\hline $\mathrm{CO}$ & & 3.021 & 0.000 & 0.000 & 656.961 \\
\hline N2 & & 1.084 & 0.000 & 0.000 & 11.859 \\
\hline $\mathrm{CO} 2$ & & 25.836 & 0.000 & 0.000 & 94.868 \\
\hline $\mathrm{MEOH}$ & & 3.601 & 520.901 & 173.499 & 0.000 \\
\hline DME & & 0.909 & 0.000 & 0.000 & 0.000 \\
\hline $\mathrm{H} 2 \mathrm{O}$ & & 0.013 & 0.054 & 21.084 & 0.000 \\
\hline ETOH & & 0.000 & 0.043 & 0.386 & 0.000 \\
\hline $\mathrm{C} 3 \mathrm{OH}$ & & 0.000 & 0.000 & 0.063 & 0.000 \\
\hline $\mathrm{C} 4 \mathrm{OH}$ & & 0.000 & 0.000 & 0.026 & 0.000 \\
\hline $\mathrm{IBOH}$ & & 0.000 & 0.000 & 0.085 & 0.000 \\
\hline $\mathrm{C} 5 \mathrm{OH}$ & & 0.000 & 0.000 & 0.018 & 0.000 \\
\hline MEAC & & 0.170 & 0.002 & 0.000 & 0.000 \\
\hline MEFM & & 1.415 & 0.000 & 0.000 & 0.000 \\
\hline C1 & & 0.077 & 0.000 & 0.000 & 0.000 \\
\hline $\mathrm{C} 2$ & & 0.095 & 0.000 & 0.000 & 0.000 \\
\hline C3 & & 0.067 & 0.000 & 0.000 & 0.000 \\
\hline OIL & & 0.000 & 0.000 & 0.032 & 0.000 \\
\hline Total molar flow & & 39.9 & 521.0 & 195.2 & 2371.7 \\
\hline Total mass flow & $\mathrm{lb} / \mathrm{hr}$ & 1,521 & 16,694 & 5,980 & 26,150 \\
\hline Enthalpy & MMBtu/hr & -5.147 & -53.303 & -19.938 & -46.877 \\
\hline \multicolumn{6}{|l|}{ mol\% } \\
\hline $\mathrm{H} 2$ & & 9.048 & 0.000 & 0.000 & 67.800 \\
\hline $\mathrm{CO}$ & & 7.572 & 0.000 & 0.000 & 27.700 \\
\hline N2 & & 2.718 & 0.000 & 0.000 & 0.500 \\
\hline $\mathrm{CO} 2$ & & 64.755 & 0.000 & 0.000 & 4.000 \\
\hline $\mathrm{MEOH}$ & & 9.026 & 99.981 & 88.885 & 0.000 \\
\hline DME & & 2.278 & 0.000 & 0.000 & 0.000 \\
\hline $\mathrm{H} 2 \mathrm{O}$ & & 0.033 & 0.010 & 10.802 & 0.000 \\
\hline ETOH & & 0.001 & 0.008 & 0.198 & 0.000 \\
\hline $\mathrm{C} 3 \mathrm{OH}$ & & 0.000 & 0.000 & 0.033 & 0.000 \\
\hline $\mathrm{C} 4 \mathrm{OH}$ & & 0.000 & 0.000 & 0.013 & 0.000 \\
\hline $\mathrm{IBOH}$ & & 0.000 & 0.000 & 0.044 & 0.000 \\
\hline $\mathrm{C} 5 \mathrm{OH}$ & & 0.000 & 0.000 & 0.009 & 0.000 \\
\hline MEAC & & 0.425 & 0.000 & 0.000 & 0.000 \\
\hline MEFM & & 3.546 & 0.000 & 0.000 & 0.000 \\
\hline C1 & & 0.193 & 0.000 & 0.000 & 0.000 \\
\hline $\mathrm{C} 2$ & & 0.237 & 0.000 & 0.000 & 0.000 \\
\hline C3 & & 0.168 & 0.000 & 0.000 & 0.000 \\
\hline OIL & & 0.000 & 0.000 & 0.017 & 0.000 \\
\hline Total & & 100 & 100 & 100 & 100 \\
\hline Vapor Fraction & & 1.000 & 0.000 & 0.000 & 1.000 \\
\hline Liquid Fraction & & 0.000 & 1.000 & 1.000 & 0.000 \\
\hline Mol. Wt. Mix & & 38.132 & 32.042 & 30.634 & 11.026 \\
\hline Mol. Wt. Vapor & & -0.003 & & & 11.026 \\
\hline Mol. Wt. Liquid & & & 32.042 & 30.634 & \\
\hline Density & LB/ CUFT & & 48.306 & 45.200 & 1.377 \\
\hline Vapor Density & LB/CUFT & & & & 1.377 \\
\hline Liquid Density & LB/ CUFT & & 48.306 & 45.200 & \\
\hline
\end{tabular}




\subsection{UPDATE OF THE PUBLIC DESIGN REPORT}

\subsection{DESIGN AND EQUIPMENT CHANGES}

Over the first three years of operation, the $\mathrm{LPMEOH}^{\mathrm{TM}}$ demonstration unit achieved an availability in excess of $97 \%$. Engineering data was collected and analyzed so that the engineering tools that are necessary for the design of larger-scale $\mathrm{LPMEOH}^{\mathrm{TM}}$ plants could be improved. Much of the work associated with process optimization was completed, and ideas to reduce the number of rotating equipment items which simplify the process were successfully implemented.

Early performance of the proprietary gas sparger within the $\mathrm{LPMEOH}^{\mathrm{TM}}$ reactor $(7.5$ ' internal diameter) met expectations for gas distribution and reactor hydrodynamics, but the

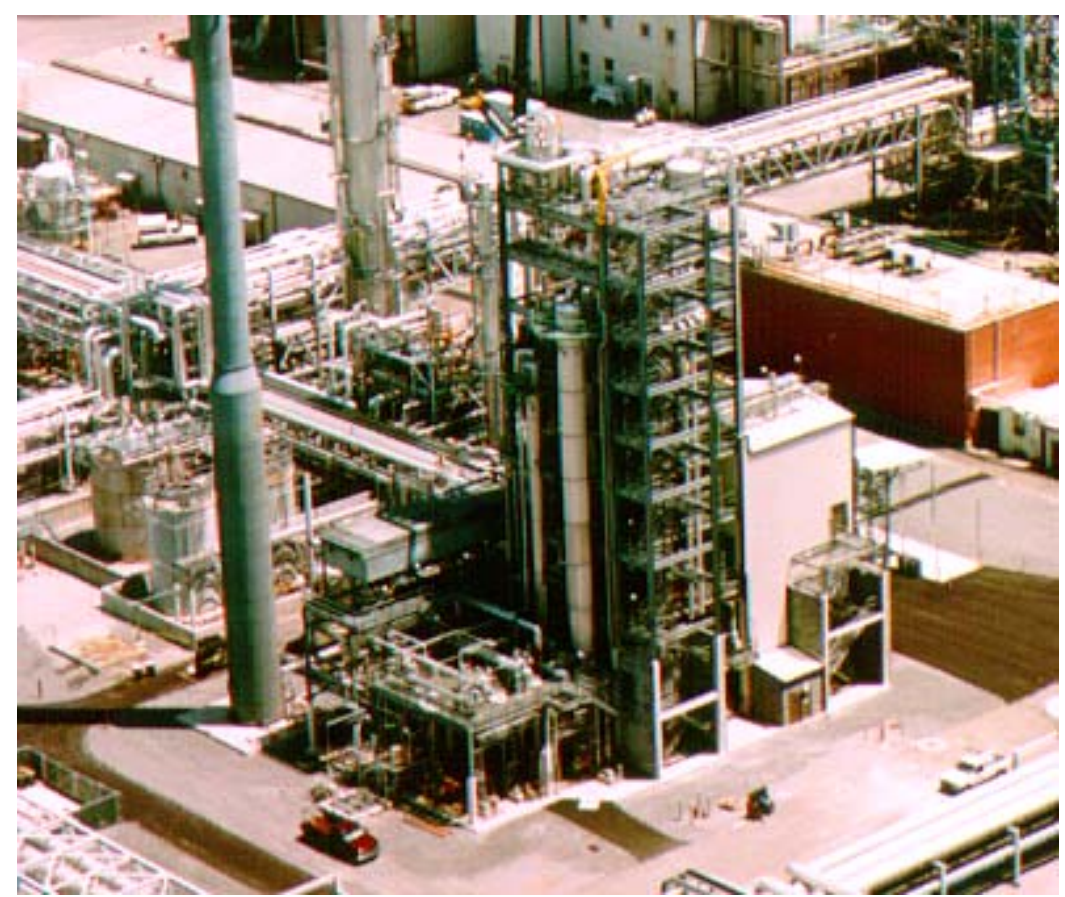
pressure drop across the device increased over time. Ultimately, the flow resistance across the sparger reached a value that severely limited the quantity of syngas that could be processed. After some proprietary studies conducted by Air Products, two updated spargers, designed by Air Products and fabricated by Eastman for the Partnership, were placed into service, the latest being in March of 1999. As detailed in Section 5.3, this device has shown excellent performance, with no increase in pressure drop over time.

Another technical challenge was the impact of trace contaminants present in the coal-derived syngas (which is the primary feedstock to the $\mathrm{LPMEOH}^{\mathrm{TM}}$ reactor) on the long-term performance and life of the methanol synthesis catalyst. These species, which are typically found in coal and are present in syngas streams in parts-per-billion levels, reduce the life of the catalyst, thus adversely affecting the economics of the LPMEOH ${ }^{\mathrm{TM}}$ Process. During the first year of operation, the rate of deactivation of the methanol synthesis catalyst was significantly higher that the target value which had been previously determined in a 4-month proof-of-concept test at the LaPorte AFDU. Significant progress was made in identifying both the species of catalyst poisons present in the syngas and the adsorbents which, when used upstream in the catalyst guard bed vessels, can effectively and economically remove these contaminants. Additional information is provided in Section 5.2. 


\subsubsection{Condensed Oil (29G-01) and Oil Makeup (29G-03) Pumps}

During plant commissioning activities, two sets of pumps required additional attention and impacted the mode of operation of the LPMEOH ${ }^{\mathrm{TM}}$ demonstration unit during startup.

The 29G-01 condensed oil pumps were designed to return condensed and entrained oil and catalyst from the 29C-05 secondary oil knock-out drum and 29C-06 cyclone to the 29C-01 LPMEOH $^{\mathrm{TM}}$ reactor. A twin-screw design was selected due to the potential for high solids loadings at reactor temperatures and pressures. The 29G-03 oil make-up pumps were intended to provide seal flush to the condensed oil pumps, oil addition to the reactor loop, and high-pressure (1,100 psig) piping flush oil. The pumps also employed a twin-screw design with extremely tight clearances to generate high pressure differential, as the make-up oil was stored in the 29D30 oil storage tank at low pressure (less than $10 \mathrm{psig}$ ). During initial commissioning activities in January of 1997, these pumps operated well during testing at the required discharge pressure of 700 to 900 psig. However, during subsequent testing, both oil make-up pumps exhibited difficulty in delivering oil at the required pressure. Notably, since the oil make-up pumps could not function at rated conditions to supply the necessary seal flush, the condensed oil pumps could not operate at full suction pressure.

During the plant design phase, in anticipation of operating problems with the condensed oil pumps, the elevation of the slurry collection equipment (secondary oil knock-out drum and cyclone) was raised high enough to permit any entrained or condensed material to gravity-drain back to the reactor. Because of the inability of the oil make-up pumps to provide seal flush for the condensed oil pumps, operation in the free-draining mode began at startup, and initial results were positive. Fresh make-up oil was added to the process by using the 29G-30 slurry transfer pump, which was designed to transfer catalyst slurry from the 29C-30 catalyst reduction vessel to the LPMEOH ${ }^{\mathrm{TM}}$ reactor. The slurry transfer pump packing also requires flush from the oil make-up pumps; however, it was determined that operation of the slurry transfer pump in cleanoil service without packing flush would not adversely affect the service life of the pump. Accordingly, make-up oil was batch-transferred from the oil storage tank to the catalyst reduction vessel, and then pumped to the reactor by the slurry transfer pump.

The gravity-drain line did exhibit intermittent plugging or vapor-locking during operation. Early in the operating campaign, blockages could be cleared by opening a utility line between the secondary oil knock-out drum and the catalyst reduction vessel and briefly blowing down to low pressure; piping connections to provide flush oil were rendered useless by the inoperable highpressure oil make-up pumps. However, on 25 April 1997, a blockage occurred in the free-drain line that could not be removed by this method. Since the solids concentration of the condensed and entrained oil and catalyst slurry was relatively low, it was determined that the slurry transfer pump could pump this material without a packing flush on the pump. Condensed oil was batchtransferred from the secondary oil knock-out drum to the catalyst reduction vessel, and then pumped to the reactor. The frequency of the transfer to the catalyst reduction vessel was about once every three hours, and the catalyst reduction vessel was pumped to the reactor about once every 10 hours. The calculated accumulation rate of condensed and entrained slurry (1.5 to 2.0 gpm) matched the expected liquid traffic within the oil/catalyst collection equipment. This early 
operating experience confirmed that the ability to flush piping systems in slurry service was an important operability requirement.

After an engineering review by Air Products and Eastman, a new 29G-03 oil make-up pump was specified with a simpler design than the original twin-screw configuration. Only one of these new pumps was purchased and installed to develop operational experience at minimum capital cost. The new pump, priced at $\$ 7,900$, was brought online in October of 1997 and met all operational requirements. The availability of this pump to flush out periodic blockages in the gravity-drain line established the viability of that concept to return condensed and entrained slurry to the LPMEOH ${ }^{\mathrm{TM}}$ reactor, and as a result, the condensed oil pumps were not put into service under operating conditions. The potential benefits are tremendous for future designs, including: significant capital cost savings from the elimination of two slurry pumps and their ancillaries (and perhaps the redundant oil make-up pump); increased operating flexibility; and lower maintenance costs by eliminating the seal system for the slurry pumps.

The long-term success of the gravity-draining system to return entrained slurry and condensed oil to the LPMEOH ${ }^{\mathrm{TM}}$ reactor eliminated the need for the condensed oil pumps and their continuous seal flush requirement. As a result, the single oil make-up pump has continued to operate in batch mode only. In this mode, the pump has added oil to the LPMEOH ${ }^{\mathrm{TM}}$ Process to provide flush oil to piping and instrumentation associated with the LPMEOH ${ }^{\mathrm{TM}}$ reactor and cyclone; the amount of flush oil can be optimized to match the required amount of make-up oil that is necessary to overcome the average oil loss rate with the methanol product (nominally 0.1 to $0.2 \mathrm{gpm}$ ). The new pump has operated well in over five years of operation in this batch mode.

\subsubsection{Slurry Return Pump (29G-02)}

During the initial startup of the LPMEOH ${ }^{\mathrm{TM}}$ demonstration unit, individual batches of methanol catalyst slurry were activated in the 29C-30 catalyst reduction vessel and then pressuretransferred into the 29D-02 slurry tank. After activation of the ninth and final batch, the entire charge was to be pumped from the slurry storage tank to the reactor using the 29G-02 slurry return pump. This pump included a packing design which required a continuous flush of clean oil from the oil storage tank using the 29G-34 oil feed pump. During the transfer operation, seal oil leaked through the packing at a significantly higher rate than expected. If this condition had continued throughout the transfer, the oil would have diluted the slurry considerably, perhaps to the point of overfilling the reactor vessel. The operations team decided to apply $\mathrm{N}_{2}$ at $45-50 \mathrm{psig}$ to the slurry tank and pressure-transfer the remaining slurry to the reactor. This procedure was accomplished successfully, and the technique was used for all remaining slurry transfer steps when the slurry tank was utilized. This pump will be eliminated in future designs, providing an opportunity for capital savings and improved operability.

\subsubsection{Availability of Hydrogen Gas ( $\mathrm{H}_{2} \underline{\text { Gas) }}$}

During the design phase for the LPMEOH ${ }^{\mathrm{TM}}$ demonstration unit, one of the feed syngas streams was the purge stream from the existing gas-phase methanol unit (called hydrogen gas or $\mathrm{H}_{2} \mathrm{Gas}$ ). This stream contained an excess of $\mathrm{H}_{2}$ over the stoichiometric balance for the production of methanol, and was expected to be used to adjust the $\mathrm{H}_{2}: \mathrm{CO}$ ratio during several of the tests 
within the demonstration test plan. However, due to pressure control issues in the Eastman chemicals-from-coal complex, the operating pressure for $\mathrm{H}_{2} \mathrm{Gas}$ had to be reduced to less that the operating pressure of the LPMEOH ${ }^{\mathrm{TM}}$ demonstration unit. As a consequence, $\mathrm{H}_{2}$ Gas was not available as a feed gas. The impact of this change from the plant design basis on the ability to meet the technical objectives for the LPMEOH ${ }^{\text {TM }}$ Demonstration Project was minimal; details are provided in Section 4.1.

\subsubsection{Gas Sparger}

Because the performance of a slurry bubble column reactor depends heavily on the method of introduction of feed gas, the gas sparger design is a key feature of the overall LPMEOH ${ }^{\mathrm{TM}}$ reactor design. The gas sparger design for the $\mathrm{LPMEOH}^{\mathrm{TM}}$ demonstration unit was based on the device used during the successful 4-month proof-of-concept run at the LaPorte AFDU in 1988/89. In general, the process scaleup from the LaPorte AFDU to commercial scale was a significant objective for the LPMEOH ${ }^{\mathrm{TM}}$ Demonstration Project, and the gas sparger was one of the key components in this area.

Three different gas sparger designs were utilized during the operation of the LPMEOH ${ }^{\mathrm{TM}}$ demonstration unit. The original gas sparger design was used from startup in April of 1997 until November of 1997. The second gas sparger design was a modification of the first sparger using similar design principles and was installed in December of 1997. This design was used until March of 1999. A modified sparger design, again using the same design principles as the original device, was installed in March of 1999 and was used for the remainder of the demonstration test program. Details on the performance of the three devices are provided in Section 5.3.

\subsection{DEMONSTRATION PLANT EQUIPMENT COST UPDATE}

The updated equipment cost summary for the LPMEOH ${ }^{\mathrm{TM}}$ demonstration unit is provided in Table 3.2-1. The only additional equipment that was purchased during the demonstration period was the replacement for the 29G-03 oil makeup pump (described in Section 3.1.1). It should be noted that, if the pumps and associated equipment described in Section 3.1 had not been installed, the equipment cost of the LPMEOH ${ }^{\mathrm{TM}}$ demonstration unit would have been reduced by almost 5\% (\$210,000 out of $\$ 4.4$ million). 
Table 3.2-1

Kingsport LPMEOH ${ }^{\mathrm{TM}}$ Demonstration Unit - Update of Equipment Cost Summary

(Dollars in Thousands)

Area Item Description

Total Subtotal

A Feed Gas Purification

$\$ 77.0 \quad \$ 77.0$

B Compression

$\$ 776.8$

Compression

$\$ 699.6$

Exchangers

$\$ 37.6$

Separators

$\$ 39.6$

C Reactor Loop and Catalyst Reduction

$\$ 2,202.1$

Equipment

Exchangers

Pumps

$\$ 1,487.8$

$\$ 332.3$

$\$ 382.0$

D Distillation

$\$ 703.4$

Equipment

$\$ 309.5$

Exchangers

$\$ 214.7$

Tanks

$\$ 131.3$

Pumps and Misc.

$\$ 47.9$

E Storage and Miscellaneous

$\$ 648.6 \$ 648.6$

Total $\$ \mathbf{\$ 4 , 4 0 7 . 9} \$ 4,407.9$

\subsection{DEMONSTRATION PLANT OPERATING COST UPDATE}

Table 3.3-1 summarizes the updated operating costs for the LPMEOH ${ }^{\mathrm{TM}}$ demonstration unit. A new category of costs was added to cover the changeout and disposal of the adsorbent from the 29C-40 carbonyl guard bed (the costs and consumption utilized at the end of the demonstration period are used in the tabulation of costs). The costs were developed using the performance following the successful demonstration of the in-situ activation procedure and temperature programming (details are provided in Section 5.6) to extend the life of the methanol synthesis catalyst. 
Table 3.3-1

Kingsport LPMEOH ${ }^{\mathrm{TM}}$ Demonstration Unit - Update of Operating Costs

Base Year $\underline{2002}$

\begin{tabular}{lr}
\multicolumn{2}{c}{ ANNUAL FIXED OPERATING COST } \\
\hline \\
Number of Operators per Shift & 1.5 \\
Number of Shifts per Week & 4.2 \\
Operating and Technical Support Labor Rate, $\$ / h r$ & $\$ 76.71$ \\
& \\
& \\
Total Annual Operating and Technical Support Labor Cost & $\$ 671,971$ \\
Total Annual Maintenance Labor Cost & $\$ 510,440$ \\
Total Annual Maintenance Material Cost & $\$ 249,999$ \\
Total Annual Administration and Support Labor Cost & $\$ 1,925,670$ \\
TOTAL ANNUAL FIXED O\&M COST & $\$ 3,358,081$
\end{tabular}

VARIABLE OPERATING COST

Commodity

Compressed Air

Demineralized Water

Electricity

Filtered Water

High Pressure Steam

Low Pressure Steam

Medium Pressure Steam

Nitrogen

Synthesis Gas

Catalyst

Mineral Oil

Guard Bed Adsorbent (incl. disposal)

Waste Water

Slurry Reclaiming

Distillation of 29C-20 Underflow

Area Services (laboratory, general services)

\begin{tabular}{|c|c|c|c|}
\hline Unit & $\$ /$ Unit $^{(1)}$ & Quantity/hr & $\$ / \mathrm{hr}$ \\
\hline 1,000 SCF & 0.22 & 18.00 & 3.95 \\
\hline $1,000 \mathrm{Lb}$ & 0.66 & $2,500.00$ & 1.65 \\
\hline kWh & 0.04 & 770.00 & 33.82 \\
\hline $1,000 \mathrm{Gal}$ & 0.49 & 0.30 & 0.15 \\
\hline 1,000 Lb & 5.49 & 6.00 & 32.94 \\
\hline 1,000 Lb & 4.94 & -1.00 & -4.94 \\
\hline $1,000 \mathrm{Lb}$ & 4.39 & 12.50 & 54.90 \\
\hline 1,000 SCF & 0.66 & 4.00 & 2.64 \\
\hline 1,000 SCF & 4.48 & 850.00 & $3,805.62$ \\
\hline $1 \mathrm{Lb}$ & 10.29 & 5.21 & 53.58 \\
\hline $1 \mathrm{Gal}$ & 3.03 & 7.18 & 21.78 \\
\hline $1 \mathrm{Lb}$ & 9.07 & 2.81 & 25.52 \\
\hline 1 year & $15,152.12$ & & 1.97 \\
\hline $1 \mathrm{Lb}$ & 0.38 & 7.81 & 2.95 \\
\hline $1 \mathrm{Gal}$ & 0.05 & 781.25 & 42.89 \\
\hline 1 month & $86,985.60$ & & 135.92 \\
\hline
\end{tabular}

TOTAL VARIABLE OPERATING COST

$4,215.33$

TOTAL ANNUAL OPERATING HOURS FOR DEMONSTRATION

7,680

(1) - These unit costs reflect the costs incurred by the Air Products Liquid Phase Conversion Company, L.P. (the Partnership) and are typical of published utility costs (for example, Process Economics Program Report 136A, "Plant Utility Costs", published by SRI International, Menlo Park, CA), and have been indexed for inflation from 1997 to 2002 using data from the Producer Price Index - Chemicals and Allied Products. 


\subsection{DEMONSTRATION PROGRAM}

\subsection{TEST PLANS}

A Demonstration Test Plan ${ }^{(a)}$ was prepared from the Technical Objectives set for the project. This original version was comprised of 37 specific tests. These are given in Table 3-2 of the Public Design Report (Final Report - Volume 1). The conditions imposed by each of these tests were incorporated in the process design of the LPMEOH ${ }^{\mathrm{TM}}$ demonstration unit.

Based upon the results from the initial three years of operation of the LPMEOH ${ }^{\mathrm{TM}}$ demonstration unit as well as the identification of new tests of significant commercial interest, an update to the Demonstration Test Plan was proposed by Air Products in 2000. The impact of catalyst poisons, both as post-construction debris and as present in the Balanced Gas feed, on the long-term performance of the catalyst altered the timeline for completing the objectives as stated in the Section 1.3.1 of this report. As a result, operating activities were focused upon studying the effects of catalyst concentration in the reactor (an important parameter in plant economics) on reactor hydrodynamics. As noted in Section 5.1, the weight of catalyst in the reactor reached a maximum of $151 \%$ of design during this step-wise approach to determining the operating limits for the slurry bubble column reactor.

Operation of the LPMEOH ${ }^{\mathrm{TM}}$ demonstration unit was different relative to the original design concept, thus eliminating either the ability or the need to complete several of the tests which had been included in the original Demonstration Test Plan (refer to Table 3.2 of the Public Design Report [Final Report - Volume 1] for the relevant test number and description):

1) In the original plant configuration, $\mathrm{H}_{2}$ Gas was included as one of the feed syngas streams to the LPMEOH ${ }^{\text {TM }}$ demonstration unit. However, as noted in Section 3.1, $\mathrm{H}_{2}$ Gas was not available as a feed gas. This eliminated the ability to complete Test 12 . Tests 13 and 14 also became redundant, as these conditions were covered in other tests.

2) Based upon the inspection of the cyclone separator and feed/product economizer at the vapor outlet of the LPMEOH ${ }^{\mathrm{TM}}$ reactor, it was concluded that some form of separation device which limits the flow of entrained slurry from the reactor to the tubes of the heat exchanger will be required in future designs. This eliminated the need to perform the portion of Test 19 during which the cyclone would be bypassed.

3) A consequence of increasing the catalyst slurry concentration in the LPMEOH reactor beyond the design value was that the extent of conversion of $\mathrm{CO}$ was increased. As the amount of $\mathrm{CO}$ is depleted in the reactor effluent and recycle gas streams, the $\mathrm{H}_{2}$ : $\mathrm{CO}$ ratio at the reactor feed was increased. Adequate data had already been acquired at elevated $\mathrm{H}_{2}: \mathrm{CO}$ ratios such that a separate test for natural gas reformer-type syngas (Test 24) was no longer required.

4) Since the restart of the LPMEOH ${ }^{\mathrm{TM}}$ demonstration unit on the second charge of fresh catalyst in December of 1997, the majority of operating time was spent at a reactor 
temperature of $235^{\circ} \mathrm{C}$. This allowed for additional study of catalyst performance as a function of operating temperature, which has importance for the LPMEOH ${ }^{\mathrm{TM}}$ Process in applications regarding coal-derived syngas (effect of operating temperature on the impact of catalyst poisons) and natural gas systems (extending catalyst life in the absence of poisons).

5) The amount of time allocated in the original Demonstration Test Plan to the study of catalyst performance above the original design temperature of $250^{\circ} \mathrm{C}$ was overestimated. Also, it was not logical to return to lower temperature in the reactor following operation at elevated temperature; this eliminated the need to perform Test 29.

6) During the operating program for the LPMEOH ${ }^{\mathrm{TM}}$ demonstration unit, modes of operation which were not anticipated during the development of the original Demonstration Test Plan were identified. The ability to activate the methanol synthesis catalyst within the LPMEOH ${ }^{\mathrm{TM}}$ reactor by using syngas which is diluted with $\mathrm{N}_{2}$ (so-called in-situ activation) can result in capital cost savings of about $10 \%$ by elimination of the separate processing equipment which is used at the demonstration unit. Also, the life of the methanol synthesis catalyst can be extended by operating the $\mathrm{LPMEOH}^{\mathrm{TM}}$ reactor at low temperatures at the outset and slowly increasing temperature with time to maintain a constant production of methanol (socalled temperature programming).

A tabulation of the conditions that were operated during the execution of the Demonstration Test Plan is provided in Table 4.1-1. This shows the test runs and the operating conditions. The time chart for execution of the Plan is provided in Figure 4.1-1. The changes to the Plan allowed for the satisfactory completion of the objectives from the Statement of Work while also providing the ability to perform new tests of significant commercial interest.

\subsection{OPERATING PROCEDURES}

Summaries of the main procedures associated with the startup, operation, and shutdown of the LPMEOH $^{\mathrm{TM}}$ demonstration unit are provided. The P\&ID's, located in Appendix A of the Public Design Report (Final Report - Volume 1), contain references to equipment and instrumentation systems. 


\section{Table 4.1-1}

Test Conditions at LPMEOH ${ }^{\mathrm{TM}}$ Demonstration Unit

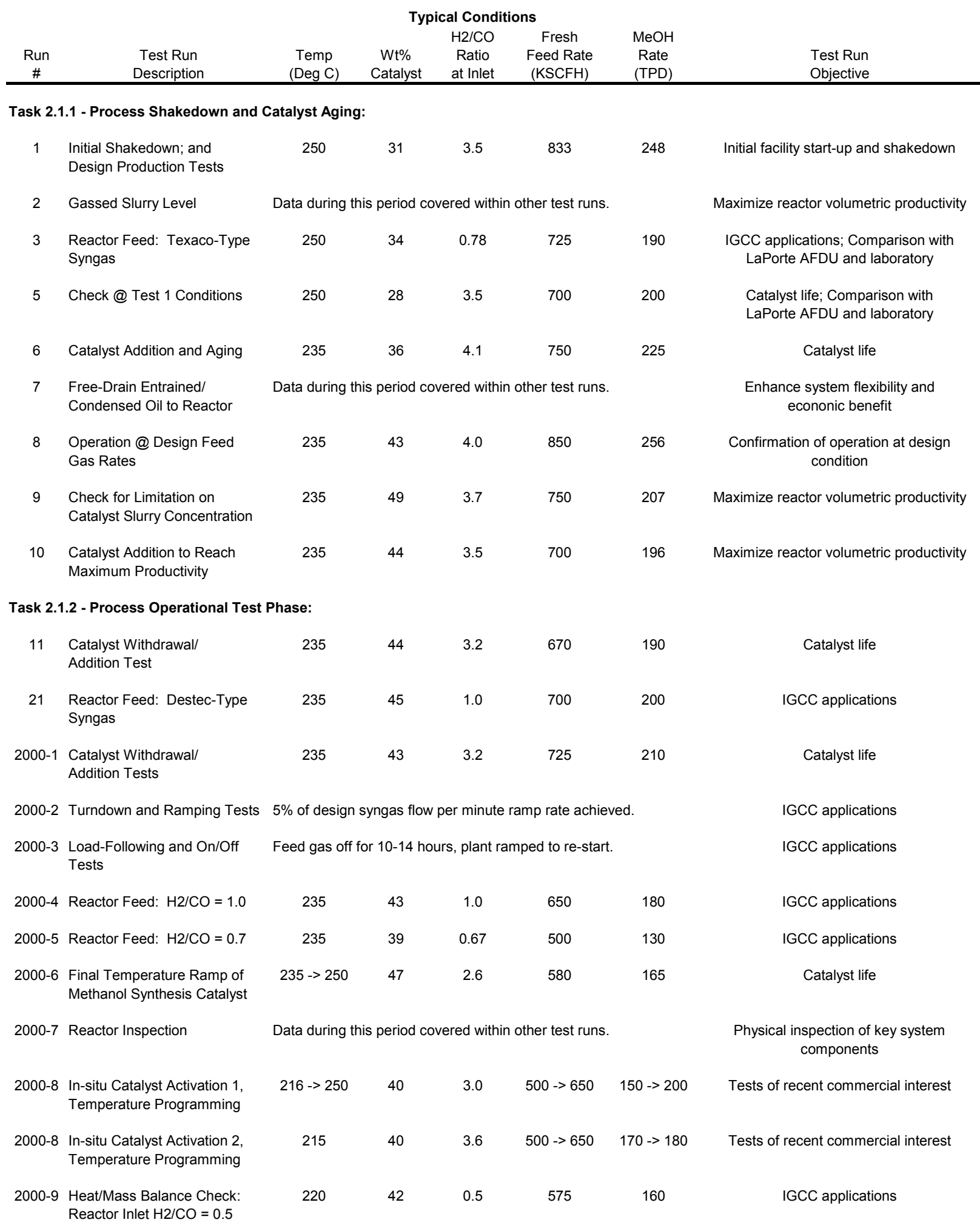




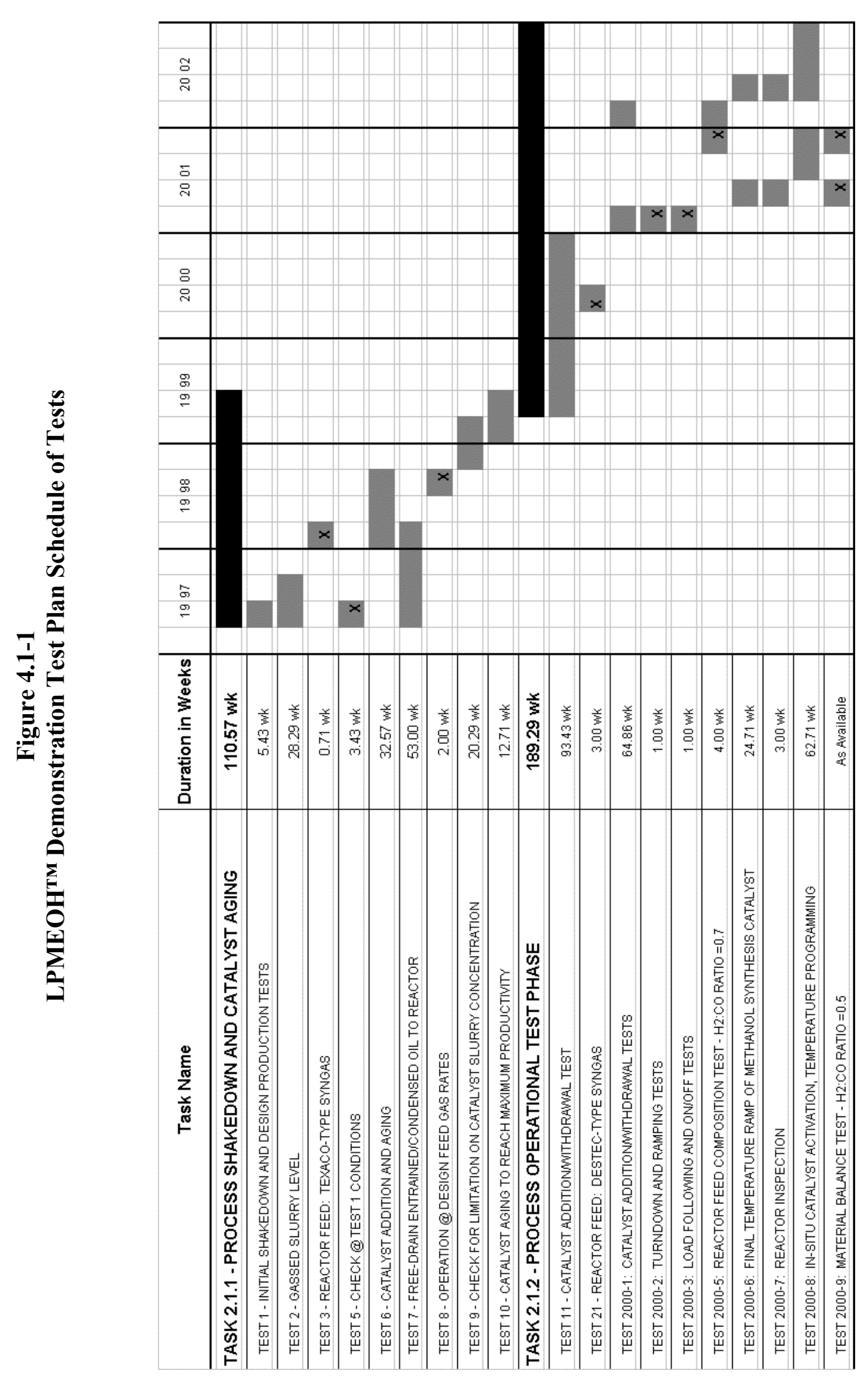

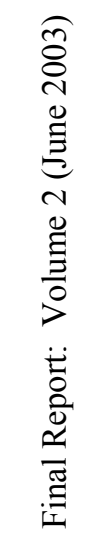




\section{$\underline{\text { Startup Procedure: }}$}

The following procedure describes the startup of the LPMEOH ${ }^{\mathrm{TM}}$ reactor system. It is assumed that the reactor system has been properly purged with $\mathrm{N}_{2}$ through the syngas loop and 29C-01 $\mathrm{LPMEOH}^{\mathrm{TM}}$ reactor. If this procedure is being implemented for the first time, or if the reactor was open to atmosphere for a significant period of time during a shutdown, a hot function test with syngas and mineral oil (in the absence of catalyst) to at least $200^{\circ} \mathrm{C}$ should be performed followed prior to the startup to minimize the production of metal carbonyls during normal operation. If this is a re-start procedure, it will not be necessary to perform this part of the procedure. The distillation system should be started on total recycle (see below).

The 29K-01 recycle compressor is started on total recycle (complete internal recycle operation). $\mathrm{N}_{2}$ is introduced into the bottom of the reactor. The reduced catalyst slurry is then pressure transferred from the 29D-02 slurry tank to the LPMEOH ${ }^{\mathrm{TM}}$ reactor. If an in-situ activation was used to reduce the catalyst, or if the reactor was shutdown for only a brief period, the catalyst slurry would already be in the reactor.

The flow from the syngas recycle compressor is then introduced to the reactor by closing the recycle flow control valve. The increased gas flow from the recycle compressor will assist in heat transfer in the reactor during the heat-up phase. Once positive gas flow through the reactor has been observed on the flowmeter at the inlet to the reactor, the $\mathrm{N}_{2}$ flow introduced at the bottom of reactor can be stopped.

Boiler feedwater flow to the 29C-02 steam drum (including the reactor tubes) is introduced to heat the catalyst slurry at a maximum rate of $30^{\circ} \mathrm{C} /$ hour. Startup steam, at $600 \mathrm{psig}$, is injected into the heat exchanger risers, as needed, to maintain this heat-up rate until the reaction initiation temperature (a maximum of $220^{\circ} \mathrm{C}$ ) is reached.

Fresh feed gas is slowly started to the unit. The main valves upstream and downstream of the 29C-40 carbonyl guard bed are closed initially. A small manual valve is opened to slowly pressurize the carbonyl guard bed to avoid fluidization and damage of the adsorbent. Once the carbonyl guard bed has reached the syngas header pressure (nominally $750 \mathrm{psig}$ ), the main inlet and outlet valves to the carbonyl guard bed can be opened. The LPMEOH ${ }^{\mathrm{TM}}$ reactor, the carbonyl guard bed, and the syngas loop are then pressurized to syngas header pressure. Methanol product flow can then be taken to the distillation system (see below).

\section{Major LPMEOH ${ }^{\mathrm{TM}}$ Reactor Control Loops:}

The reactor pressure is controlled using the 29PC-150 control loop which achieves a desired reactor pressure set-point by controlling the rate of flow of unreacted syngas through the purge gas valve, $29 \mathrm{FV}-157 \mathrm{~A}$. LPMEOH ${ }^{\mathrm{TM}}$ reactor bulk temperature is tightly controlled to the desired setpoint by using the 29TC-109 temperature control loop to adjust the steam drum pressure using control valve 29PV-109. The 29E-02 syngas feed / product economizer effluent temperature is controlled using the 29TC-101 control loop which achieves the desired economizer effluent 
temperature set-point by controlling the rate of reactor feed flow through the 29TV-101 syngas feed / product economizer bypass valve.

\section{Distillation System Startup Procedure:}

The 29C-12 stabilizer feed drum, the 29C-10 stabilizer column, and the 29C-20 rectifier column are first purged with $\mathrm{N}_{2}$. The $\mathrm{N}_{2}$ pressure is maintained until the syngas is started to the unit. Cooling water flow is then introduced to the 29E-11 stabilizer condenser and the 29E-22 stabilizer subcooler, and the fans on the 29E-21 rectifier air cooler are started. The stabilizer feed drum, stabilizer column, and rectifier column are filled with methanol from the methanol lot tanks (29D-20 or 29D-21). The stabilizer and rectifier columns are then heated using steam in their respective reboilers (29E-10 and 29E-20).

A recycle flow loop from the stabilizer feed drum through to the stabilizer and rectifier columns is then established. The methanol product takeoff from the 29C-21 methanol rectifier reflux drum and the underflow from the rectifier column are returned to the stabilizer feed drum until syngas flow is started to reactor. The rectifier column is set on total reflux during this time. Once methanol is available from the process at the 29C-03 high-pressure methanol separator, the distillation system is taken off of total recycle operation and the crude-grade methanol is sent to distillation capacity within the Eastman chemicals-from-coal complex for further processing. Raw methanol is then introduced from the high-pressure methanol separator into the stabilizer feed drum.

\section{Batch-wise Slurry Withdrawal and Catalyst Activation Procedure:}

The 29C-30 catalyst reduction vessel is designed to replace a portion (in 2,000 pound increments) of spent methanol catalyst slurry in the reactor with an equal amount of freshly activated catalyst. Spent catalyst slurry is pressure-transferred from the reactor to the catalyst reduction vessel through the control valve (29PV-424) at the discharge of the 29G-30 slurry transfer pump. The slurry is then cooled to less than $45^{\circ} \mathrm{C}$ using the $29 \mathrm{E}-33$ utility oil cooler, at which temperature it can be safely drained into drums.

Mineral oil is charged to the vessel from the 29D-30 fresh oil tank. This mineral oil is preheated and catalyst is added. The slurry is agitated using the 29Y-30 agitator, and a reducing gas (consisting of a dilute mixture of $\mathrm{CO}$ Gas in $\mathrm{N}_{2}$ ) is introduced at the bottom of the catalyst reduction vessel. The agitator is stopped once gas flow has been established. The catalyst is then activated using a series of temperature steps which are programmed into the distributed control system logic. The heat of reduction is released to the slurry and is removed via an external heat exchanger jacket on the catalyst reduction vessel. Bulk temperature control is accomplished by varying the temperature of utility oil, which flows through the heat exchanger jacket and which is controlled at the outlet of the 29E-32 utility oil heater. The operating pressure for the catalyst activation procedure is controlled at the vapor outlet of the $29 \mathrm{C}-31$ catalyst reduction vessel separator. Once the catalyst reduction procedure has been completed, the reduced catalyst is pumped to the reactor using the slurry transfer pump. 
In-situ Activation Procedure:

In-situ activation is the reduction of an entire charge (nominally 40,000 to 50,000 pounds) of fresh catalyst within the reactor vessel. Following the removal and drumming of the spent catalyst from the reactor, batches of fresh catalyst and mineral oil are mixed in the catalyst reduction vessel and pressure transferred (without reducing or activating the batches) into the reactor. During the loading procedure, $\mathrm{N}_{2}$ is introduced into the bottom of the reactor to assist in mixing and heat transfer. Once a full charge of fresh catalyst is added to the reactor, the recycle compressor is started to further mix the catalyst slurry. The catalyst slurry is then activated using a series of temperature program steps. A dilute mixture of Balanced $\mathrm{Gas}_{\text {in }} \mathrm{N}_{2}$ is used as the reducing gas and enters the reactor at the bottom of the vessel. Once positive gas flow from the recycle compressor through the reactor has been observed on the flowmeter at the inlet to the reactor, the $\mathrm{N}_{2}$ flow introduced at the bottom of reactor can be stopped. The heat of reaction is released to the slurry and is removed via the internal heat exchanger. Bulk temperature control is accomplished by initially manually varying the stream drum pressure. Once the steam drum pressure exceeds the steam header pressure sufficiently, the temperature ramp can be automatically controlled through the distributed control system. The operating pressure for the in-situ activation is controlled using the 29PC-150 control loop which achieves a desired reactor pressure set-point by controlling the rate of flow of unreacted syngas through the purge gas valve, 29FV-157A. Once the in-situ catalyst reduction procedure has been completed, the reactor is started up normally using the procedure described above.

Stand-by Conditions Procedure:

Following a shutdown of the LPMEOH ${ }^{\mathrm{TM}}$ demonstration unit, a standby condition is used to maintain conditions for subsequent re-start. The reactor temperature is held at $180^{\circ} \mathrm{C}$ during this stand-by condition, using $600 \mathrm{psig}$ startup steam, as required. The recycle compressor is generally kept in operation during stand-by to assist in heat transfer and to allow for gas flow to continue through the reactor system. Generally, a reactor pressure of $95 \mathrm{psig}$ is maintained with the recycle compressor in operation. $\mathrm{N}_{2}$ makeup can be introduced to the system once the $\mathrm{N}_{2}$ header pressure exceeds the compressor suction pressure of approximately $75 \mathrm{psig}$. The distillation system is placed in recycle operation. If the recycle compressor is not available, $\mathrm{N}_{2}$ is introduced into the bottom of the reactor.

Shutdown Procedure:

To shutdown the LPMEOH ${ }^{\mathrm{TM}}$ demonstration unit, the fresh feed gas valves controlling the flow of Balanced Gas and CO Gas are closed. If this is expected to be a short-term shutdown, the stand-by conditions are established (see above).

If this is a longer-term shutdown, for instance a maintenance inspection, the catalyst slurry in the $\mathrm{LPMEOH}^{\mathrm{TM}}$ reactor is pressure transferred to the slurry tank. The reactor can be depressurized very quickly to $95 \mathrm{psig}$. Once this pressure is reached, the recycle compressor can be put into internal recycle operation and subsequently shutdown, if required. $\mathrm{N}_{2}$ can then be introduced into the bottom of the reactor to maintain mixing of the slurry while it is cooling. The slurry is 
cooled in the reactor at a rate of $30-35^{\circ} \mathrm{C}$ per hour to a final temperature of $150^{\circ} \mathrm{C}$. The slurry is then transferred either to the slurry tank for storage or to the catalyst activation vessel for further cooling using the utility oil cooler and subsequent draining into drums.

If the catalyst is to be reused after the shutdown, the catalyst will be pressure transferred from the slurry tank back to the reactor at the conclusion of the maintenance outage. The 29Y-02 agitator is used to maintain the slurry in suspension, and a steam jacket is used to minimize heat losses from the slurry tank. If the catalyst is to be replaced with freshly reduced catalyst, batches of spent catalyst are then pressure transferred with $\mathrm{N}_{2}$ from the slurry tank to the catalyst reduction vessel for cooling to less than $45^{\circ} \mathrm{C}$ and drumming. Alternatively, these batches of spent catalyst can be directly transferred from the reactor to the catalyst reduction vessel for cooling and drumming, if desired.

\subsubsection{Instrumentation and Data Acquisition}

Within the LPMEOH ${ }^{\mathrm{TM}}$ Process, measurement of the flow and pressure of the catalyst slurry or the three-phase reactor fluid was required in order to assess the performance of the technology at the commercial demonstration of $260 \mathrm{sT} / \mathrm{D}$. Transmitters with diaphragm seal(s) and oil flush connections were used to provide accurate readings in this difficult environment. In addition, nuclear density gauges were used on the LPMEOH ${ }^{\mathrm{TM}}$ reactor (to determine the expanded slurry height) and the 29C-30 catalyst preparation vessel (to measure the three-phase density and expanded slurry height). No other specialty instrumentation systems were required.

The LPMEOH ${ }^{\mathrm{TM}}$ demonstration unit utilized an existing computer network that controlled operating plants at the Eastman chemicals-from-coal complex. A distributed control system was used for automatic control, monitoring, and non-critical process and equipment shutdowns. A data acquisition was tied into the data highway for the control system so that real-time plant data could be accessed both at a office trailer (separate from the operating control room) at the LPMEOH $^{\mathrm{TM}}$ demonstration unit as well as at Air Products' corporate headquarters in Allentown, PA. A dedicated programmable logic controller was used so that critical process shutdowns could be initiated independent of the control system hardware.

\subsubsection{Test Methods}

Appendix A, Table A-1 provides the streams, component lists and frequency of sampling for the routine analytical measurements. Appendix A also contains a description of the sampling and analytical methods used to quantify the concentration of arsenic (reported as arsine) and iron carbonyl in the fresh feed gas to the LPMEOH ${ }^{\mathrm{TM}}$ demonstration unit. The simplified process flow diagram, Figure 2.4-1, shows the measurement points.

\subsection{ANALYSIS OF FEEDSTOCKS, PRODUCTS AND REAGENTS}

In order to perform the routine material balance calculations, gas chromatographs were used to analyze the syngas feed streams, the streams entering and exiting the LPMEOH ${ }^{\mathrm{TM}}$ reactor, and the purge streams leaving both the main reactor loop and the distillation section. Analysis of the two methanol streams (Crude-Grade Methanol and Refined-Grade Methanol) was also 
performed. Appendix B contains samples of material balance calculation sheets that include the typical analysis of these streams for two operating scenarios: Appendices B-1 and B-2 provides data when Balanced Gas is fed to the LPMEOH ${ }^{\mathrm{TM}}$ demonstration unit, and Appendices B-3 and B-4 provide data during operation when CO-rich syngas is fed to the LPMEOH ${ }^{\mathrm{TM}}$ reactor.

In addition, syngas sampling was performed to determine the levels of trace components within the various syngas streams that may be poisons to methanol synthesis catalysts. A summary of these results is provided in Section 5.2.

Throughout the operating program, samples were taken of catalyst slurry from the LPMEOH reactor on a routine basis to analyze for the presence of known catalyst poisons and to track some of the key physical properties of the methanol synthesis catalyst. Section 5.2 contains the results of these analyses for the four different catalyst campaigns that were completed during the performance period.

\subsection{DATA ANALYSIS METHODOLOGY}

Appendix C, Table 1 contains the major field instrumentation signals, analytical measurements, and calculations which were used in determining the material and energy balance and $\mathrm{LPMEOH}^{\mathrm{TM}}$ reactor performance. The simplified process flow diagram, Figure 2.4-1, also shows the measurement points. Two sets of material balances were performed:

- Across the LPMEOH ${ }^{\mathrm{TM}}$ reactor, using the Reactor Feed Flowrate (Stream 109) and Reactor Effluent Flowrate (Stream 120); and

- Around the LPMEOH ${ }^{\mathrm{TM}}$ demonstration unit, using the major plant feeds and product streams as noted in Appendix C, Table 1.

Part of the process of data reduction is the elimination of those operating periods when one or more key inputs to the material balance calculation is invalid (for example, a failure of a key process flowmeter or an upset of the analytical system). If the material balance cannot be closed due to such an instrument failure, a portion of a data period will be eliminated from the material balance calculation. This analysis will be performed at the spreadsheet level, so that the historian files will always contain the raw data from field instruments and analytical equipment.

A comprehensive set of the formulas used to calculate the parameters listed in Appendix C, Table 1 is provided in Appendix C-2. These calculations were based upon actual measurements from the $\mathrm{LPMEOH}^{\mathrm{TM}}$ demonstration unit.

\subsection{DATA SUMMARY}

The operating program for the LPMEOH ${ }^{\mathrm{TM}}$ demonstration unit can be broken into four operating campaigns based upon the use of a fresh charge (full or partial) of methanol synthesis catalyst in the LPMEOH ${ }^{\mathrm{TM}}$ reactor. Kingsport Catalyst Campaign 1 was conducted between April of 1997 and November of 1997. This campaign was concluded on 03 November 1997 after 171 days of operation. Kingsport Catalyst Campaign 2 was conducted between December of 1997 and 
August of 2001. The campaign was concluded on 06 August 2001 after 1,325 days of operation. Kingsport Catalyst Campaign 3 was conducted between August of 2001 and June of 2002. The campaign was concluded on 04 June 2002 after 284 days of operation. The fourth Kingsport Catalyst Campaign began on 28 June 2002 and included process and analytical data until the end of the operating program on 31 December 2002 (a total of 187 days of operation).

Appendix D, Tables D-1 through D-4 provide the results from the operation of the LPMEOH ${ }^{\mathrm{TM}}$ demonstration unit during the 69-month operating phase. These data represent daily averages, typically from a 24-hour material balance period, and those days with less than 12 hours of stable operation are omitted. Since startup, about 103.9 million gallons of methanol was produced. Eastman accepted all of the available methanol for use in the production of methyl acetate, and ultimately cellulose acetate and acetic acid. The analysis of the key results is provided in Section 5.

\subsection{OPERABILITY AND RELIABILITY}

Table 4.6-1 contains the availability of the LPMEOH ${ }^{\mathrm{TM}}$ demonstration unit during the 69-month demonstration test program (availability is defined as the percentage of time that the LPMEOH $^{\mathrm{TM}}$ demonstration unit was available to operate, with the exclusion of scheduled outages). The overall availability was $97.5 \%$.

The causes of unplanned outages are also provided in Table 4.6-1. Startup was completed in two days, and nameplate production of 80,000 gallons per day (260 sT/D) was achieved within four days, and production rates exceeding $115 \%$ of design were achieved within six days.

Unexpected poisoning of the catalyst due to the presence of iron contamination in 1997 led to the

Table 4.6-1

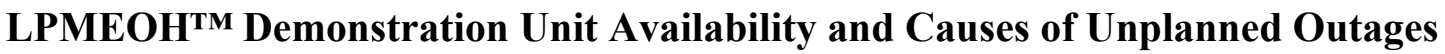

\begin{tabular}{|l|c|c|c|c|c|c|}
\hline Operating Year $^{\mathrm{a}}$ & 1997 & 1998 & 1999 & 2000 & 2001 & $2002^{\mathrm{b}}$ \\
\hline Availability (\%) & 94.9 & 99.54 & 99.4 & 96.3 & 97.7 & 94.1 \\
\hline & & & & & & \\
\hline $\begin{array}{l}\text { Total Hours of } \\
\text { Unplanned Outages }\end{array}$ & $\mathbf{3 2 5 . 6}$ & $\mathbf{4 5 . 1}$ & $\mathbf{5 2 . 8}$ & $\mathbf{3 1 1 . 4}$ & $\mathbf{1 6 6 . 3}$ & $\mathbf{1 9 8 . 9}$ \\
\hline & & & & & & \\
\hline Catalyst & 149.3 & 0.0 & 0.0 & 0.0 & 38.7 & 0.0 \\
\hline Carbonyl Guard Bed & 0.0 & 0.0 & 0.0 & 118.9 & 120.6 & 198.9 \\
\hline Electrical & 20.7 & 24.6 & 0.0 & 42.3 & 0.0 & 0.0 \\
\hline Instrumentation & 12.8 & 1.3 & 0.0 & 4.7 & 7.0 & 0.0 \\
\hline Mechanical & 142.8 & 19.2 & 52.8 & 145.5 & 0.0 & 0.0 \\
\hline
\end{tabular}

a. Operating year defined as April-March.

b. Through 31 December 2002. 
only unexpected outage related to catalyst performance. Given the very high level of catalyst poisoning present, the team felt that the full replacement of the catalyst charge, and the outage that would result, was necessary to achieve overall program goals. During operation of the system, it was found that some of the oil return lines to the reactor were plugging and one heat exchanger developed a leak at a flange connection. Redesign and replacement were undertaken in 1997 , creating a permanent solution.

In 1998, non-routine maintenance related to instrumentation tubing around the recycle compressor caused a portion of the reported unplanned outages. Also, electrical transients resulted in two additional short outages. The longest continuous operating run without interruption of any kind was 94 days (July-October of 1998); an earlier campaign of 65 days of continuous operation was completed in April of 1998.

In 1999, an unexpected leak developed in the boiler feed water piping system and two heat exchangers, causing the need to make repairs.

In 2000, a leak in the tubing associated with a flow transmitter in the boiler feed water system and an unrelated failure of a solenoid valve controlling boiler water feed to the steam drum resulted in downtime. An electrical outage outside of the $\mathrm{LPMEOH}^{\mathrm{TM}}$ demonstration unit caused the failure of rupture discs for the cooling water system.

As noted in Section 5.2, plant activities associated with the changeout of the adsorbent in the 29C-40 carbonyl guard bed began. The philosophy associated with the design of this equipment was that the adsorbent would not need to be changed during the demonstration test period; as a consequence, the ability to isolate the vessel from the remainder of the $\mathrm{LPMEOH}^{\mathrm{TM}}$ demonstration unit for maintenance was not included in the engineering design. In future designs, the required isolation valves would be installed, so that the outages that were taken in 2000 through 2002 would be eliminated.

In 2001, a controls signal error caused the unit to drop off line for a very short period of time. Also, operation could not be continued during a catalyst withdrawal/addition operation; the $\mathrm{LPMEOH}^{\mathrm{TM}}$ reactor was restarted following the addition of a batch (2,000 pounds) of fresh catalyst from the catalyst preparation vessel.

A monthly production record of 2,500,000 gallons of methanol was reached during October of 2002. For a 23-day period, production of nameplate capacity (80,000 gallons per day) or higher was achieved. The October monthly average production was $101 \%$ of nameplate capacity. Production rates as high as $117 \%$ of nameplate capacity were also achieved for shorter periods.

In addition to producing syngas for the $\mathrm{LPMEOH}^{\mathrm{TM}}$ demonstration unit, the Eastman's coal gasification facility produces raw material for a gas-phase methanol production plant and a carbon monoxide facility. The fluctuating needs of the impurities removal facility causes some variance in the quantity of syngas produced. Given the ability of the LPMEOH ${ }^{\mathrm{TM}}$ demonstration unit to tolerate changes in the composition and flow of syngas, this facility is used as the swing facility to manage changes in syngas production. Through all of this fluctuation, the 
LPMEOH $^{\mathrm{TM}}$ demonstration unit produced methanol to its full projected capacity based on the composition and flow of syngas available.

\subsection{SECTION 4 BIBLIOGRAPHY}

a. "Commercial Demonstration of the Liquid Phase Methanol (LPMEOH ${ }^{\mathrm{TM}}$ ) Process - Demonstration Test Plan", Prepared by Air Products Liquid Phase Conversion Co., L.P., DOE Cooperative Agreement No. DE-FC22-95PC93052, September 1996. 


\subsection{TECHNICAL PERFORMANCE}

\subsection{CATALYST PERFORMANCE}

As indicated in Section 4.5, there were four catalyst campaigns which characterize the operating program of the $\mathrm{LPMEOH}^{\mathrm{TM}}$ demonstration unit. A comparison of the catalyst campaigns is given in Table 5.1-1. The first campaign involved batch-wise catalyst activation along with the addition of fresh slurry to maintain catalyst productivity. The second campaign involved batchwise catalyst activation along with withdrawal of spent catalyst slurry and addition of fresh slurry to maintain catalyst productivity. The third and fourth campaigns used an in-situ activation procedure to prepare a full charge of methanol synthesis catalyst. Temperature programming was used in the third campaign to maintain productivity. During the fourth catalyst campaign, productivity was essentially maintained by virtue of the very low catalyst deactivation rates and, therefore, temperature programming was not used during the period of performance. Methanol synthesis catalyst (baseline and alternative) from two different suppliers was used during the operating program.

As shown in Figures 1.2.3-1 and 2.4-1, two catalyst guard beds were available to limit the levels of trace contaminants entering the $\mathrm{LPMEOH}^{\mathrm{TM}}$ demonstration unit. The long-term performance of the methanol synthesis catalyst was adversely impacted by the presence of species such as arsenic (detected in the Balanced Gas stream) and iron (apparently generated during certain operating periods within the $\mathrm{LPMEOH}^{\mathrm{TM}}$ demonstration unit). A review of the work on the adsorbents used during the period of performance of the $\mathrm{LPMEOH}^{\mathrm{TM}}$ Demonstration Project is provided in Section 5.2.

Table 5.1-1

Kingsport LPMEOH ${ }^{\mathrm{TM}}$ Operating Program Campaigns

\begin{tabular}{|c|c|c|c|c|c|c|c|c|}
\hline $\begin{array}{c}\text { Kingsport } \\
\text { Campaign } \\
\#\end{array}$ & $\begin{array}{c}\text { Run Start } \\
\text { Date }\end{array}$ & $\begin{array}{c}\text { Run End } \\
\text { Date }\end{array}$ & $\begin{array}{c}\text { Days } \\
\text { Onstream }\end{array}$ & $\begin{array}{c}\text { Catalyst } \\
\text { Type } \\
\text { Used }\end{array}$ & $\begin{array}{c}\text { Starting } \\
\text { Catalyst } \\
\text { Charge } \\
\text { (lbs) }\end{array}$ & $\begin{array}{c}\text { Activation } \\
\text { Method }\end{array}$ & $\begin{array}{c}\text { Productivity } \\
\text { Control } \\
\text { Method }\end{array}$ & $\begin{array}{c}\text { Operating } \\
\text { Temperature } \\
\left({ }^{\circ} \mathrm{C}\right)\end{array}$ \\
\hline 1 & $4 / 6 / 97$ & $11 / 3 / 97$ & 171 & Baseline & 20,300 & Batch & $\begin{array}{c}\text { Catalyst } \\
\text { Addition } \\
\text { Only }\end{array}$ & 250 to 260 \\
\hline 2 & $12 / 20 / 97$ & $8 / 6 / 01$ & 1,325 & $\begin{array}{c}\text { Baseline }+ \\
\text { Alternative }\end{array}$ & 19,500 & Batch & $\begin{array}{c}\text { Catalyst } \\
\text { Withdrawal } / \\
\text { Addition }\end{array}$ & $235^{\mathrm{a}}$ \\
\hline 3 & $8 / 24 / 01$ & $6 / 4 / 02$ & 284 & Alternative & 41,580 & In-situ & $\begin{array}{c}\text { Temperature } \\
\text { Programming }\end{array}$ & 216 to 242 \\
\hline 4 & $6 / 28 / 02$ & Ongoing $^{\mathrm{b}}$ & Ongoing $^{\mathrm{b}}$ & Alternative & 40,040 & In-situ & - & 215 \\
\hline
\end{tabular}

a. Primarily $235^{\circ} \mathrm{C}$ with brief operation at other temperatures.

b. The LPMEOH ${ }^{\mathrm{TM}}$ demonstration unit operating program ended 12/31/02 with 187 days onstream in Catalyst Campaign 4. 


\subsubsection{Catalyst Performance: Catalyst Campaign 1}

An in-house kinetic model was used to assess the performance of the methanol synthesis catalyst and to eliminate the effects of varying feed composition or operating conditions. This model can be used to study changes in catalyst performance over stable periods of operation (typically two weeks or more); results over shorter durations must be considered in light of the influence of operating conditions (for example, variations in the bulk syngas composition). The "age" of the catalyst can be expressed in terms of a dimensionless variable eta $(\eta)$, which is defined as the ratio of the rate constant at any time to the rate constant for freshly reduced catalyst (as determined in the laboratory autoclave). Figure 5.1.1-1 shows performance results from the $\mathrm{LPMEOH}^{\mathrm{TM}}$ reactor during Catalyst Campaign 1. Typical exponential decay appeared as a straight line on a semi-log-plot, as shown. The curve fit to data from a 4-month test at the LaPorte AFDU in 1988/89 (this run was performed on CO-rich syngas derived from natural gas at a reactor temperature of $250^{\circ} \mathrm{C}$ ) and laboratory autoclave data from 1996 are included for reference. During this catalyst campaign, the $\mathrm{LPMEOH}^{\mathrm{TM}}$ reactor operated at $250^{\circ} \mathrm{C}$, except for brief operation at $260^{\circ} \mathrm{C}$ at the very end of the campaign. Catalyst additions are noted on the figure.

A partial charge (20,300 pounds out of a design of 40,000 pounds) of fresh catalyst was activated in 9 batches within the $29 \mathrm{C}-30$ catalyst preparation vessel and added to the LPMEOH ${ }^{\mathrm{TM}}$ reactor

Figure 5.1.1-1

Kingsport LPMEOH ${ }^{\mathrm{TM}}$ Catalyst Life (Catalyst Campaign 1)

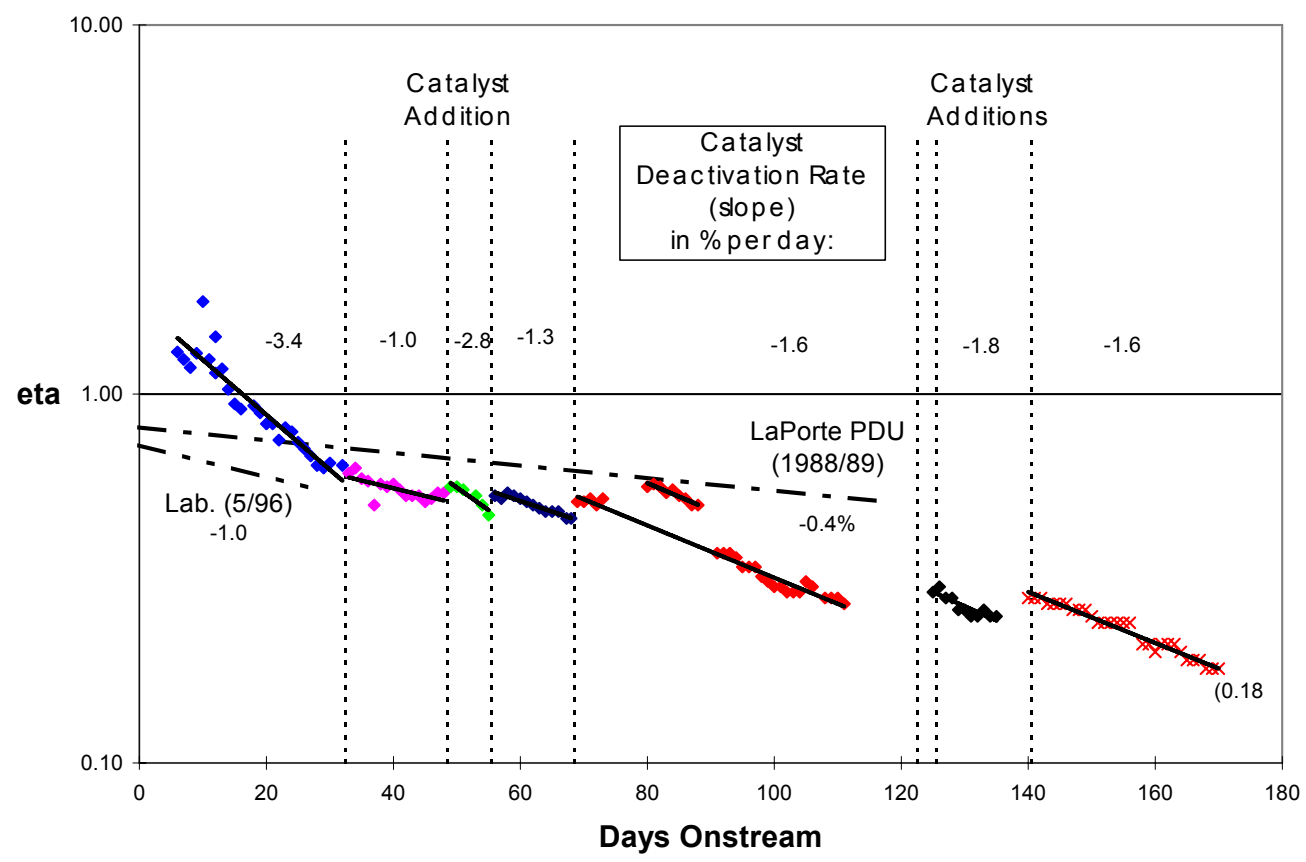


in early April of 1997. The initial performance of the catalyst was equivalent to the results from the laboratory autoclave, indicating that the catalyst activation was successful. The highest methanol production rate over a 24-hour period occurred on 19 April 1997 (89,900 gallons per day, or $292.2 \mathrm{sT} / \mathrm{D}$ ); for shorter balance periods (approximately 12 hours), methanol production rates of 92,900 to 94,500 gallons per day (302 to 307 sT/D) were measured.

Over the next several weeks, the catalyst life data indicated that an accelerated negative change in performance occurred. During the April/May of 1997 operating period, it was not immediately apparent whether this decline in $\eta$ was a result of a decline in catalyst activity or hydrodynamic effects related to an increase in pressure drop across the gas sparger at the inlet to the $\mathrm{LPMEOH}^{\mathrm{TM}}$ reactor. However, upon restarting the LPMEOH ${ }^{\mathrm{TM}}$ demonstration unit following a planned outage in June of 1997, the value of $\eta$ was determined to be unaffected by the performance of the sparger. Therefore, it was concluded that the catalyst activity was declining more rapidly than expected. The catalyst deactivation rate for the first 30 days of operation was $3.4 \%$ per day; the higher catalyst deactivation during this period was later linked to high concentrations of iron on the reactor catalyst samples. These higher iron concentrations were most likely due to construction debris (refer to Section 5.2 for additional information).

Following the initial operating period, the catalyst performance continued to decline more rapidly than expected; however, as noted on Figure 5.1.1-1, the rate of change was slower than during the April/May operation. During the remaining period of operation during Catalyst Campaign 1 from June through November of 1997, deactivation rates were higher than expected based on experience from the LaPorte AFDU (catalyst deactivation rate of $0.4 \%$ per day). In fact, the catalyst life was similar to the baseline deactivation results obtained during laboratory autoclave testing (catalyst deactivation rate of $1.0 \%$ per day). Eliminating the catalyst performance results for the first month due to catalyst hyperactivity and the presence of iron construction debris, the average deactivation rate for the entire campaign was $1.3 \%$ per day.

Fresh catalyst was activated and added to the $\mathrm{LPMEOH}^{\mathrm{TM}}$ reactor on six occasions during this first catalyst campaign to maintain catalyst productivity and increase catalyst loading. On 04 July 1997, the first catalyst batch of 2,300 pounds of fresh catalyst activated and added to the LPMEOH $^{\mathrm{TM}}$ reactor. This same quantity of catalyst was activated and added to the reactor on 11 July, 23 July, 12 September, 17 September, and 03 October 1997.

Based upon the results of unit operation and catalyst performance, DOE accepted a recommendation by Air Products and Eastman in October of 1997 to drain the initial charge of catalyst from the reactor and replace the charge with fresh catalyst. Prior to this catalyst turnaround, the operating temperature of the $\mathrm{LPMEOH}^{\mathrm{TM}}$ reactor was raised from $250^{\circ} \mathrm{C}$ to $260^{\circ} \mathrm{C}$ for about one week of operation. 


\subsubsection{Catalyst Performance: Catalyst Campaign 2}

Catalyst Campaign 2 was the longest of the operating program at 1,325 days. During most of this catalyst campaign, the operating temperature in the $\mathrm{LPMEOH}^{\mathrm{TM}}$ reactor was lowered to $235^{\circ} \mathrm{C}$. By using the lowest possible temperature necessary to achieve the required methanol production rate, the life of the methanol synthesis catalyst was potentially extended. Catalyst life data during the first portion of Catalyst Campaign 2 (covering operations in 1997 and 1998) is shown in Figure 5.1.2-1. At the start of this campaign in December of 1997, only a partial charge (19,500 pounds) of fresh catalyst was activated in the catalyst preparation vessel and added to the reactor system; this limited the amount of material exposed to poisons at the outset. During this first portion of the campaign, fresh catalyst was activated and added to the $\mathrm{LPMEOH}^{\mathrm{TM}}$ reactor on a periodic basis (as noted on the figure) to achieve the desired reactor performance and to determine if hydrodynamic limitations could be reached at high slurry concentrations (the design value was 40 weight $\%[\mathrm{wt} \%]$ ). The rate of catalyst deactivation for periods of stable operations (typically 2 weeks or longer) are indicated on the figure.

At a reactor temperature of $235^{\circ} \mathrm{C}$, the decrease in $\eta$ with time from the starting date of 20 December 1997 through Day 38 was calculated to be $1.0 \%$ per day, which represented a significant improvement over the $3.4 \%$ per day decline measured during the initial six weeks of operation of Catalyst Campaign 1. The deactivation rate also improved from the longer-term rate of $1.6 \%$ per day calculated throughout the summer and autumn of 1997.

Figure 5.1.2-1

Kingsport LPMEOH ${ }^{\mathrm{TM}}$ Catalyst Life (Catalyst Campaign 2: 1997-1998)

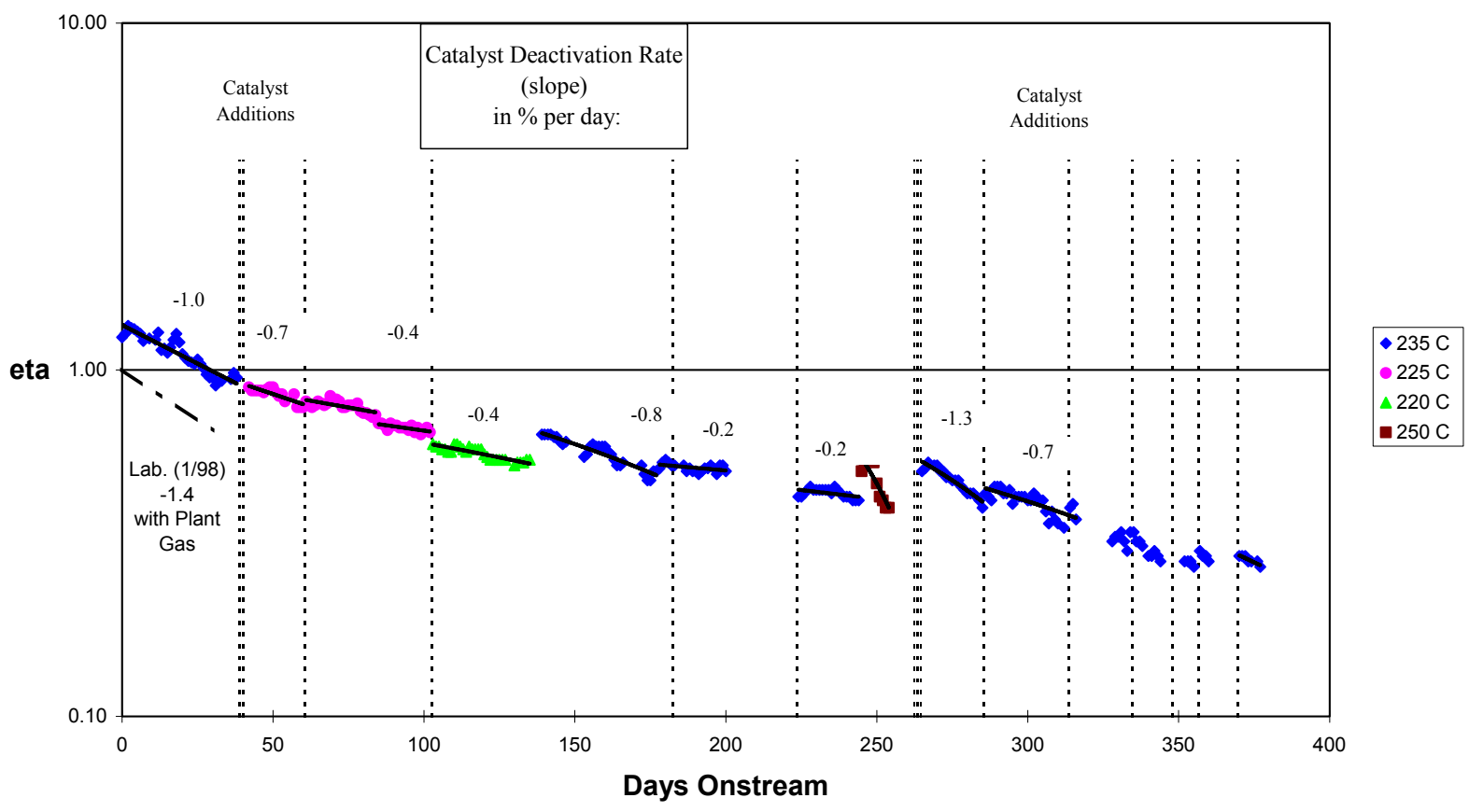


Based on this improvement, DOE accepted a recommendation by Air Products and Eastman to further decrease the reactor temperature to $225^{\circ} \mathrm{C}$. The initial operation at this temperature (from Day 42 through Day 60) showed a modest improvement in the deactivation rate to $0.7 \%$ per day. During two additional stable operating periods between Day 61 and Day 101, deactivation rates of $0.27 \%$ and $0.36 \%$ per day were calculated. These results compare favorably with the performance from the 4-month proof-of-concept run at the LaPorte AFDU in 1988/89.

The reactor temperature was then lowered further to $220^{\circ} \mathrm{C}$ between Day 104 and Day 135 . During a one-month test at a reactor temperature of $220^{\circ} \mathrm{C}$ and a Balanced Gas flowrate of 550$600 \mathrm{KSCFH}$, the rate of decline of $\eta$ was $0.4 \%$ per day, which matched the performance at $225^{\circ} \mathrm{C}$. Beginning on Day 139 , the temperature of the $\mathrm{LPMEOH}^{\mathrm{TM}}$ reactor was increased to $235^{\circ} \mathrm{C}$, which was the operating temperature after the December 1997 restart. After the catalyst addition on Day 182, the weight of catalyst in the $\mathrm{LPMEOH}^{\mathrm{TM}}$ reactor had reached $80 \%$ of the design value of 40,000 pounds.

The LPMEOH ${ }^{\mathrm{TM}}$ demonstration unit completed a 24-day stable period of operation on Day 206 at a reactor temperature of $235^{\circ} \mathrm{C}$ and a flowrate of Balanced Gas of approximately $700 \mathrm{KSCFH}$. Over this period, the rate of decline of $\eta$ was $0.2 \%$ per day. This performance was superior to the original target from the 4-month proof-of-concept run at the LaPorte AFDU in 1988/89 ( $0.4 \%$ per day).

On Day 244, a test at a reactor temperature of $250^{\circ} \mathrm{C}$ was initiated. The test at the higher reactor temperature was completed on Day 254 when accelerated changes in the calculated value for $\eta$ were observed. From Day 261 to Day 267, three batches of fresh catalyst were activated and added to the $\mathrm{LPMEOH}^{\mathrm{TM}}$ reactor, which brought the catalyst loading to slightly above the design value of 40,000 pounds.

Six additional batches of fresh catalyst were activated and added to the $\mathrm{LPMEOH}^{\mathrm{TM}}$ reactor between Day 285 and Day 376. At this point, the catalyst loading in the $\mathrm{LPMEOH}^{\mathrm{TM}}$ reactor had been increased to about $140 \%$ of design. No hydrodynamic instability was detected as the catalyst slurry concentration in the reactor ranged from 46 to $48 \mathrm{wt} \%$.

For the first year of operation under Catalyst Campaign 2, the average rate of catalyst deactivation was calculated to be $0.65 \%$ per day. This result was a significant improvement over the catalyst performance during Catalyst Campaign 1 (1.3\% per day).

Catalyst life data during the second portion of Catalyst Campaign 2 (covering operations in 1999) is shown in Figure 5.1.2-2. The use of catalyst withdrawal and addition (as noted on the figure) was first practiced during this portion of the campaign in order to achieve the desired performance of the $\mathrm{LPMEOH}^{\mathrm{TM}}$ reactor. 
Figure 5.1.2-2

Kingsport LPMEOH ${ }^{\mathrm{TM}}$ Catalyst Life (Catalyst Campaign 2: 1999)

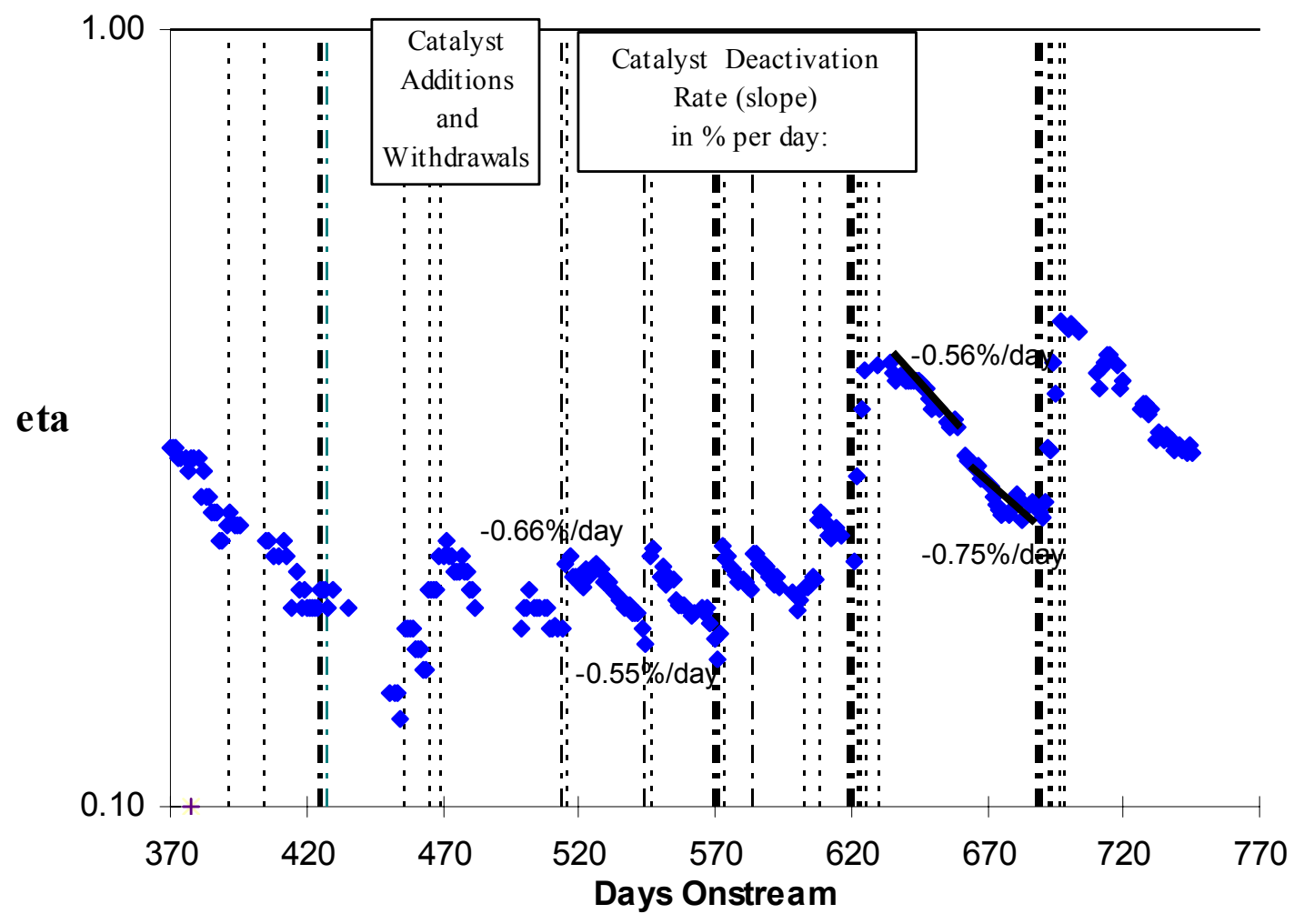

Between Day 377 and Day 466, the LPMEOH ${ }^{\mathrm{TM}}$ demonstration unit continued to perform well with high slurry concentrations in the LPMEOH ${ }^{\mathrm{TM}}$ reactor. Slurry concentrations greater than $48 \mathrm{wt} \%$ were achieved during this period with no apparent hydrodynamic instability. Three batches of fresh catalyst were activated and added during this time, bringing the catalyst loading to $151 \%$ of design, which was the maximum value achieved during the entire operating program.

Starting on Day 424, three separate transfers of catalyst slurry from the reactor were conducted in order to dilute the slurry concentration in anticipation of an upcoming outage in March of 1999.

These steps reduced the calculated slurry concentration in the reactor from in excess of $48 \mathrm{wt} \%$ to approximately $40 \mathrm{wt} \%$. Reactor conditions were held at $235^{\circ} \mathrm{C}$ except for a brief production test, between Days 431 through Day 435, when reactor temperature was increased to $240^{\circ} \mathrm{C}$. The LPMEOH $^{\mathrm{TM}}$ demonstration unit was shutdown between Day 437 through Day 449 in order to complete the planned outage. A second planned Eastman complex outage was taken between Day 483 and Day 494.

The average catalyst deactivation rate for calendar year 1999 was calculated to be $0.58 \%$ per day. This result was equivalent to the performance in 1998 and was slightly greater than the baseline 
deactivation rate from the 4-month proof-of-concept run at the LaPorte AFDU in 1988/89 (0.4\% per day).

The catalyst life performance during the final portion of Catalyst Campaign 2 is provided in Figure 5.1.2-3. Catalyst withdrawals and additions are indicated as dotted vertical lines in the figure. A schedule for catalyst withdrawal and addition was developed that allowed for the desired methanol production rate to be maintained with minimum disruption to the operations staff. The overall schedule for catalyst withdrawals and additions was generally undertaken every two months, and the typical amount of catalyst that was exchanged was about 11,000 pounds.

A comparison of the performance of the methanol synthesis catalyst with different syngas compositions was able to be made. Between Day 825 and Day 844, during which a feed gas with a $\mathrm{H}_{2} / \mathrm{CO}$ ratio of 1:1 was fed to the LPMEOH ${ }^{\mathrm{TM}}$ reactor, a catalyst deactivation rate of $1.24 \%$ per day was calculated. Shortly after that test, a catalyst deactivation rate of $0.89 \%$ per day was calculated for the period from Day 875 to Day 903, during which Balanced Gas alone was used as feed to the LPMEOH ${ }^{\mathrm{TM}}$ demonstration unit. An analysis of these results determined that the two data sets were statistically similar, given the scatter in the calculated values for the catalyst rate constant.

Figure 5.1.2-3

Kingsport LPMEOH ${ }^{\mathrm{TM}}$ Catalyst Life (Catalyst Campaign 2: 2000-2001)

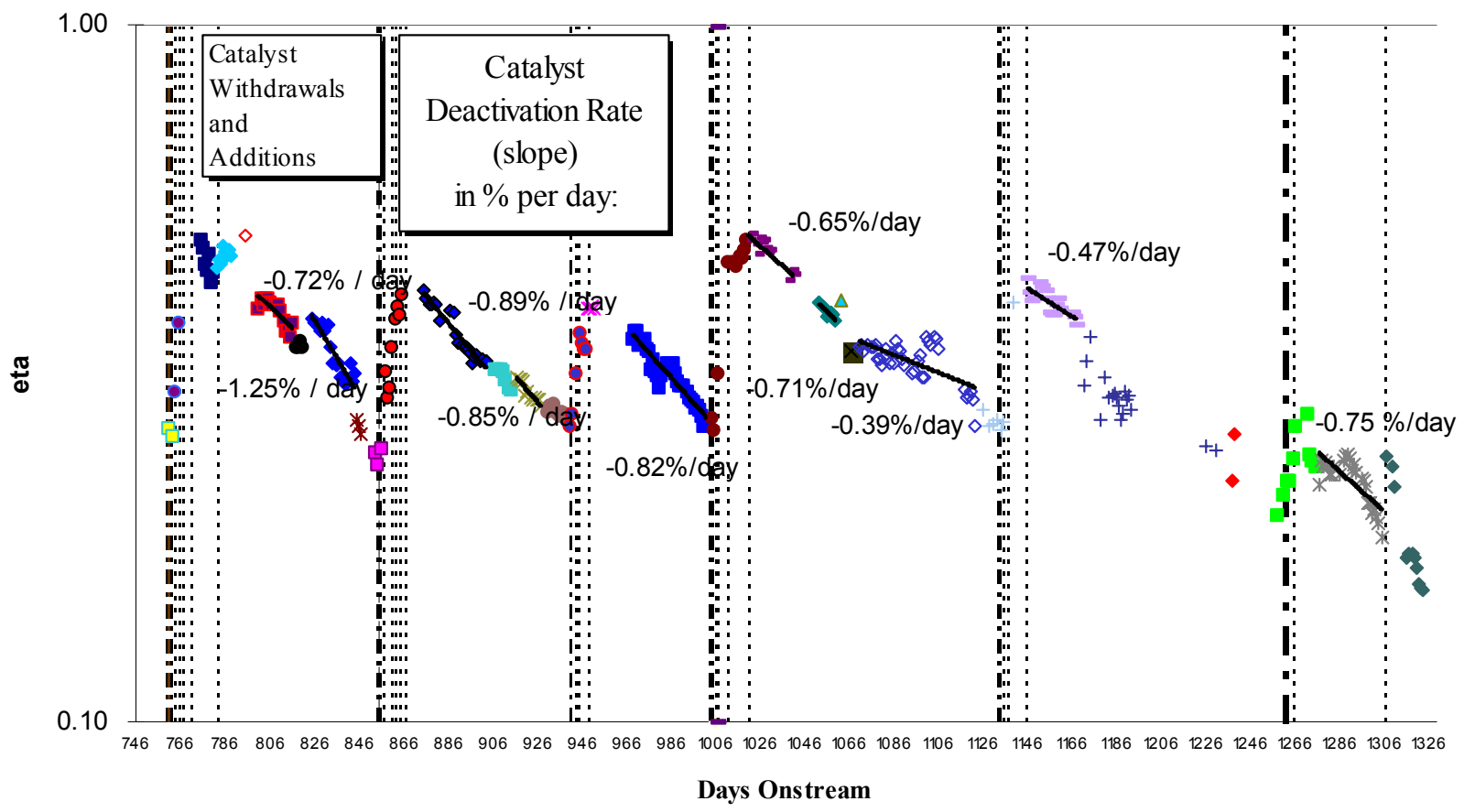


The catalyst performance was also used during this operating period to gauge the effectiveness of the 29C-40 carbonyl guard bed. As described in Section 5.2, the carbonyl guard bed was charged with manganese dioxide (targeting arsenic) and activated carbon (targeting iron and nickel) during this time. When the carbonyl guard bed was in service with aged adsorbents (approximately one year of service), a catalyst deactivation rate of $0.85 \%$ per day was calculated over a 12-day period (Days 917 through 928). When the carbonyl guard bed was bypassed over a 33-day period from Day 969 to Day 1002, a catalyst deactivation rate of $0.82 \%$ per day was calculated. These results were statistically the same and indicated that the aged adsorbents in the carbonyl guard bed were no longer effective in removing trace contaminants. Note that the carbonyl guard bed was bypassed for the remainder of Catalyst Campaign 2. The results for catalyst deactivation rates shown on Figure $5.1 .2-3$ varied from $0.4 \%$ to $0.7 \%$ per day over this operating period, which could indicate that the levels of trace contaminants entering the LPMEOH ${ }^{\mathrm{TM}}$ demonstration unit were likely varying in concentration during this time.

The average rate of catalyst deactivation during the final portion of Catalyst Campaign 2 was calculated to be $0.64 \%$ per day. For the entire campaign, the catalyst deactivation rate was determined to be $0.63 \%$ per day, which was greater than the value calculated from the 4-month proof-of-concept run at the LaPorte AFDU in 1988/89 (0.4\% per day change in catalyst activity).

\subsubsection{Catalyst Performance: Catalyst Campaign 3}

Catalyst Campaign 3 involved a demonstration of in-situ activation procedure. A full charge (greater than 40,000 pounds) of fresh methanol synthesis catalyst was placed into the $\mathrm{LPMEOH}^{\mathrm{TM}}$ reactor and activated at one time. This was in contrast to the batch-wise activation of smaller catalyst quantities (approximately 2,000 pounds each) used earlier in the demonstration.

As shown in Figure 5.1.3-1, the initial activity of the methanol synthesis catalyst for Catalyst Campaign $3(\eta \cong 0.7)$ was less than expected when compared with data from the laboratory $(\eta=$ 1.0). Information on the analysis of these initial performance results is provided in Section 5.6. Following the completion of the in-situ catalyst activation procedure, conditions were selected to deal with the hyperactivity that typically occurs when fresh methanol synthesis catalyst is initially exposed to syngas. During the first few weeks of operation, conditions were varying between a reactor pressure of 550-600 psig, reactor temperature of $212-220^{\circ} \mathrm{C}$, and flowrate of Balanced

Gas of 500-525 KSCFH. Once the test had proceeded beyond the period of hyperactivity, operating conditions were set at $218^{\circ} \mathrm{C}$ reactor temperature, 685 psig reactor pressure, and 600 $650 \mathrm{KSCFH}$ of Balanced Gas. 
Figure 5.1.3-1

\section{Kingsport LPMEOH ${ }^{\mathrm{TM}}$ Catalyst Life (Catalyst Campaign 3)}

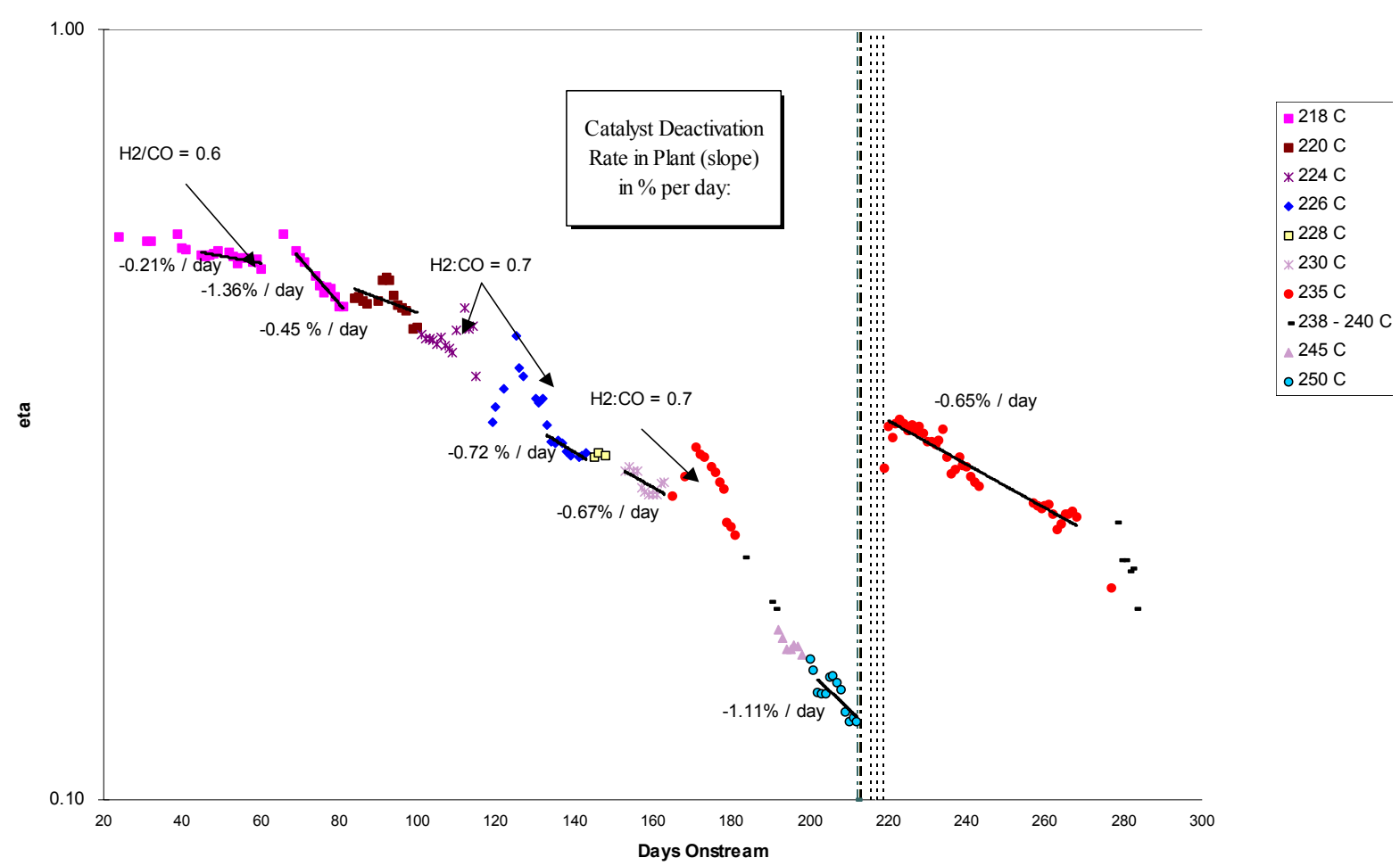

As noted in Table 5.1-1, temperature programming (as opposed to catalyst withdrawal and addition) was used as a productivity control method during Catalyst Campaign 3. The reactor temperature was gradually increased as necessary to control reactor purge flowrate and maintain catalyst productivity as the operating campaign progressed. Temperature changes were managed such that sufficient performance data could be achieved at each temperature (minimum of two weeks of operation at each condition to determine catalyst life performance data). Over the entire period of Catalyst Campaign 3, the reactor temperature ranged from $216^{\circ} \mathrm{C}$ to $242^{\circ} \mathrm{C}$.

The rates of catalyst deactivation that were computed during this period are indicated in Figure 5.1.3-1. Note that, for two performance periods during the first 100 days onstream, the calculated rate of catalyst deactivation was significantly lower than the average results during Catalyst Campaign 2 (0.63\% per day), and was equivalent to or better than the results from the 4-month proof-of-concept run at the LaPorte AFDU in 1988/89 (0.4\% per day). Following the two periods of improved catalyst performance, the catalyst deactivation rates for Catalyst Campaign 3 approached historical values of 0.6 to $0.7 \%$ per day.

The first operating test using methanol synthesis catalyst activated in-situ (within the LPMEOH $^{\mathrm{TM}}$ reactor as opposed to the $29 \mathrm{C}-30$ catalyst preparation vessel) and temperature programming was completed on Day 213 when a catalyst withdrawal and addition campaign was undertaken to increase catalyst activity. A series of three withdrawals was conducted on Day 213 to Day 214. Four batches of fresh catalyst were activated and added to the reactor between 
Day 215 and Day 220. At the conclusion of the catalyst withdrawal/addition catalyst campaign, the LPMEOH ${ }^{\mathrm{TM}}$ demonstration unit was operated at a constant reactor temperature of $235^{\circ} \mathrm{C}$ and a reactor pressure of $700 \mathrm{psig}$.

\subsubsection{Catalyst Performance: Catalyst Campaign 4}

Based on the lower than expected activity achieved during the first in-situ activation, a decision was made to perform a second in-situ activation using a revised procedure. As detailed in Section 5.6.3, this revised procedure was developed to eliminate the step that resulted in the storage of the fresh slurry at elevated temperatures prior to activation.

The second in-situ activation was undertaken in late June of 2002. Performance results for the methanol synthesis catalyst following the second in-situ activation are presented in Figure 5.1.41. The initial catalyst activity was excellent, and matched the performance expected with properly activated catalyst from the laboratory autoclave. The initial operating conditions (reactor temperature of $214^{\circ} \mathrm{C}$, reactor pressure of 450 psig, Balanced Gas flowrate of 500-600 $\mathrm{KSCFH}$ ) were selected to deal with the hyperactivity that is typical of freshly activated methanol

Figure 5.1.4-1

\section{Kingsport LPMEOH ${ }^{\mathrm{TM}}$ Catalyst Life (Catalyst Campaign 4)}

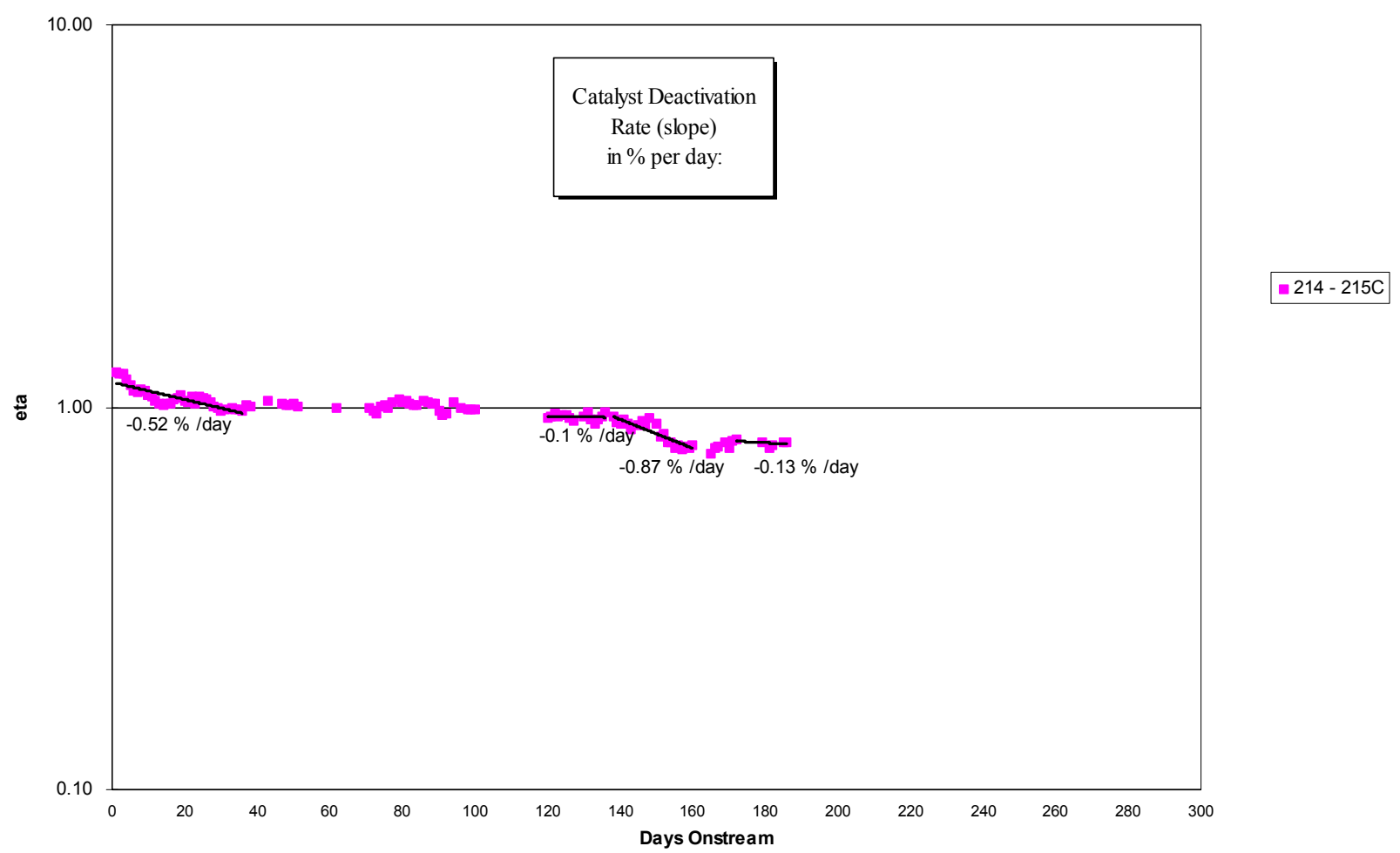


synthesis catalysts. Including the initial period of hyperactivity (approximately 3 weeks) that is typical of methanol synthesis catalysts, the catalyst deactivation rate over the first 52 days of operation was $0.52 \%$ per day; if the hyperactivity period is excluded, the rate of change of $\eta$ over the first six months of this catalyst campaign was calculated to be in the range of 0.1 to $0.2 \%$ per day. These results were a significant improvement over the historical average of 0.6 to $0.7 \%$ per day and the results from the proof-of-concept run at the LaPorte AFDU in 1988/89 $(0.4 \%$ per day), and may have been related to the performance of the adsorbent in the carbonyl guard bed, the removal of carbon steel components from the reactor internals (refer to Section 5.2), and the use of temperature programming to control the production rate across the LPMEOH $^{\mathrm{TM}}$ reactor. Due to the low rate of catalyst deactivation, the reactor temperature was not increased during the 6-month operating period for this campaign (the operating program of the LPMEOH ${ }^{\mathrm{TM}}$ Demonstration Project ended on 31 December 2002). Reactor pressure was raised from 450 psig to 500 psig on 11 November 2002 to improve the conversion efficiency of the process.

The change in the rate of catalyst deactivation at Day 140 may have been caused by a breakthrough in arsenic (reported as arsine) through the adsorbent in the carbonyl guard bed. A thermal treatment of the adsorbent in the carbonyl guard bed (described in Section 5.2) may have resulted in the improvement in performance beginning on Day 160, and provides evidence of the impact of the presence of trace contaminants in coal-derived syngas on the life of methanol synthesis catalyst.

For the entire campaign (including the period of hyperactivity), the average rate of catalyst deactivation was calculated to be $0.17 \%$ per day, which was significantly lower than performance results from the laboratory, the LaPorte AFDU, or the earlier portions of the operating program for the LPMEOH ${ }^{\mathrm{TM}}$ Demonstration Project.

\subsubsection{Summary}

Catalyst performance was tracked throughout the 69-month operating program at the $\mathrm{LPMEOH}^{\mathrm{TM}}$ demonstration unit. The design for the project used the performance during the 4month proof-of-concept run at the LaPorte AFDU ( $0.4 \%$ per day on CO-rich syngas derived from natural gas at a reactor temperature of $250^{\circ} \mathrm{C}$ ) as the basis. One of the key objectives of the commercial demonstration was to determine the long-term performance of the methanol synthesis catalyst on coal-derived syngas, and to quantify the rate of catalyst deactivation for use in any future projects. An in-house kinetic model was used to calculate the ratio of the rate constant at any time to the rate constant for freshly reduced catalyst (as determined in the laboratory autoclave). The rate of change of this parameter $(\eta)$ improved over the demonstration program. Following an accelerated rate of catalyst deactivation that was linked to the presence of post-construction debris in the system, the initial results at the design operating temperature of $250^{\circ} \mathrm{C}$ (averaging $1.3 \%$ per day) were significantly higher than the design basis.

The project team and DOE agreed that a second catalyst campaign be undertaken using a lower reactor temperature. During this 3+ year operating test, a long-term program of catalyst withdrawal and addition was demonstrated as an effective means to maintain catalyst 
productivity. Most of the data during Catalyst Campaign 2 was taken at a reactor temperature of $235^{\circ} \mathrm{C}$, and the rate of catalyst deactivation improved to $0.6 \%$ per day.

During the execution of the operating program for the LPMEOH ${ }^{\mathrm{TM}}$ Demonstration Project, modes of operation that were not anticipated during the development of the original Demonstration Test Plan were identified. The ability to activate the methanol synthesis catalyst within the LPMEOH ${ }^{\mathrm{TM}}$ reactor by using syngas that is diluted with $\mathrm{N}_{2}$ (so-called in-situ activation) can result in lower capital cost. Also, the life of the methanol synthesis catalyst can be extended by operating the LPMEOH ${ }^{\mathrm{TM}}$ reactor at low temperatures at the outset and slowly increasing temperature with time to maintain a constant production of methanol (so-called temperature programming). The third catalyst campaign used this in-situ activation procedure to activate a full charge (in excess of 40,000 pounds) of fresh catalyst slurry inside the reactor. The catalyst did not reach proper initial activity compared to the results from the laboratory autoclave. The selection of operating conditions not associated with the activation was identified as the cause of the lower initial catalyst activity (refer to Section 5.6). Temperature programming was first practiced during Catalyst Campaign 3 to minimize the operating temperature and increase as necessary to maintain catalyst productivity. Levels of iron, arsenic, and sulfur were increasing on the catalyst during this campaign. The average catalyst deactivation rate for Catalyst Campaign 3 was similar to the result for Catalyst Campaign 2 $(0.6 \%$ per day).

Catalyst Campaign 4 also involved an in-situ activation with an improved procedure to avoid high temperature storage of fresh catalyst slurry prior to activation. The activation resulted in the proper initial activity of the methanol synthesis catalyst. The average rate of catalyst deactivation during the 6-month duration of this campaign was $0.17 \%$ per day, which was $1 / 2$ of the design basis for the LPMEOH ${ }^{\mathrm{TM}}$ demonstration unit. The reactor was operated at a constant low temperature of $215^{\circ} \mathrm{C}$ during this campaign.

The improvement in the long-term performance of the methanol synthesis catalyst can likely be attributed to several factors that were investigated as part of the operating program for the LPMEOH $^{\mathrm{TM}}$ Demonstration Project. The negative effects of certain trace contaminants in coalderived syngas may have had the most significant impact on catalyst life; Section 5.2 provides details on the results of analyses of catalyst samples from the LPMEOH ${ }^{\mathrm{TM}}$ reactor, laboratory work on trace contaminant removal, and the change of adsorbent materials within the existing catalyst guard bed system at the LPMEOH ${ }^{\mathrm{TM}}$ demonstration unit. The ability to maintain the desired rate of methanol production using the concept of temperature programming was likely another factor, and the development of the in-situ activation procedure allowed for the minimum operating temperature to be utilized; Section 5.6 provides additional details on the work in this area. 


\subsection{IDENTIFICATION AND REMOVAL OF TRACE CONTAMINANTS IN COAL- DERIVED SYNGAS}

One of the major technical risks associated with the design of the LPMEOH ${ }^{\mathrm{TM}}$ demonstration unit was the magnitude of the impact of trace contaminants in coal-derived syngas on the longterm performance of the methanol synthesis catalyst. Catalyst consumption is a major component in the variable cost of operation of methanol production plants, and the results from the 4-month proof-of-concept test at the LaPorte AFDU were obtained using CO-rich syngas produced from natural gas. During the operation of the LPMEOH ${ }^{\mathrm{TM}}$ demonstration unit, attempts were made to determine the impact of trace contaminants on the performance of the methanol synthesis catalyst. The presence of certain elements was identified from samples of spent catalyst, spent adsorbent materials from catalyst guard beds, and syngas entering the LPMEOH $^{\mathrm{TM}}$ demonstration unit. The effects of certain elements were identified in laboratory studies, and the adsorbents in the catalyst guard bed system were changed based upon these results. ${ }^{(a)}$

A description of the Eastman upstream gas cleanup systems was provided in a topical report. ${ }^{\text {(b) }}$ These systems include a Rectisol gas clean-up plant located downstream of the Texaco coal gasification system and a catalyst guard bed (equipment number 10C-30), which was installed by Eastman upstream of the fixed-bed methanol plant. Figure 1.2.3-1 shows the location of this equipment in relation to the syngas generation system and to both the fixed-bed methanol plant and the LPMEOH ${ }^{\mathrm{TM}}$ demonstration unit. The Rectisol unit was primarily designed to remove sulfur compounds from the syngas stream. The Eastman catalyst guard bed was installed to remove trace contaminants (in particular, compounds of sulfur and arsenic) which adversely impact the long-term performance of methanol synthesis catalysts.

The 29C-40 carbonyl guard bed (as shown in Figure 2.4-1) is a fixed adsorbent guard bed that protects methanol synthesis catalyst in the LPMEOH ${ }^{\mathrm{TM}}$ reactor against possible upsets of contaminants from the upstream gas cleanup units. The unit is four feet in diameter with an active bed length of 12 feet. Normal process flow is downward; the design also included a thermal regeneration system to reclaim performance of the adsorbent following saturation with metal carbonyls.

During the design phase of the LPMEOH ${ }^{\mathrm{TM}}$ Demonstration Project, the basis for the rate of catalyst deactivation ( $0.4 \%$ per day) was selected based upon the results from the 4-month test at the LaPorte AFDU. The experiences at the pilot unit had identified iron and nickel carbonyl as significant poisons to methanol synthesis catalyst. In addition, a field test was performed at the Kingsport chemicals-from-coal complex in 1996 using autoclaves housed in a transportable laboratory, the Alternative Fuels Field Development Unit (AFFTU); a photograph is provided in Figure 5.2.1-1. As documented in a topical report, ${ }^{(\mathrm{c})}$ the performance of the methanol synthesis catalyst in the autoclave was not impacted by the presence of trace quantities of iron, nickel, sulfur, arsenic (expected to be in the form of arsine $\left[\mathrm{AsH}_{3}\right]$ ), and chloride that were detected on spent catalyst, even with no catalyst guard adsorbent materials in service.

Based upon these results, the basis for the design of the equipment to protect the methanol synthesis catalyst from trace contaminants in the coal-derived syngas was to utilize the existing 
10C-30 catalyst guard bed within the Eastman chemicals-from-coal complex, which was charged with zinc oxide (targeting sulfur) and manganese dioxide on alumina (targeting arsenic), and to install the 29C-40 carbonyl guard bed utilizing activated carbon for removal of iron and nickel carbonyl. Both vessels were designed to operate at system pressure (nominally $750 \mathrm{psig}$ ) and ambient temperature.

\section{Figure 5.2-1}

Photograph of Alternative Fuels Field Test Unit (AFFTU)

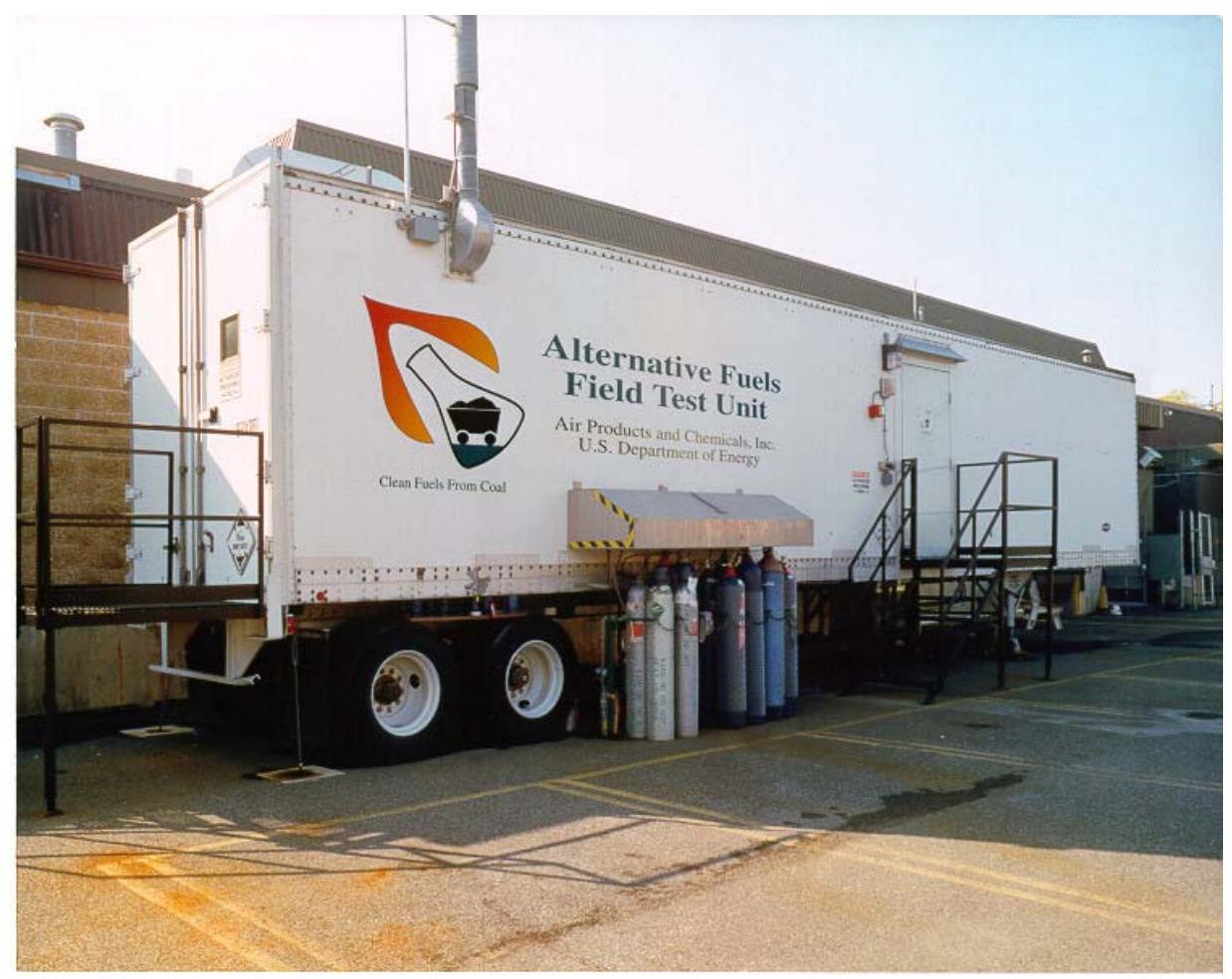




\subsubsection{Kingsport Catalyst Campaign 1}

Although there were no spent catalyst withdrawals during the campaign, freshly reduced catalyst was added to the $\mathrm{LPMEOH}^{\mathrm{TM}}$ reactor to maintain productivity starting in July of 1997. Analyses of early samples from Kingsport Catalyst Campaign 1 indicated a step-change increase in the concentration of iron on the catalyst surface during the initial six weeks, which could not be correlated to the presence of iron carbonyl in the feed gas streams. This finding was most likely related to the detection of post-construction debris within various parts of the facility. During this period, higher than expected levels of arsenic were also found on the catalyst samples. Table 5.2.1-1 lists elemental composition of freshly reduced and spent catalyst samples from Kingsport Catalyst Campaign 1. The presence of arsenic in sample K0597-2 indicated that the manganese dioxide in the Eastman catalyst guard bed was no longer effective in removing arsenic from the Balanced Gas feed. Given this result, Eastman replaced both adsorbents (zinc oxide and manganese dioxide) with fresh material in October of 1997.

\subsubsection{Kingsport Catalyst Campaign 2}

Fresh methanol catalyst was activated and transferred to the $\mathrm{LPMEOH}^{\mathrm{TM}}$ reactor in December of 1997 in preparation for this operating campaign. Given that the adsorbents in the Eastman catalyst guard bed had recently been replaced with fresh material, it was decided to replace the activated carbon in the carbonyl guard bed with fresh adsorbent. At the same time, the AFFTU was returned to the Eastman chemicals-from-coal complex to obtain real-time laboratory data in parallel with the unit operation. ${ }^{(\mathrm{d})}$ At the baseline operating conditions for laboratory testing (including a reactor temperature of $250^{\circ} \mathrm{C}$ ), the rate of catalyst deactivation in the autoclave in the AFFTU was statistically similar to the results using contaminant-free syngas. During the parallel test for the $\mathrm{LPMEOH}^{\mathrm{TM}}$ reactor (at a reactor temperature of $235^{\circ} \mathrm{C}$ ), the catalyst deactivation in the $\mathrm{LPMEOH}^{\mathrm{TM}}$ demonstration unit was about $1 \%$ per day (as noted in Section 5.1-2), which was still higher than the results from the 4-month proof-of-concept test at the LaPorte AFDU in $1988 / 89\left(0.4 \%\right.$ per day at a reactor temperature of $\left.250^{\circ} \mathrm{C}\right)$. Analytical results

Table 5.2.1-1

\section{Kingsport Catalyst Campaign 1 - Elemental Composition of Solids from Slurry Samples}

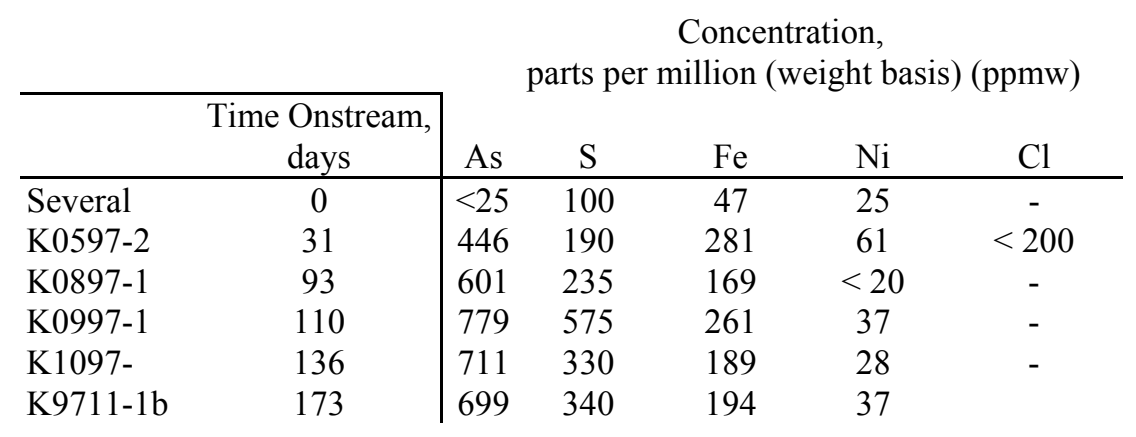


also detected the presence of arsenic in the Balanced Gas feed ( $>31$ parts per billion by volume [ppbv]), carbonyl sulfide (COS) (10-20 ppbv), and an average total sulfur concentration of about 37 ppbv.

During the test period, there were numerous withdrawals of aged catalyst slurry and additions of freshly activated catalyst to the reactor resulting in a mixture of aged and fresh catalyst as the run proceeded. This complicated the interpretation of analytical data. Catalyst slurry samples for analysis at Air Products were taken at least monthly and were routinely monitored for expected trace contaminants including arsenic, sulfur, chlorine, iron, and nickel. As shown in Figure 5.2.2-1, arsenic, sulfur, and iron were detected on the catalyst in significant concentrations and, of these, arsenic was by far the most abundant. Catalyst additions and withdrawals caused periodic decreases in arsenic concentration but these values subsequently increase with time on stream.

Given that arsenic was the largest species detected on the samples of spent catalyst, laboratory studies were performed to determine its impact on catalyst life. The results showed that arsenic (in the form of arsine) was a strong catalyst poison, and that its effects were not determined during earlier autoclave testing in the AFFTU due to the high background rate of catalyst deactivation that is inherent to the laboratory setting (around $0.05 \%$ per hour or $1.2 \%$ per day vs. $0.4 \%$ per day at the LaPorte AFDU) and the low concentration of arsenic in the Balanced Gas feed (measured at $39 \mathrm{ppbv}$ in a sample taken upstream of the Eastman catalyst guard bed in June of 1999). Figure 5.2.2-2 shows the fit of autoclave data for the impact of arsine on the life of methanol synthesis catalyst.

Figure 5.2.2-1

\section{Kingsport Catalyst Campaign 2 - Trace Contaminant Concentrations on Slurry Samples}

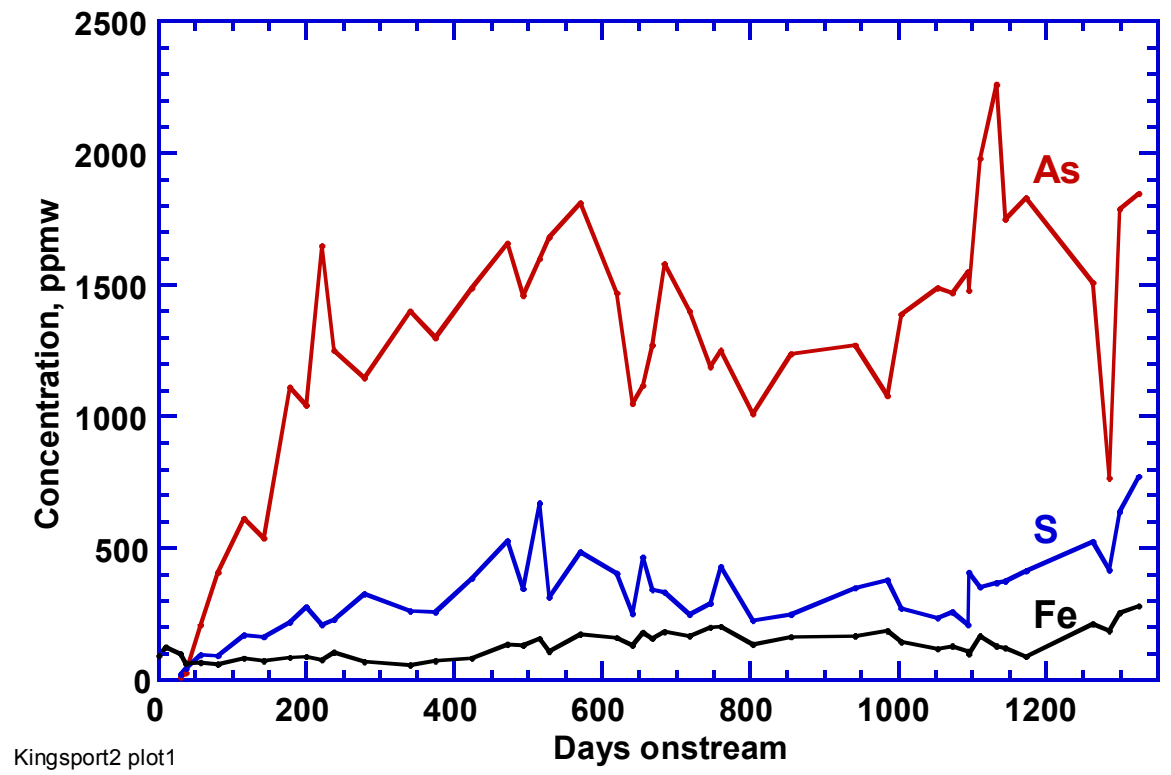


Figure 5.2.2-2

\section{Effect of Arsine Concentration on Methanol Catalyst Deactivation Rate in Autoclave}

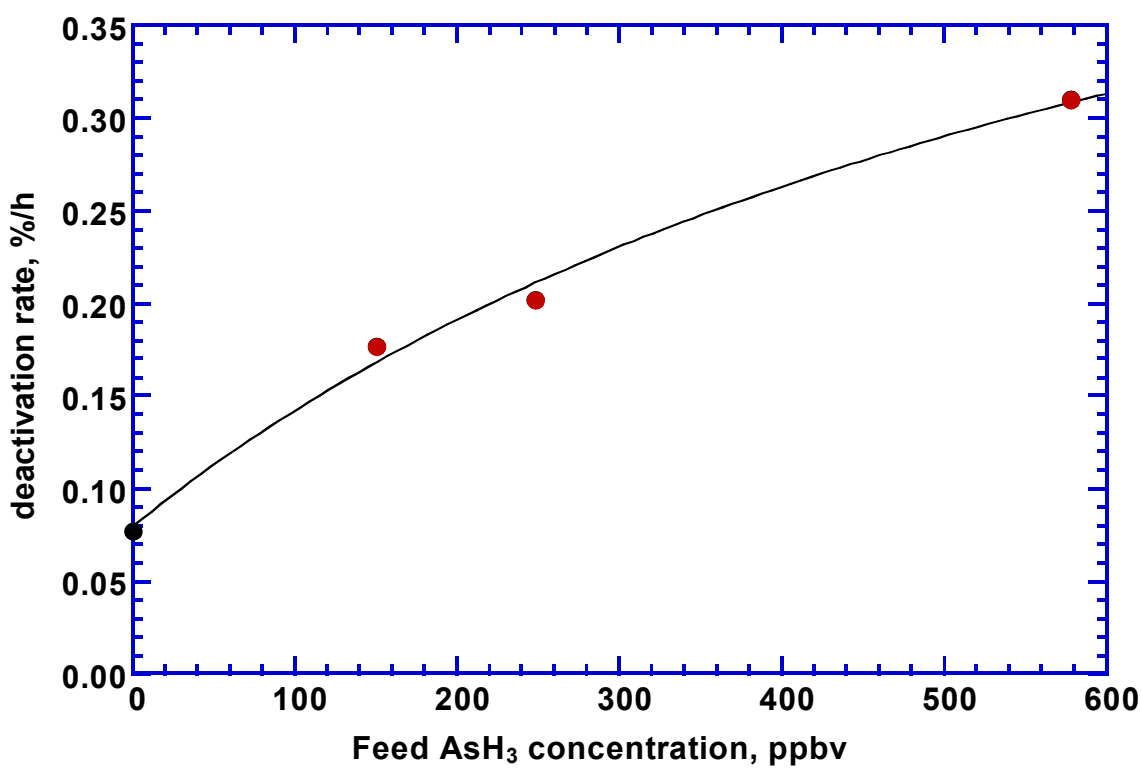

Given the increasing concentration of arsenic on the samples of spent catalyst, the adsorbents in both the Eastman catalyst guard bed and the carbonyl guard bed were changed. In June of 1999, the Eastman catalyst guard bed was charged with only manganese dioxide for arsine removal, and the carbonyl guard bed was split between manganese dioxide and activated carbon (as the carbon may have affinity for other species beyond iron and nickel carbonyl). The spent activated carbon was analyzed for presence of trace contaminants; the results are provided in Table 5.2.21. The fresh adsorbent contained substantial concentrations of sulfur, $\mathrm{N}_{2}$, and iron and thus an accurate accounting of these elements in the spent samples was difficult. In particular, the fresh adsorbent sulfur concentration was too high to obtain meaningful sulfur loadings on the bed. The results indicated a fairly uniform arsenic concentration throughout the bed implying that activated carbon was largely ineffective for removal of arsenic-containing contaminants.

Table 5.2.2-1

Elemental Analysis Results for Spent Activated Carbon from 29C-40 Carbonyl Guard Bed (June 1999)

\begin{tabular}{llccccccccc}
\hline & & \multicolumn{1}{c}{ Elemental Concentrations, ppmw, vs. Fresh Adsorbent ${ }^{\mathrm{a}}$} \\
Sample No. & \multicolumn{1}{c}{ Description } & $\mathrm{As}$ & $\mathrm{S}$ & $\mathrm{N}$ & $\mathrm{Zn}$ & $\mathrm{Mn}$ & $\mathrm{Fe}$ & $\mathrm{Ni}$ & $\mathrm{Cr}$ & $\mathrm{Cu}$ \\
\hline AGB-57 & fresh adsorbent & 6.0 & 5,930 & 5,000 & 2.6 & 10.7 & 2,010 & 39.6 & 5.0 & 18.6 \\
AGB-42 & bed inlet & 1,630 & $\leq 360$ & 2,400 & 225 & 141 & nd & nd & nd & nd \\
AGB-46 & 5' from bed inlet & 1,570 & $\leq 330$ & - & 213 & 135 & nd & nd & nd & nd \\
AGB-50 & 12' from bed inlet & 1,990 & $\leq 430$ & 3,400 & 122 & 79 & nd & nd & nd & nd \\
\hline
\end{tabular}

a. for spent adsorbent, elemental concentrations were corrected for concentrations on fresh adsorbent; nd $=$ none detected. 
During the first two months of service, the pressure drop across the carbonyl guard bed began to increase gradually. By the end of July of 1999, the pressure drop was measured at over 20 psi; the expected pressure drop was less than 1 psi. During a vessel inspection on 12 August 1999, changes to the bottom support screen and its support were made. During this maintenance, samples of the two adsorbents were analyzed. The results for the manganese dioxide are provided in Table 5.2.2-2. Arsenic was found throughout the manganese dioxide, but sulfur above that on the fresh adsorbent was found only on the inlet sample. For the activated carbon portion of the bed, arsenic concentrations were determined to be greater than that of the fresh adsorbent throughout the bed with a gradient from inlet to outlet (Table 5.2.2-3). This implied that arsine had broken through the bed.

Based upon these results, a laboratory screening program was initiated to identify alternate adsorbent materials with affinity for arsine that could be utilized in the Eastman catalyst guard bed and/or the carbonyl guard bed within the LPMEOH ${ }^{\mathrm{TM}}$ demonstration unit. Of the adsorbents examined, an activated carbon impregnated with copper oxide $(\mathrm{CuO} / \mathrm{C})$ was viewed as the material most likely to remove $\mathrm{AsH}_{3}$ and other contaminants from the Balanced Gas feed. It was reasoned that the $\mathrm{CuO}$ portion would remove $\mathrm{AsH}_{3}, \mathrm{COS}$, and hydrogen sulfide $\left(\mathrm{H}_{2} \mathrm{~S}\right)$ while the carbon portion would function as it did previously to remove contaminants such as iron and nickel carbonyl as well as trace organics. The carbonyl guard bed was determined to provide adequate contact time and mixing length of the $\mathrm{CuO} / \mathrm{C}$ adsorbent.

Table 5.2.2-2

Analysis of Fresh and Spent Manganese Dioxide from 29C-40 Carbonyl Guard Bed (11 August 1999)

\begin{tabular}{|c|c|c|c|c|c|c|c|c|c|c|c|c|}
\hline \multirow[b]{2}{*}{ Sample } & \multirow[b]{2}{*}{ description } & \multicolumn{2}{|c|}{ conc., wt $\%$} & \multicolumn{9}{|c|}{ Concentration, ppmw } \\
\hline & & $\mathrm{Al}$ & $\mathrm{Mn}$ & As & $\mathrm{As}^{\mathrm{a}}$ & $\mathrm{S}$ & $\mathrm{S}^{\mathrm{a}}$ & $\mathrm{Mg}$ & $\mathrm{Zn}$ & Mo & $\mathrm{Ga}$ & $\mathrm{Ba}$ \\
\hline & fresh adsorbent & 36.2 & 24.4 & $<46$ & 6.3 & 150 & 210 & 180 & nd & nd & nd & nd \\
\hline AGB81199-1 & Top & 34.2 & 22.2 & 940 & 200 & 280 & 410 & 270 & 90 & 40 & nd & nd \\
\hline AGB81199-3 & $2 \mathrm{ft}$ down & 34.6 & 21.7 & 800 & 130 & 80 & 260 & $<300$ & nd & nd & 30 & nd \\
\hline AGB81199-6 & $5 \mathrm{ft}$ down & 34.4 & 21.9 & 580 & 66 & 90 & 250 & 240 & 40 & nd & nd & 120 \\
\hline
\end{tabular}

a. Concentration determined by elemental analysis; $\mathrm{nd}=$ not detected.

Table 5.2.2-3

Analysis of Fresh and Spent Activated Carbon from 29C-40 Carbonyl Guard Bed (11 August 1999)

\begin{tabular}{clccccccccc}
\hline & & \multicolumn{9}{c}{ Concentration, ppmw } \\
Sample & \multicolumn{1}{c}{ Description } & $\mathrm{S}$ & $\mathrm{S}^{\mathrm{a}}$ & $\mathrm{As}$ & $\mathrm{As}^{\mathrm{a}}$ & $\mathrm{Na}$ & $\mathrm{Mn}$ & $\mathrm{Mo}$ & $\mathrm{Ba}$ & $\mathrm{Zr}$ \\
\hline & fresh adsorbent & 11,400 & $370^{\mathrm{b}}$ & $<16$ & 2.1 & 400 & 12 & nd & nd & nd \\
AGB 81199-9 & 8' down, top C $^{\prime}$ & 10,700 & $400^{\mathrm{b}}$ & 1,000 & 1,000 & 700 & 40 & 10 & 130 & 40 \\
AGB 81199-11 & 10' down, middle C $^{\prime}$ & 9,800 & $330^{\mathrm{b}}$ & 240 & 260 & 800 & 30 & 10 & 130 & 30 \\
AGB 81199-13 & 12' down, bottom C & 8,300 & $320^{\mathrm{b}}$ & 320 & 410 & 300 & 50 & 10 & 80 & nd \\
\hline
\end{tabular}

a. Concentration determined by elemental analysis.

b. Large errors because of high background S; nd = not detected. 
Laboratory testing was performed to determine any safety implications of using this material at ambient temperature. Exposure of $\mathrm{CuO} / \mathrm{C}$ adsorbent to Balanced $\mathrm{Gas}$ at $750 \mathrm{psig}$ and $30^{\circ} \mathrm{C}$ resulted in temperature increases of $4.5^{\circ} \mathrm{C}$ or less, implying that no significant reduction (in this case, the reaction of the copper oxide with a reductant such as $\mathrm{CO}$ or $\mathrm{H}_{2}$ to copper metal and either $\mathrm{CO}_{2}$ or $\mathrm{H}_{2} \mathrm{O}$ ) to metallic copper occurred at near ambient temperature. No methanol or other organics were observed in the bed exit gases, implying that the adsorbent had no methanol synthesis catalytic activity. Following reduction to a copper-impregnated carbon $(\mathrm{Cu} / \mathrm{C})$ adsorbent using dilute $\mathrm{H}_{2}$ in $\mathrm{N}_{2}$, temperature increases upon syngas exposure were almost the same as for the unreduced material. Again, the bed outlet showed no sign of methanol or other organics meaning that the $\mathrm{Cu} / \mathrm{C}$ material had negligible catalytic activity at near ambient temperatures. Additional testing at temperatures up to $250^{\circ} \mathrm{C}$ resulted in little to no formation of methanol or other organics.

The new adsorbent material was loaded into the carbonyl guard bed, and the vessel was operationally tested on 03 August 2000. Within 30 minutes of the introduction of Balanced Gas, temperatures in the carbonyl guard bed began to rise beyond the expected values based upon the results of the laboratory testing. The Eastman operations team moved quickly to depressurize the carbonyl guard bed by venting the syngas to the Eastman purge gas header. No environmental issues were experienced due to this incident. The carbonyl guard bed was then isolated from the feed syngas streams so that the LPMEOH ${ }^{\mathrm{TM}}$ demonstration unit could continue to operate.

The results of additional laboratory testing indicated that the probable cause of this temperature excursion was the reduction of copper oxide to copper metal. A procedure was then developed to reduce the copper oxide on the adsorbent to copper metal at $100^{\circ} \mathrm{C}$ using a dilute stream of Balanced Gas in $\mathrm{N}_{2}$ over a 2-day period. The existing charge of adsorbent was subjected to the reduction procedure on 17-19 April 2001. Little uptake of $\mathrm{H}_{2}$ or $\mathrm{CO}$ was measured, indicating that the adsorbent material had been essentially reduced during the initial operations in August of 2000. The carbonyl guard bed vessel was brought onstream on 26 April 2001. The carbonyl guard bed internal temperatures increased by about $30-40^{\circ} \mathrm{C}$ and then stabilized following the introduction of syngas. This was consistent with the temperature rise that would be expected due to the adsorption of $\mathrm{CO}$ on the guard bed material. However, sampling of the syngas entering and leaving the carbonyl guard bed indicated that breakthrough of arsine through the adsorbent had occurred within the first 6 days of operation versus an expected life of 1 to 2 months. Samples of spent material from the carbonyl guard bed indicated that the exposure to elevated temperatures during the upset in August of 2000 may have damaged the adsorbent.

Air Products and Eastman decided to replace the used adsorbent with fresh material. On 24 July 2001, the carbonyl guard bed was emptied and refilled with the same commercially available adsorbent. During this reduction procedure, a dilute stream of Balanced Gas in $\mathrm{N}_{2}$ was preheated and used to reduce the copper oxide to copper metal in a temperature controlled manner. The temperature control during the procedure was excellent, and the uptake of CO and $\mathrm{H}_{2}$ approached the theoretical value based upon the concentration of copper oxide on the adsorbent. The reduction was completed on 28 July 2001. After cooling with $\mathrm{N}_{2}$, a pressure check to full supply pressure with Balanced Gas was conducted. The adsorbent temperatures increased by about $25^{\circ} \mathrm{C}$ and stabilized during this examination. The carbonyl guard bed was 
bypassed after the pressure check, and was brought onstream at the start of the third catalyst campaign.

\subsubsection{Kingsport Catalyst Campaign 3}

Unlike previous campaigns, the third Kingsport campaign involved an in-situ activation of a full charge (greater than 40,000 pounds) of catalyst. Methanol synthesis catalyst in the oxide form and mineral oil were loaded into the $\mathrm{LPMEOH}^{\mathrm{TM}}$ reactor without prior activation. The entire contents of the reactor were then reduced, or activated, using dilute Balanced Gas in $\mathrm{N}_{2}$. In previous campaigns at the LPMEOH ${ }^{\mathrm{TM}}$ demonstration unit, catalyst had been reduced with dilute $\mathrm{CO}$ in $\mathrm{N}_{2}$ in smaller batches (approximately 2,000 pounds per batch) in the catalyst preparation system and transferred into the LPMEOH ${ }^{\mathrm{TM}}$ reactor. The initial performance of the catalyst was less than expected when compared with data from the laboratory. Additional information on this procedure is provided in Section 5.3.

Over the entire campaign, only two contaminants (iron and arsenic) were found on the catalyst. As shown in Figure 5.2.3-1, iron concentrations increased at a substantial rate while the increase in arsenic was much more modest. The final sample contained 534 ppmw iron. Arsenic concentrations reached a maximum of only 318 ppmw and 203 ppmw for the final sample analyzed (213 days). Sulfur was below its limit of detection (160 ppmw or lower) throughout the campaign. Although a direct comparison of data from Campaigns 2 and 3 is complicated by

Figure 5.2.3-1

Kingsport Catalyst Campaign 3 - Trace Contaminant Concentrations on Slurry Samples

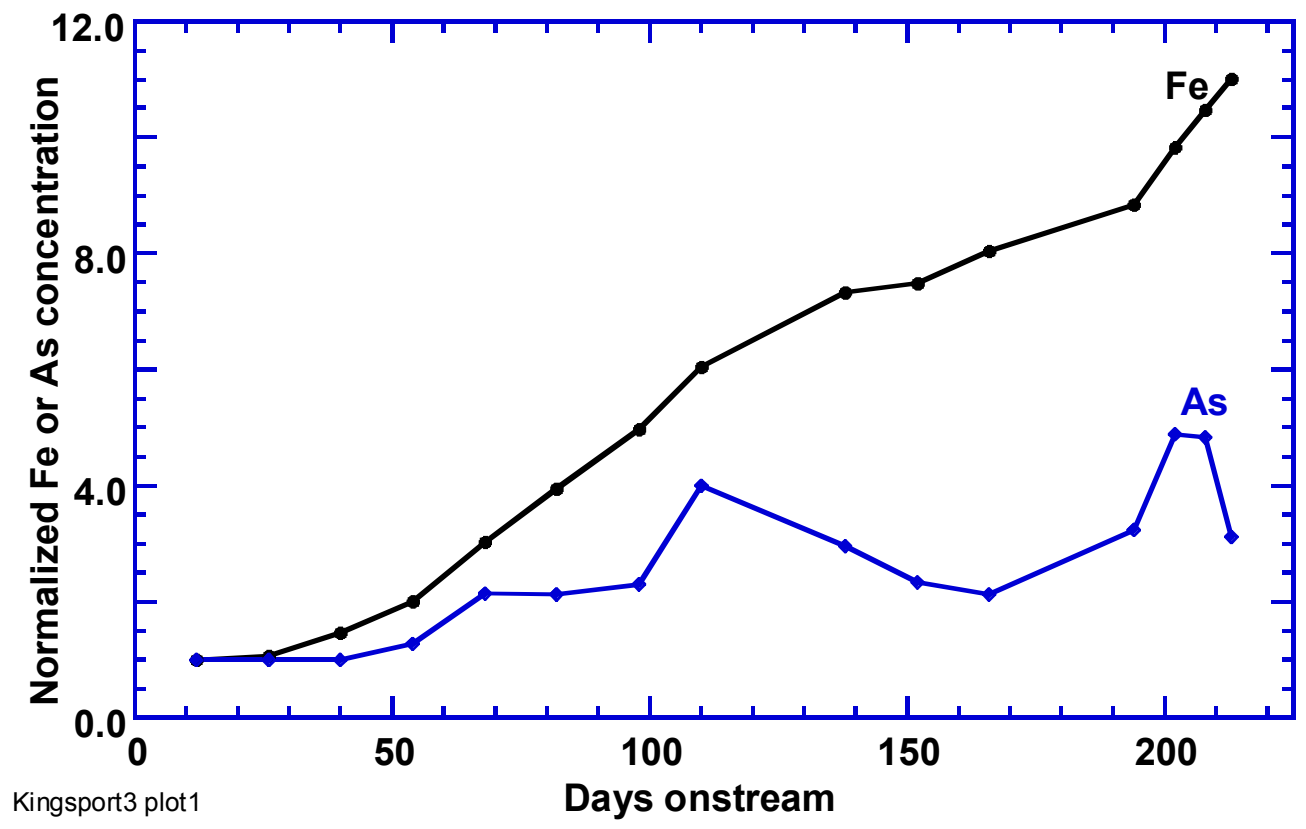


differences in total syngas exposure, some conclusions can be drawn. The arsenic loading on the Campaign 2 catalyst contained 277 ppmw sulfur while no sulfur was detected on the Campaign 3 catalyst. However, iron on the Campaign 2 catalyst was only 89 ppmw.

The use of the $\mathrm{Cu} / \mathrm{C}$ adsorbent in the carbonyl guard bed was instrumental in lowering the quantity of arsine entering the LPMEOH ${ }^{\mathrm{TM}}$ demonstration unit. In order to confirm the observations during the laboratory evaluations, the effectiveness of the adsorbent was followed by monitoring $\mathrm{AsH}_{3}$ concentrations in the carbonyl guard bed outlet. Samples were collected by passing syngas through an activated carbon trap followed by subsequent analysis for arsenic. During the first 27 days of service, the outlet $\mathrm{AsH}_{3}$ concentration was less than 4 ppbv while the inlet arsine concentration was $52 \mathrm{ppbv}$ ( 6 days) and 63 ppbv (28 days). Thus, the bed was effective for $\mathrm{AsH}_{3}$ removal. The outlet concentration was next determined on the $68^{\text {th }}$ day and found to be $5.6 \mathrm{ppbv}$, indicating that some breakthrough had occurred. The outlet concentration appeared to increase with time on stream and reached 30 ppbv by Day 102, indicating substantial breakthrough.

During the laboratory assessment of the $\mathrm{Cu} / \mathrm{C}$ adsorbent, it was determined that the bond between copper and arsine was irreversible, and it was theorized that the rate limiting step in the reaction of $\mathrm{Cu} / \mathrm{C}$ with $\mathrm{AsH}_{3}$ was the diffusion of bound arsenic away from the $\mathrm{Cu}$ surface and into the bulk. It was reasoned that a "purge" of $120^{\circ} \mathrm{C} \mathrm{N} \mathrm{N}_{2}$ would warm the bed sufficiently to increase the rate of surface arsenic diffusion into the bulk and thus provide fresh copper surface for $\mathrm{AsH}_{3}$ adsorption. During Catalyst Campaign 3, a thermal treatment was conducted in order to extend the useful life of the $\mathrm{Cu} / \mathrm{C}$ adsorbent. The results of syngas sampling at the outlet of the carbonyl guard bed showed that the $\mathrm{AsH}_{3}$ outlet concentration was below its limit of detection following both treatments. Thus, this thermal treatment extended the useful life of the adsorbent. Arsine was detected in the outlet of the carbonyl guard bed after 42 days on stream, which indicated that the performance of the adsorbent was beginning to degrade. A second thermal treatment was conducted, and once again arsine was not detected in the outlet from the carbonyl guard bed.

Based upon the decrease in the effective onstream time of the current charge of adsorbent, it was decided to replace the adsorbent in the carbonyl guard bed with fresh material. The spent $\mathrm{Cu} / \mathrm{C}$ adsorbent was removed from the carbonyl guard bed and sampled; results of the analysis are provided in Table 5.2.3-1. The arsenic concentration varied in a regular fashion down the bed with 9,260 ppmw and 2,280 ppmw at the inlet and outlet, respectively. Sulfur concentrations were corrected for that of the fresh adsorbent and, because of high background sulfur concentration, the level of sulfur could be calculated only for the inlet sample. Similarly, high background iron precluded quantification of iron adsorption. No other contaminants were found on the spent adsorbent samples.

The fresh charge of $\mathrm{CuO} / \mathrm{C}$ adsorbent was reduced and brought onstream on 08 March 2002. Initial performance following the replacement of the adsorbent was acceptable, as the average concentration of arsine was reduced from an inlet value of approximately 55 ppbv to 3 ppbv. The performance of the adsorbent began to degrade by late April of 2002, as the concentration of 
Table 5.2.3-1

Analysis of Fresh and Spent Cu/C Adsorbent from 29C-40 Carbonyl Guard Bed

(20 February 2002)

\begin{tabular}{llccccccc}
\hline & & \multicolumn{9}{c}{ Concentration, ppmw } \\
Sample no. & Description & As & $\mathrm{S}^{\text {a }}$ & Fe & Ni & $\mathrm{P}$ & $\mathrm{Cr}$ & Mo \\
\hline $18141-88-1$ & inlet & 9,260 & 5,900 & $\leq 1,400$ & $\leq 27$ & $\leq 150$ & $<8$ & $\leq 140$ \\
$18141-88-3$ & $3^{\text {rd }}$ from inlet & 8,720 & nd & $\leq 1,400$ & $\leq 27$ & $\leq 150$ & $<8$ & $\leq 140$ \\
$18141-88-6$ & $6^{\text {th }}$ from inlet & 5,100 & nd & $\leq 1,400$ & $\leq 27$ & $\leq 150$ & $<8$ & $\leq 140$ \\
$18141-88-9$ & $9^{\text {th }}$ from inlet & 4,250 & nd & $\leq 1,400$ & $\leq 27$ & $\leq 150$ & $<8$ & $\leq 140$ \\
$18141-88-12$ & $12^{\text {th }}$ from inlet & 3,240 & nd & $\leq 1,400$ & $\leq 27$ & $\leq 150$ & $<8$ & $\leq 140$ \\
$18141-88-16$ & $16^{\text {th }}$ from inlet & 3,150 & nd & $\leq 1,400$ & $\leq 27$ & $\leq 150$ & $<8$ & $\leq 140$ \\
$18141-88-19$ & outlet & 2,280 & nd & $\leq 1,400$ & $\leq 27$ & $\leq 150$ & $<8$ & $\leq 140$ \\
\hline
\end{tabular}

a. Concentration corrected for background on the fresh adsorbent; nd = none detected.

arsine at the outlet of the carbonyl guard bed had increased to $10 \mathrm{ppbv}$. This charge of adsorbent was used until the end of Catalyst Campaign 3 on 05 June 2002.

During this campaign, one result of note was the substantial increase in iron on the catalyst with time. The most likely and possibly the only source of iron contamination is iron carbonyl. The volatile carbonyl present in the syngas feed can enter the LPMEOH ${ }^{\mathrm{TM}}$ reactor if breakthrough of the adsorbent in the carbonyl guard bed occurred. A laboratory evaluation had earlier showed that the $\mathrm{Cu} / \mathrm{C}$ adsorbent had a very high removal capacity for iron carbonyl. Furthermore, results from gas sampling performed on 23 April 2002 found $<8$ ppbv iron carbonyl in the carbonyl guard bed inlet and outlet. Another possibility was that iron carbonyl was generated within the stainless steel metallurgy in the LPMEOH ${ }^{\mathrm{TM}}$ reactor or the associated recycle loop hardware. Based on laboratory experiments, this also seemed unlikely. Although the concentration of iron detected in slurry samples was likely sufficient to adversely impact the long-term catalyst activity during this campaign, its presence was not related to poor adsorbent performance in the carbonyl guard bed or to some problem with the in-situ activation procedure.

It was subsequently determined that the most likely source of the iron was the incorrect installation of carbon steel parts inside the reactor during a maintenance outage in April of 2001. The correct stainless steel parts were installed after the conclusion of Kingsport Catalyst Campaign 3 in June of 2002. A hot function test with a CO-rich syngas and mineral oil (in the absence of catalyst) showed low levels of iron carbonyl (approximately $30 \mathrm{ppbv}$ ) in the reactor feed gas stream after three days of testing. 


\subsubsection{Kingsport Catalyst Campaign 4}

The in-situ activation procedure was successfully demonstrated during the final Catalyst Campaign at the LPMEOH ${ }^{\mathrm{TM}}$ demonstration unit; details are provided in Section 5.3. The results of analysis of spent catalyst samples from this campaign are listed in Table 5.2.4-1. No significant quantities of any of the contaminants analyzed were found during the first three months of this catalyst campaign.

A fresh charge of $\mathrm{CuO} / \mathrm{C}$ adsorbent was charged to the carbonyl guard bed, reduced, and brought onstream at the start of Catalyst Campaign 4. During the first week in service, gas sampling was performed to assess the initial performance of the adsorbent. The outlet concentration of arsine was determined to be less than the detection limit of the analysis ( $2 \mathrm{ppbv})$. These results provide evidence that the adsorbent in the carbonyl guard bed was performing well during the first week of operation.

Based upon results from Catalyst Campaign 3, an operating schedule for the adsorbent was developed. Fresh adsorbent can be used for about two months before breakthrough of arsine can be expected. A thermal treatment can then be performed on the adsorbent to provide increased capacity for arsine removal, and the material can be used for another month before the adsorbent needs to be replaced. Based upon this timetable, a thermal treatment was completed in late August of 2002. The spent adsorbent was removed after about 3 months of use, and fresh material was reduced and brought onstream in mid-October of 2002. (At the same time, Eastman replaced the manganese dioxide in the 10C-30 catalyst guard bed with fresh adsorbent.) The timing for the thermal treatment for this charge was accelerated by one week (to 06 December 2002) due to an observed increase in the rate of catalyst deactivation (as described in Section 5.1.4).

Table 5.2.4-1

\section{Kingsport Catalyst Campaign 4 - Elemental Composition of Solids from Slurry Samples}

\begin{tabular}{|c|c|c|c|c|c|c|}
\hline & \multirow[b]{2}{*}{$\begin{array}{c}\text { Time Onstream } \\
\text { days }\end{array}$} & \multicolumn{5}{|c|}{ Concentration, ppmw } \\
\hline & & As & $\mathrm{S}$ & $\mathrm{Fe}$ & $\mathrm{Ni}$ & $\mathrm{Cl}$ \\
\hline K0206-1 & 0 & $<20$ & $<40$ & $<23$ & $<10$ & $<100$ \\
\hline K0109-1 & 12 & $<2$ & $<19$ & 28 & $<7$ & na \\
\hline K0109-3 & 26 & 4.2 & $<25$ & 44 & $<7$ & na \\
\hline K0110-1 & 40 & 5.4 & $<39$ & 40 & $<6$ & na \\
\hline K0110-2 & 54 & 19 & $<47$ & 58 & $<7$ & na \\
\hline
\end{tabular}




\subsubsection{Summary}

Significant progress was made during the operating phase of the LPMEOH ${ }^{\mathrm{TM}}$ Demonstration Project regarding the quantification of the impact of trace contaminants in coal-derived syngas on the performance of methanol synthesis catalyst and the study and use of adsorbents to remove targeted catalyst poisons. The 29C-40 carbonyl guard bed was originally designed for ambient temperature operation and to target the removal of carbonyl contaminants that could be present in coal-derived syngas. With the exception of two instances of the accidental introduction of iron to the system in Catalyst Campaign 1 (construction debris) and Catalyst Campaign 3 (incorrectly installed carbon steel parts in the $\mathrm{LPMEOH}^{\mathrm{TM}}$ reactor), iron and nickel carbonyls did not adversely impact the performance of the methanol synthesis catalyst at the LPMEOH ${ }^{\mathrm{TM}}$ demonstration unit.

Arsenic, and to a lesser degree sulfur, were the main contaminants that were detected on the samples of catalyst slurry taken from the LPMEOH ${ }^{\mathrm{TM}}$ reactor. Two adsorbents to target arsenic and sulfur were evaluated at the LPMEOH ${ }^{\mathrm{TM}}$ demonstration unit during Catalyst Campaigns 2 through 4. During Catalyst Campaign 2, the carbonyl guard bed was charged with $50 \%$ by volume manganese dioxide and 50\% activated carbon. The manganese dioxide adsorbent displayed affinity for arsenic removal but the adsorbent bed broke through (based on gas-phase arsine analysis) after approximately one month of service. During Catalyst Campaigns 3 and 4, a copper oxide-impregnated activated carbon adsorbent was reduced and placed into service. This adsorbent was effective in arsine removal as determined by gas-phase analysis and catalyst sample results. The $\mathrm{Cu} / \mathrm{C}$ adsorbent had a service life of about two months at the LPMEOH ${ }^{\mathrm{TM}}$ demonstration unit. An innovative thermal treatment was employed to extend the service life of the adsorbent for two additional months.

The improved performance of the catalyst guard system may have had a direct impact on the results for catalyst life during Catalyst Campaign 4 (catalyst deactivation rate of 0.1 to $0.2 \%$ per day versus an average of 0.6 to $0.7 \%$ per day during the previous 3 years of operation). By controlling the exposure of methanol synthesis catalyst to poisons, the targeted economics for coproduction of methanol in an IGCC power plant (as detailed in Section 9) can be achieved. 


\subsection{GAS SPARGER PERFORMANCE}

The sparger is a proprietary gas distribution device used to introduce the feed gas into the bottom of the LPMEOH ${ }^{\mathrm{TM}}$ reactor. The sparger was developed on a proprietary basis by Air Products and is intended to introduce the feed gas to the slurry bubble column reactor. It must also be able to withstand interruptions to gas flow without negative impact on operations. The principles for the design of the sparger at the LPMEOH ${ }^{\mathrm{TM}}$ demonstration unit were first utilized during the 4-month proof-of-concept test of the LPMEOH ${ }^{\mathrm{TM}}$ Process at the LaPorte AFDU, during which no sparger-related outages were encountered.

Pressure drop can be expressed by the following equation:

$$
\Delta \mathrm{P}=\frac{\mathrm{K} *(\mathrm{~V} * \mathrm{MW})^{2}}{\rho}
$$

where:

$$
\begin{aligned}
\Delta \mathrm{P} & =\text { pressure drop across sparger }(\mathrm{psi}) \\
\mathrm{K} & =\text { sparger resistance coefficient }(\text { dimensionless }) \\
\mathrm{V} & =\text { vapor volumetric flowrate }(\mathrm{KSCFH}) \\
\mathrm{MW} & =\text { vapor molecular weight }(\mathrm{lb} / \mathrm{lb} \text { mole }) \\
\rho & =\text { vapor density }\left(\mathrm{lb} / \mathrm{ft}^{3}\right)
\end{aligned}
$$

This equation shows that changes in gas composition or flowrate can influence pressure drop measurements dramatically. Tracking the resistance coefficient $(\mathrm{K})$ over time can indicate any change in the gas flow path through the gas sparger. For a given gas volumetric flowrate and density, an increase in $\mathrm{K}$ (caused by a restriction in the flow path, for example), will cause an increase in pressure drop.

As noted in Section 3.1.3, three different gas sparger designs were utilized during the operation of the Kingsport LPMEOH ${ }^{\mathrm{TM}}$ demonstration unit. A review of the performance of the devices during the 69-month operating program is provided.

\subsubsection{Initial Sparger Design (April - November 1997)}

The LPMEOH ${ }^{\mathrm{TM}}$ demonstration unit was first brought onstream on 02 April 1997. Initial results indicated that the scaled-up gas sparger did provide the necessary distribution of syngas at the bottom of the reactor so that actual hydrodynamic behavior matched design expectations. In addition, the heat transfer coefficient of the internal heat exchanger exceeded the design value, further indicating good mixing. However, the measured pressure drop across the gas sparger increased considerably throughout the first few weeks onstream. As shown in Figure 5.3.1-1, the value for the resistance coefficient also reflected this trend, indicating the possibility that an obstruction of the flow path of the reactor feed gas was occurring. During this same time, periods of operation with no vapor flow through the gas sparger appeared to have no impact the rate of change of pressure drop. 
Figure 5.3.1-1

\section{Sparger Resistance Coefficient - Sparger Design \#1 (April - November 1997)}

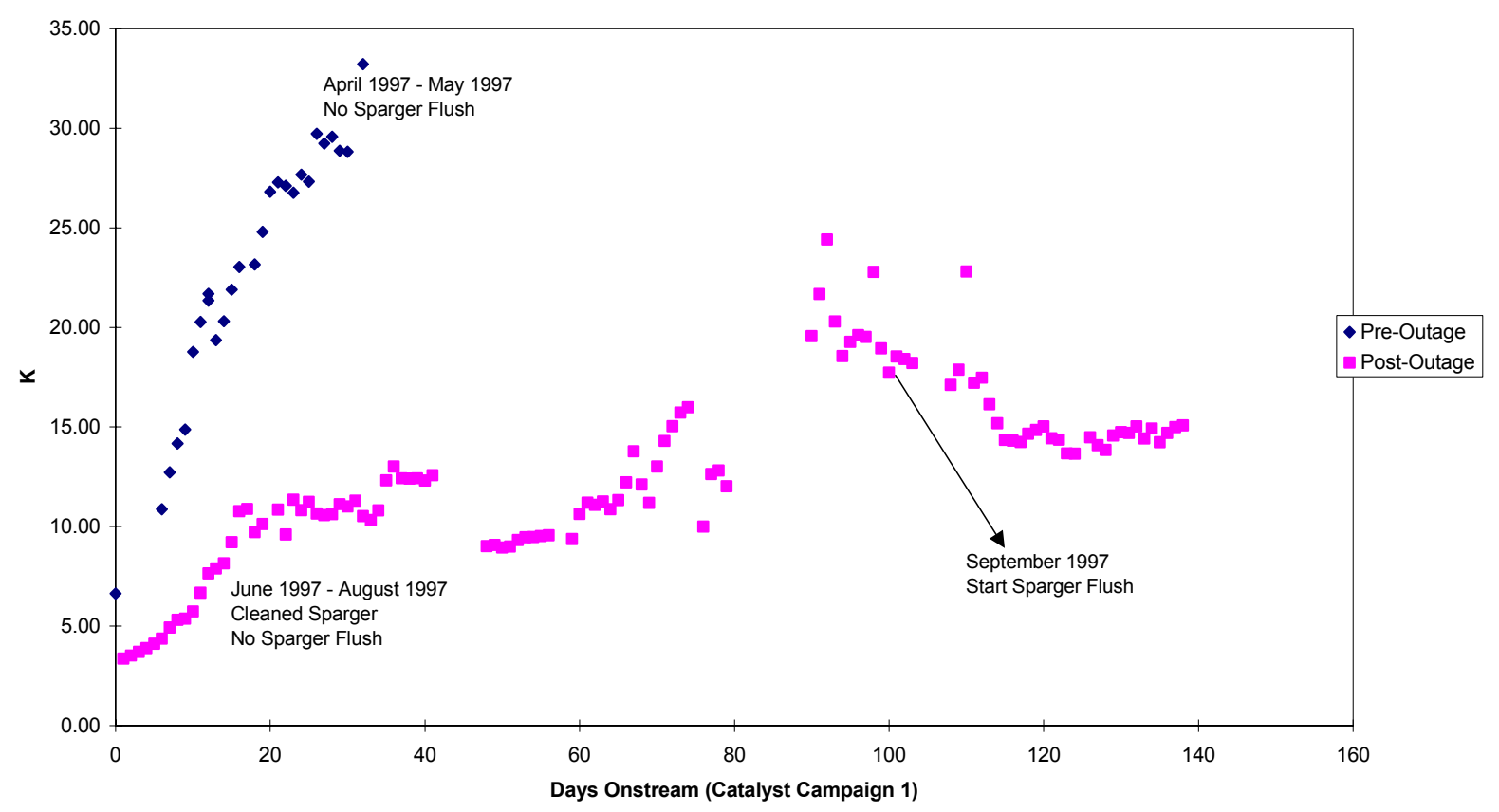

During a scheduled outage in May of 1997, an inspection of equipment associated with the reactor, particularly the gas sparger, was performed. About 800 pounds of residual catalyst was removed from the bottom head of the reactor during this exercise. A solid material (presumably methanol synthesis catalyst) appeared to block about $50 \%$ of the flow path through the sparger; a small amount of catalyst was found in the inlet piping to the sparger. There was no discernible pattern to the blockage by the catalyst, and no significant construction debris was found in the inlet piping or in the sparger. The sparger was removed from the reactor and cleaned. Structural modifications increased the maximum allowable pressure differential across the sparger, but no changes were made to its flow distribution characteristics. In addition to the inspection, a flush connection of fresh process oil from the 29D-30 oil storage tank via the 29G-30 slurry transfer pump to the gas inlet line to the reactor was added.

Upon restarting the LPMEOH ${ }^{\mathrm{TM}}$ demonstration unit on 17 June 1997, the pressure drop across the gas sparger returned to its design value. However, the gas sparger pressure drop and resistance coefficient did continue to increase with time onstream, although not as rapidly as the April/May operation (see Figure 5.3.1-1). A flush by fresh oil through the new connection at the gas inlet line yielded a decline in pressure drop through the gas sparger. However, the effects were temporary, and the flow resistance continued to increase. Additional flushing with fresh oil was limited, because fresh oil can only be added to the process at an average of 0.1 to $0.2 \mathrm{gpm}$ to match the rate of oil loss with the methanol product. 
The resistance coefficient experienced a significant step-change increase during a week-long shutdown in early September of 1997. A practice of flushing the gas sparger with entrained slurry from the 29C-06 cyclone and 29C-05 secondary oil knock-out drum was then initiated; this was supplied at the average rate of liquid flow in the secondary oil knock-out drum and cyclone (1 to $2 \mathrm{gpm}$ ). This flushing procedure was a batch-wise pumping process using the 29C30 catalyst reduction vessel and the slurry transfer pump. Flow resistance through the gas sparger was stabilized at a manageable level by flushing in this manner (refer to Figure 5.3.1-1). The rate of addition of the flush was $30 \mathrm{gpm}$, and it was performed 2 to 3 times per day at the average rate of liquid flow through the cyclone and secondary oil knock-out drum.

On 09 October 1997 (Day 114), a new procedure was tested to gravity-drain the condensed oil and entrained slurry continuously to the flush connection at the average rate of liquid flow in the reactor loop, thus eliminating the batch-transfer operating steps. An inventory of condensed oil was collected in the secondary oil knock-out drum, and the gravity-drain line to the flush connection was then placed in service. Level in the secondary oil knock-out drum dropped and the temperature at the bottom of the reactor fell slightly, confirming the flowing path of oil to the reactor despite the already high pressure drop through the gas sparger.

During subsequent operation, the gravity-drain line became obstructed about twice per day. This blockage, either resulting from accumulation of catalyst or from vapor-locking within the piping system, cleared easily with a brief flush of clean oil from the oil storage tank via the $29 \mathrm{G}-03$ oil makeup pump. At this frequency of operation, the amount of fresh oil added to the process during line flushing was less than the average oil loss rate with the methanol product ( 0.1 to 0.2 gpm). During the gravity-drain operation, the flow resistance coefficient across the gas sparger showed some modest improvement, compared to the period in September when the condensed oil and entrained slurry were pumped batch-wise via the slurry transfer pump.

On 03 November 1997, the LPMEOH ${ }^{\mathrm{TM}}$ demonstration unit was shut down in order to prepare a second batch of fresh catalyst slurry. After the system was drained of spent catalyst, the $\mathrm{LPMEOH}^{\mathrm{TM}}$ reactor was inspected by video camera. Dried catalyst slurry was observed in the bottom head and around the gas sparger.

Preparations were then made to restart the $\mathrm{LPMEOH}^{\mathrm{TM}}$ reactor with a second partial charge of fresh methanol synthesis catalyst. Batches of fresh catalyst slurry were activated in the catalyst reduction vessel and stored in the slurry tank. On 26 November 1997, the first seven batches of freshly reduced catalyst slurry were pressure-transferred from the slurry storage tank to the LPMEOH ${ }^{\mathrm{TM}}$ reactor. $\mathrm{N}_{2}$ flow was introduced through the gas sparger prior to beginning the transfer operation, and the recycle compressor was started under $\mathrm{N}_{2}$ at the completion of the transfer. While this was occurring, the activation of the eighth batch of catalyst was proceeding in the catalyst reduction vessel. Heat-up of the reactor using 600 psig steam on the internal heat exchanger proceeded smoothly; however, the pressure drop at the bottom of the reactor increased slowly, from 1.4 psi to 2.1 psi over a four-hour period. When the gas sparger was flushed at the gas inlet piping connection using fresh oil from the oil storage tank, the pressure drop across the sparger rose to about $7 \mathrm{psi}$. Then, when the eighth batch of slurry was transferred to the reactor using the slurry transfer pump, the pressure drop rose to 14 psi. After this transfer, the recycle compressor began to approach surge, indicating significant blockage at the sparger. Attempts to 
clean the flow path were unsuccessful, and the contents of the reactor were pressure-transferred back to the slurry tank.

After completing the slurry transfer and securing the steam and syngas supplies, the manway on the bottom of the reactor was opened. The gas sparger was found to be plugged with fresh catalyst. In addition, a review of the data during the slurry transfer indicates that the $\mathrm{N}_{2}$ flow to the reactor was quite low, and that there was evidence that the gas inlet piping to the reactor had filled with slurry during the transfer operation. Settling of the fresh catalyst appeared to have occurred in the reactor and gas inlet piping, which resulted in the plugging of the gas sparger.

\subsubsection{Second Sparger Design (December 1997 - February 1999)}

Following the attempted restart of the LPMEOH ${ }^{\mathrm{TM}}$ demonstration unit in November of 1997, a modified sparger design was developed by Air Products and fabricated and installed by Eastman. Part of the reasoning for draining the initial charge of catalyst slurry from the process was to demonstrate that the operation of the gas sparger could be maintained at the design flow resistance coefficient by gravity-draining the condensed oil and entrained slurry to the flush connection at the gas inlet piping to the $\mathrm{LPMEOH}^{\mathrm{TM}}$ reactor. Within 24 hours of restarting the $\mathrm{LPMEOH}^{\mathrm{TM}}$ demonstration unit, the gravity-draining flow path for this material was placed in service. As shown in Figure 5.3.2-1, the flow resistance through the gas sparger of the $\mathrm{LPMEOH}^{\mathrm{TM}}$ reactor could be stabilized by use of this continuous flush. Performance of the second sparger design showed significant improvement over the operating results from 1997; however, a slight increase in resistance coefficient over time was still apparent.

On 15 October 1998 (Day 299), maintenance work was performed on the oil flush system that cleans the taps used to measure the pressure drop across the gas sparger. Upon completion of this work, the measured pressure drop increased by 2.0 psi. An analysis of other pressure readings around the reactor was performed to determine the rate of increase of this pressure drop. It appeared that the increase in pressure drop across the sparger occurred around the time of the maintenance work. Another step-change increase in pressure drop occurred after restarting from a complex-wide power outage in early November of 1998.

As a result of the greater sparger pressure drop, condensed oil and entrained slurry could not be gravity-drained to the flush connection at the gas inlet line to the reactor. In order to overcome the pressure drop, the streams were batch-transferred to the catalyst reduction vessel and returned to the reactor via the slurry transfer pump. This procedure was last used with the initial sparger design in October of 1997. During periods when the catalyst reduction vessel was otherwise in use, the condensed oil and entrained slurry streams were free-drained directly to a connection on the reactor where the pressure drop was not limiting. 
Figure 5.3.2-1

\section{Sparger Resistance Coefficient - Sparger Design \#2 (December 1997 - February 1999)}

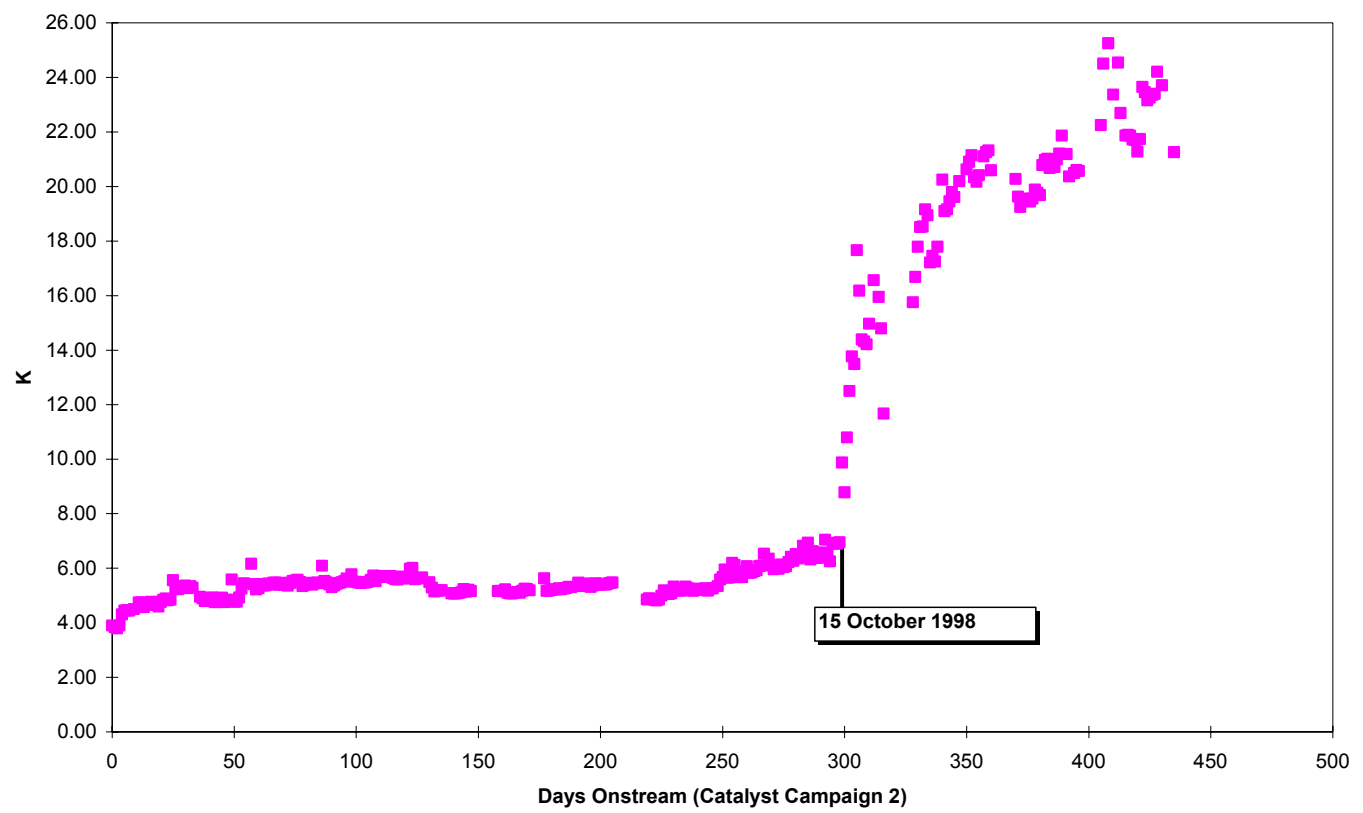

During January and February of 1999 (around Days 377-435), the sparger resistance coefficient across the LPMEOH ${ }^{\mathrm{TM}}$ reactor continued to increase beyond the step-change experienced in October of 1998 (refer to Figure 5.3.2-1). The associated higher pressure drop within the reactor loop limited the quantity of Balanced Gas that could be fed to the LPMEOH ${ }^{\mathrm{TM}}$ demonstration unit.

During a schedule outage in March of 1999, the second version of the gas sparger was removed from the LPMEOH ${ }^{\mathrm{TM}}$ reactor and inspected. It was estimated that the blockage in the sparger was consistent with the resistance coefficient that was calculated prior to shutdown.

\subsubsection{Current Sparger Design (March 1999 - Present)}

During the outage in March of 1999, a modified gas sparger was installed in the reactor; Air Products developed this design using the same principles as the previous two devices. During that outage, a gravity drain line piping modification was also made to separate the condensed oil from the oil knockout vessel from the entrained slurry from the cyclone. The condensed oil stream is relatively clean and was used to continuously flush the sparger; the slurry from the cyclone was sent directly into the reactor. The separation of these streams reduced plugging and improved the overall reliability of the sparger flush and the oil return. Upon restarting on 14 March 1999, the performance of the new sparger met or exceeded the design expectations for pressure drop and reactor operation, and stable operation was maintained for over 500 days (refer to Figure 5.3.3-1). 
Figure 5.3.3-1

Sparger Resistance Coefficient - Sparger Design \#3 (March 1999 - August 2001)

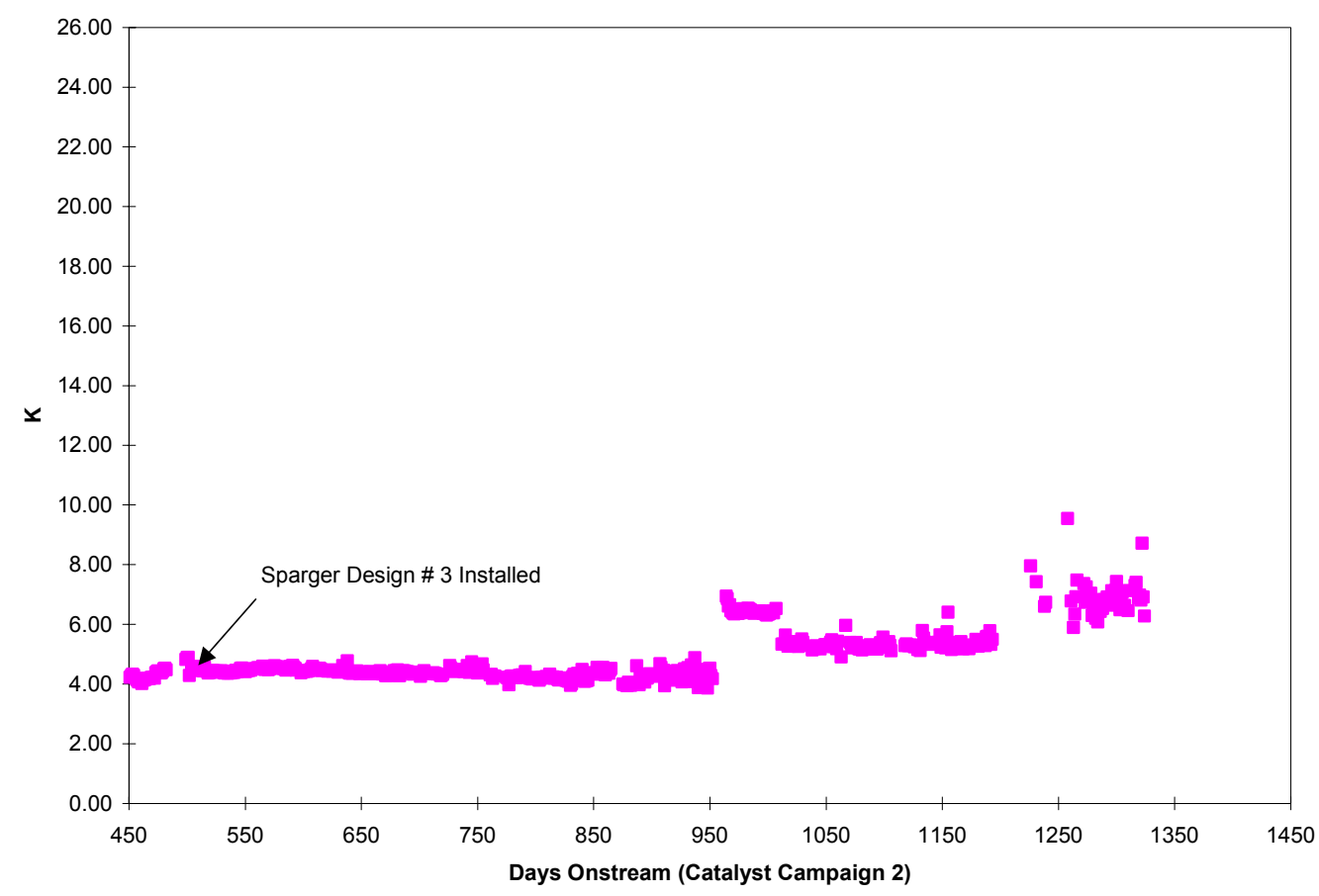

After the restart of the LPMEOH ${ }^{\mathrm{TM}}$ demonstration unit on 04 August 2000 (Day 958 of Catalyst Campaign 2), the resistance coefficient increased approximately 50\% (from an average of about 4.3 to 6.6). Subsequent flushing of the sparger with clean oil resulted in a sizable reduction of the increased flow resistance (to an average of 5.3). During the operating period between March 2001 (Day 1193 of Catalyst Campaign 2), the resistance coefficient did not appear to be further increasing over time.

During this biennial outage, the sparger was removed from the LPMEOH ${ }^{\mathrm{TM}}$ reactor for inspection and cleaning. In addition, all differential pressure transmitters around the sparger and reactor were calibrated, and the pressure taps were cleaned. Following the restart of the unit (Day 1217 of Catalyst Campaign 2), the resistance coefficient was higher than the value that was calculated following the March 1999 outage. The most likely cause is that the recalibration of the differential pressure transmitters had experienced a shift in their baseline measurement. The sparger resistance continued to show no significant increase over time, which was consistent with the operating history with this device.

In August of 2001, Catalyst Campaign 3 was started, during which the catalyst inventory was removed and a new in-situ activation procedure was used to activate a full load of fresh catalyst inside the reactor vessel (refer to Section 5.1). Figure 5.3.3-2 shows the sparger performance for this operating period (August of 2001 to June of 2002). The sparger resistance showed no increase over time during this period. 
Figure 5.3.3-2

Sparger Resistance Coefficient - Sparger Design \#3 (August 2001 - June 2002)

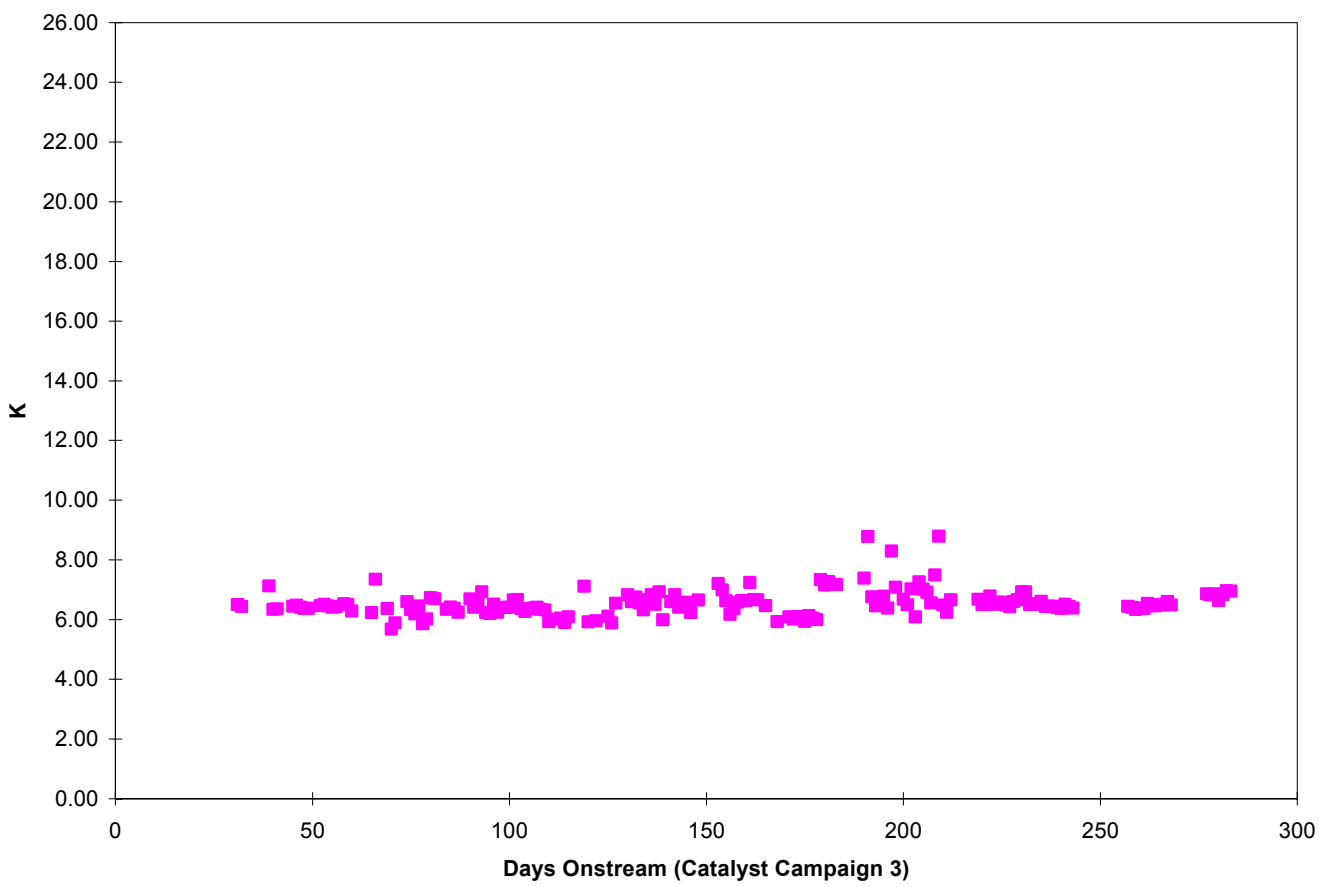

During the preparations for Catalyst Campaign 4 in June of 2002, the sparger was inspected and cleaned. As shown in Figure 5.3.3-3, the performance of the sparger showed no significant increase in resistance between following the restart on 27 June 2002 through to the end of the operating program on 31 December 2002. 
Figure 5.3.3-3

Sparger Resistance Coefficient - Sparger Design \#3 (June 2002 - 31 December 2002)

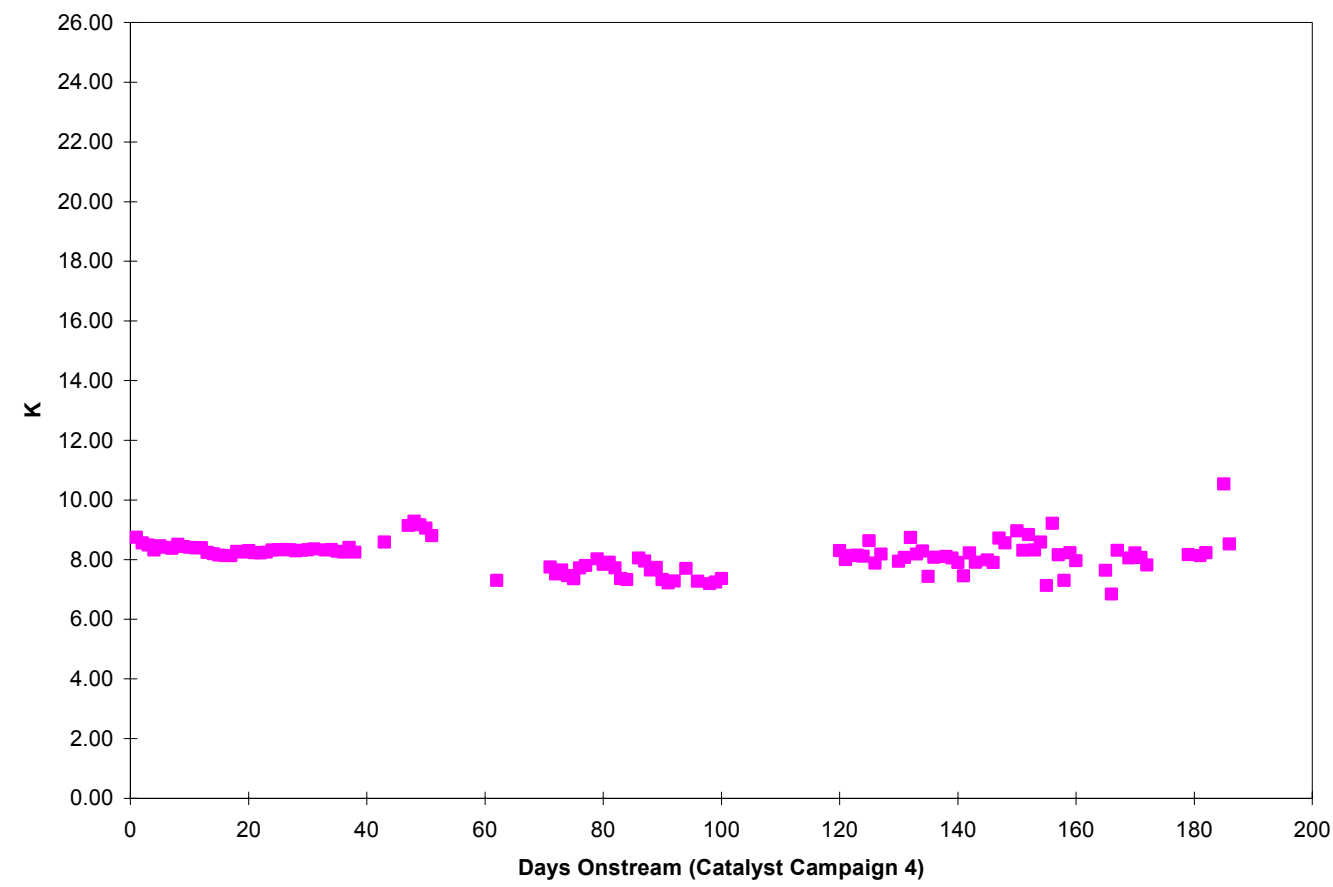

\subsubsection{Summary}

The current design of the gas sparger for the LPMEOH ${ }^{\mathrm{TM}}$ reactor has been demonstrated to meet the requirements for initial pressure drop and long-term performance. The device provides operating flexibility through all modes of operation. The use of condensed or entrained slurry, either by pump or by gravity draining, as a continuous or periodic flush through the sparger has contributed greatly to the reliability of the sparger operation. This flushing system and procedure is now a standard part of the design package for the LPMEOH ${ }^{\mathrm{TM}}$ Process. 


\subsection{PROCESS VARIABLE TESTS: H2$_{2}:$ CO RATIO}

Syngas ratios will vary with the type of gasifier and feed used in an IGCC power plant application. A key commercialization goal of the LPMEOH ${ }^{\mathrm{TM}}$ Demonstration Project was to operate the $\mathrm{LPMEOH}^{\mathrm{TM}}$ reactor utilizing a wide variety of syngas feed ratios. Three different feed gas streams were diverted from existing operations to the $\mathrm{LPMEOH}^{\mathrm{TM}}$ demonstration unit:

1) $\mathrm{H}_{2}$ Gas, containing an excess of $\mathrm{H}_{2}$ over the stoichiometric balance for the production of methanol (as noted in Section 3.1, this stream was not used during the demonstration test program);

2) $\mathrm{CO}$ Gas, a syngas containing primarily $\mathrm{CO}$; and

3) Balanced Gas, a syngas with a composition of $\mathrm{H}_{2}, \mathrm{CO}$, and $\mathrm{CO}_{2}$ in stoichiometric balance $\left(\left[\mathrm{H}_{2}-\mathrm{CO}_{2}\right] /\left[\mathrm{CO}+\mathrm{CO}_{2}\right]=2.05\right)$ for the production of methanol.

With the availability of these feed gas streams, a wide range of syngas feed ratios, including those from modern coal gasifiers, could be examined (subject to syngas availability). The $\mathrm{H}_{2}$ : $\mathrm{CO}$ ratio at the reactor inlet was set to the desired value by adjusting the total quantity of fresh feed syngas and the Recycle Gas.

As noted in Section 2.1, the LPMEOH ${ }^{\mathrm{TM}}$ Process is particularly well suited to coal-derived syngas which is rich in $\mathrm{CO}$. Unlike gas-phase reactors, shift and $\mathrm{CO}_{2}$ removal are not required to adjust the composition to a particular requirement. Low $\mathrm{H}_{2}$-to-CO ratios are acceptable as is any $\mathrm{CO}_{2}$ content. These capabilities make the $\mathrm{LPMEOH}^{\mathrm{TM}}$ Process a potentially lower-cost conversion route to methanol, especially when methanol coproduction is added to a coal-based IGCC power plant. As shown in Table 4.1-1, several test campaigns were undertaken to study the performance of the LPMEOH ${ }^{\mathrm{TM}}$ Process using CO-rich syngas. Three ranges of CO-rich feed gases were generally tested: a syngas with a $\mathrm{H}_{2}: \mathrm{CO}$ ratio at the reactor inlet of approximately 0.5 , a syngas with a $\mathrm{H}_{2}: \mathrm{CO}$ ratio at the reactor inlet of about 0.7 , and a syngas with a $\mathrm{H}_{2}$ : $\mathrm{CO}$ ratio at the reactor inlet of approximately 1.0. A table detailing all of the CO-rich testing performed during the demonstration test program at the $\mathrm{LPMEOH}^{\mathrm{TM}}$ demonstration unit is given in Table 5.4-1.

A total of 4 days of testing with a CO-rich syngas at a $\mathrm{H}_{2}: \mathrm{CO}$ ratio of about 0.5 (around 57 volume $\%[\mathrm{vol} \%]$ in the reactor feed gas stream) was conducted during the operating program. The results for methanol production matched the performance based upon studies in the laboratory autoclave. Due to the short duration of these tests, the rate of catalyst deactivation could not be calculated. 
Table 5.4-1

Kingsport LPMEOH ${ }^{\mathrm{TM}}$ Process - $\mathrm{H}_{2}$ :CO Ratio Testing

\begin{tabular}{|c|c|c|c|c|c|c|}
\hline $\begin{array}{c}\text { Date } \\
\text { Started }\end{array}$ & $\begin{array}{c}\text { Date } \\
\text { Ended }\end{array}$ & $\begin{array}{c}\text { Duration } \\
\text { (days) }\end{array}$ & $\begin{array}{c}\mathbf{H}_{2}: \text { CO Ratio } \\
\text { a Reactor } \\
\text { Inlet }\end{array}$ & $\begin{array}{c}\text { Reactor } \\
\text { Temperature } \\
\left({ }^{\circ} \mathbf{C}\right)\end{array}$ & $\begin{array}{c}\text { Methanol } \\
\text { Production } \\
(\mathbf{s T} / \mathbf{D})\end{array}$ & $\begin{array}{c}\text { Catalyst } \\
\text { Deactivation } \\
\text { Rate } \\
(\% \text { per day) }\end{array}$ \\
\hline $5 / 7 / 97$ & $5 / 8 / 97$ & 2 & 0.43 & 250 & 70 & na $^{\text {a }}$ \\
\hline $8 / 1 / 97$ & $8 / 12 / 97$ & 12 & 0.80 & 250 & 190 & -1.70 \\
\hline $2 / 8 / 97$ & $2 / 12 / 98$ & 5 & 0.78 & 225 & 192 & na \\
\hline $8 / 24 / 98$ & $8 / 26 / 98$ & 3 & 0.96 & 250 & 228 & na \\
\hline $12 / 2 / 99$ & $12 / 10 / 99$ & 8 & 1.02 & 235 & 204 & na \\
\hline $2 / 23 / 00$ & $2 / 23 / 00$ & 1 & 0.57 & 235 & 177 & na \\
\hline $3 / 21 / 00$ & $4 / 13 / 00$ & 24 & 1.03 & 235 & 180 & na \\
\hline $5 / 9 / 00$ & $5 / 10 / 00$ & 1 & $\sim 0.5$ & 250 & NA & na \\
\hline $11 / 15 / 00$ & $11 / 18 / 00$ & 4 & 1.08 & 235 & 220 & na \\
\hline $5 / 9 / 01$ & $5 / 13 / 01$ & 5 & 0.65 & 235 & 117 & na \\
\hline $10 / 29 / 01$ & $10 / 29 / 01$ & 1 & 0.64 & 218 & 156 & na \\
\hline $12 / 12 / 01$ & $12 / 17 / 01$ & 6 & 0.68 & 224 & 142 & \\
\hline $12 / 24 / 01$ & $12 / 29 / 01$ & 6 & 0.76 & 226 & 143 & \\
\hline
\end{tabular}

a. na $=$ operating campaigns were of insufficient length to calculate rate of catalyst deactivation.

A total of 35 days of testing with a CO-rich syngas at a $\mathrm{H}_{2}: \mathrm{CO}$ ratio of about 0.7 was conducted during the operating program. During a 12-day campaign that was undertaken during Catalyst Campaign 1 (early August of 1997), the rate of catalyst deactivation was calculated to be 1.7\% per day. This result was statistically similar to the rates calculated during this campaign when Balanced Gas was used as the feed to the LPMEOH ${ }^{\mathrm{TM}}$ demonstration unit.

A total of 39 days of testing with a syngas at a $\mathrm{H}_{2}: \mathrm{CO}$ ratio of around 1.0 was conducted during the operating program. A 24-day test was performed from 21 March 2000 to 13 April 2000. The catalyst performance for this test period was calculated as a deactivation rate of $1.24 \%$ per day. This rate was also statistically similar to the rates calculated using Balanced Gas during this same period during Catalyst Campaign 2 (refer to Section 5.1.2).

In summary, a variety of $\mathrm{H}_{2}$ : $\mathrm{CO}$ ratios were tested in the Kingsport LPMEOH ${ }^{\mathrm{TM}}$ demonstration unit to evaluate the effect of syngas compositions on the performance of the LPMEOH ${ }^{\mathrm{TM}}$ Process. All of the results met the expectations for methanol production rate based upon earlier studies in the laboratory. Catalyst performance for the $\mathrm{LPMEOH}^{\mathrm{TM}}$ reactor with lower $\mathrm{H}_{2}: \mathrm{CO}$ ratios were not significantly impacted based on the calculated rate of catalyst deactivation. These results provide additional confirmation (beyond the performance during the 4-month proof-of-concept test at the LaPorte AFDU in 1988/89 on CO-rich syngas) of the capability of the LPMEOH ${ }^{\mathrm{TM}}$ Process to process syngas directly from all modern syngas generation systems, including coal gasifiers. 


\subsection{RAMPING AND ON/OFF TESTING}

The ability of the LPMEOH ${ }^{\mathrm{TM}}$ Process to start and stop rapidly is an important feature within an IGCC power plant application. In addition, the capability of the LPMEOH ${ }^{\mathrm{TM}}$ Process to perform in an electrical demand environment will be required for the technology to be successfully dispatched in these power generation applications. Although the host site for the LPMEOH demonstration unit was a chemical production facility, a test protocol was developed to evaluate the ability of the reactor to ramp up and shut down quickly, and cycle on and off. These ramping and on/off tests were conducted within the limitations of the rate of response of the existing Eastman complex, in particular the limits on rate-of-change on the parallel fixed-bed methanol plant and the impact of purge flow from the LPMEOH ${ }^{\mathrm{TM}}$ demonstration unit on the operation of the downstream boiler system.

Opportunities to test the ability of the LPMEOH ${ }^{\mathrm{TM}}$ process to stop quickly occurred throughout the operating program. Syngas could be stopped as quickly as the other systems within Eastman's chemicals-from-coal complex could handle the additional flow. It was also shown that the recycle compressor could continue to operate until the reactor pressure, which decreased either due to purge losses or continued consumption of $\mathrm{H}_{2}$ and $\mathrm{CO}$, reached the minimum flow based upon approach to surge (around 85 psig).

In designing the test for the restart of the LPMEOH ${ }^{\mathrm{TM}}$ demonstration unit, a goal of 5 to $10 \%$ change in design flow per minute, which meets the requirements for an IGCC system, was established. The first test of the ability to ramp the LPMEOH ${ }^{\mathrm{TM}}$ reactor from a standby condition to production rates was performed 13 June 2000. This test simulated the ramping that must be performed within the startup requirements of an IGCC facility. An average ramping rate of $3 \%$ of the design flow ( $990 \mathrm{KSCFH})$ per minute and a maximum ramp rate of $4 \%$ of the design flow per minute was achieved, which approached the minimum target rate of $5 \%$ per minute. Figure 5.5-1 shows the results of this initial ramping test.

Three additional ramping tests were performed between 04 and 13 March 2001. For the first two tests (on 04 and $06 \mathrm{March}$ ), the reactor standby temperature was $216^{\circ} \mathrm{C}$ and $212^{\circ} \mathrm{C}$, respectively; from this starting point, a reasonable ramping rate could not be reached. During the third test on 13 March 2001, a standby reactor temperature of $227^{\circ} \mathrm{C}$ was used; for all of the tests performed in March of 2001, gas flow from the recycle compressor was maintained to the LPMEOH ${ }^{\mathrm{TM}}$ reactor. Balanced Gas was then introduced to the process as quickly as possible (within the limitations of other systems at the Eastman chemicals-from-coal complex). As shown in Figure $5.5-2$, a maximum ramp rate of $5.7 \%$ full load per minute and an average ramp rate of $4.2 \%$ full load per minute were achieved during this testing. This ramp performance approached the minimum target ramp rate of 5\% full load per minute. For each test, once Balanced Gas flowrate 


\section{Figure 5.5-1 \\ Ramping Study at LPMEOH'M Demonstration Unit (13 June 2000)}

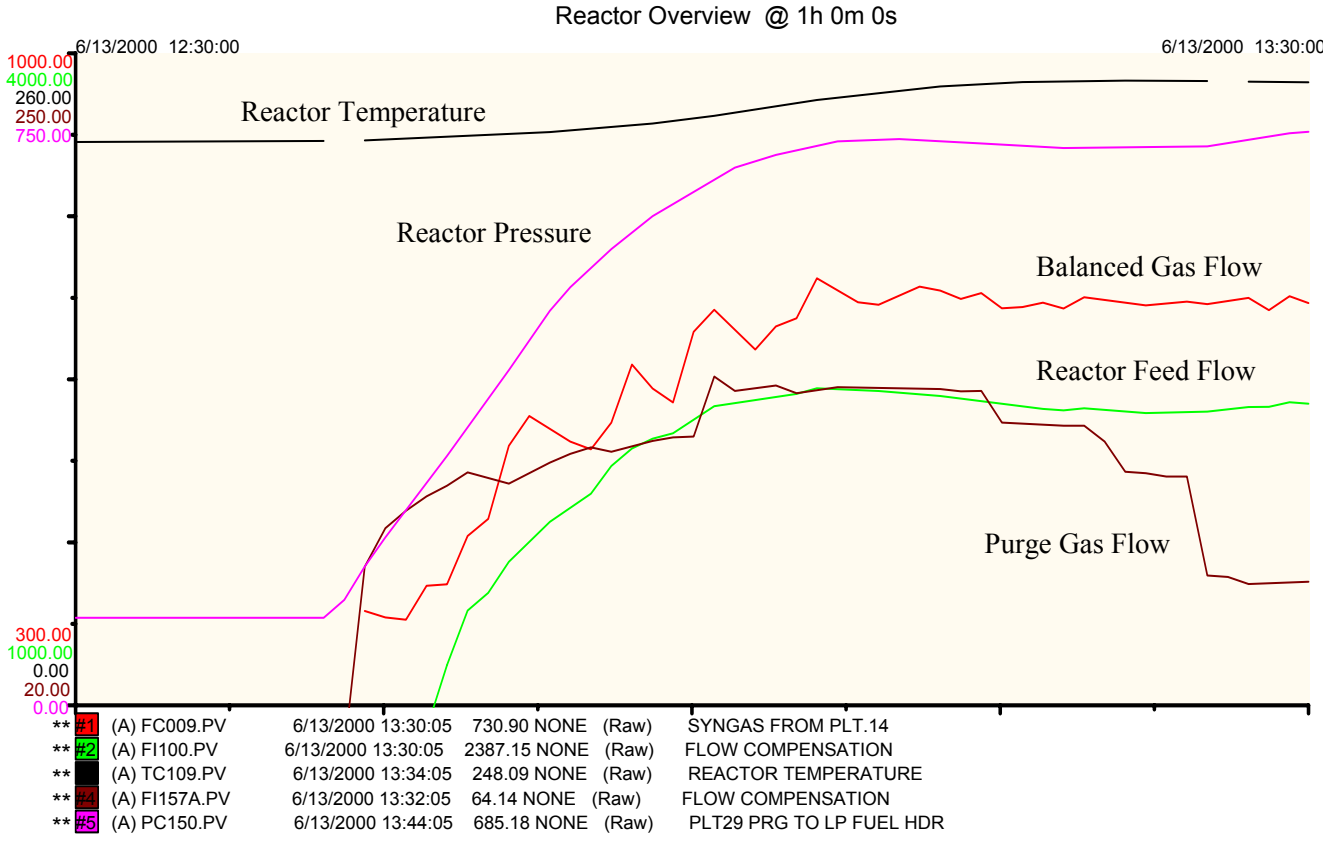

Figure 5.5-2

\section{Ramping Study at LPMEOH'M Demonstration Unit (13 March 2001)}

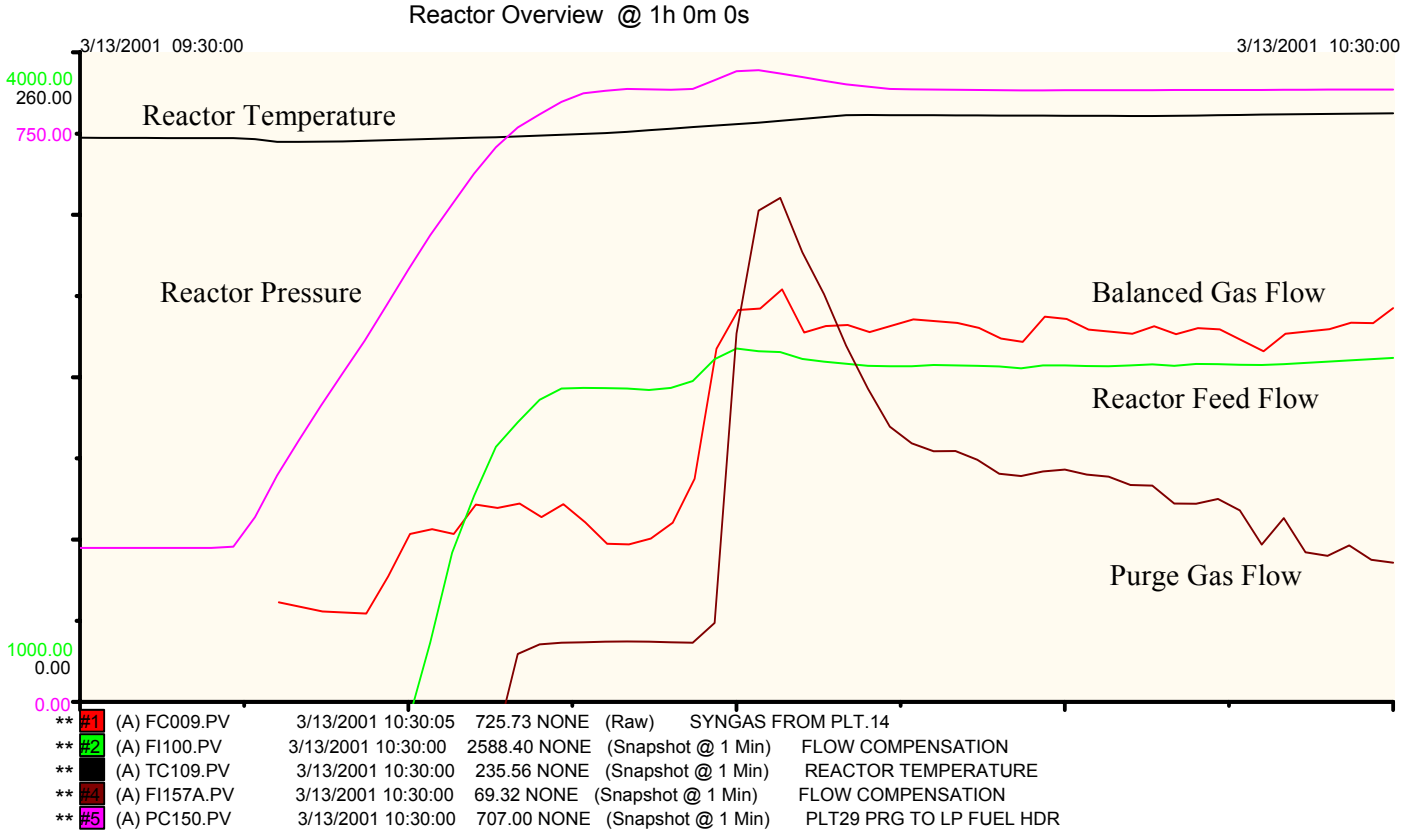


was reestablished and reactor temperature and pressure were placed into control, the performance of the LPMEOH ${ }^{\mathrm{TM}}$ demonstration unit was determined to have returned to the condition prior to the shutdown.

Two tests of the ability of the LPMEOH ${ }^{\mathrm{TM}}$ reactor to operate in a load-following environment were performed during the week of 15 January 2001. For two consecutive days, the reactor was taken offline for 12 hours, and then Balanced Gas was introduced to the process as quickly as possible (within the limitations of other systems at the Eastman chemicals-from-coal complex). The attempts to perform these ramping tests were hampered by the standby conditions that were selected, including the lack of flow to the reactor (which lowered the reactor heat transfer coefficient) and the reactor temperature $\left(180^{\circ} \mathrm{C}\right)$. Once Balanced Gas flowrate was reestablished and reactor temperature and pressure were placed into control, the performance of the

$\mathrm{LPMEOH}^{\mathrm{TM}}$ demonstration unit, including the gas sparger in the reactor, was determined to have returned to the condition prior to the shutdown.

During these tests, it was shown that the LPMEOH ${ }^{\mathrm{TM}}$ demonstration unit was capable of meeting the ramping requirements for an IGCC system by achieving the goal of a minimum 5\% change in design flow per minute. Tests of the ability of the LPMEOH ${ }^{\mathrm{TM}}$ reactor to operate in a loadfollowing environment were also successful; the performance of the LPMEOH ${ }^{\mathrm{TM}}$ demonstration unit, including the gas sparger in the reactor, was determined to have returned to the condition prior to the commencement of the on/off testing.

\subsection{IN-SITU ACTIVATION AND TEMPERATURE PROGRAMMING}

Depending upon the $\mathrm{H}_{2}$ : $\mathrm{CO}$ ratio and level of catalyst poisons in the fresh feed gas and sitespecific requirements, it may be economical to operate the LPMEOH ${ }^{\mathrm{TM}}$ Process in the same manner as conventional gas-phase reactor systems - that is, charge the maximum amount of unreduced catalyst slurry to the LPMEOH ${ }^{\mathrm{TM}}$ reactor, perform the catalyst reduction (reacting metal oxides [for example, copper oxide] with a reductant such as $\mathrm{CO}$ or $\mathrm{H}_{2}$ to produce the base metal plus either $\mathrm{CO}_{2}$ or $\mathrm{H}_{2} \mathrm{O}$ ) within the reactor vessel (so-called in-situ activation), and practice temperature programming (the increase of reactor temperature as necessary to control the reactor purge flowrate and maintain reactor volumetric productivity) to extend the catalyst life. In this scenario, eliminating the need for a separate catalyst activation vessel, slurry addition pump, and other subsystems can lower capital costs. There has been interest from potential customers for the LPMEOH ${ }^{\mathrm{TM}}$ Process to demonstrate in-situ catalyst activation at the LPMEOH $^{\mathrm{TM}}$ demonstration unit; as a result, tests of both the activation procedure (a base case and an improved procedure) and the subsequent temperature programming were performed during the demonstration.

\subsubsection{Preparatory Engineering and Laboratory Work}

Preliminary process simulation work was performed in January of 2000 in order to determine the operating conditions that could be used (based upon site-specific limitations) during a potential test of in-situ catalyst activation within the LPMEOH ${ }^{\mathrm{TM}}$ reactor. For example, the amount of purge gas flow from the LPMEOH ${ }^{\mathrm{TM}}$ demonstration unit (Stream 148 of Figure 2.4-1) was limited based upon the capacity of the downstream boiler system; this established the maximum 
quantity of gas (dilute Balanced Gas in $\mathrm{N}_{2}$ ) that could be fed during the catalyst activation procedure. A test to determine the minimum operating pressure and corresponding flowrate of $\mathrm{N}_{2}$ that could be generated by the recycle compressor was performed in March of 2000. This information was then used to modify the procedure and determine conditions for a confirmation test in the laboratory autoclave. Laboratory testing of the proposed procedure was then undertaken to verify the operating conditions.

In July of 2000, Air Products and Eastman initiated the engineering activities in support of the demonstration of the in-situ activation of methanol synthesis catalyst in the LPMEOH ${ }^{\mathrm{TM}}$ reactor. Piping and instrumentation changes were needed to allow for the introduction of the Balanced Gas and $\mathrm{N}_{2}$ streams at the proper flowrates per the proposed procedure. Air Products released a process engineering specification for these changes in August of 2000. Eastman then developed a detailed design package that defined the necessary modifications to the piping and instrument systems. In order to minimize downtime, the field modifications were completed during a scheduled code biennial inspection of all pressure vessels within the LPMEOH ${ }^{\mathrm{TM}}$ demonstration unit in March of 2001. A detailed operating procedure was drafted by Air Products and reviewed by Eastman prior to the initiation of the first in-situ activation of methanol synthesis catalyst in August of 2001.

\subsubsection{In-situ Activation Procedure and Results - August 2001}

The LPMEOH ${ }^{\mathrm{TM}}$ demonstration unit was shutdown on 06 August 2001 to prepare for the first test of the in-situ catalyst activation procedure. The slurry contents of the reactor from Catalyst Campaign 2 were drained from the system. Beginning on 13 August 2001, batches of fresh catalyst were mixed with mineral oil in the catalyst reduction vessel, heated to $150^{\circ} \mathrm{C}$, and transferred, without being reduced (or activated), to the slurry tank. A total of ten batches of fresh catalyst slurry, each containing about 4,000 pounds of fresh catalyst, were prepared in this manner. After the final transfer, the total catalyst inventory in the slurry tank was 41,580 pounds of fresh catalyst, which was approximately the design catalyst inventory for the LPMEOH ${ }^{\mathrm{TM}}$ reactor. The catalyst loading and transfer operation to the slurry tank was completed on 21 August 2001.

The common inlet and outlet line of the slurry tank (2" diameter) developed a plug during the transfer of the tenth batch of fresh catalyst slurry from the catalyst reduction vessel. After modifications to the piping system were made, Eastman operations personnel were able to clear this obstruction, and the contents of the slurry tank were then successfully transferred into the $\mathrm{LPMEOH}^{\mathrm{TM}}$ reactor. The transfer of fresh catalyst slurry to the reactor was completed 22 August 2001.

Immediately upon completion of the slurry transfer, the recycle compressor was started on $\mathrm{N}_{2}$ to begin to cool the reactor contents to less than $90^{\circ} \mathrm{C}$, which was the desired initial temperature for catalyst activation. After this step was completed, the in-situ catalyst activation procedure was started at $2300 \mathrm{hrs}$ on 22 August 2001. Make-up $\mathrm{N}_{2}$ flow was controlled at $52 \mathrm{KSCFH}$, and a small quantity of Balanced Gas was introduced into the discharge of the recycle compressor to ensure that sufficient reductant was present at all times in the reactor inlet. Temperature control was a manual ramping operation using the steam drum pressure as a control point. A reactor 
temperature ramp from $88^{\circ} \mathrm{C}$ to $215^{\circ} \mathrm{C}$ over a 27 -hour period was used. The in-situ catalyst activation procedure ended at $0100 \mathrm{hrs}$ on 24 August 2001.

The progress of the in-situ catalyst activation procedure was tracked by evaluating the uptake of reductant $\left(\mathrm{H}_{2}\right.$ and $\left.\mathrm{CO}\right)$ by the catalyst. An uptake of $70 \%$ of the theoretical value was calculated based upon analytical data and measured flowrates. Figure 5.6-1 shows the uptake performance during the first in-situ activation as compared to the performance obtained in the laboratory autoclave during the testing in 2000. The LPMEOH ${ }^{\mathrm{TM}}$ demonstration unit was then restarted at $1200 \mathrm{hrs}$ on 24 August 2001. As described in Section 5.1.3, the performance of the methanol synthesis catalyst was also lower than expected as calculated from an in-house kinetic model. Catalyst samples that were taken from the reactor following the in-situ catalyst activation did not provide conclusive results.

An assessment of the performance of the methanol synthesis catalyst following the completion of the in-situ activation procedure in August of 2001 was completed. Based on laboratory studies, it was found that storage of the fresh catalyst in the presence of mineral oil at elevated temperatures (the experiments were performed at approximately $200^{\circ} \mathrm{C}$ ) prior to reduction was the cause of the lower than expected catalyst activity. During the initial demonstration of the insitu activation procedure at the LPMEOH ${ }^{\mathrm{TM}}$ demonstration unit, the slurry was approached this temperature in the slurry tank, where batches of fresh catalyst slurry were stored during the catalyst loading procedure.

Figure 5.6-1

Reductant Gas Uptake vs. Temperature - In-Situ Catalyst Activation (22-24 August 2001)

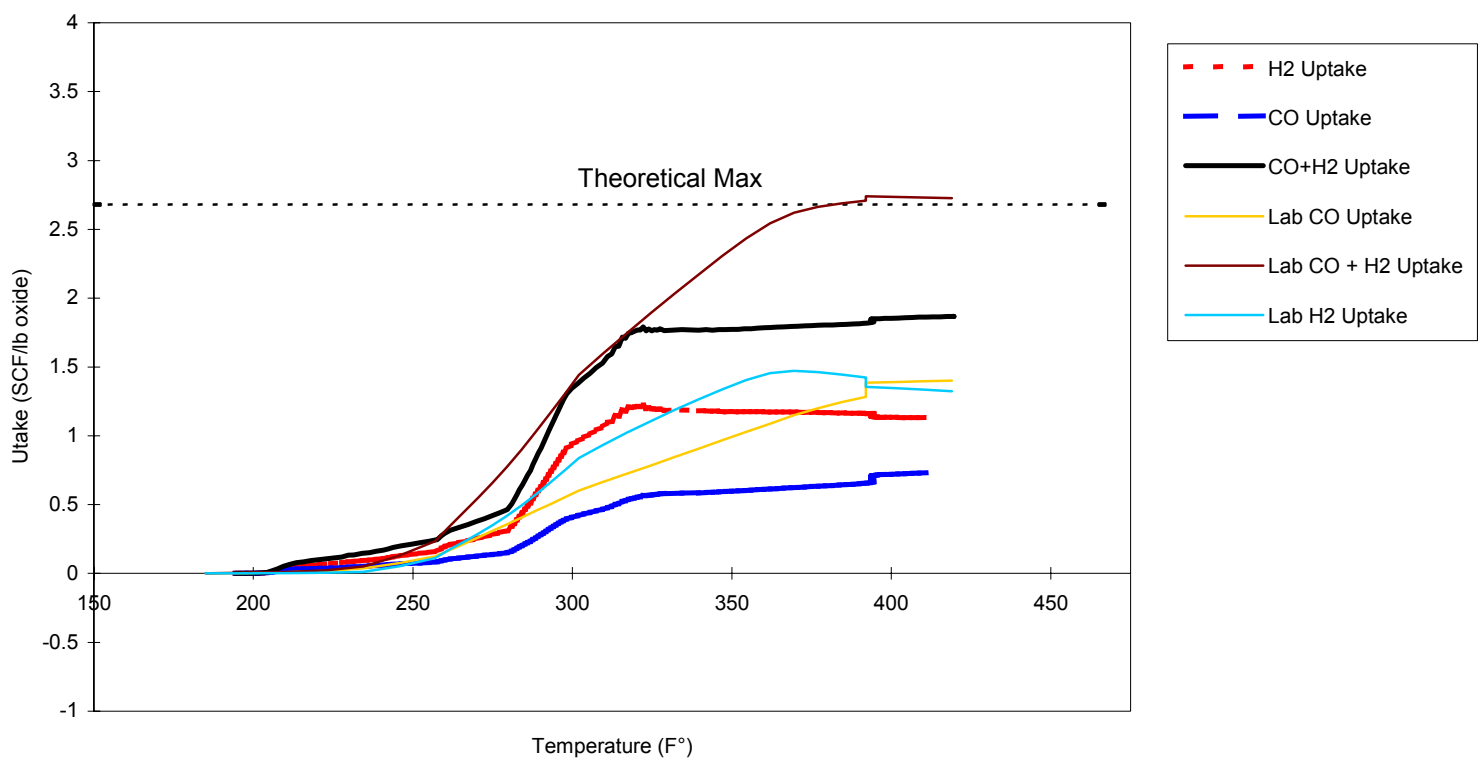




\subsubsection{Temperature Programming (August 2001 - March 2002)}

Following the completion of the in-situ catalyst activation procedure, conditions were selected to deal with the hyperactivity that typically occurs when fresh methanol synthesis catalyst is initially exposed to syngas. During the first few weeks of operation, conditions were varying between a reactor pressure of 550-600 psig, reactor temperature of $212-220^{\circ} \mathrm{C}$, and flowrate of Balanced Gas of 500-525 KSCFH. Once the hyperactivity period had passed, operating conditions were set at $218^{\circ} \mathrm{C}$ reactor temperature, 685 psig reactor pressure, and $600-650 \mathrm{KSCFH}$ of Balanced Gas.

As part of the operating protocol following the completion of the in-situ activation of methanol synthesis catalyst in the $\mathrm{LPMEOH}^{\mathrm{TM}}$ reactor, temperature programming continued during the operating period; this involved the increase of reactor temperature as necessary to control the reactor purge flowrate and maintain reactor productivity. Over the entire period spanning August of 2001 to March of 2002, the reactor temperature was increased from $218^{\circ} \mathrm{C}$ to the final temperature of $250^{\circ} \mathrm{C}\left(250^{\circ} \mathrm{C}\right.$ was the design temperature for the LPMEOH ${ }^{\mathrm{TM}}$ demonstration unit). The reactor pressure was increased from 685 psig to 700 psig on 12 November 2001 and maintained at that level for the balance of the operating period. The flowrate of Balanced Gas was controlled at an average value of $630 \mathrm{KSCFH}$ during this time.

The first operating test using methanol synthesis catalyst activated in-situ was completed on 25 March 2002 when a catalyst withdrawal and addition campaign was undertaken to increase catalyst activity.

\subsubsection{Second In-situ Activation Procedure and Results (June 2002)}

Based upon the results of the laboratory assessment following the August 2001 in-situ catalyst activation, operating steps were modified so that the fresh methanol catalyst would not be exposed to temperatures in excess of $100^{\circ} \mathrm{C}$ prior to the introduction of dilute syngas. A recommendation to DOE to perform a second test of the in-situ catalyst activation procedure was accepted.

Beginning on 21 June 2002, batches of fresh catalyst were mixed with mineral oil in the catalyst reduction vessel, heated to $100^{\circ} \mathrm{C}$, and transferred, without being reduced or activated, directly to the reactor. Since the slurry tank was not used to collect the batches, the process was greatly simplified and shortened (from 8 days to 3 days) compared with the first in-situ activation procedure in August of 2001. A total of eleven batches of fresh catalyst slurry, each containing about 3,700 pounds of fresh catalyst, was prepared in this manner. After the final transfer, the total amount of fresh catalyst in the reactor was 40,040 pounds, which is approximately the design catalyst inventory for the LPMEOH ${ }^{\mathrm{TM}}$ demonstration unit. $\mathrm{N}_{2}$ was introduced in the bottom of the reactor during the entire loading procedure, and the unreduced catalyst in the reactor was maintained at $100^{\circ} \mathrm{C}$ by adding steam as necessary to the steam drum and internal heat exchanger. The catalyst loading and transfer operation was completed on 24 June 2002. 
The reactor was cooled overnight to the desired initial temperature for catalyst activation; the recycle compressor was started on $\mathrm{N}_{2}$ to assist in cooling the reactor contents. By 0800 hours on 25 June 2002, the reactor inlet flow was set at approximately $300 \mathrm{KSCFH}$, and $52 \mathrm{KSCFH}$ of make-up $\mathrm{N}_{2}$ was introduced at the compressor suction. Reactor pressure was set at 85 psig. Cooling was completed after the reactor temperature reached $86^{\circ} \mathrm{C}$.

The in-situ catalyst activation procedure was started at $1200 \mathrm{hrs}$ on 25 June 2002 . In addition to the $52 \mathrm{KSCFH}$ of $\mathrm{N}_{2}$, a small quantity of Balanced Gas was introduced into the discharge of the recycle compressor to ensure that sufficient reductant was present at all times in the reactor inlet. A temperature ramp from $87^{\circ} \mathrm{C}$ to $215^{\circ} \mathrm{C}$ was conducted over a period of 51 hours, which was a slower ramp rate than was used during the first in-situ activation. The in-situ catalyst activation procedure ended at $0200 \mathrm{hrs}$ on 27 June 2002.

The progress of the in-situ catalyst activation procedure was tracked by evaluating the uptake of reductant by the catalyst. A reductant gas uptake of $98 \%$ of the theoretical value was calculated based upon analytical data and measured flowrates, which was an indication that the methanol synthesis catalyst was properly activated during the in-situ catalyst activation procedure. Figure 5.6-2 shows the excellent uptake performance of the second in-situ activation as compared to the performance obtained in the laboratory autoclave.

Figure 5.6-2

Reductant Gas Uptake vs. Temperature - In-Situ Catalyst Activation (25-27 June 2002)

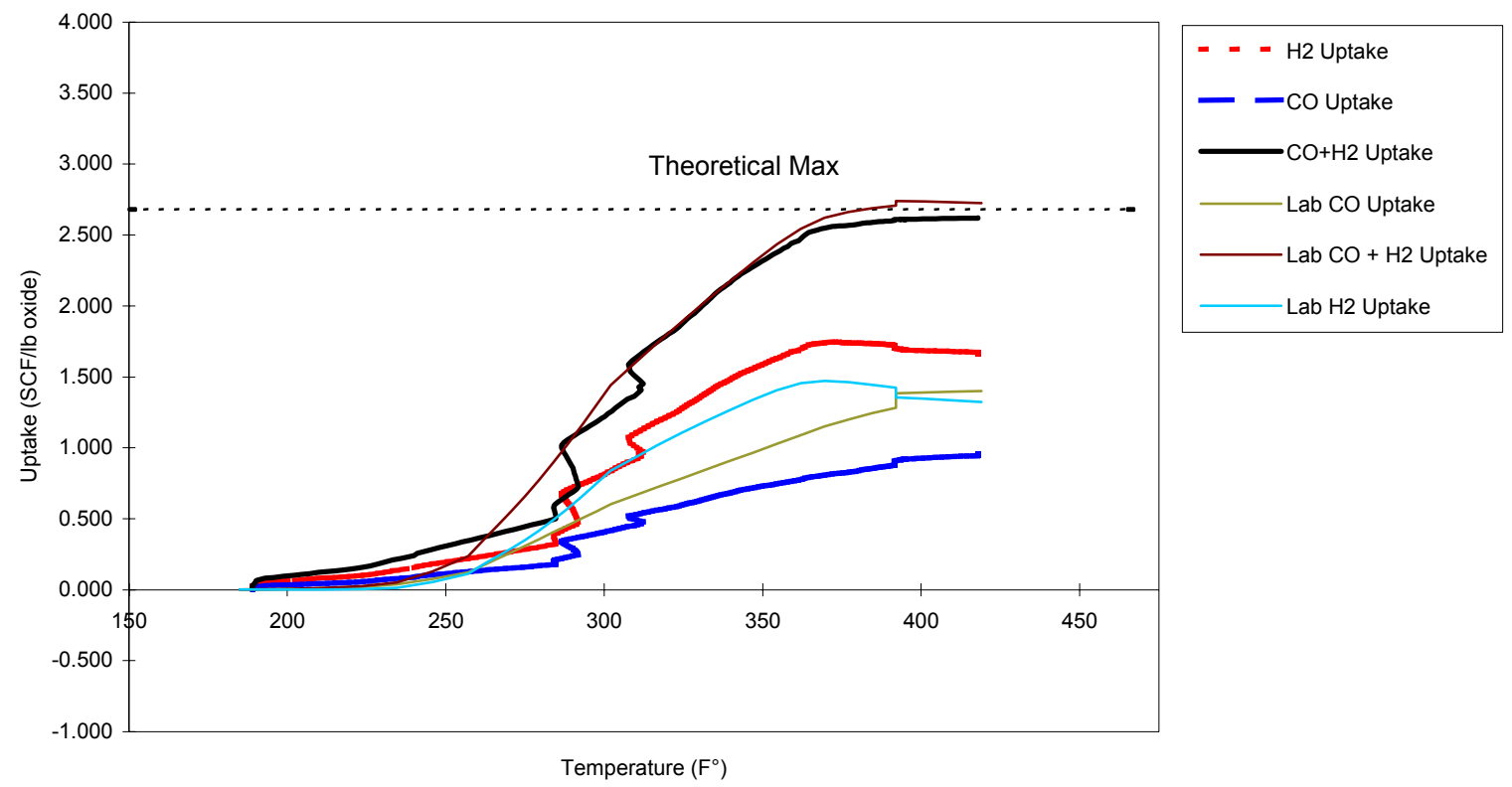


The LPMEOH ${ }^{\mathrm{TM}}$ demonstration unit was then re-started at $1500 \mathrm{hrs}$ on 27 June 2002. In addition, the initial value for $\eta$ (as defined in Section 5.1) was calculated to be 1.23, which was representative of a properly activated catalyst. In addition, the startup conditions for this charge of methanol synthesis catalyst were less severe (pressure of 450 psig and $214^{\circ} \mathrm{C}$ reactor temperature) than those following the first in-situ catalyst activation (550-600 psig, reactor temperature of $\left.212-220^{\circ} \mathrm{C}\right)$ while processing a greater quantity of Balanced Gas $(603 \mathrm{KSCFH}$ vs. 500-525 KSCFH). These results showed a clear improvement when compared with the performance of the methanol synthesis catalyst following the first in-situ activation procedure. As noted in Section 5.1.4, due to the low catalyst deactivation rate experienced following the second in-situ activation, the practice of temperature programming was not required during the remainder of the operating program of the LPMEOH ${ }^{\mathrm{TM}}$ Demonstration Project.

\subsubsection{Summary}

The in-situ activation procedure was successfully demonstrated at the LPMEOH ${ }^{\mathrm{TM}}$ demonstration unit. Following the initial trial in August of 2001, revisions to the activation procedure, including a limitation on the storage temperature for the fresh catalyst slurry and a much slower temperature ramp rate during the activation procedure, were made. Temperature programming was found to be a very practical approach to maintaining reactor productivity during the operating program following the first in-situ activation; although the reactor temperature did not have to be increased during Catalyst Campaign 4 (June-December of 2002), the selection of the minimum reactor temperature necessary to meet the desired methanol production rate may have been a factor in the low rate of catalyst deactivation that was calculated during this operating period (as described in Section 5.1.4).

\subsection{SECTION 5 BIBLIOGRAPHY}

a. "Removal of Trace Contaminants from Coal-Derived Synthesis Gas", Prepared by Air Products Liquid Phase Conversion Co., L.P., DOE Cooperative Agreement No. DE-FC22-95PC93052, March 2003.

b. "Project Data on Eastman Chemical Company's Chemicals-from-Coal Complex in Kingsport, TN", Prepared by Air Products Liquid Phase Conversion Co., L.P., DOE Cooperative Agreement No. DEFC22-95PC93052, March 2003.

c. "Design and Construction of the Alternative Fuels Field Test Unit and Liquid Phase Methanol Feedstock and Catalyst Life Testing at Eastman Chemical Company (Kingsport, TN)", Topical Report Prepared by Air Products and Chemicals, Inc., DOE Cooperative Agreement No. DE-FC2295PC93052, March 1997.

d. "Alternative Fuels Field Test Unit Support to Kingsport LPMEOH'M Demonstration Unit Topical Report (December 1997 - January 1998)", Topical Report Prepared by Air Products Liquid Phase Conversion Co., L.P., DOE Cooperative Agreement No. DE-FC22-92PC90543, November 1998. 


\subsection{ENVIRONMENTAL PERFORMANCE}

\subsection{INTRODUCTION}

As part of the requirements for DOE to fulfill its responsibility under the National Environmental Policy Act (NEPA) of 1969, the Partnership prepared a detailed Environmental Information Volume (EIV) ${ }^{(a)}$ describing the environmental aspects and projected impacts of the LPMEOH $^{\text {TM }}$ Demonstration Project. DOE then prepared an Environmental Assessment (EA) ${ }^{(b)}$ for the Project, and determined that an Environmental Impact Statement was not required. A Finding of No Significant Impact (FONSI) was issued on 30 June 1995.

The Partnership then prepared an Environmental Monitoring Plan (EMP) ${ }^{(\mathrm{c})}$ which described in detail the environmental monitoring activities to be performed during the operation of the LPMEOH ${ }^{\mathrm{TM}}$ demonstration

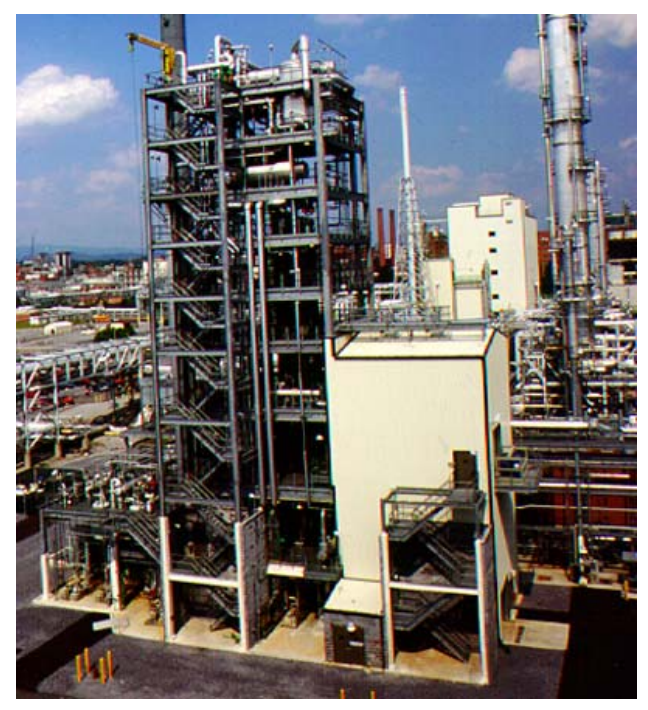
unit. In order to quantify the environmental performance of the $\mathrm{LPMEOH}^{\mathrm{TM}}$ demonstration unit, a comparison of the estimated quantities of emissions, effluents, and solids for disposal from the EA with the results from the LPMEOH ${ }^{\mathrm{TM}}$ demonstration unit is provided in this Section.

\subsection{WASTE STREAMS AND THEIR DISPOSAL}

\subsubsection{Spent Catalyst Slurry}

The LPMEOH ${ }^{\mathrm{TM}}$ Process uses conventional low-temperature methanol synthesis catalyst (comprised primarily of oxides of copper and zinc) in powder form, slurried in a mineral oil that is inert at reaction conditions. Over time, these catalysts, whether used in conventional fixedbed reactor systems or the LPMEOH ${ }^{\mathrm{TM}}$ Process, will show a decrease in catalytic activity. This aging phenomenon is caused by both the presence of the catalyst at the reaction conditions (most likely temperature) and by the chemical poisoning of the catalyst by trace contaminants within the system (for example: sulfur, iron, nickel, and arsenic are known catalyst poisons). In order to maintain the same level of production of methanol across the reactor, one of two methods can be used:

1) The process conditions can be altered to increase the rate of production of methanol (this is typically accomplished by slowly increasing the reactor temperature with time, and is the method that is used in the fixed-bed methanol processes)

2) A portion of the volume of catalyst slurry within the reactor can be removed and replaced with an equal volume of fresh catalyst slurry.

As noted in Section 5.1, the original design of the LPMEOH ${ }^{\text {TM }}$ Process called for the use of catalyst withdrawal and addition to maintain the production rate of methanol. This method tends 
to use larger quantities of methanol synthesis catalyst, as a portion of the catalyst that is removed from the LPMEOH ${ }^{\mathrm{TM}}$ reactor has greater activity than the average catalyst particle within the process.

However, the operating tests following the in-situ activation of methanol synthesis catalyst within the $\mathrm{LPMEOH}^{\mathrm{TM}}$ reactor have also demonstrated the ability to temperature program the reactor and maximize the on-stream time of the catalyst (refer to Section 5.6).

Table 6.2-1 provides the annual amount of spent catalyst slurry that was generated by the LPMEOH $^{\mathrm{TM}}$ Process during the demonstration test period. The average annual generation rate is less than the projected rate as reported in the final EA for the LPMEOH ${ }^{\mathrm{TM}}$ Demonstration Project. During the period from April of 1997 through July of 2001, the catalyst withdrawal/addition method was used to maintain the rate of production of methanol across the $\mathrm{LPMEOH}^{\mathrm{TM}}$ reactor. In addition to this periodic transfer of a portion of the catalyst slurry from the process, the entire contents of the LPMEOH ${ }^{\mathrm{TM}}$ reactor were drained on two occasions (in November of 1997, following the initial accelerated rate of deactivation related to the presence of iron on the catalyst; and in July of 2001, in preparation for the first attempt to activate the methanol catalyst using the in-situ activation procedure). Between August of 2001 and March of 2002, temperature programming was used following the in-situ activation of the methanol synthesis catalyst within the LPMEOH ${ }^{\mathrm{TM}}$ reactor. A brief period of catalyst withdrawal and addition then followed until the contents of the reactor were drained in June of 2002 and the second attempt to demonstrate the in-situ activation procedure was successfully completed.

All of the spent catalyst slurry was shipped on a periodic basis from the LPMEOH ${ }^{\mathrm{TM}}$ demonstration unit to a company which reclaimed the metallic components (copper and zinc) from the catalyst.

Table 6.2-1

Spent Catalyst Slurry from LPMEOH'M Demonstration Unit

\begin{tabular}{|c|c|c|}
\hline Year of Operation & $\begin{array}{c}\text { Spent Catalyst Slurry to } \\
\text { Reclaimer, pounds }\end{array}$ & Comments \\
\hline & & Onstream 02 April 1997 \\
\hline April 1997 - March 1998 & 91,100 & \\
\hline April 1998 - March 1999 & 22,500 & \\
\hline April 1999 - March 2000 & 126,400 & \\
\hline April 2000 - March 2001 & 76,450 & \\
\hline April 2001 - March 2002 & 145,140 & \\
\hline April 2002 - December 2002 & 95,205 & Projected to March 2003 $^{(b)}$ \\
\hline Annual Average & & Refer to Final EA for Project \\
\hline Expected Value & 103,100 to 128,000 & \\
\hline
\end{tabular}




\subsubsection{C-30 Catalyst Guard Bed}

As shown in Figure 1.2.3-1, the 10C-30 catalyst guard bed is located within the Eastman chemicals-from-coal complex, upstream of both the LPMEOH ${ }^{\mathrm{TM}}$ demonstration unit and the existing gas-phase methanol reactor. Prior to the startup of the LPMEOH ${ }^{\mathrm{TM}}$ demonstration unit, this catalyst guard bed had been charged with both zinc oxide and manganese dioxide in order to remove trace quantities of sulfur and arsenic that are present in Balanced Gas. Table 6.2-2 shows the type and quantity of adsorbent materials that were used in this service during the demonstration period for the LPMEOH ${ }^{\mathrm{TM}}$ Process at Kingsport.

\subsubsection{C-40 Carbonyl Guard Bed}

As shown in Figure 2.4-1, the 29C-40 carbonyl guard bed is located within the LPMEOH demonstration unit, and was designed to remove trace levels of metal carbonyls (iron and nickel) that could be present in either the Balanced Gas or CO Gas streams. Table 6.2-3 shows the type and quantity of adsorbent materials that were used in this service during the demonstration program for the LPMEOH ${ }^{\mathrm{TM}}$ Process at Kingsport. Details on the technical selection for the adsorbent materials used in the carbonyl guard bed are provided in Section 5.2. The expected quantity of adsorbent during the design phase of the project was a single charge of 10,000 pounds of activated carbon over a four-year period. Due to the adverse impact of trace contaminants (in particular arsenic) that are poisons to methanol synthesis catalysts, additional types and combinations of adsorbents were used in the carbonyl guard bed.

In Section 4.4.2 of the EMP, incineration was considered to be the means of disposal of the spent activated carbon. Given the change in the type of adsorbent and the presence of arsenic, Eastman performed the testing necessary to characterize the copper-impregnated activated carbon and determine the appropriate means of disposal. The Toxicity Characteristic Leaching Procedure

Table 6.2-2

10C-30 Catalyst Guard Bed Adsorbents Used during Operation of LPMEOH ${ }^{\mathrm{TM}}$ Demonstration Unit

\begin{tabular}{|c|c|c|}
\hline Adsorbent Material & $\begin{array}{c}\text { Targeted Catalyst } \\
\text { Poison }\end{array}$ & Time in Service \\
\hline $\begin{array}{c}\text { (1) Zinc Oxide (155 cubic feet) } \\
\text { (2) Manganese Dioxide (75 cubic feet) }\end{array}$ & $\begin{array}{c}\text { (1) Sulfur } \\
\text { (2) Arsenic }\end{array}$ & $1995-$ September 1997 \\
\hline $\begin{array}{c}\text { (1) Zinc Oxide (155 cubic feet) } \\
\text { (2) Manganese Dioxide (75 cubic feet) }\end{array}$ & $\begin{array}{c}\text { (1) Sulfur } \\
\text { (2) Arsenic }\end{array}$ & October 1997 - June 1999 \\
\hline Manganese Dioxide (230 cubic feet) & Arsenic & June 1999- October 2002 \\
\hline Manganese Dioxide (230 cubic feet) & Arsenic & $\begin{array}{c}\text { October 2002 - 31 December } 2002 \\
\text { (continuing) }\end{array}$ \\
\hline
\end{tabular}


Table 6.2-3

29C-40 Carbonyl Guard Bed

Adsorbents Used during Operation of LPMEOH'M Demonstration Unit

\begin{tabular}{|c|c|c|}
\hline Adsorbent Material & $\begin{array}{c}\text { Targeted Catalyst } \\
\text { Poison }\end{array}$ & Time in Service \\
\hline Activated Carbon (6,300 pounds) & Iron, Nickel & April 1997 - November 1997 \\
\hline Activated Carbon (6,553 pounds) & Iron, Nickel & December 1997 - June 1999 \\
\hline $\begin{array}{c}\text { (1) Manganese Dioxide (2,900 pounds) } \\
\text { (2) Activated Carbon (2,200 pounds) }\end{array}$ & $\begin{array}{c}\text { (1) Arsenic } \\
\text { (2) Iron, Nickel }\end{array}$ & August 2000 - July 2001 \\
\hline $\begin{array}{c}\text { Copper Oxide-impregnated Activated } \\
\text { Carbon (4,892 pounds) }\end{array}$ & $\begin{array}{c}\text { Arsenic, Sulfur, } \\
\text { Iron, Nickel }\end{array}$ & August 2001 - February 2002 \\
\hline $\begin{array}{c}\text { Copper Oxide-impregnated Activated } \\
\text { Carbon (5,336 pounds) }\end{array}$ & $\begin{array}{c}\text { Arsenic, Sulfur, } \\
\text { Iron, Nickel }\end{array}$ \\
\hline $\begin{array}{c}\text { Copper Oxide-impregnated Activated } \\
\text { Carbon (5,073 pounds) }\end{array}$ & $\begin{array}{c}\text { Arsenic, Sulfur, } \\
\text { Iron, Nickel }\end{array}$ & March 2002 - June 2002 \\
\hline $\begin{array}{c}\text { Copper Oxide-impregnated Activated } \\
\text { Carbon (5,810 pounds) }\end{array}$ & $\begin{array}{c}\text { Arsenic, Sulfur, } \\
\text { Iron, Nickel }\end{array}$ & June 2002 - October 2002 \\
\hline $\begin{array}{c}\text { Copper Oxide-impregnated Activated } \\
\text { Carbon (5,225 pounds) }\end{array}$ & $\begin{array}{c}\text { Arsenic, Sulfur, } \\
\text { Iron, Nickel }\end{array}$ & $\begin{array}{c}\text { October 2002 - 31 December 2002 } \\
\text { (continuing) }\end{array}$ \\
\hline
\end{tabular}

(TCLP) was used to determine the metals and total concentration for organics; the results from the testing for various samples are provided in Environmental Monitoring Report Nos. 14, 19, and 22 (References 36, 39, and 44 in Section 12). Only one of the three samples exceeded the regulatory limit for arsenic. Even though the other material could have been incinerated, Eastman decided to classify the material as hazardous for arsenic (U.S. Environmental Protection Agency (EPA) Hazardous Waste Code D004) under the Resource and Conservation Recovery Act (RCRA) due to the uncertainty associated with the detection limit for arsenic. However, the incinerator did not accept material with this waste code. This led to the selection of a permitted hazardous waste landfill as the site to dispose of this spent adsorbent. Prior to landfilling, this facility stabilized the material to ensure that the leachate contained less than 5 ppmw arsenic.

\subsubsection{Waste Oil}

As part of the design of the LPMEOH ${ }^{\mathrm{TM}}$ demonstration unit, an oil-water separator was included to collect any spill of the process mineral oil during operation or maintenance. During the demonstration program, oil was collected on a periodic basis and sent to incinerator equipment within the Eastman chemicals-from-coal complex for energy recovery. Table 6.2-4 shows the quantity of waste oil that was collected in the oil-water separator during the demonstration program for the LPMEOH ${ }^{\mathrm{TM}}$ Process at Kingsport. During the design phase, the annual quantity of waste oil from the oil-water separator was expected to be 13,000 pounds; the average amount observed during the demonstration period should be used as the basis during the design of future plants. 
Table 6.2-4

Waste Oil from LPMEOH'M Demonstration Unit

\begin{tabular}{|c|c|c|}
\hline Year of Operation & Waste Oil, pounds & Comments \\
\hline & & Onstream 02 April 1997 \\
\hline April 1997 - March 1998 & 24,000 & \\
\hline April 1998 - March 1999 & 24,000 & \\
\hline April 1999 - March 2000 & 42,000 & \\
\hline April 2000 - March 2001 & 6,000 & \\
\hline April 2001 - March 2002 & 0 & \\
\hline April 2002 - December 2002 & 48,000 & \\
\hline & & \\
\hline Annual Average & 25,040 & Refer to Final EA for Project $^{(\mathrm{b})}$ \\
\hline Expected Value & 13,000 & \\
\hline
\end{tabular}

In addition, a one-time test was performed in June of 2002 to identify potential sources of iron contamination within the LPMEOH ${ }^{\mathrm{TM}}$ Process. Mineral oil (in the absence of methanol synthesis catalyst) was heated in the presence of syngas, and sampling of the syngas stream was performed to determine the concentration of iron carbonyl. This quantity of oil $(35,600$ pounds) was also incinerated for energy recovery.

\subsubsection{Recovered Distillation Liquids}

As shown in Figure 2.4-1, a Crude-Grade Methanol stream containing about $25 \%$ of the methanol that was produced in the $\mathrm{LPMEOH}^{\mathrm{TM}}$ reactor was sent to existing distillation equipment within the Eastman chemicals-from-coal complex for further distillation. This stream contained a small quantity of the mineral oil that is used in the preparation of the methanol catalyst slurry. Table 6.2-5 shows the quantity of oil that was collected in the Eastman

Table 6.2-5

\section{Oil Collected in Distillation Equipment from LPMEOH ${ }^{\mathrm{TM}}$ Process}

\begin{tabular}{|c|c|c|}
\hline Year of Operation & Oil Collected, pounds & Comments \\
\hline & & Onstream 02 April 1997 \\
\hline April 1997 - March 1998 & 0 & \\
\hline April 1998 - March 1999 & 178,269 & \\
\hline April 1999 - March 2000 & 34,100 & \\
\hline April 2000 - March 2001 & 116,533 & \\
\hline April 2001 - March 2002 & 221,855 & \\
\hline April 2002 - December 2002 & 110,557 & \\
\hline & & \\
\hline Annual Average & 115,010 & Refer to Final EA for Project $^{(\text {b) }}$ \\
\hline Expected Value & 324,000 & \\
\hline
\end{tabular}


distillation equipment during the demonstration period for the LPMEOH ${ }^{\mathrm{TM}}$ Process at Kingsport. The average annual generation rate is less than the projected rate as reported in the final EA for the LPMEOH ${ }^{\mathrm{TM}}$ Demonstration Project.

\subsubsection{Waste Water}

The chemistry for the production of methanol from syngas (refer to Section 2.1) also yields water as a byproduct. This water is separated from the Refined-Grade Methanol in the 29C-20 methanol rectifier column, and exits the $\mathrm{LPMEOH}^{\mathrm{TM}}$ demonstration unit with the Crude-Grade Methanol stream. After further distillation in existing equipment within the Eastman chemicalsfrom-coal complex, the water from the LPMEOH ${ }^{\mathrm{TM}}$ Process is combined with other streams and fed to the Eastman water treatment system. During the operation of the LPMEOH'M demonstration unit, Eastman provided reports on the samples taken at the discharge point from the water treatment system to the Holston River. As noted in the Environmental Monitoring Reports (referenced in Section 12), there were no excursions for any of the parameters that were tested as required by the National Pollutant Discharge Elimination System (NPDES) permit for the Eastman chemicals-from-coal complex.

\subsection{POTENTIAL ENVIRONMENTAL CONCERNS}

Based upon the excellent environmental performance at the LPMEOH ${ }^{\mathrm{TM}}$ demonstration unit, the use of the technology in future applications should cause no significant impact on the local environment. Site-specific considerations should be made regarding the disposal options for the spent catalyst slurry (for example, the cost of and proximity to a catalyst reclaiming operation). In addition, the benefits of recovery and reuse of the oil streams from the oil-water separator and the distillation system (where used) should also be evaluated on a site-by-site basis.

\subsection{SECTION 6 BIBLIOGRAPHY}

a. "Commercial-Scale Demonstration of the Liquid-Phase Methanol (LPMEOH $\left.{ }^{\mathrm{TM}}\right)$ Process Environmental Information Volume", Prepared by Air Products Liquid Phase Conversion Co., L.P., DOE Cooperative Agreement No. DE-FC22-95PC93052, May 1996.

b. "Final Environmental Assessment for the Liquid Phase Methanol (LPMEOH $\left.{ }^{\mathrm{TM}}\right)$ Project", DOE/EA1029, June 1995.

c. "Commercial-Scale Demonstration of the Liquid-Phase Methanol (LPMEOH ${ }^{\mathrm{TM}}$ ) Process - Final Environmental Monitoring Plan”, Prepared by Air Products Liquid Phase Conversion Co., L.P., DOE Cooperative Agreement No. DE-FC22-95PC93052, August 1996. 


\subsection{METHANOL PRODUCT-USE TESTING}

\subsection{INTRODUCTION}

The LPMEOH ${ }^{\mathrm{TM}}$ Process is a very effective technology for converting a portion of an IGCC electric power plant's coal-derived syngas to methanol, as depicted in Figure 7.1-1. The process has the flexibility to handle wide variations in syngas composition. It can be designed to operate in a continuous, baseload manner, converting syngas from oversized gasifiers or from a spare gasifier. Alternatively, the process can be designed to operate only during periods of off-peak electric power demand, consuming a portion of the excess syngas and reducing the electricity output from the combined-cycle power unit. In this scenario, the gasification unit continues to operate at full baseload capacity, so that the IGCC facility's major capital asset is always fully utilized.

In either baseload or cycling operation, partial conversion of between $20 \%$ and $33 \%$ of the IGCC plant's syngas is optimal, and conversion of up to $50 \%$ is feasible. The required degree of conversion of syngas, or the quantity of methanol relative to the power plant size, determines the design configuration for the LPMEOH ${ }^{\mathrm{TM}}$ unit. In its simplest configuration, syngas at maximum available pressure from the IGCC power plant's gasifier system passes once-through the $\mathrm{LPMEOH}^{\mathrm{TM}}$ unit and is partially converted to methanol without recycle, water-gas shift, or $\mathrm{CO}_{2}$

Figure 7.1-1

Once-through Methanol Coproduction with IGCC Electric Power

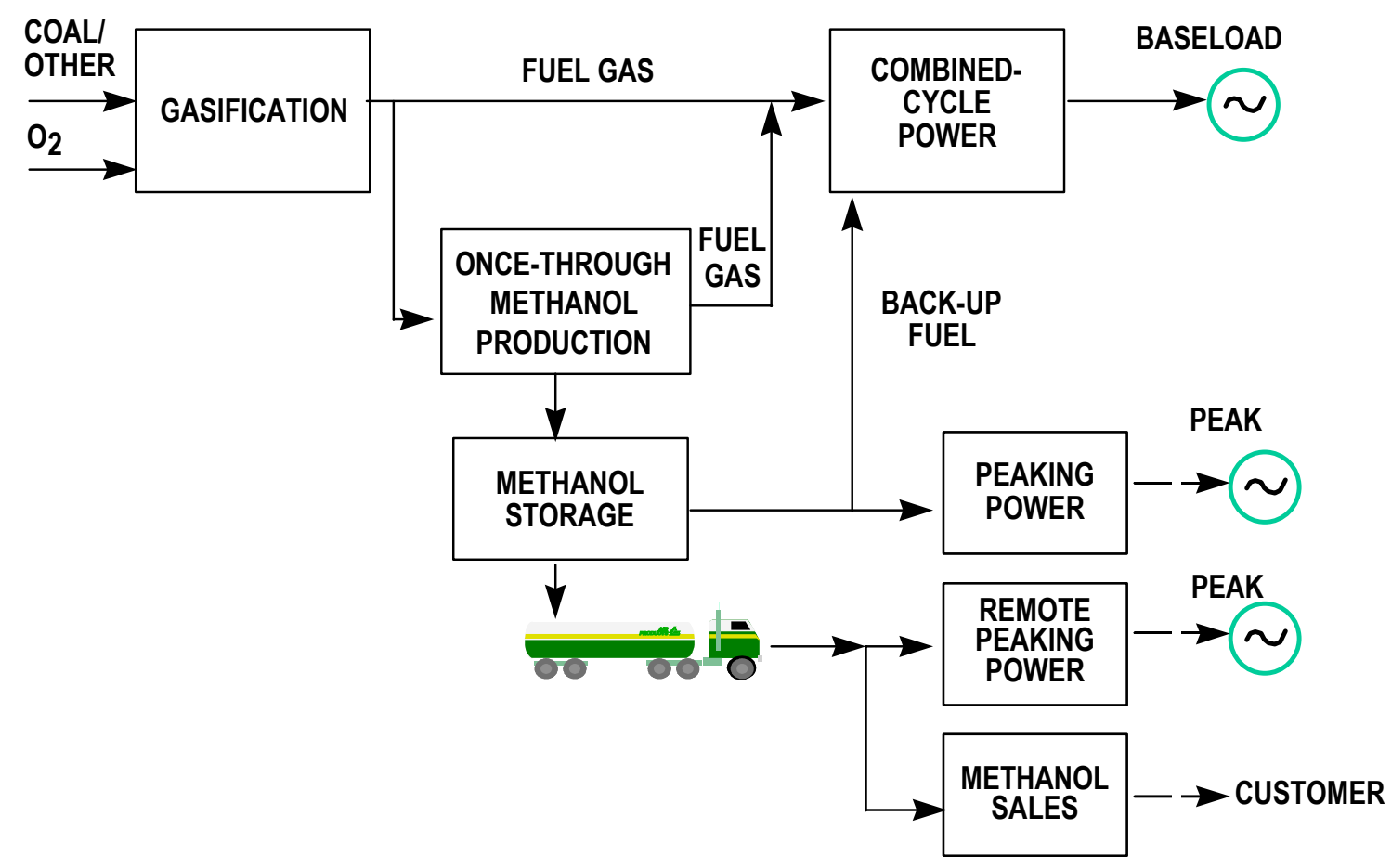


removal. The unreacted gas is returned to the IGCC power plant's combustion turbines. If greater syngas conversion is required, different design options are available.

Methanol which is produced directly from CO-rich syngas has only $1 \mathrm{wt} \% \mathrm{H}_{2} \mathrm{O}$ in the condensed stream entering the first distillation column. Significant capital and operating costs (corresponding to a purification cost of $\$ 0.02$ to $\$ 0.04$ per gallon of methanol) can be avoided if stabilized methanol, which is produced via removal of dissolved gases such as $\mathrm{CO}_{2}$ from the first column, can be directly used in some chemical and power systems. The Statement of Work from the Cooperative Agreement defines the scope of work for the studies associated with the testing of this as-produced methanol:

"The methanol product must be adequate for its intended use. Therefore, the economic upgrading of the methanol product will be demonstrated as part of Phase III, Task 2.1 (LPMEOH ${ }^{\mathrm{TM}}$ Process

Demonstration Facility Operation - Methanol Operation), and the suitability of using the product will be demonstrated as part of Phase III, Tasks 3 (On-site Testing (Product Use Demonstration)) and 4 (Off-site Testing (Product Use Demonstration)). The product use demonstrations will include fuel use and chemical use product testing. The fuel use applications may include use in transit buses and car pools and for the generation of stationary power for public, industrial and electric utilities."

\subsection{ON-SITE TESTING OF METHANOL}

As noted in Section 1.2.4, the methanol that is produced at the LPMEOH ${ }^{\mathrm{TM}}$ demonstration unit was used by Eastman in the production of methyl acetate and, ultimately cellulose acetate and acetic acid. Beginning with the startup of the $\mathrm{LPMEOH}^{\mathrm{TM}}$ demonstration unit, Eastman monitored the quality of the Refined-Grade Methanol as determined by a set of in-house fitnessfor-use criteria. These criteria, as well as a summary of the results of the analysis of over 7.19 million gallons of Refined-Grade Methanol produced in 1997, are provided in Table 7.2-1. Occasionally, a lot tank sample fell outside an internal manufacturing limit. Through 31 December 1997, a total of 24 samples of refined methanol failed to meet one of the analytical tests. Refined-Grade Methanol is pumped from the methanol lot tanks within the battery limits of the LPMEOH ${ }^{\mathrm{TM}}$ demonstration unit to a primary methanol storage tank elsewhere within the Eastman complex. When results of a sample of Refined-Grade Methanol fall outside the fitnessfor-use criteria, Eastman evaluates the impact of this material on the contents of this primary storage tank. As long as the properties of the methanol in this tank stay within the methanol specification, the lot of Refined-Grade Methanol can be accepted. All 24 lots of Refined-Grade Methanol that have failed to meet all of the fitness-for-use criteria have been accepted in this manner. Over the entire 69-month operating program for the LPMEOH ${ }^{\mathrm{TM}}$ demonstration unit, over 103.9 million gallons of methanol was produced, and Eastman accepted all of the available methanol for use in the production of methyl acetate, and ultimately cellulose acetate and acetic acid.

An opportunity to demonstrate the use of methanol directly from the LPMEOH ${ }^{\mathrm{TM}}$ Process in the production of methyl acetate occurred on 08 February 1998. During a planned five-day outage in Eastman's shift reactor, operations continued in the LPMEOH ${ }^{\mathrm{TM}}$ demonstration unit with a $\mathrm{H}_{2}$ : $\mathrm{CO}$ ratio in the reactor feed of 0.7 , while Eastman's gas-phase methanol plant was forced to shut down. Furthermore, Eastman took the opportunity to shut down their methanol distillation 


\section{Table 7.2-1 \\ Refined-Grade Methanol from LPMEOH ${ }^{\mathrm{TM}}$ Demonstration Unit Quality and Fitness for Use (1997)}

\begin{tabular}{|c|c|c|c|c|c|c|c|}
\hline Property & $\begin{array}{c}1 \\
\text { LIML }\end{array}$ & $\begin{array}{c}2 \\
\text { UIML }\end{array}$ & $\begin{array}{c}3 \\
\text { \# Obs. }\end{array}$ & $\begin{array}{c}4 \\
\text { Avg. }\end{array}$ & $\begin{array}{c}5 \\
\text { Min. }\end{array}$ & $\begin{array}{l}6 \\
\text { Max. }\end{array}$ & $\begin{array}{c}7 \\
\text { \# Out IMLs }\end{array}$ \\
\hline Acetone, ppm & & 125 & 207 & 11.217 & 10 & 30 & 0 \\
\hline Appearance & pass & pass & 207 & & & & 3 \\
\hline Color by pcs & & 5 & 207 & 5 & 5 & 5 & 0 \\
\hline Decane, ppm & & 12 & 207 & 10.642 & 10 & 76 & 5 \\
\hline Ethanol, ppm & & 500 & 207 & 101.01 & 100 & 220 & 0 \\
\hline Water, $\%$ by Coulemetric & & & 170 & 0.0094 & 0.0023 & 0.0571 & \\
\hline Water, \% by Titration & & 0.03 & 96 & 0.0127 & 0.0023 & 0.0581 & 5 \\
\hline Acetic Acid, \% & & 0.003 & 207 & 0.0004 & 0.0002 & 0.003 & 0 \\
\hline Methanol, \% & 99.9 & & 207 & 99.985 & 99.92 & 100 & 0 \\
\hline Alkalinity, ppm & & 0.8 & 51 & 0.596 & 0.1 & 2.3 & 11 \\
\hline Specific Gravity @ 20/20 & 0.792 & 0.793 & 96 & 0.7928 & 0.792 & 0.793 & 0 \\
\hline
\end{tabular}

Notes:

1) Terms:

Column 1 - Lower Internal Manufacturing Limit Column 2 - Upper Internal Manufacturing Limit

Column 3 - Number of lot tank samples analyzed for this test

Column 4 - Average value of analytical test for all lot tank samples

Column 5 - Minimum value of analytical test for all lot tank samples

Column 6 - Maximum value of analytical test for all lot tank samples

Column 7 - Number of lot tank samples falling outside Internal Manufacturing Limit

2) Analysis is performed on each lot with the exception of:

Alkalinity - every 4th lot

Specific Gravity - every other lot

3) The Coulemetric water test was replaced by a water titration in August of 1997.

equipment for maintenance, leaving no flow path for the Crude-Grade Methanol underflow from the second, rectifier column in the $\mathrm{LPMEOH}^{\mathrm{TM}}$ demonstration unit. However, because of the CO-rich feed, the rectifier column could be shut down for the production of stabilized methanol (98+ wt \% methanol, $<1 \mathrm{wt} \% \mathrm{H}_{2} \mathrm{O}$ ). Approximately 12,000 gallons of stabilized methanol was loaded into trailers and shipped off-site for future product-use testing. During the remainder of this operating period, approximately 181,800 gallons ( 600 short tons) of stabilized methanol (99.3 wt $\%$ methanol, $0.3 \mathrm{wt}^{2} \mathrm{H}_{2} \mathrm{O}$ ) was pumped directly from the $\mathrm{LPMEOH}^{\mathrm{TM}}$ demonstration unit to Eastman's methyl acetate plant, bypassing the normal route through the distillation equipment.

This methanol was considered acceptable by Eastman because of the low levels of all impurities. In particular, the $\mathrm{H}_{2} \mathrm{O}$ concentration of the stabilized methanol was significantly lower than what is produced during operation on the normal Balanced Gas supply (typically 3-4 wt $\% \mathrm{H}_{2} \mathrm{O}$ ). This is a result of operation on a $\mathrm{CO}$-rich syngas with a relatively low $\mathrm{CO}_{2}$ concentration. This test 
was the first attempt to feed a stabilized methanol stream with low water content directly into one of Eastman's downstream chemical processes, providing another indication of the flexibility of the LPMEOH ${ }^{\mathrm{TM}}$ Process. Eastman's only alternative was to flare the syngas stream, which was undesirable both environmentally and economically.

\subsection{OFF-SITE PRODUCT-USE TESTING OF METHANOL}

The product-use test program attempted to develop broader market applications and commercial fuels comparisons by evaluating new utility dispersed electric power developments, and possibly new mobile transport engine developments. The objective of the product-use test program was to demonstrate commercial market applications for the stabilized methanol as a replacement fuel and as a fuel supplement. During the program definition phase, attempts were made to develop sites to test stabilized methanol in municipal, industrial, and utility applications and as fuel supplements for gasoline, diesel, and natural gas. These tests were envisioned based upon the U.S. energy market needs projected through the 2018 time period when the LPMEOH ${ }^{\mathrm{TM}}$ technology is expected to be commercialized.

Because the generation of electric power is not a feature of the demonstration project at Kingsport, the coproduction of methanol with electric power could not be demonstrated. However, the product-use test program was developed to provide data on potential applications of stabilized methanol in order to enhance the early commercial acceptance of central clean coal technology processing facilities, coproducing electricity and methanol to meet the needs of the local community. These applications required testing of the product to confirm its suitability.

A limited quantity of the stabilized methanol from the demonstration unit was made available for product-use tests. Product-use tests commenced during the first year of demonstration operations. As noted in Section 7.2, an initial inventory of approximately 12,000 gallons of stabilized methanol was produced at LPMEOH ${ }^{\mathrm{TM}}$ demonstration unit to supply the needs of the product-use test program. Analysis of the stabilized methanol from tests conducted using a COrich feed gas is shown in Table 7.3-1. Results from two Kingsport tests are quite comparable with results from a test campaign at the LaPorte AFDU. The difference in the concentrations of $\mathrm{H}_{2} \mathrm{O}$ and higher alcohols of the two Kingsport samples is related to the age or activity of the catalyst and the amount of $\mathrm{CO}_{2}$ in the reactor feed gas.

Table 7.3-1

Stabilized Methanol Composition - CO-rich Feed Gas $\left(\mathrm{H}_{2}: \mathrm{CO}=0.7\right)$

$\begin{array}{lccc}\text { Kingsport } & \begin{array}{c}\text { Kingsport } \\ \text { Sample \#1 }\end{array} & \begin{array}{c}\text { LaPorte AFDU } \\ \text { Sample }\end{array} \\ \text { Methanol } & 98.08 & 99.26 & 98.40 \\ \text { Ethanol } & 0.31 & 0.25 & 0.60 \\ \text { C3+ } & 0.40 & 0.18 & 0.46 \\ \text { Water } & 1.22 & 0.31 & 0.54\end{array}$


The status of the seven projects which have been defined within the product-use test program is reviewed. Two categories of potential applications of stabilized methanol were under investigation, transportation systems and power generation systems.

\subsubsection{Transportation Systems}

A total of five vehicles have been tested on fuel blends made from stabilized methanol from the LPMEOH $^{\text {TM }}$ Demonstration Project. These tests, which have been performed at three different locations, were designed to determine if there are any differences in fuel economy, maintenance, or exhaust emissions when compared to the performance with fuels made with chemical-grade methanol.

\subsubsection{Florida Institute of Technology Bus \& Light Vehicles}

Three of the vehicles are located at the Florida Institute of Technology, and all were tested on stabilized methanol from the LPMEOH ${ }^{\mathrm{TM}}$ Demonstration Project. A 1988 Chevrolet Corsica flexible-fuel vehicle (FFV) was driven a total of 4,455 miles on M-85 (85 vol\% methanol/15 vol\% gasoline) and M-100 (100 vol\% methanol) fuel blends. Repairs were of a routine nature and independent of the type of methanol used or the fuel blend. A total of 32 refuelings were performed under the sponsorship of the product-use program, with an average fuel economy of 10.88 miles per gallon (mpg). When compared with the EPA rated gasoline mileage of 19.0 mpg, the methanol blends are less efficient on an energy density basis (methanol has a lower energy content per gallon than gasoline). Additional data on the base gasoline performance is necessary in order to complete this analysis.

The second vehicle is a 1993 Ford Taurus FFV which was acquired during the project. During the project, a total of 7,648 miles were accumulated on fuel blends with stabilized methanol content ranging from M-85 to M-15. Since the car was acquired in July of 1998, the car operated well; the fuel pump was replaced due to routine wear not related to the use of either stabilized methanol or chemical-grade methanol fuel blends. The fuel economy ranged from $14.68 \mathrm{mpg}$ on M-85 to $19.81 \mathrm{mpg}$ for M-15. This latter figure matched both the measured fuel economy with pure gasoline and the EPA rated gasoline mileage.

A bus which had been operated by the Jacksonville Transportation Authority was driven a total of 937 miles on M-100 during the project. Due to the costs associated with hiring a driver for this vehicle, no further tests beyond the initial shakedown of the bus were conducted.

\subsubsection{ARCADIS Geraghty \& Miller Flexible Fuel Vehicle}

A second set of FFV trials was performed at ARCADIS Geraghty \& Miller in a 1996 Ford Taurus FFV. During sponsorship by the product-use program, the FFV was driven a total of 3,206 miles on a M-85 fuel blended from chemical-grade methanol, and 3,479 miles were accumulated on M-85 produced from stabilized methanol. The fuel economy of about $16 \mathrm{mpg}$ was the same for both fuel blends (Table 7.3.1-1). 


\section{ARCADIS Geraghty \& Miller FFV \\ Fuel Economy Results}

\begin{tabular}{lcc} 
& \multicolumn{2}{c}{ Fuel Economy, mpg } \\
& $\begin{array}{c}\text { Chemical -Grade } \\
\text { M-85 }\end{array}$ & $\begin{array}{c}\text { M-85 w/ LPMEOH } \\
\text { Stabilized Methanol }\end{array}$ \\
In-use & 16.2 & 16.4 \\
Emission Test on Dynamometer & 16.9 & 16.3
\end{tabular}

Results of emissions testing on a dynamometer are presented in Table 7.3.1-2. The FFV exhibited higher emissions for total hydrocarbons, $\mathrm{CO}, \mathrm{CO}_{2}$, and methane for the stabilized methanol fuel blend; emissions of non-methane hydrocarbons and $\mathrm{NO}_{\mathrm{x}}$ were higher for the $\mathrm{M}-85$ fuel blended with chemical-grade methanol. For each of these parameters, emissions for both fuels were within the standards established by the State of California. Emissions of methanol and formaldehyde were greater for the stabilized methanol blend, and the readings for formaldehyde were above the California standard for both fuel blends (there is no standard for methanol emissions). It was concluded that further engine tuning would bring the formaldehyde emissions into compliance for both fuel blends.

Overall, the FFV operated by ARCADIS Geraghty \& Miller exhibited similar performance characteristics for both fuel economy and emissions when the vehicle was operated on fuel blends from either stabilized methanol or chemical-grade methanol.

Table 7.3.1-2

\section{ARCADIS Geraghty \& Miller FFV} Emissions Results

\begin{tabular}{|c|c|c|c|}
\hline & Constituent Emis & n Rate, grams/mile & California \\
\hline & $\begin{array}{c}\text { Chemical -Grade } \\
\text { M-85 }\end{array}$ & $\begin{array}{l}\text { M-85 w/ LPMEOH } \\
\text { Stabilized Methanol }\end{array}$ & $\begin{array}{c}\text { Emission } \\
\text { Standard, grams/mile }\end{array}$ \\
\hline Carbon Dioxide & 334 & 346 & No Standard \\
\hline Carbon Monoxide & 0.867 & 0.923 & 3.4 \\
\hline Nitrogen Oxides & 0.138 & 0.121 & 0.4 \\
\hline Total Hydrocarbons & 0.093 & 0.132 & No Standard \\
\hline Methane & $<0.001$ & 0.011 & No Standard \\
\hline Non-methane Hydrocarbons & 0.120 & 0.118 & 0.25 \\
\hline Methanol & 0.143 & 0.252 & No Standard \\
\hline Formaldehyde & 0.0194 & 0.0337 & 0.015 \\
\hline
\end{tabular}




\subsubsection{West Virginia University Study of Stabilized Methanol in Transit Bus}

West Virginia University (WVU) has developed a transportable laboratory facility which specializes in the measurement of emissions from heavy-duty vehicles. Figure 7.3.1-1 is a photograph of the laboratory, and one of the pieces of test equipment.

Under this effort, three buses operated on M-100 by Tri-Boro Coach in New York were tested. The buses were manufactured in 1993 and 1994 by Transit Motor Corp. The Detroit Diesel 6V92 methanol engines in the buses are rated at 253 horsepower. All buses were operated on the Central Bus District Cycle, which is intended to simulate the use of a transit bus in city service and is also used to rate the performance of new buses. One bus was also tested using a 5-mile cycle, which uses five different segments of acceleration, cruise, and deceleration.

The results from the average vehicle emissions for this product-use test are presented in Table 7.3.1-3. On average, emissions of hydrocarbons (primarily unburned methanol and aldehydes)

Figure 7.3.1-1

West Virginia University

Transportable Heavy Duty Emissions Testing Laboratory


WVU mobile testing equipment 


\section{Table 7.3.1-3 \\ West Virginia University - Tri-Boro Coach \\ Emissions Results}

$\begin{array}{ccc}\begin{array}{c}\text { Constituent Emission Rate, grams/mile } \\ \begin{array}{c}\text { Chemical -Grade } \\ \text { M-85 }\end{array}\end{array} & \begin{array}{c}\text { M-85 w/ LPMEOH } \\ \text { Stabilized Methanol }\end{array} & \begin{array}{c}\text { New Diesel Engine } \\ \text { w/ Diesel Fuel }\end{array} \\ 2,773 & 2,811 & 2,611 \\ 10.41 & 9.60 & 4.9 \\ 5.60 & 5.11 & 30.1 \\ 5.39 & 6.88 & 0.13 \\ 0.21 & 0.24 & 0.24\end{array}$

and particulate matter were increased slightly when stabilized methanol is used as the fuel. Also shown for reference are recent test results as reported by the laboratory for a new diesel engine; methanol fuels offer substantial advantages in lower emissions of $\mathrm{NO}_{\mathrm{x}}$ with minor changes in other components when compared with diesel fuel.

\subsubsection{Power Generation Systems}

As indicated in Figure 7.1-1, one of the primary applications for stabilized methanol derived from syngas streams rich in $\mathrm{CO}$ is in the generation of electric power. The more classical approach is to generate electricity in a methanol-fired gas turbine at the power plant during periods of peak power demand. In recent years, changes in the power generation and transmission industry and technological improvements in smaller turbine and fuel cell systems have spawned the concept of distributed power. A local power producing system will be able to provide the electricity for a small number of users (for example, the heating and air conditioning needs of an office complex or shopping center). Methanol, produced at a centrally located coalfired IGCC plant, can be produced at prices which are competitive in these distributed power applications.

The product-use test program was designed to study the uses of stabilized methanol in a variety of power generation systems (turbines, fuel cells, generators).

\subsubsection{West Virginia University Stationary Gas Turbine}

This program was designed to compare the emissions and operational aspects of gas turbine operation on stabilized methanol compared with conventional liquid fuel. At WVU, a research aircraft was built using a GTC-85-72 gas turbine as the power source. This unit, which is rated at 235 horsepower in the form of compressor bleed air, was used in this study. Several of the turbine subsystems (fuel tank and pumps, speed and fuel flow controller, ignition system, bleed air load controller) had to be modified to accommodate the stabilized methanol fuel.

Testing has shown that the present configuration of the gas turbine does not allow operation on methanol at startup. Conventional fuel (in the form of Jet A) was used for initial turbine firing, 
and a fuel emulsifier was added to assure a smooth transition from Jet A to stabilized methanol. At low power loads, flameout occurred during the transition to methanol; this appears to be the result of the higher heat of vaporization of methanol when compared with Jet A. Two glow plugs were added to overcome this problem. Initial testing was also performed without any additives in order to determine if the trace amounts of the inert oil from the LPMEOH ${ }^{\mathrm{TM}}$ Process were sufficient to provide the necessary lubrication for the fuel pump and controller. It was determined that the mineral oil levels in the stabilized methanol did not adequately lubricate these systems.

Testing was performed by the WVU Transportable Heavy Duty Emissions Testing Laboratory in order to compare the emissions generated from Jet A and stabilized methanol fuels. The results are provided in Figure 7.3.2-1, and demonstrate the capability of stabilized methanol to significantly reduce the levels of $\mathrm{NO}_{\mathrm{x}}$ in gas turbine exhausts.

Following this work, a second set of performance tests and emissions measurements were performed with stabilized methanol and the selected lubricant to determine if any differences from the earlier testing could be determined. Figure 7.3.2-2 contains a representative set of results for a $2 \%$ mixture of the lubricant in methanol; emissions of $\mathrm{NO}_{\mathrm{x}}$ were again substantially lower than for a kerosene fuel, and levels of $\mathrm{CO}$, hydrocarbons, and particulates were also reduced.

The investigators recommend that additional work could be focused on optimizing the selection and concentration of the lubricant and solving the problems with operation at low power load.

Figure 7.3.2-1

West Virginia University Stationary Gas Turbine Emissions Test Results - 1998 Testing

Emissions during fuel type change over from Jet-A to Methanol at $\mathrm{t}=5$ minutes and back to Jet $\mathrm{A}$ at $\mathrm{t}=11$ minutes at $45 \%$ power level, August 18, 1998

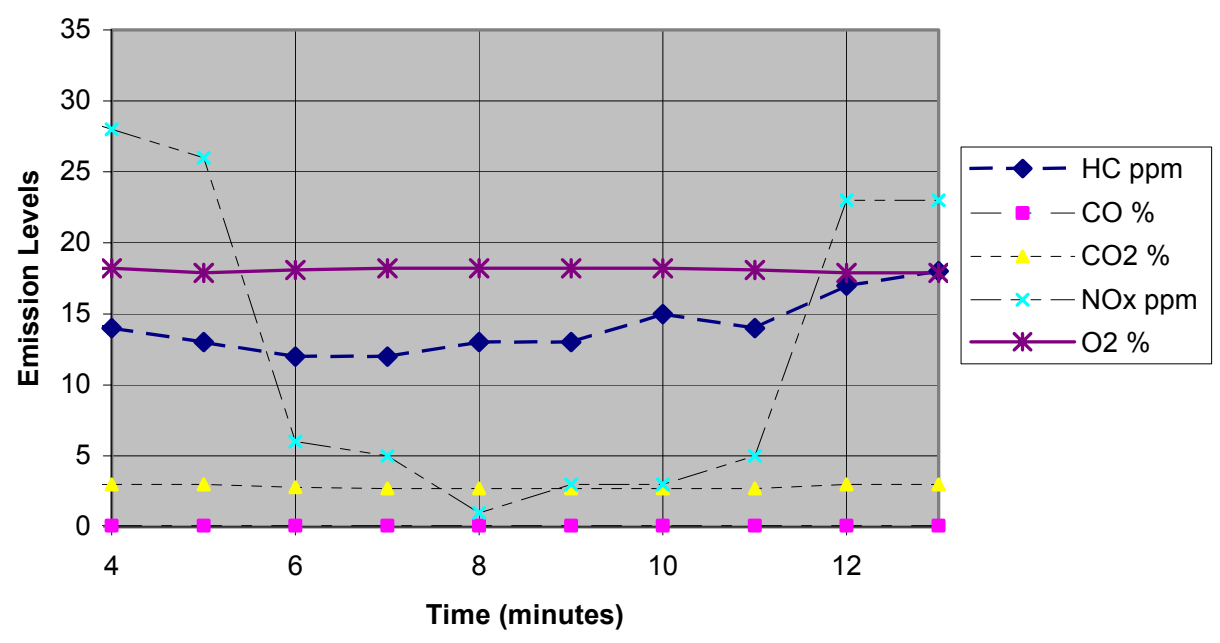


Figure 7.3.2-2

\section{West Virginia University Stationary Gas Turbine Emissions Test Results - 2000 Testing}

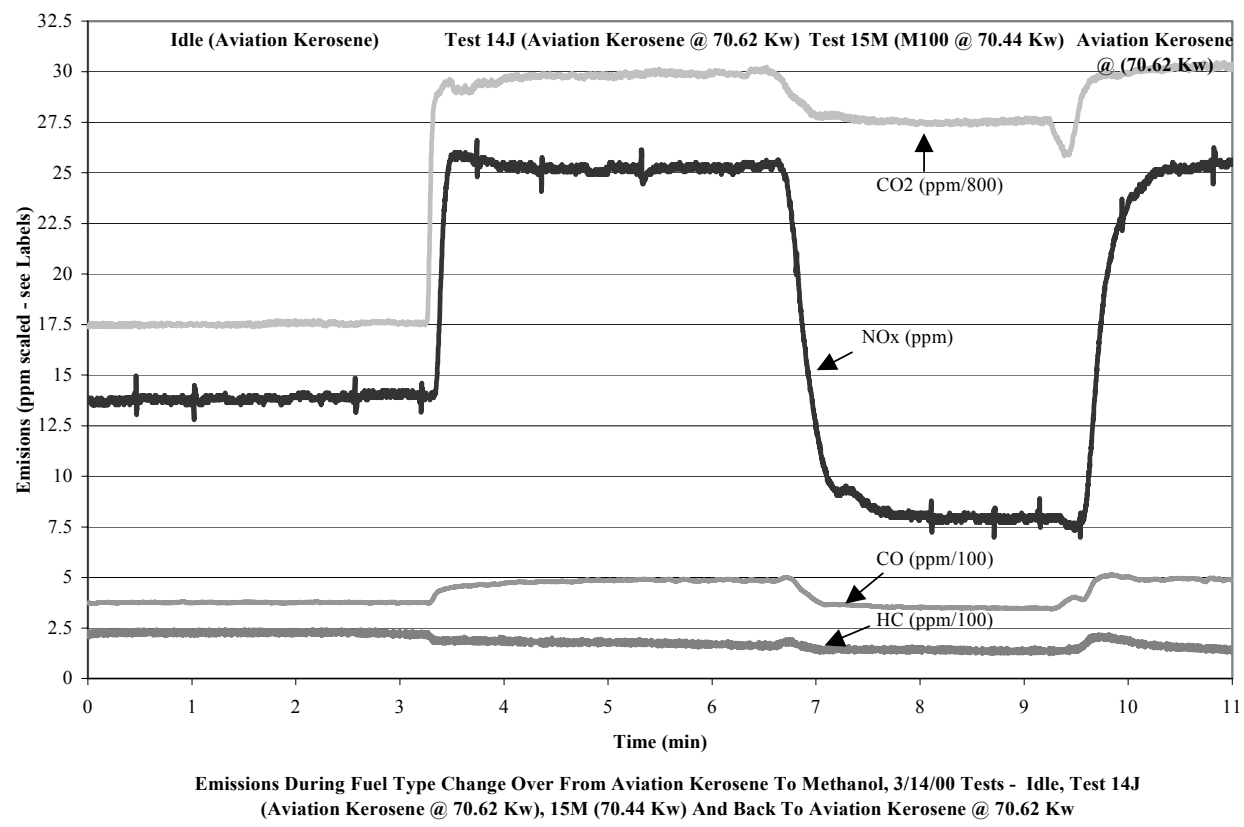

\subsubsection{Aircraft Ground Support Equipment}

In preparation for the possibility that combustion sources at U.S. Air Force bases may be required to reduce their emissions of $\mathrm{NO}_{\mathrm{x}}$, the Air Force had become interested in the evaluation of possible approaches to controlling $\mathrm{NO}_{\mathrm{x}}$ emissions from aircraft ground support equipment (AGSE) diesel generators (part of a class of off-road power generation systems). These generators are very high $\mathrm{NO}_{\mathrm{x}}$ emitters. It has been determined that the AGSE accounts for nearly 40 to 60 percent of a typical base's emissions of $\mathrm{NO}_{\mathrm{x}}$ and the diesel generator accounts for 70 to 90 percent of the AGSE emissions. Replacement of these systems is expensive, and other alternative fuels (such as liquefied or compressed natural gas or liquefied petroleum gas) are not feasible. One $\mathrm{NO}_{\mathrm{x}}$ control approach applicable to these engines is the use of a diesel/water emulsion fuel in place of standard diesel fuel.

The use of diesel/water emulsions containing nominally 5-percent methanol have been shown to be effective in achieving nominally 40-percent $\mathrm{NO}_{\mathrm{x}}$ reductions from some engines. However, the diesel/water emulsion experience base is quite limited, and the long-term effects of such emulsions on engine performance were unknown. Thus, there was a need to evaluate the effectiveness and the long-term performance of this $\mathrm{NO}_{\mathrm{x}}$ control approach when applied to AGSE.

ARCADIS Geraghty \& Miller developed a project to perform an extended evaluation of the use of a diesel/water/methanol emulsion, prepared using stabilized methanol from the LPMEOH ${ }^{\mathrm{TM}}$ 
Demonstration Project as the methanol component. Testing was planned on an Air Force flight line generator at Tyndall Air Force Base (AFB), Florida. Previous work supported by the Air Force Green AGSE Program developed an additive package that is effective in both stabilizing a diesel/water emulsion and preventing engine part corrosion. Two of these generators at Tyndall AFB were made available to this project. Of these, one was to be operated on the emulsion fuel during the evaluation, and the other was to be run on a military jet fuel (specification JP-8). JP-8 jet fuel is used in the mobility applications of the generators, and the Air Force has standardized the use of JP-8 in diesel engines to reduce the need to manage and maintain two fuel types and fueling systems. Engine performance and emissions testing were planned to be conducted before the start and after the end of this 6-month period to quantify emission reductions and performance impacts. Engine inspections were also planned, to address durability and corrosion issues.

The water-in-fuel (WIF) emulsion containing the stabilized methanol and additives was the emulsion fuel that was evaluated in these tests. The WIF emulsion was prepared to contain nominally 30 percent water, 5 percent methanol, and 1 percent additives, with the balance being JP-8.

When this project was originally planned, substantial support of the effort was offered by several Air Force and contractor organizations at Tyndall AFB. As the project proceeded, however, mission priorities of all the Air Force organizations supporting the evaluation changed to the point that further support of the project was not possible. As a result of these changes, support for the project could no longer be offered after May of 1999, and the project needed to be concluded. Up to that point, a series of initial performance and emissions tests had been completed.

In the initial performance and emissions tests that were completed, engine emissions of $\mathrm{O}_{2}, \mathrm{CO}$, $\mathrm{CO}_{2}, \mathrm{NO}_{\mathrm{x}}$, and unburned hydrocarbons (UHC) were measured from engines fueled with both WIF and JP-8. Particulate emissions measurements were also performed using a dilution tunnel measurement technique. However, the 30-minute sampling time at each test load was not long enough to allow collecting measurable quantities of particulate on the sampling train filters.

Results of the tests were as follows:

- As shown in Figure 7.3.2-3, the use of the WIF emulsion reduced engine $\mathrm{NO}_{\mathrm{x}}$ emissions by 21 to $57 \%$ over the engine load range, with the greater emission reductions achieved at lower engine loads. The International Organization for Standardization (ISO) cycle weighted average $\mathrm{NO}_{\mathrm{x}}$ emissions were reduced 34\% from $1,550 \mathrm{ppm}$ at $15 \% \mathrm{O}_{2}$ with JP-8 fuel to $1,030 \mathrm{ppm}$ at $15 \% \mathrm{O}_{2}$ with the emulsion.

- $\mathrm{CO}$ emissions from the engine did not vary significantly with load for the JP-8 fuel, and were nominally $500 \mathrm{ppm}$ at $15 \% \mathrm{O}_{2}$. With the WIF emulsion, $\mathrm{CO}$ emissions were relatively constant at engine loads from full load to 50 percent load, but increased substantially at lower engine loads. 
Figure 7.3.2-3

\section{Aircraft Ground Support Equipment

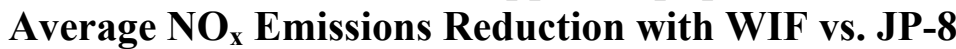

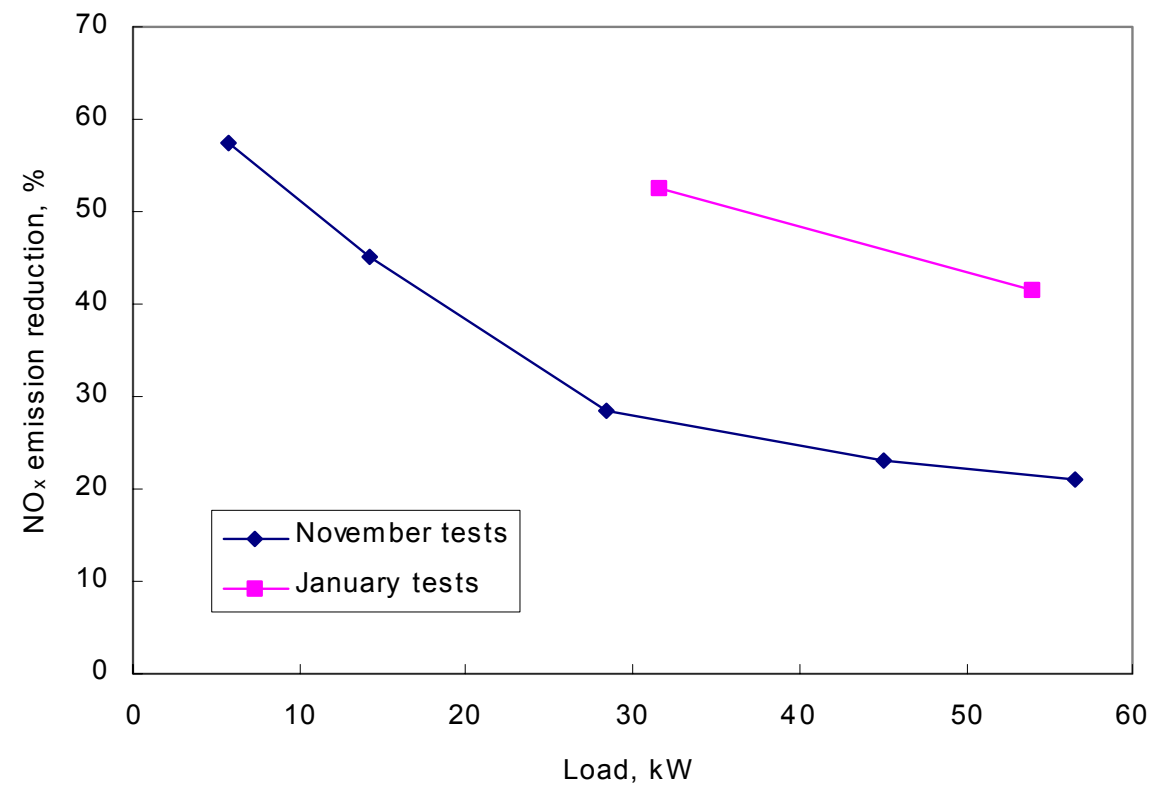

- Relative $\mathrm{CO}$ emissions for the two test fuels showed inconsistent behavior. For one series of tests, CO emissions with the WIF emulsion were lower than with JP-8 at engines loads of $50 \%$ or greater, but were higher at lower engine loads. ISO-cycle weighted average emissions for this test series were comparable for both fuels. For a second test series, $\mathrm{CO}$ emissions were substantially higher with the WIF emulsion than with JP-8 at all engine loads tested.

Stabilized methanol from the LPMEOH ${ }^{\mathrm{TM}}$ Demonstration Project was successfully used to produce the WIF emulsion which was used in this project. Although $\mathrm{NO}_{\mathrm{x}}$ emissions reduction with the WIF were impressive, severe problems with cold starting and operation at low ambient temperatures were experienced. A few approaches to solve these problems were tried during this abbreviated project, but without success. Until the cold start problem is solved, WIF use in Air Force applications was not recommended.

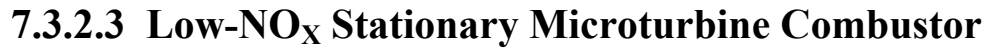

As originally proposed by ARCADIS Geraghty \& Miller, the objective of the subject project was to demonstrate cost-effective volatile organic compound (VOC) destruction by a small gas turbine operating in a distributed power generation application fired with stabilized methanol from the LPMEOH ${ }^{\mathrm{TM}}$ Demonstration Project. However, after an exhaustive search, no host site willing to participate in the project was identified. 
At this point, a decision was made to shift the environmental focus of the project. California, as well as the EPA, regulates $\mathrm{NO}_{\mathrm{x}}$ as an ozone precursor. As a consequence, California continues to pursue very aggressive $\mathrm{NO}_{\mathrm{x}}$ control strategies to facilitate bringing California ozone nonattainment regions into attainment. Moreover, such strategies will become more commonplace in the Midwestern and Northeastern states in response to EPA's decision to implement a $\mathrm{NO}_{\mathrm{x}}$ cap and trade program in both the Northeastern states as well as the Midwestern states that contribute to the ozone nonattainment status of regions of the Northeast via transported ozone.

Given these mandates, it was clear that any new distributed generation capacity will need to be low $\mathrm{NO}_{\mathrm{x}}$ emitting units. In response to this need, Alzeta Corporation, with support from the California Energy Commission, the DOE's National Energy Technology Laboratory, and a number of gas turbine manufacturers, has been developing an advanced low $\mathrm{NO}_{\mathrm{x}}$ surface stabilized combustor technology for stationary microturbines in distributed generation applications. The opportunity arose for the LPMEOH ${ }^{\mathrm{TM}}$ Demonstration Project to participate in this program and extend demonstration testing to stabilized methanol. Accordingly, a decision was made to redirect the project on VOC control to focus on completing a series of tests using stabilized methanol as a fuel for a low $\mathrm{NO}_{\mathrm{x}}$ microturbine combustor targeted for use in a distributed generation application. In testing performed with natural gas fuel, it was possible to achieve combustor $\mathrm{NO}_{\mathrm{x}}, \mathrm{CO}$, and UHC emissions approaching 2 ppm at 15 percent $\mathrm{O}_{2}$. Parallel testing with stabilized methanol was performed in these tests to evaluate whether comparable performance could be achieved.

As shown in Figure 7.3.2-4, $\mathrm{NO}_{\mathrm{x}}$ emissions with stabilized methanol from the LPMEOH ${ }^{\mathrm{TM}}$ Demonstration Project were comparable to and, for several conditions, lower than those with natural gas fuel. Results of the tests showed that combustor $\mathrm{NO}_{\mathrm{x}}$ emissions could be held below $6 \mathrm{ppm}$ at 15 percent $\mathrm{O}_{2}$ over the range of combustor firing rates corresponding to turbine idle to full load. Emissions as low as 1 ppm at 15 percent $\mathrm{O}_{2}$ were achieved at a number of test conditions, and were 3 ppm at 15 percent $\mathrm{O}_{2}$ or lower for all but the highest load tested. The low $\mathrm{NO}_{\mathrm{x}}$ emissions were achieved with $\mathrm{CO}$ emissions at 20 ppm (at 15 percent $\mathrm{O}_{2}$ ) or lower. $\mathrm{CO}$ emissions when stabilized methanol was used as fuel were also comparable to those with natural gas fuel. In fact, $\mathrm{CO}$ emissions were 4 ppm at 15 percent $\mathrm{O}_{2}$ or lower at all but low load (firing rate) and high load.

In summary, stabilized methanol from the LPMEOH ${ }^{\mathrm{TM}}$ Process would seem to represent an acceptable liquid fuel for advanced low emission microturbines using the Alzeta combustor technology, offering emissions performance at or slightly better than the levels achieved with natural gas fuel. 
Figure 7.3.2-4

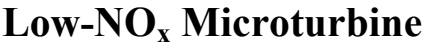

NO $_{\mathrm{x}}$ Emissions with Stabilized Methanol vs. Natural Gas

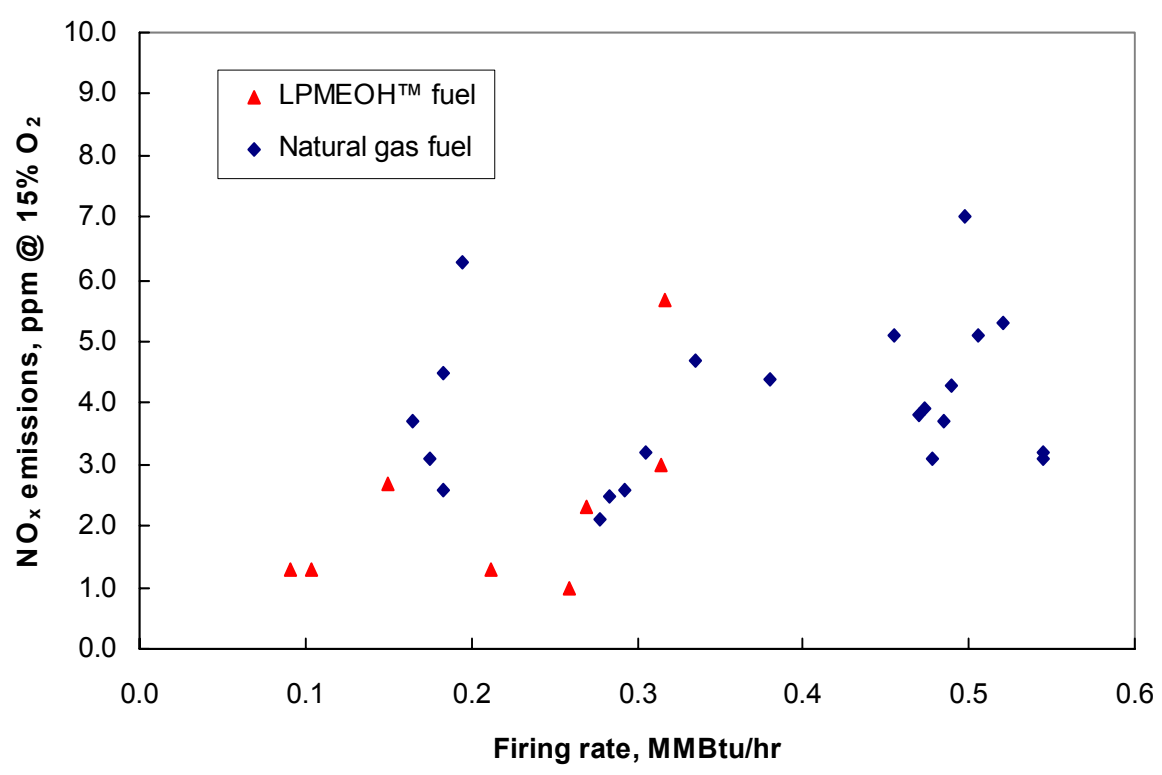

\subsubsection{University of Florida Fuel Cell}

Over the past few years, progress has continued in the development of fuel cells, which can be used in either transportation or power applications.

While pure gaseous $\mathrm{H}_{2}$ is the ideal fuel for fuel cell power systems, it is also relatively expensive, difficult to transport, and difficult to store for onboard transportation systems. Consequently, there has been, and is, considerable interest in utilizing liquid hydrocarbon fuels for transportation fuel cell applications. For a liquid fuel to be a feasible alternative to $\mathrm{H}_{2}$, it must be possible and practical to utilize a fuel processing system to transform the liquid fuel into a $\mathrm{H}_{2}$-rich gas. More specifically, the $\mathrm{H}_{2}$-rich gas must be compatible with long-term operation of the fuel cell system within which it would be utilized, with little or no degradation in performance. In earlier demonstrations with phosphoric acid fuel cells, chemical-grade methanol has been used successfully as the source of $\mathrm{H}_{2}$.

Clearly, the implication is that a suitable fuel-fuel processor combination must maintain the ability to provide almost complete conversion of the liquid fuel feedstock into an acceptable $\mathrm{H}_{2}$-rich gas over a long period of time and many cycles of operation. "Acceptable" $\mathrm{H}_{2}$-rich gas in this case means a maximum concentration of $\mathrm{H}_{2}$ and virtually zero concentration of contaminants (primarily unreacted components from the liquid fuel) which would degrade the life and/or performance of the fuel cell stack. To meet this acceptability requirement, the fuel processor must also not undergo any significant decrease in its ability to convert the liquid fuel in a continuing and consistent manner. A prime mechanism for the fuel processor to experience a 
significant decrease in conversion ability would be through a deactivation of the catalyst in a catalyst-driven processor such as the steam reformer.

Catalyst deactivation can occur for many reasons including excess temperature, rapid temperature transients, or the introduction of $\mathrm{O}_{2}$. However, with the introduction of a new liquid fuel such as stabilized methanol, it is obvious that deactivation can occur as a result of one or more contaminants (such as higher alcohols or the trace quantity of mineral oil from the $\mathrm{LPMEOH}^{\mathrm{TM}}$ Process) contained in the liquid fuel. Given the cost of distillation (\$0.02 to \$0.04 per gallon) of stabilized methanol to chemical-grade purity, a fuel cell test site of this potential source of $\mathrm{H}_{2}$ was sought. The University of Florida had facilities and equipment in the Fuel Cell Research and Training Laboratory to perform this type of research, as well as two operational methanol-fueled fuel cell engines. As a result, an agreement was reached for the University of Florida to undertake the evaluation of the stabilized methanol as a suitable fuel for steamreformed methanol/phosphoric acid fuel cell systems.

Since it was obviously important not to damage the operational fuel cell engines, the procedure was to fabricate small steam reformers using catalyst pellets of the type (copper oxide-zinc oxide) typically used for methanol steam reformation. The apparatus was designed so as to allow determination of areas of deactivation if they occurred as a result of the stabilized methanol fuel. A parallel reformer operating simultaneously with chemical-grade methanol was used as a control.

Initial results showed very rapid degradation of the catalyst exposed to the stabilized methanol. Analysis of the results indicated that a likely cause of the deactivation was the presence of high boiling point components in the stabilized methanol feedstock. A potential scenario for this deactivation was a probable coating of the catalyst with trace quantities of the mineral oil which is used as the liquid medium in the LPMEOH ${ }^{\mathrm{TM}}$ reactor. Subsequent tests and modifications to the reformer unit were performed as well as the utilization of a higher temperature reformer catalyst to avoid rapid catalyst degradation. Higher temperatures did, as expected, result in less effect due to the mineral oil, but it also resulted in a more unfavorable balance among $\mathrm{H}_{2}$, methane, $\mathrm{CO}_{2}$, and $\mathrm{CO}$ in the reformate.

The results to date indicate that for the relatively low-temperature steam reforming of stabilized methanol, the trace mineral oil in the stabilized methanol would most likely have to be removed in order for it to be a suitable fuel. On the other hand, the limited higher temperature results indicate that possibly for auto-thermal reforming and probably for partial oxidation reforming, the stabilized methanol would be acceptable as a fuel. Methanol from the LPMEOH ${ }^{\mathrm{TM}}$ Process that is purified to chemical-grade specifications should be suitable for use in this application.

\subsection{SUMMARY}

Methanol from the LPMEOH ${ }^{\mathrm{TM}}$ demonstration unit was tested in a variety of chemical and fuel applications. A test methodology was developed by Eastman to satisfy the criteria for use of methanol in their chemicals-from-coal complex. Over the entire 69-month operating program for the LPMEOH ${ }^{\mathrm{TM}}$ demonstration unit, over 103.9 million gallons of methanol was produced, 
and Eastman accepted all of the available methanol for use in the production of methyl acetate, and ultimately cellulose acetate and acetic acid.

Stabilized methanol from the project was also made available to seven test locations to study its feasibility as feedstock in transportation and power generation applications. Use in these applications is expected to enhance the flexibility of and revenue from IGCC electric power plants. In bus and FFV trials, stabilized methanol provided the same environmental benefits as chemical-grade methanol with no penalty on performance or fuel economy. Tests in a gas turbine and a diesel generator showed that levels of $\mathrm{NO}_{\mathrm{x}}$ in the exhaust air can be lowered when stabilized methanol or methanol emulsions are used instead of conventional oil fuels. As with the chemical-grade methanol, lubrication additives will likely be required when stabilized methanol is fed to a gas turbine. Testing of stabilized methanol as the source of $\mathrm{H}_{2}$ to a phosphoric acid fuel cell showed that conventional steam reforming catalysts are not compatible with the trace mineral oil present in the stabilized methanol; when auto-thermal reforming or partial oxidation reforming are used, the stabilized methanol would possibly be acceptable as a fuel. Methanol from the LPMEOH ${ }^{\mathrm{TM}}$ Process that is purified to chemical-grade specifications should be suitable for use in this application.

Product-use testing proved that coal-derived methanol, free of sulfur and other impurities, could be used one day as a replacement for petroleum in transportation, a peaking fuel in combustion turbines IGCC power plants, a $\mathrm{H}_{2}$ source for small fuel cells, or as a chemical feedstock. Implementation of the LPMEOH ${ }^{\mathrm{TM}}$ technology and the use of stabilized methanol in transportation and power systems will add significant flexibility and dispatch benefits to IGCC electric power plants, which traditionally have been viewed as strictly a baseload power generation technology. Now, central clean coal technology processing plants, making coproducts of electricity and methanol, can meet the needs of local communities for dispersed power and transportation fuel. Methanol coproduction studies show that methanol can be produced at economically competitive levels from an abundant, non-inflationary local fuel source, such as coal. The coproduced methanol may be an economical $\mathrm{H}_{2}$ source for small fuel cells, as a transportation fuel, and an environmentally advantaged fuel for dispersed electric power.

\subsection{SECTION 7 BIBLIOGRAPHY}

a. "Off-site Testing of Stabilized Methanol from the Liquid Phase Methanol (LPMEOH ${ }^{\mathrm{TM}}$ ) Process", Topical Report Prepared by Air Products Liquid Phase Conversion Co., L.P., DOE Cooperative Agreement No. DE-FC22-92PC90543, February 2002.

b. "Off-site Testing of Stabilized Methanol from the Liquid Phase Methanol (LPMEOH ${ }^{\mathrm{TM}}$ ) Process, Volume 1 - Transportation Systems", Topical Report Prepared by Air Products Liquid Phase Conversion Co., L.P., DOE Cooperative Agreement No. DE-FC22-92PC90543, February 2002.

c. "Fleet Trials for Fuel Grade Methanol Under USDOE Cooperative Agreement No. DE-FC2292PC90543", Prepared by Florida Institute of Technology for Air Products and Chemicals, Inc., August 1999).

d. "Final Report: Liquid-Phase Methanol (LPMEOH ${ }^{\mathrm{TM}}$ ) Demonstration Project - Light-Duty FlexibleFueled Vehicle Demonstration", Prepared by ARCADIS Geraghty \& Miller for Air Products and Chemicals, Inc., April 1999. 
e. "Exhaust Emissions Testing Performed for Air Products Corporation on Transit Buses Fueled by Air Products Brand Methanol Fuel", Prepared by West Virginia University for Air Products and Chemicals, Inc., August 1998.

f. "Off-site Testing of Stabilized Methanol from the Liquid Phase Methanol (LPMEOH ${ }^{\mathrm{TM}}$ ) Process, Volume 2 - Power Generation Systems", Topical Report Prepared by Air Products Liquid Phase Conversion Co., L.P., DOE Cooperative Agreement No. DE-FC22-92PC90543, February 2002.

g. "Emissions and Operational Aspects of Methanol as an Alternative Fuel in a Stationary Gas Turbine", Prepared by West Virginia University for Air Products and Chemicals, Inc., August 2000.

h. "Evaluation of a Water Emulsion Fuel in Air Force Aircraft Ground Support Equipment Diesel Generator Sets", Prepared by ARCADIS Geraghty \& Miller for Air Products and Chemicals, Inc., January 2000.

i. "Evaluation of Liquid-Phase Methanol (LPMEOH ${ }^{\mathrm{TM}}$ ) in a Low-NOx Stationary Gas Turbine Combustor", Prepared by Arthur D. Little, Inc. for Air Products and Chemicals, Inc., February 2001.

j. "An Investigation Into the Acceptability of Stabilized Methanol as a Fuel for Phosphoric-Acid Fuel Cell Power Systems", Prepared by the University of Florida for Air Products and Chemicals, Inc., February 2001. 


\subsection{LIQUID PHASE DIMETHYL ETHER (LPDMETM) DESIGN VERIFICATION TESTING (DVT)}

\subsection{INTRODUCTION}

The Statement of Work from the Cooperative Agreement defined a Secondary Objective for the LPMEOH ${ }^{\mathrm{TM}}$ Demonstration Project regarding the demonstration of Air Products' Liquid Phase Dimethyl Ether (LPDMETM) Process:

"Subject to Design Verification Testing (DVT), the Partnership proposes to enhance the Project by including the demonstration of the slurry reactor's capability to produce DME as a mixed co-product with methanol. The production of DME from synthesis gas is a natural extension of the LPMEOH ${ }^{\text {TM }}$ Process in that three reactions occur concurrently in a single liquid phase reactor, methanol synthesis, methanol dehydration and water-gas shift. This process enhancement can significantly improve the overall conversion of coal derived synthesis gas to a storable blend of methanol and DME...

"The enhanced (DME production) demonstration is complementary to ongoing studies being sponsored by DOE's Liquid Fuels Program... the enhancement will expand DOE's liquid fuels technology data base and will demonstrate the versatility of liquid phase synthesis.

"DVT is required to address issues such as catalyst activity and stability and to provide data for engineering design and demonstration decision making. The DVT plan will be coordinated with and utilize the resources of the DOE's Liquid Fuels Program as technology experts. The essential steps required for Project decision making regarding the methanol/DME co-product enhancement are:

- "DVT, including laboratory R\&D to develop engineering data and to verify the market through engine tests and through market and economic study. (Phase I, Task 5).

- "DVT, including Process Development Unit Verification Testing utilizing the LaPorte AFDU for proof of concept tests. (Phase III, Task 6).

- "Final decision making to implement the full-scale methanol/DME co-product demonstration. (Phase III, Task 2.2).

"At the conclusion of each of the DVT steps, a joint Partnership/DOE decision will be made regarding continuation of methanol/DME demonstration."

The LPDMETM Process uses a physical mixture of a commercial methanol catalyst and a commercial dehydration catalyst in a single slurry reactor to coproduce DME with methanol. This process provides high syngas conversion, efficient heat transfer, and directly converts a variety of feed gas compositions. There are three simultaneous reactions in this system, namely,

Methanol synthesis: $\quad \mathrm{CO}+2 \mathrm{H}_{2} \Leftrightarrow \mathrm{CH}_{3} \mathrm{OH}$

Water gas shift:

$\mathrm{CO}+\mathrm{H}_{2} \mathrm{O} \Leftrightarrow \mathrm{CO}_{2}+\mathrm{H}_{2}$

Methanol dehydration:

$2 \mathrm{CH}_{3} \mathrm{OH} \Leftrightarrow \mathrm{CH}_{3} \mathrm{OCH}_{3}+\mathrm{H}_{2} \mathrm{O}$

The methanol synthesis catalyst promotes Reactions 1 and 2, and the dehydration catalyst promotes Reaction 3. Both catalysts are micron-sized powders suspended in an inert hydrocarbon liquid, usually a mineral oil. The mineral oil acts as a temperature moderator and a 
heat removal medium, transferring the heat of reaction from the catalyst surface via the liquid slurry to boiling water in an internal tubular heat exchanger. As a result of this capability to remove heat and maintain a constant, highly uniform temperature through the entire length of the reactor, the slurry reactor can manage the high syngas conversion per pass that can be achieved in the LPDMETM Process.

These capabilities make the LPDMETM Process a potentially lower-cost conversion route to DME, especially when DME coproduction is added to a coal-based IGCC power plant. In this application, the overall reaction of syngas to DME is:

DME from CO-rich syngas: $\quad 3 \mathrm{CO}+3 \mathrm{H}_{2} \Leftrightarrow \mathrm{CH}_{3} \mathrm{OCH}_{3}+\mathrm{CO}_{2}$

This is the "once-through" CO-rich syngas concept for the LPDMETM Process utilizing a single slurry reactor. Conversion per pass, with CO-rich syngas, can be higher than for the LPMEOH ${ }^{\mathrm{TM}}$ Process. Methanol may also be produced, as a mixed coproduct with the DME, and can easily be separated and recovered. The separation of $\mathrm{DME}$ from $\mathrm{CO}_{2}$ will be necessary for certain market applications.

\subsection{DME MARKET STUDIES}

A topical report ${ }^{(a)}$ provided information on the status of the current market for DME and an outlook on potential market developments through 2006 . Over $50 \%$ of the demand for DME worldwide (currently between 100,000 and 150,000 metric tons per year) is for use as a projectile agent. DME is also being used as a methylating agent, and as a cleaning material for laboratory systems and some high precision, high value added applications, such as in electronics.

DME has potential applications as a chemical building block. In addition, since the physical properties of DME are similar to those of liquefied petroleum gas (LPG), it has been speculated that DME could be used in large scale power production, in home heating, in replacement of LPG for automobiles, and as a diesel fuel substitute or combustion supplement. In these applications, the specification for the purity of DME has been reported to be lower than the 99 $\mathrm{wt} \%$ requirement for current uses, which may provide an opportunity for savings in capital and operating costs for product distillation. If these markets are developed, production capacity for DME will need to increase by an order of magnitude over current levels of about 143,000 metric tons per year. Projects to meet this future market are under development, including two large natural gas-based opportunities serving markets in India and Japan and a coal-based opportunity in China.

\subsection{DVT ECOMONIC STUDIES}

The economics studies, for once-through coproduction (with an IGCC power plant, for example) on syngas rich in carbon oxides, show that the LPDMETM Process will have an economic advantage greater than the LPMEOH ${ }^{\mathrm{TM}}$ Process. A once-through LPDMETM reactor is able to convert greater than $50 \%$ of such a syngas, whereas a once-through LPMEOH ${ }^{\mathrm{TM}}$ reactor can convert only about $30 \%$. The economics, of course, depend upon the end-use (purity) of the 
DME and upon the gasification plant's coproduct mix (amount of power, methanol, DME, etc.). The same liquid phase reactor design options to increase syngas conversion, such as feed gas compression and/or CO-rich gas recycle; are also applicable for the LPDMETM Process. So, the

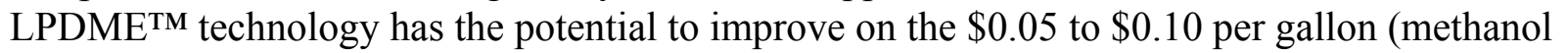
equivalent) advantage over the LPMEOH ${ }^{\mathrm{TM}}$ Process for the coproduction of DME to serve local markets.

As with the LPMEOH ${ }^{\mathrm{TM}}$ Process, gas-phase process technology must be considered as the economic competitor. The gas-phase DME process ${ }^{(\mathrm{b})}$ must run with $\mathrm{H}_{2}$-rich syngas. In the IGCC coproduction flow sheet (shown in Figure 7.1-1), gas-phase technology is at an economic disadvantage, since separate shift and $\mathrm{CO}_{2}$ removal are required. As is the case for methanol, inexpensive remote natural gas would therefore be the economic plant site choice for gas-phase technology. A comparison of coproduction of DME in an IGCC facility using the LPDMETM Process compared with DME imported from remote gas facilities, shows an advantage of 20$30 \%$ for locally produced DME relative to imported DME. The transportation cost to import DME is much higher than for methanol, and the LPDMETM coproduction advantage is even greater than that for the LPMEOH ${ }^{\mathrm{TM}}$ Process (vs. methanol import). Dehydration of imported methanol to make DME is not competitive. Therefore, for DME in local markets, coproduction using the LPDMETM Process should have a clear economic advantage over imported DME.

With $\mathrm{H}_{2}$-rich syngas, the LPDMETM Process loses its (once-through, high conversion per pass) economic advantage. The overall reaction, with $(>2: 1) \mathrm{H}_{2}$-rich syngas is:

DME from $\mathrm{H}_{2}$-rich syngas: $\quad 2 \mathrm{CO}+4 \mathrm{H}_{2} \Leftrightarrow \mathrm{CH}_{3} \mathrm{OCH}_{3}+\mathrm{H}_{2} \mathrm{O}$

Since water inhibits the methanol dehydration reaction, the slurry reactor must be staged, with water removal between stages. Staging could be by high ratio gas recycle, and/or with multiple reactors; but the once-through simplicity is lost. Therefore, it is unlikely that the LPDMETM Process would be developed for use in $\mathrm{H}_{2}$-rich syngas applications.

A cost estimate of commercial-scale LPDMETM plants has been performed. This work has helped quantify the targets for the laboratory research and development program (summarized below). From these studies, a commercially successful LPDMETM system was defined for a Texaco-type syngas $\left(35 \mathrm{vol} \% \mathrm{H}_{2}, 51 \mathrm{vol} \% \mathrm{CO}, 13 \mathrm{vol} \% \mathrm{CO}_{2}\right)$ available at $500 \mathrm{psig}$. At a reactor operating pressure of $950 \mathrm{psig}$ and a space velocity of 4,000 liters $/ \mathrm{hr}-\mathrm{kg}$ catalyst, the LPDMETM catalyst system must have a methanol equivalent productivity of $14 \mathrm{~mol} / \mathrm{kg}$ catalyst-hr after 6 months of operation, producing at least $75 \%$ (by heating value) DME and $25 \%$ methanol.

\subsection{DVT CATALYST STUDIES}

A research and development program was initiated by Air Products in 1994, with DOE's sponsorship under the Liquid Fuels Program, to develop a catalyst system for the LPDMETM Process that met the economic targets. This work resulted in an invention of aluminum phosphate as the dehydration catalyst. ${ }^{(\mathrm{c})}$ The aluminum phosphate provided an active and stable catalyst system. The system met the program targets under standard test process conditions of an initial methanol equivalent productivity of 28 gmole per $\mathrm{kg}$ catalyst - hr, a $\mathrm{CO}_{2}$-free, carbon 
selectivity of $80 \%$ to DME, and stability of both catalysts equivalent to that of the methanol catalyst in the absence of the aluminum phosphate. Because the aluminum phosphate catalyst was not commercially available, a scaleup project was initiated with a commercial catalyst vendor to prepare a total of 800 pounds of aluminum phosphate to provide for two reactor charges and some additional material for testing. ${ }^{(d)}$ Eight 160 pound pilot batches of uncalcined catalyst were prepared. The reproducibility of the aluminum to phosphate $(\mathrm{Al} / \mathrm{P})$ ratio, an important physical property of the catalyst, from batch to batch was poor. Of these eight lots, two were qualified as yielding acceptable performance under the proposed LaPorte AFDU trial life test conditions. One of the batches was tested under conditions which allow direct comparison to the lab benchmark aluminum phosphate. This batch gave faster deactivation of the methanol catalyst than did the lab material, showing it to be of inferior quality. Two additional batches were prepared at half-dilution to alleviate any mixing problems which might have caused the poor reproducibility in the original eight batches. However, the Al/P ratio of both of these batches was high. One was tested, and shown to give unacceptable performance. All scaleup work on aluminum phosphate was suspended in November of 1998, as a commercially-available catalyst discussed below was identified which performed equivalently.

The deactivation rates of the methanol and the dehydration catalyst were correlated to reaction conditions. The correlations suggested a dependence of the deactivation rates on reaction conditions. The trends suggested by the correlations were confirmed by additional experiments. Better stability was obtained using the aluminum phosphate catalyst system by operating at favorable process conditions. The same improvement was also demonstrated with the gamma alumina catalyst system. However, there was a 10-20\% trade-off in the productivity when shifting from the optimal conditions to the stable conditions for both the catalyst systems. As the gamma alumina was off-the-shelf commercial material, it was chosen for the LaPorte AFDU test. A methanol catalyst to gamma alumina ratio of $95: 5$ by weight was found to be optimum for catalyst stability.

\subsection{LPDMETM PROCESS DESIGN VERIFICATION TEST RUN}

A demonstration of the production of DME by the LPDMETM Process was successfully completed at the LaPorte AFDU in October-November of 1999. A photograph of the LaPorte AFDU is provided in Figure 8.5-1. The demonstration was conducted at a pilot scale of $10 \mathrm{sT} / \mathrm{D}$ to evaluate the commercial viability of the LPDMETM Process. Based upon the improvement in the life of the catalyst system at the laboratory scale, the participants in the LPMEOH ${ }^{\mathrm{TM}}$ Demonstration Project agreed that a trial at the LaPorte AFDU was the appropriate step to demonstrate these improvements. This run was co-funded by the LPMEOH ${ }^{\mathrm{TM}}$ Demonstration Project and the DOE's Liquid Fuels program. The objectives of the run were to demonstrate the operation of the LPDMETM Process with improved catalyst life at a 10 sT/D scale, using commercially produced catalysts, obtain information to correlate the scaleup of catalyst aging from autoclave to bubble column, conduct process variable testing, and perform experiments to better understand the reactor fluid dynamics. A topical report ${ }^{(\mathrm{e})}$ was written detailing the testing at the LaPorte AFDU. 
Figure 8.5-1

\section{LaPorte Alternative Fuels Development Unit (AFDU)}

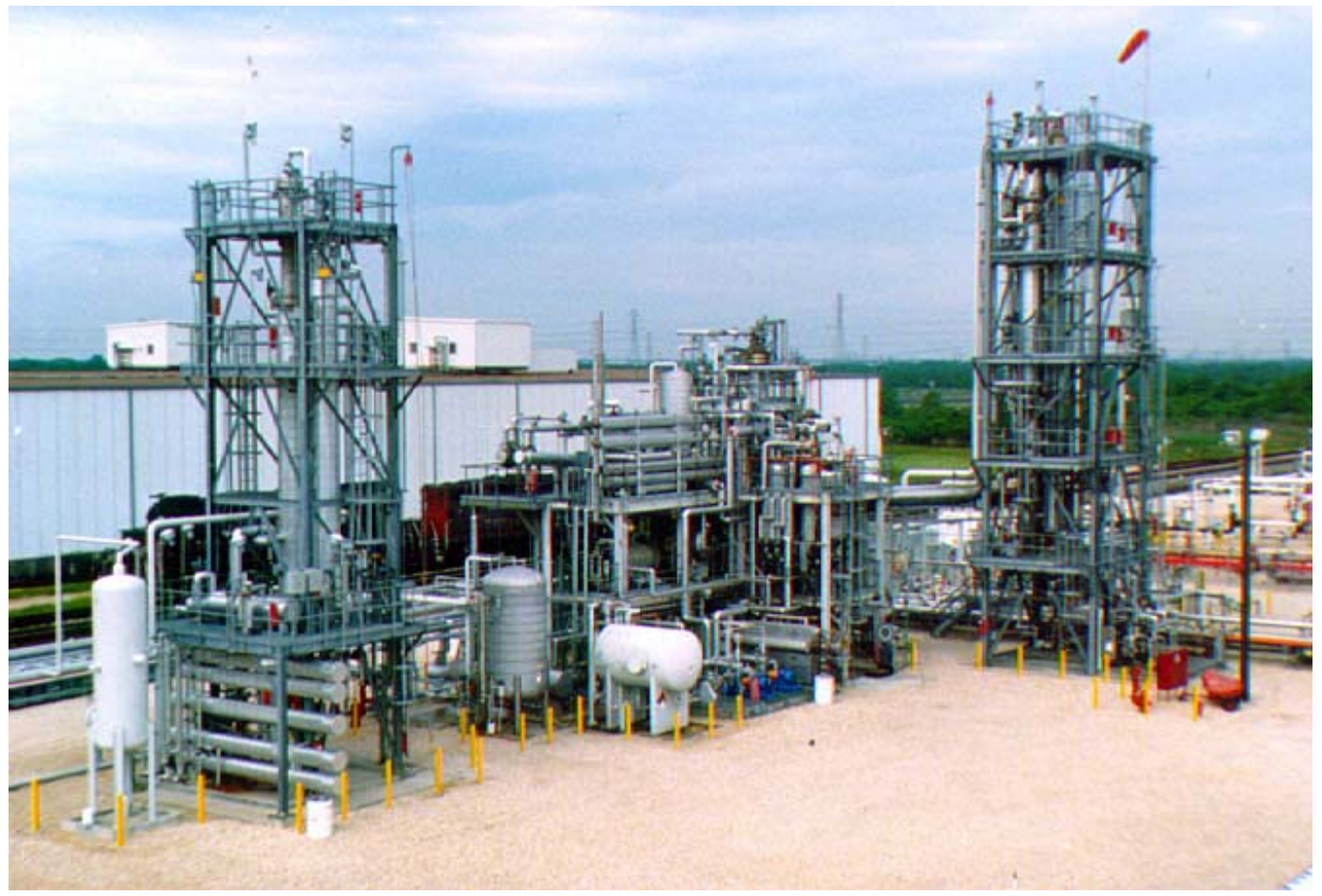

The methanol catalyst was successfully activated at the beginning of operations with dilute $\mathrm{H}_{2}$, resulting in an expected $\mathrm{H}_{2}$ uptake. The reduction was conducted with 3 vol $\% \mathrm{H}_{2}$ in $\mathrm{N}_{2}$ at 67 psig reactor pressure. The heat-up proceeded from 200 to $464^{\circ} \mathrm{F}$, as planned. The reduction appeared normal, and a cumulative uptake very close to the theoretical maximum value of 2.68 $\mathrm{SCF} \mathrm{H}_{2} / \mathrm{lb}$ oxide was obtained. The reduction was essentially complete at $390^{\circ} \mathrm{F}$ or 17 hours onstream. Nuclear Density Gauge measurements indicated an average gas holdup of 36.8 vol\%, with a catalyst concentration of $40.1 \mathrm{wt} \%$ at $392^{\circ} \mathrm{F}$ during the reduction. The catalysts appeared to have good initial activity, with DME and methanol productivity slightly exceeding expectations. This confirmed that the catalyst activation was proper. The initial DME production rate was $5.1 \mathrm{sT} / \mathrm{D}$ compared to an expectation of $4.8 \mathrm{sT} / \mathrm{D}$, while the methanol production rate was $3.6 \mathrm{sT} / \mathrm{D}$ vs $3.5 \mathrm{sT} / \mathrm{D}$ expected.

The LaPorte AFDU was operated for 25 days to compare catalyst aging in a pilot-scale slurry bubble column reactor with that in a laboratory autoclave. The proportion of two catalysts corresponded to a 95:5 methanol to dehydration catalyst ratio by weight. The methanol and dehydration catalyst activities, expressed as the ratio of the rate constant at any point in time to the rate constant for a freshly reduced catalyst (as determined in the laboratory autoclave), are plotted in Figure 8.5-2. These normalized rate constants were estimated based on a reaction model developed from laboratory data. After the expected initial aging, the catalysts appeared to be stabilizing, but there was significant scatter in the data. Gas chromatographic as well as sampling problems were discovered with methanol analysis that required use of liquid balance 
Figure 8.5-2

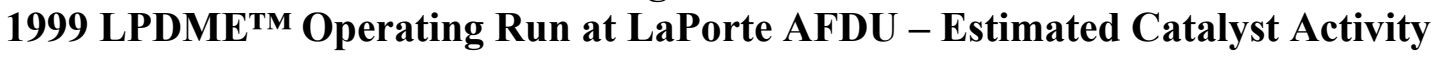

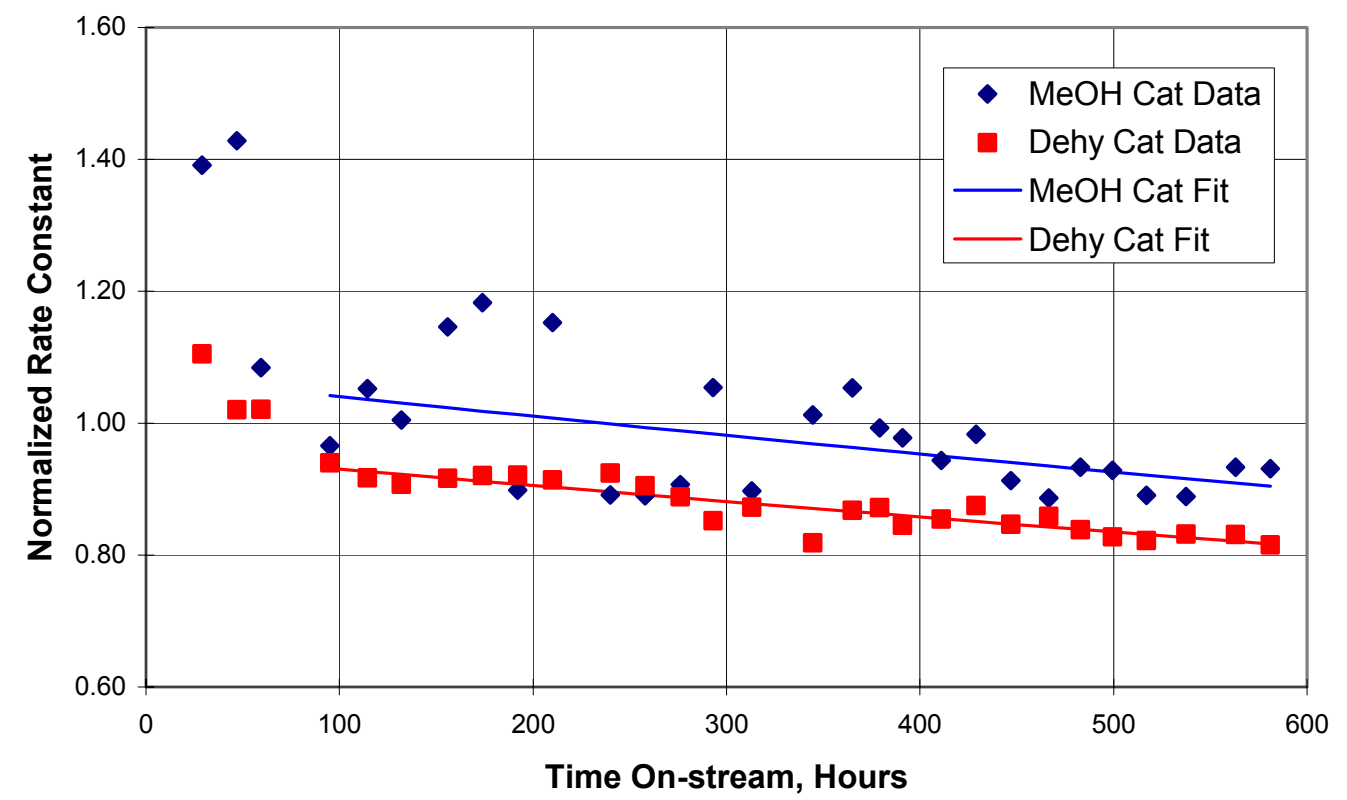

for calculations, contributing to the scatter. The problems were corrected in two days. The initial deactivation rate appeared high: $0.08 \%$ per hour ( $2 \%$ per day) for methanol catalyst with a $0.05 \%$ per hour standard error and $0.03 \%$ per hour $(0.6 \%$ per day $)$ for dehydration catalyst with a $0.009 \%$ per hour standard error. It was decided to extend the aging test to get a better estimate on catalyst deactivation rate, which was the main objective.

The LaPorte AFDU data appeared to follow the autoclave trends, with somewhat higher conversions than the autoclave throughout the test period. The methanol productivity level remained relatively constant, while the DME productivity showed a slight decline. The DME and methanol production rates through the run are shown in Figure 8.5-3. The DME production rate declined from $5.1 \mathrm{sT} / \mathrm{D}$ to $4.1 \mathrm{sT} / \mathrm{D}$ in 25 days onstream, while methanol production showed a scatter within the 3.1 to $3.8 \mathrm{sT} / \mathrm{D}$ range through the run. The scatter in data decreased significantly after the gas chromatograph and sampling problems were resolved (350 hours onstream). The performance also met the productivity and selectivity targets. The initial methanol equivalent productivity exceeded the target of 28 gmole/hr-kg catalyst, and the DME selectivity was at the target of $65 \%$ on a carbon basis. The reactor operated in a hydrodynamically stable manner, with uniform temperature profile and gas holdups. Differential pressure measurements indicated about $42 \mathrm{vol} \%$ gas holdup and $36 \mathrm{wt} \%$ catalyst concentration. Gas-, liquid-, and solid-phase mixing was studied using radioactive tracer injections. Washington University in St. Louis analyzed the tracer data as part of a DOE program on hydrodynamics of slurry bubble column reactors. 
Figure 8.5-3

1999 LPDMETM Operating Run at LaPorte AFDU - Production Results

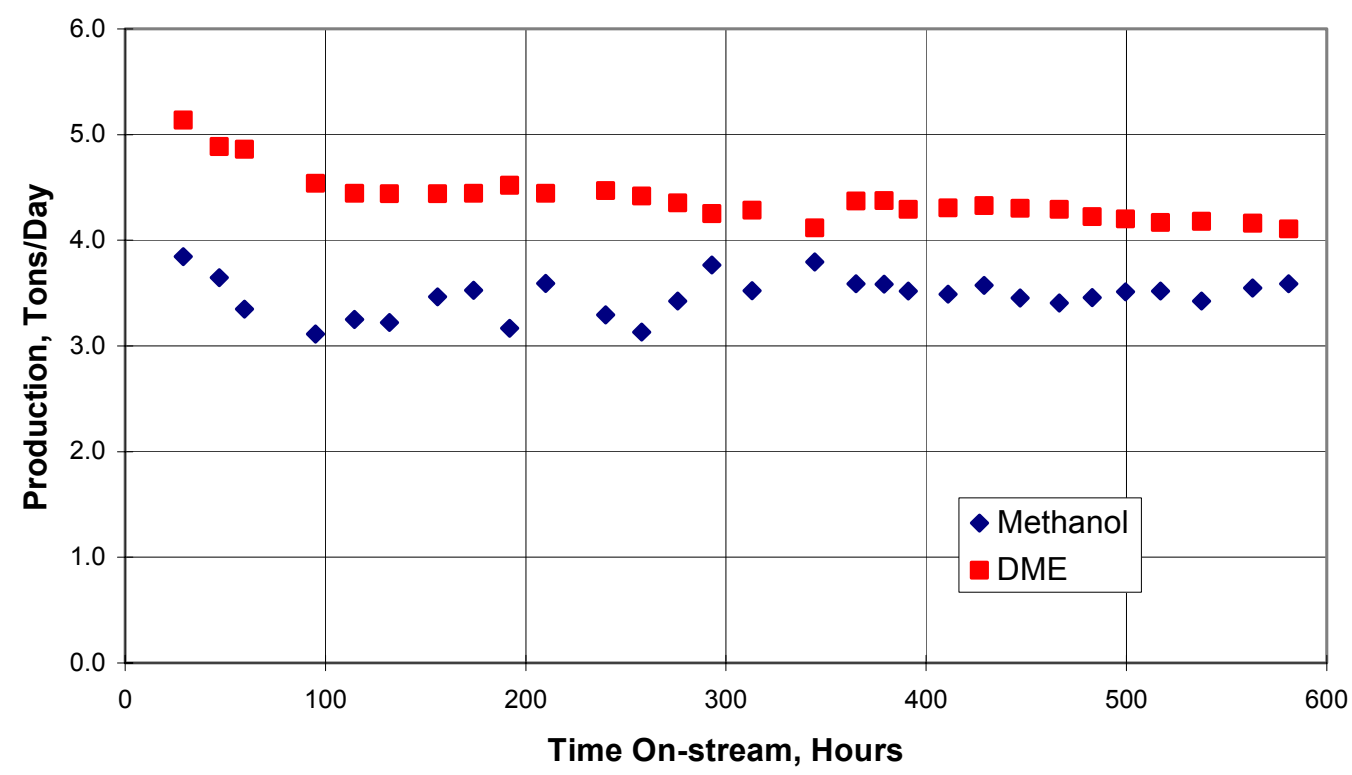

The equipment for this test was operated for the first time following a 4-year hiatus; the operations were smooth. The initial startup was very quick, with the baseline condition reached in 12 hours after the introduction of syngas. A re-start after a syngas outage took only 4 hours. The speed of the startup and re-start demonstrates the ease and flexibility of the slurry technology in response to changes.

The major accomplishments of this run are summarized below:

- Commercial viability of the LPDMETM Process was successfully evaluated on a $10 \mathrm{sT} / \mathrm{D}$ scale, using commercially produced catalysts. The LaPorte AFDU was operated for 25 days to compare catalyst aging in a pilot scale slurry bubble column with that in a laboratory autoclave. The catalyst life study was extended in favor of a planned process variable study to obtain additional data on catalyst aging. Hydrodynamic information was obtained at the baseline conditions by conducting a detailed survey of the reactor with radioactive tracer injections.

- The deactivation rate for both the catalysts was calculated to be $0.7 \%$ per day. This result was lower than the $1.2 \%$ per day which had been calculated for both the methanol synthesis and dehydration catalysts during experiments in the autoclave. The rate of deactivation was slightly higher than $0.5 \%$ per day rate which was achieved for the LPMEOH ${ }^{\text {TM }}$ Process after 3 weeks of operation at the LaPorte AFDU in 1988/89. The methanol productivity remained relatively constant throughout the test period, while the DME productivity showed a slight decline. These trends were consistent with observations from the laboratory. The standard error for the methanol catalyst deactivation rate was high $(0.25 \%$ per day $)$ due to initial scatter in the data. The scatter decreased significantly after problems in the sampling and 
analytical system were discovered and resolved at 350 hours on stream. The dehydration catalyst activity data have better statistics, with a standard error of $0.06 \%$ per day.

- The 1999 design verification test of the LPDMETM Process at the LaPorte AFDU represented a significant step forward in the development of the technology. The $0.7 \%$ per day rate of catalyst deactivation which was achieved during this campaign is a large improvement over the $4 \%$ per day rate of deactivation which was calculated from autoclave studies prior to the initial test of the LPDMETM Process at the LaPorte AFDU in 1991.

\subsection{DME DVT CONCLUSIONS}

During a Project Review Meeting on 12-13 January 2000, the preliminary results from the

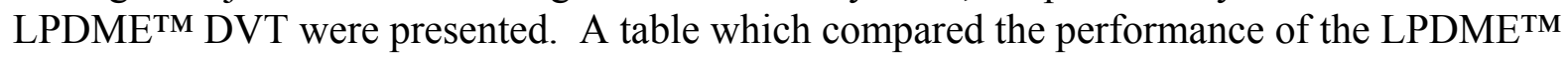
catalyst system during the DVT with results from the recent work in the laboratory autoclave and the economic targets for the LPDME ${ }^{\mathrm{TM}}$ Process was presented (Table 8.6-1). The results from the laboratory work had indicated that the targets for catalyst productivity and life can be met at lower selectivity to DME. The results from the DVT were applied to a cost estimate for a commercial-scale LPDMETM plant (Figure 8.6-1). The case that was considered was the retrofit of an existing Texaco gasifier in China which is currently used in the production of ammonia. The results of this initial work were that, for this syngas $\left(35 \mathrm{vol} \% \mathrm{H}_{2}, 51 \mathrm{vol} \% \mathrm{CO}, 13 \mathrm{vol} \%\right.$ $\mathrm{CO}_{2}$ ) available at 500 psig, the DME costs are competitive with LPG in China ( $\$ 7$ to $\$ 8$ per MMBtu). The cost of syngas assumes constant utilization for each plant size, and economies of scale are indicated by changes in the conversion and separation costs. The target DME cost can likely be achieved at larger plant sizes by extrapolating the costs to the $1,100 \mathrm{sT} / \mathrm{D}$ production rates. The sensitivity of the cost of production of DME to the life of the LPDMETM catalyst system was shown for the results from LaPorte $(0.7 \%$ per day deactivation), as well as the impact of changes to the value for catalyst life on the process economics.

As stated in the 30 July 1997 letter which transmitted Air Products' recommendation to proceed with LPDMETM DVT, the basis for commercialization of the technology must come from:

1) the results from testing of the LPDMETM catalyst system at the LaPorte AFDU; and

2) the reactor performance (methanol catalyst activity and life, hydrodynamics, and heat transfer) from the $\mathrm{LPMEOH}^{\mathrm{TM}}$ demonstration unit.

After discussing the results from the LPDMETM DVT activities and the ongoing performance results from Kingsport, the meeting participants agreed that the available resources should be directed toward improving the catalyst performance for the LPMEOH ${ }^{\mathrm{TM}}$ Process during the remaining time within the operating program. The results of this economic analysis were forwarded to the DOE's Liquid Fuels Program in order to provide direction to the ongoing catalyst development efforts. 


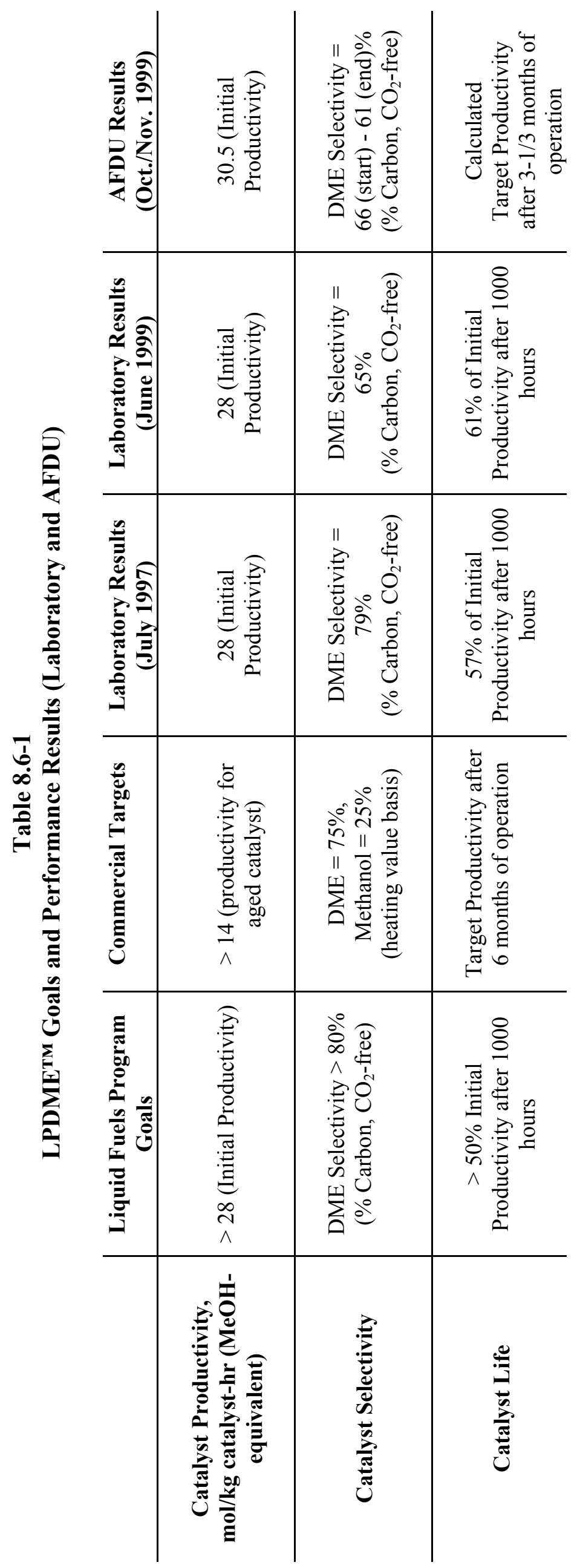


Figure 8.6-1

LPDMETM Process Economics

TEXACO-TYPE SYNTHESIS GAS

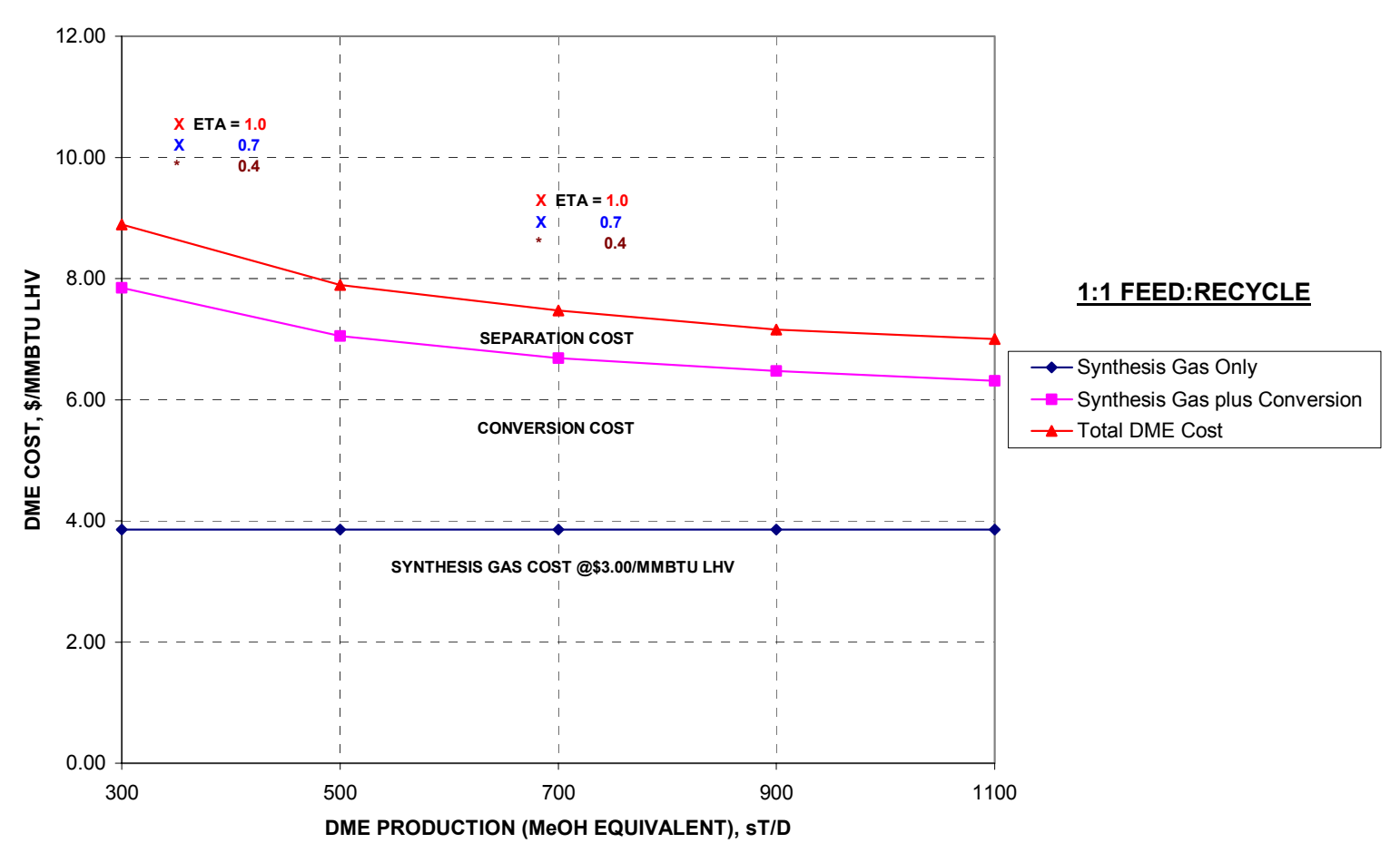

\subsection{SECTION 8 BIBLIOGRAPHY}

a. "Market Outlook for Dimethyl Ether (DME)", Topical Report Prepared by Air Products Liquid Phase Conversion Co., L.P., DOE Cooperative Agreement No. DE-FC22-92PC90543, April 2002.

b. Haldor Topsoe AS, "Preparation of Fuel Grade Dimethyl Ether", International Publication Number WO9623755, World International Property Organization, 08 August 1996.

c. "Catalyst Activity Maintenance for the Liquid Phase Synthesis Gas-to-Dimethyl Ether Process, Part I: An Investigation of the Cause and Mechanism of Catalyst Deactivation", Topical Report Prepared by Air Products and Chemicals, DOE Cooperative Agreement No. DE-FC22-95PC93052, February 2000.

d. X. D. Peng, G. E. Parris, B. A. Toseland, and P. J. Battavio (Air Products and Chemicals, Inc.), "Use of Aluminum Phosphate as the Dehydration Catalyst in Single Step Dimethyl Ether Process", U.S. Patent No. 5,753,716, 19 May 1998.

e. "Liquid Phase Dimethyl Ether Demonstration in the LaPorte Alternative Fuels Development Unit", Topical Report Prepared by Air Products Liquid Phase Conversion Co., L.P., DOE Cooperative Agreement No. DE-FC22-92PC90543, January 2001. 


\subsection{ECONOMICS}

\subsection{INTRODUCTION}

A topical report on the economics of coproduction of methanol in an IGCC power plant was published as part of the LPMEOH ${ }^{\mathrm{TM}}$ Demonstration Project. ${ }^{(\mathrm{a})}$ This study was used as the basis for the capital and operating costs for the LPMEOH ${ }^{\mathrm{TM}}$ Process that are published within this report. The assumptions for key economic parameters are provided:

Capital costs for equipment, valves, and instrumentation are calculated using costs from the 260 sT/D LPMEOH ${ }^{\mathrm{TM}}$ demonstration unit as the basis (calendar year 1995). Different multipliers are used to scale the costs. For example, costs associated with methanol distillation to the desired grade of methanol might scale directly with methanol production rates, while some of the costs within the $\mathrm{LPMEOH}^{\mathrm{TM}}$ reactor system may depend upon the volumetric gas flowrate.

Construction costs assume the same schedule (15 months) and site preparation as the LPMEOHTM Demonstration Unit.

Freight and Miscellaneous refer to project execution costs, again based upon the costs from the LPMEOH $^{\text {TM }}$ Demonstration Project.

Air Products Process Studies refer to initial process evaluations which need to be performed in order to optimize the process cycle selected for a particular IGCC application. For example, optimization of feed and recycle compression and an evaluation of the need for water injection are performed during these studies.

Air Products Technical Package refers to the final process design package for a site-specific application. This includes all heat and material balances, detailed equipment specifications for the $\mathrm{LPMEOH}^{\mathrm{TM}}$ reactor, and process specifications for other equipment items.

Project Engineering refers to the overall management of the engineering, design, and construction work, based upon the costs from the LPMEOH ${ }^{\mathrm{TM}}$ Demonstration Project.

Design Engineering refers to the detailed design work (civil, mechanical, instrument and electrical), again based upon the costs from the $\mathrm{LPMEOH}^{\mathrm{TM}}$ Demonstration Project.

Field Engineering refers to all field engineering services, including construction management at the site. These costs are again based upon the costs from the LPMEOH ${ }^{\mathrm{TM}}$ Demonstration Project.

Travel and Living costs are included as a line item.

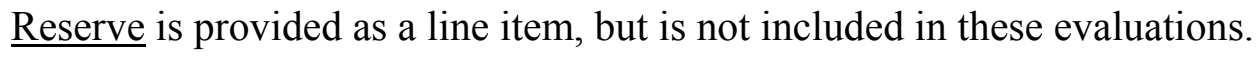

License Fee is provided as a line item, but is not included in these evaluations. 
Once these items are computed, an allowance for Owner's Cost $(25 \%$ of the equipment cost for the evaluated system) is provided. This is a nominal cost of project execution which includes costs for:
a) Initial charge of catalyst
b) Initial supply of chemicals and lubricants
c) Any applicable taxes and insurance
d) Cost of land
e) Legal and other overhead costs

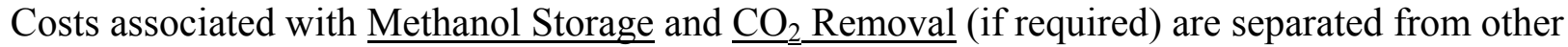
equipment items, since the costs are site-specific and are highlighted in this manner to provide a potential customer with the opportunity to optimize the required storage.

The sum of these items is the Capital Cost for the LPMEOH ${ }^{\mathrm{TM}}$ Facility. The costs are also tabulated by process area (excluding Owner's Cost, Methanol Storage Cost, and $\mathrm{CO}_{2}$ Removal Costs) to provide information on the relative costs of the different process steps, including all valves, instruments, and associated construction costs.

A calculation of the Plot Area Required, based upon the layout from the LPMEOH demonstration unit, is also given.

Operating costs are evaluated as annual costs (\$/Year) and as the cost per gallon of methanol. The annual cost is computed from the cost per unit time and the annual capacity factor. The final cost of methanol is computed as follows:

$$
\$ / \text { Gallon Methanol }=\frac{\text { Annual Costs }(\$ / \text { Year })}{365 * \text { LF } * 303 * X}
$$

where:

$$
\begin{aligned}
\mathrm{LF} & =\text { Annual Capacity Factor } \\
\mathrm{X} & =\text { Methanol Production Rate, short Tons per Day }
\end{aligned}
$$

The conversion factor 303 gallons per short ton of methanol is used in this equation.

The following is a summary of the components of the Operating Costs:

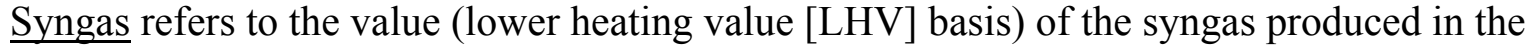
IGCC facility. When a specific application is defined, the cost (\$ per MMBtu) can be specified.

Unreacted Gas refers to the value (LHV basis) of the syngas returned from the LPMEOH ${ }^{\mathrm{TM}}$ plant to the IGCC facility. When a specific application is defined, the cost (\$ per MMBtu) can be specified. 
Power used by the LPMEOH ${ }^{\mathrm{TM}}$ Process is evaluated at $\$ 0.04 / \mathrm{kWh}$, which is assumed to be the electricity costs from the adjacent IGCC facility. Categories of power consumers (compressors, pumps, etc.) are tabulated separately.

$\underline{\text { Steam is a credit from the LPMEOH }}$ TM Plant; a typical value of $\$ 4.00 / 1,000$ pounds of steam production (including the cost for boiler feed water and the credit for condensate return) is used for the 200 psig steam produced by the LPMEOH ${ }^{\mathrm{TM}}$ Reactor.

Cooling Water is evaluated at a $20^{\circ} \mathrm{F}$ temperature rise across all cooling water heat exchangers. A cost of $\$ 0.12 / 1,000$ gallons of cooling water is used in this study.

Other Miscellaneous Utilities (such as instrument air and $\mathrm{N}_{2}$ ) are calculated based upon the costs from the LPMEOH ${ }^{\mathrm{TM}}$ Demonstration Project.

Catalyst, Chemicals and Lubes refers to the estimated costs for the methanol synthesis catalyst, process mineral oil, and other lubricants. These values are based upon the costs from the LPMEOH $^{\mathrm{TM}}$ Demonstration Project.

Zinc Oxide is used as the absorbent for the $\mathrm{H}_{2} \mathrm{~S}$ which is present with the fresh feed syngas or is produced by the COS (carbonyl sulfide) Hydrolysis catalyst within the LPMEOH ${ }^{\mathrm{TM}}$ Process. Each of these consumables is evaluated based upon present costs for each material.

Operating Labor is calculated from the original budgetary forecast for the LPMEOH Demonstration Project (which was met during the operating program).

Maintenance costs are evaluated based upon an annual budget of $2 \%$ of the total capital cost for the evaluated LPMEOH ${ }^{\mathrm{TM}}$ Facility.

Property Taxes and Insurance are estimated at an annual budget of $1.5 \%$ of the total capital cost for the evaluated LPMEOH ${ }^{\mathrm{TM}}$ Facility.

Overhead is computed at a nominal rate of $15 \%$ of the operating costs (not including the costs for syngas or the credit for the unreacted gas).

Recovery of Capital Cost, Depreciation, and ROI (Return on Investment) are computed based upon a 15 year depreciation and a ROI of about $14 \%$, which results in a total charge of $20 \%$ of the investment per year.

\subsection{ESTIMATED PROCESS CAPITAL COSTS}

Table 9.2-1 provides a summary of the estimated capital costs for a $500 \mathrm{sT} / \mathrm{D}$ LPMEOH ${ }^{\mathrm{TM}}$ plant that coproduces a fuel-grade methanol (a minimum of $97 \mathrm{wt} \%$ methanol, a maximum of $1 \mathrm{wt} \%$ water, $1.5 \mathrm{wt} \%$ higher alcohols, and $0.5 \mathrm{wt} \%$ mineral oil from the LPMEOH ${ }^{\mathrm{TM}}$ Process) from $\mathrm{CO}$-rich syngas $\left(\mathrm{H}_{2}: \mathrm{CO}=0.68\right)$ in a coal-based IGCC power plant. These costs were originally 
Table 9.2-1

Estimated Facility Investment Summary for Once-Through 500 sT/D LPMEOH ${ }^{\text {TM Plant }}$

INVESTMENT BREAKDOWN

$\underline{\text { MM-\$ }}$

COMPRESSION

$\$ 0.00$

LPMEOH $^{\text {TM }}$ EQUIPMENT

$\$ 5.09$

VALVES \& INSTRUMENTS

$\$ 3.35$

CONSTRUCTION

$\$ 10.40$

FREIGHT \& MISCELLANEOUS

$\$ 0.37$

AIR PRODUCTS PROCESS STUDIES

$\$ 0.22$

AIR PRODUCTS TECHNICAL PACKAGE

$\$ 0.97$

PROJECT ENGINEERING

$\$ 1.63$

DESIGN ENGINEERING

$\$ 3.88$

FIELD ENGINEERING

$\$ 1.15$

TRAVEL \& LIVING

$\$ 0.29$

RESERVE

LICENSE FEE

$\$ 0.00$

not incl

Sub-total Turnkey Plant

$\$ 27.35$

OWNER'S COST

METHANOL STORAGE

CO2 REMOVAL

$25 \%$ of Equipment

30 days

5.0 MM Gallons

$\$ 1.27$

$\$ 2.46$

$\$ 0.00$

TOTAL CAPITAL

$\$ 31.08$

PLOT AREA REQUIRED, ACRES

LPMEOH $^{\mathrm{TM}}=0.11$

Storage $=5.13$

TOTAL

5.24

INVESTMENT BY AREA

\begin{tabular}{ll} 
AREA & INVESTMENT \\
\cline { 3 - 3 } A & REACTOR LOOP \& CATALYST REDUCTION \\
B & FEED COMPRESSION \\
C & RECYCLE COMPRESSION \\
D & FRONT-END GAS CLEANUP \\
E & COMMON EQUIPMENT \\
$\mathrm{F}$ & SATURATOR \\
$\mathrm{G}$ & DISTILLATION \\
& RESERVE \\
& AIR PRODUCTS PROCESS STUDIES \\
& AIR PRODUCTS TECHNICAL PACKAGE \\
& LICENSE FEE
\end{tabular}

DESIGN BASIS

MM-\$

$500 \mathrm{sT} / \mathrm{D}$

0 BHP

$\$ 18.60$

0 BHP

$\$ 0.00$

$\$ 0.00$

14552 LB-MOL/HR $\$ 3.00$

$500 \mathrm{sT} / \mathrm{D}$

$\$ 0.00$

$500 \mathrm{sT} / \mathrm{D}$

$\$ 2.71$

$0.0 \%$

$\$ 0.00$

$\$ 0.22$

$\$ 0.97$

not incl

Sub-total Turnkey Plant

$\$ 27.35$

Notes: 1) Syngas $\left(\mathrm{H}_{2}: \mathrm{CO}=0.68\right)$ containing $5 \mathrm{ppmv} \mathrm{COS}$ is available at $1,000 \mathrm{psig}$.

2) Equipment from $\mathrm{LPMEOH}^{\mathrm{TM}}$ demonstration unit, escalated to $2002 \$$, was used as basis.

published in the topical report on economics (referenced above). The capital cost of the LPMEOH $^{\mathrm{TM}}$ demonstration unit, excluding the equipment items that were not used during the demonstration period (as described in Section 3.1), was used as a basis. 


\subsection{PROJECTED OPERATING AND MAINTANANCE COSTS}

Table 9.3-1 provides a summary of the projected operating and maintenance costs for a $500 \mathrm{sT} / \mathrm{D}$ $\mathrm{LPMEOH}^{\mathrm{TM}}$ plant in the IGCC plant location. The operating and maintenance costs for the distillation system can be separated from the other conversion costs to yield a methanol conversion cost (in this case, a methanol conversion cost of $\$ 0.155$ per gallon, including capital recovery, was calculated); this terminology will be used in developing the impact of changes in operating parameters on costs in Section 9.5.

Table 9.3-1

Projected Operating and Maintenance Costs for Once-Through 500 sT/D LPMEOH'M Plant

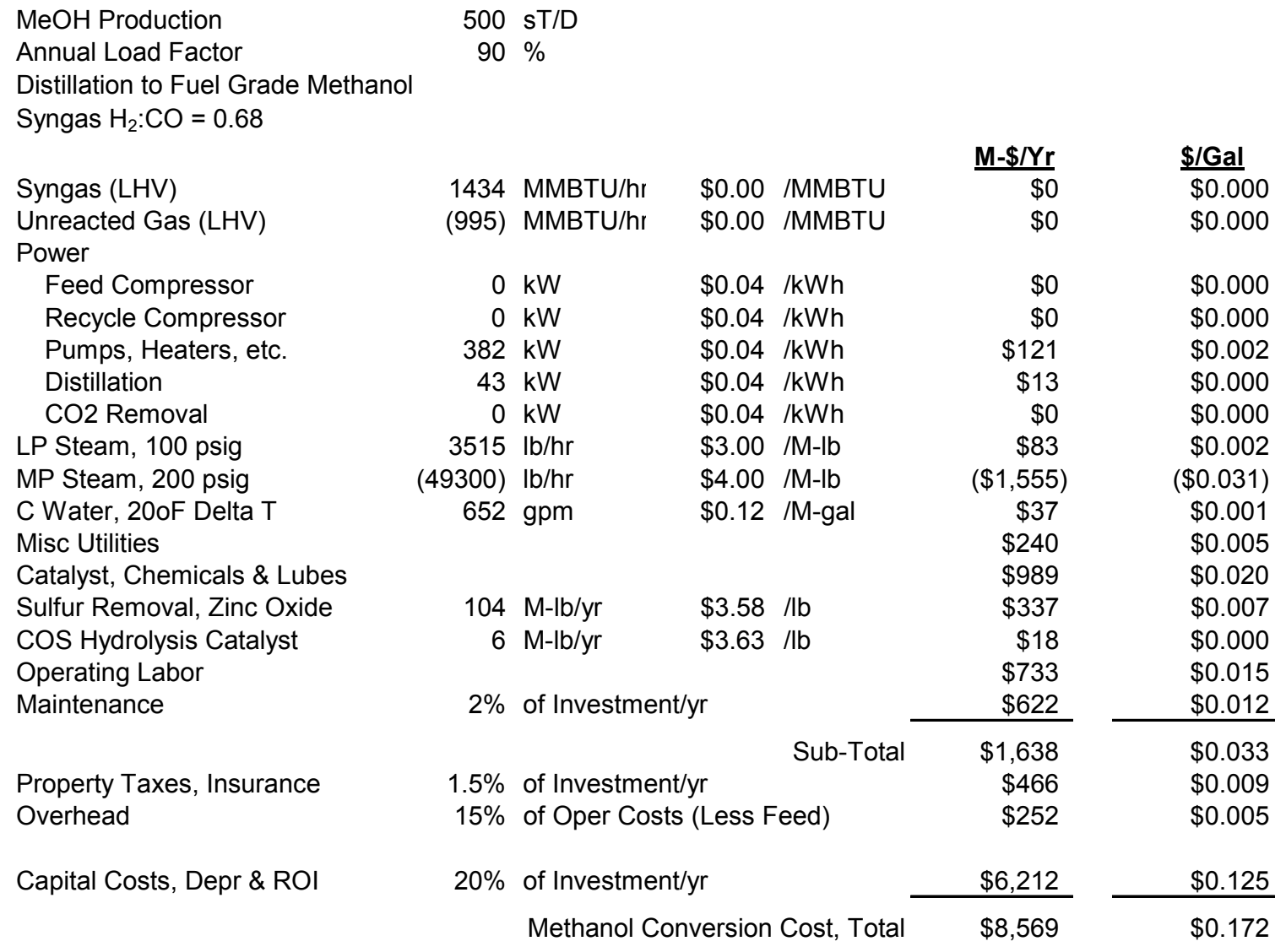

Notes: 1) Syngas $\left(\mathrm{H}_{2}: \mathrm{CO}=0.68\right)$ containing 5 ppmv $\mathrm{COS}$ is available at $1,000 \mathrm{psig}$.

2) Costs from $\mathrm{LPMEOH}^{\mathrm{TM}}$ demonstration unit, escalated to $2002 \$$, were used as basis. 


\subsection{SUMMARY OF PERFORMANCE AND ECONOMICS}

The capital cost summary for a 500 sT/D LPMEOHTM plant (Table 9.2-1) was developed based upon the design of and operating results from the LPMEOH ${ }^{\mathrm{TM}}$ demonstration unit. The scaleup of the size of the LPMEOH ${ }^{\mathrm{TM}}$ reactor (7.5' internal diameter, $260 \mathrm{sT} / \mathrm{D}$ design, greater than 300 sT/D demonstrated performance) can be managed; a topical report was issued on the construction of the reactor at the LPMEOH ${ }^{\mathrm{TM}}$ demonstration unit and the lessons learned that can be applied to the fabrication of larger diameter vessels. ${ }^{(b)}$

The operating cost summary (Table 9.3-1) was developed using the results from the 69-month operating program at the LPMEOH ${ }^{\mathrm{TM}}$ demonstration unit as the basis. Given the excellent onstream performance (availability of 97.5\%), a highly reliable system can be designed for future plants. In particular, the elimination of the slurry return pumps within the LPMEOH ${ }^{\mathrm{TM}}$ Process (refer to Section 3.1-1) was a key factor in achieving high on-stream time and lower maintenance costs. The basis for catalyst consumption is a catalyst deactivation rate of $0.4 \%$ per day, which was readily achieved during Kingsport Catalyst Campaign 4 (refer to Section 5.1.4). All other parameters (such as steam production from the LPMEOH ${ }^{\mathrm{TM}}$ reactor and steam consumption for distillation) were demonstrated during the operating phase of the $\mathrm{LPMEOH}^{\mathrm{TM}}$ Demonstration Project.

\subsection{EFFECT OF VARIABLES ON ECONOMICS}

Cases were developed to illustrate the impact of key operating variables on the methanol conversion cost (as defined in Section 9.3). The space velocity in the LPMEOH ${ }^{\mathrm{TM}}$ reactor was selected based upon an analysis contained in the topical report on the economics of coproduction of methanol with electric power. To illustrate the sensitivity, two syngas supply pressures (500 psig and 1,000 psig) were used.

\subsubsection{Plant Size}

Figure 9.5-1 shows the impact of methanol plant size on the methanol conversion cost for coalderived syngas available at 1,000 psig. The once-through process yields the lowest conversion cost; the case at 500 sT/D was used as the basis for the capital and operating costs that were provided in Sections 9.2 and 9.3. 
Figure 9.5-1

Effect of Methanol Plant Size on Methanol Conversion Cost

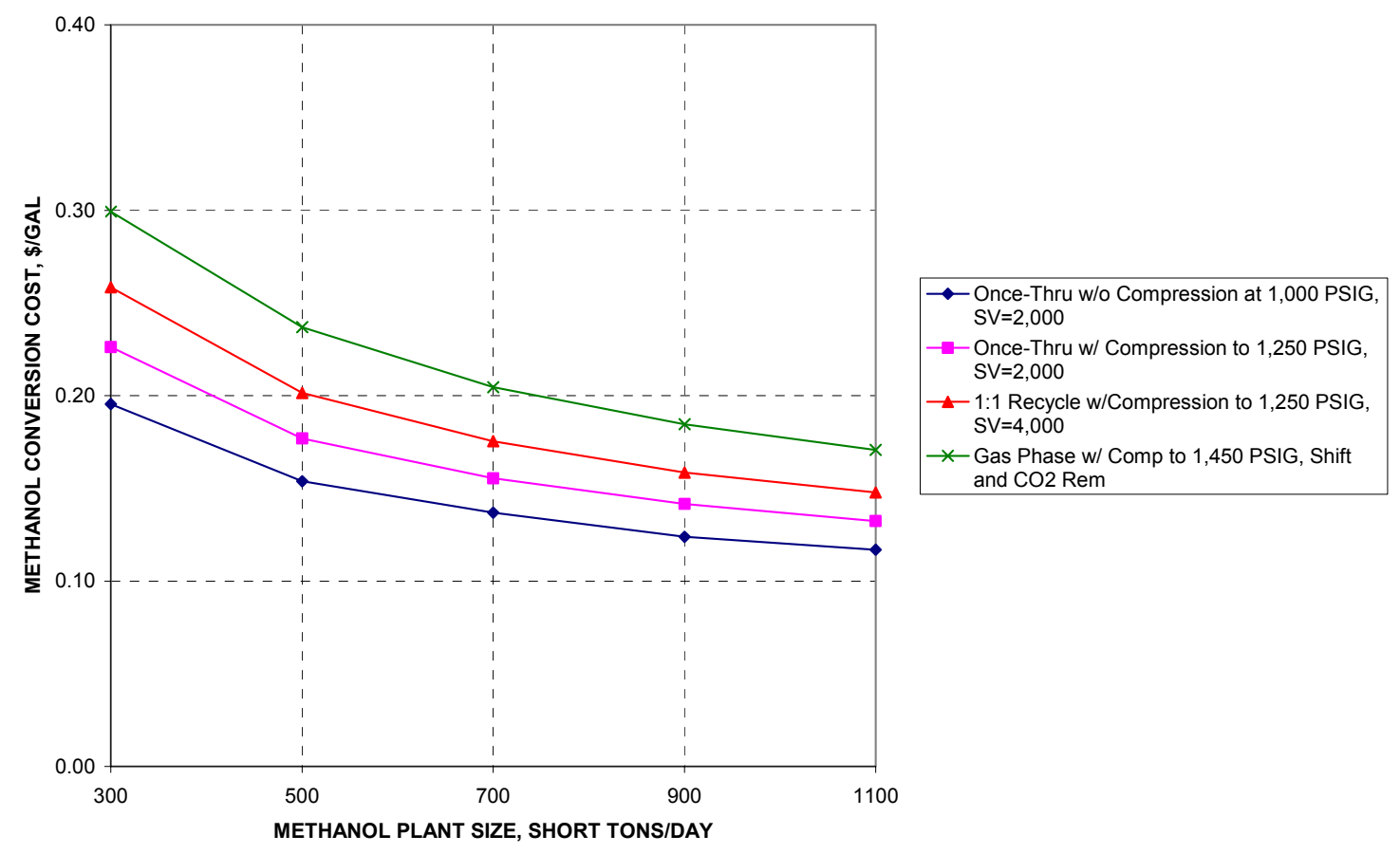

\subsubsection{Sulfur Content}

In this analysis, the fresh syngas was assumed to contain 5 ppmv of COS. To remove this catalyst poison the COS is first hydrolyzed over a metal oxide catalyst and then the $\mathrm{H}_{2} \mathrm{~S}$ produced is removed with a zinc oxide bed. COS was selected to represent sulfur species in the syngas instead of $\mathrm{H}_{2} \mathrm{~S}$ because of the higher capital cost associated with the hydrolysis step (operating costs for absorption of $\mathrm{H}_{2} \mathrm{~S}$ and $\mathrm{COS}$ after hydrolysis are the same on a sulfur weight basis). Figure 9.5-2 shows the effect of an increase to 20 ppmv of COS in the syngas feed on the methanol conversion cost at 1,000 psig syngas supply pressure. There is an increase of $\$ 0.05$ to $\$ 0.08 /$ gal in the methanol conversion cost at lower syngas conversion, as a large amount of gas must be treated. As the amount of conversion is increased (independent of the methanol conversion technology), the effect on cost becomes more modest. 
Figure 9.5-2

\section{Effect of Syngas Conversion on Methanol Conversion Cost}
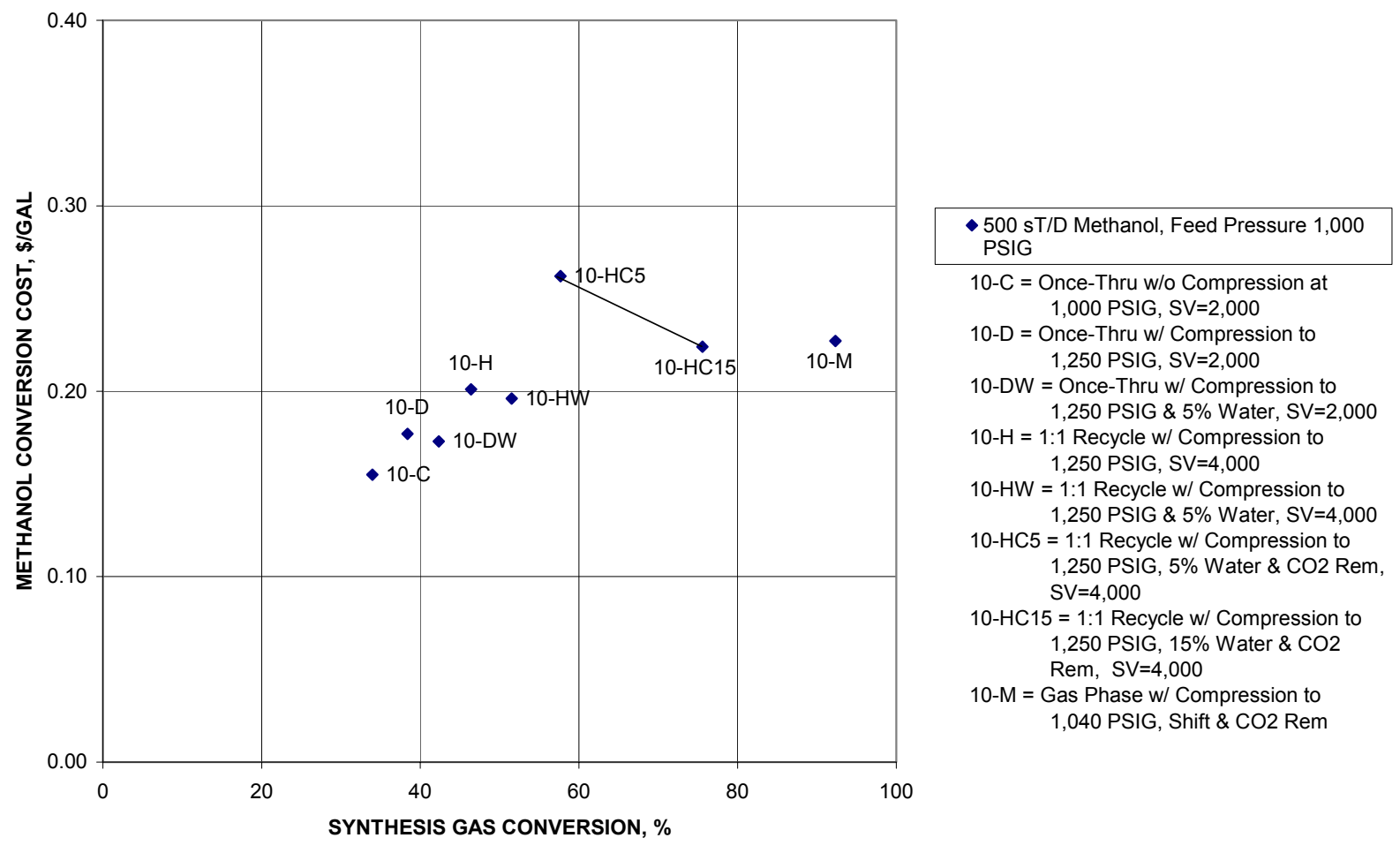

\subsubsection{Inert Content}

In this analysis, the fresh syngas was assumed to contain 1 vol\% inerts. Increased levels of inerts can result from such parameters as the $\mathrm{O}_{2}$ purity from the air separation unit feeding the coal gasifier. The greater the syngas conversion, the greater becomes the cost penalty of inert build up in the synthesis loop. Figure 9.5-3 shows the effect of an increase to $10 \%$ inerts in the feed syngas on the methanol conversion cost at 500 psig syngas supply pressure. For the oncethrough case (Case 5-A) there is a $\$ 0.044 /$ gal increase in cost along with a small reduction in conversion. With a 1:1 recycle at 1,250 psig (Case $5-\mathrm{H})$, the cost increase becomes less, $\$ 0.015 /$ gal. For the gas-phase process, the effect is much greater. In the case shown the inerts in the synthesis loop were limited to $35 \%$ to limit the impact on conversion due to lower partial pressure of reactants; this increases the methanol conversion cost by $\$ 0.027 /$ gal and greatly reduced the syngas conversion to $77 \%$. 
Figure 9.5-3

\section{Effect of Inerts Concentration on Methanol Conversion Cost}

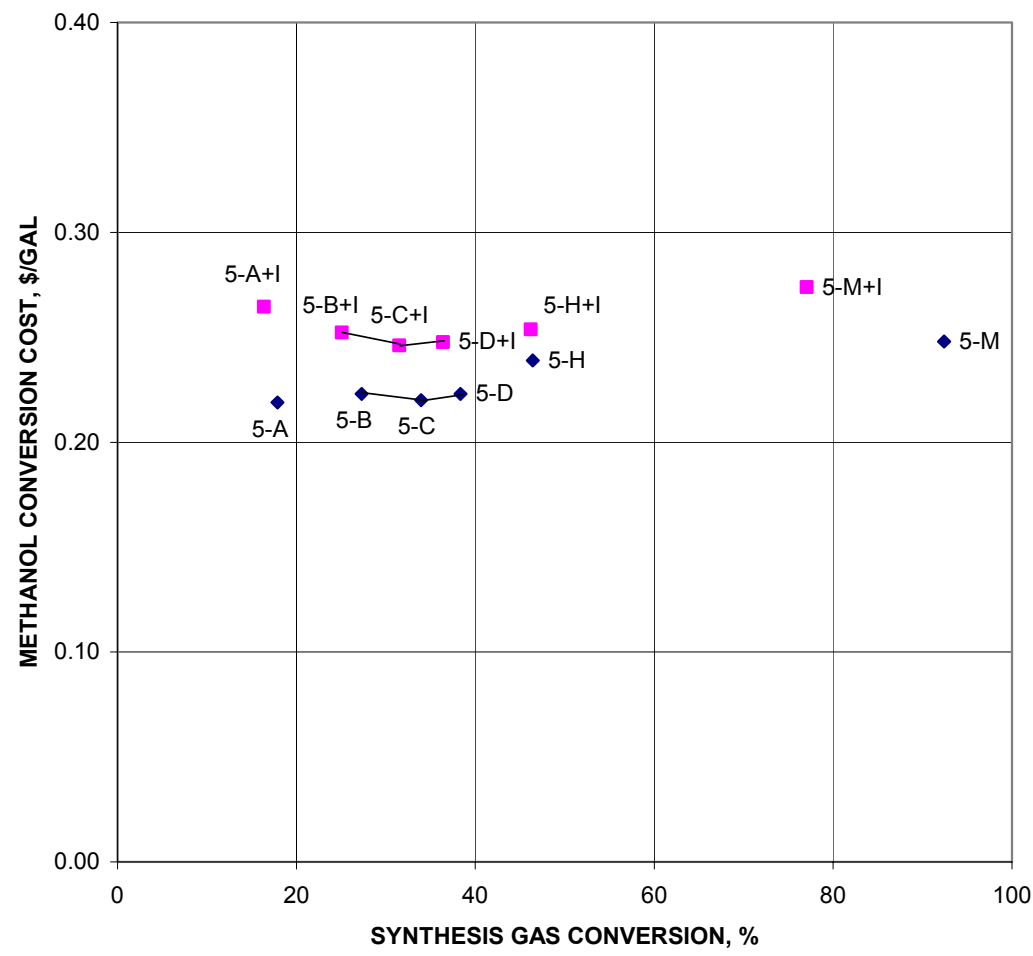

- 500 sT/D Methanol, Feed Pressure 500 PSIG,

1 vol\% Inerts

10 vol\% Inerts in Syngas

5-A = Once-Thru w/o Compression at 500 PSIG, SV=2,000

$5-B=$ Once-Thru $w /$ Compression to 750 PSIG, SV=2,000

5-C = Once-Thru w/ Compression to 1,000 PSIG, SV=2,000

$5-\mathrm{D}=$ Once-Thru $\mathrm{w} /$ Compression to 1,250 PSIG, SV $=2,000$

$5-\mathrm{H}=1: 1$ Recycle w/ Compression to 1,250 PSIG, SV $=4,000$

$5-\mathrm{M}=$ Gas Phase $\mathrm{w} /$ Compression to 1,040 PSIG, Shift \& CO2 Rem

\subsubsection{Capacity Factor}

The depreciation and return on investment have a significant impact on the methanol conversion cost. These are magnified by the capacity factor, as this term is inversely related to the unit cost of methanol (\$ per gallon). All of the figures and tables presented to this point in this Section have used a capacity factor of $90 \%$. An analysis was performed to determine the change in methanol conversion cost when the capacity factor is lowered to $70 \%$. This is more representative of the coproduction of methanol with electric power in an IGCC load-following application. When syngas is available at $500 \mathrm{psig}$, the effect of lowering the capacity factor from $90 \%$ to $70 \%$ is to increase the methanol conversion cost by $\$ 0.05$ to $\$ 0.06$ per gallon of methanol. When the feed syngas is available at 1,000 psig, the methanol conversion cost increases by $\$ 0.04$ to $\$ 0.05$ per gallon of methanol when the capacity factor is lowered from $90 \%$ to $70 \%$. 


\subsection{SECTION 9 BIBLIOGRAPHY}

a. "LPMEOH"M Process as an Add-On to Integrated Gasification Combined Cycle (IGCC) for Coproduction - Economic Analysis", Topical Report Prepared by Air Products Liquid Phase Conversion Co., L.P., DOE Cooperative Agreement No. DE-FC22-92PC90543, October 1998.

b. "Design and Fabrication of the First Commercial-Scale Liquid Phase Methanol (LPMEOH ${ }^{\mathrm{TM}}$ ) Reactor", Topical Report Prepared by Air Products Liquid Phase Conversion Co., L.P., DOE Cooperative Agreement No. DE-FC22-92PC90543, October 1998. 


\subsection{COMMERCIALIZATION POTENTIAL AND PLANS}

\subsection{MARKET ANALYSIS}

\subsubsection{Applicability of the Technology}

The LPMEOH ${ }^{\text {TM }}$ Process is a very effective technology for converting a portion of the $\mathrm{H}_{2}$ and $\mathrm{CO}$ in an IGCC electric power plant's coal-derived syngas to methanol. The process is very flexible in being able to process many variations in syngas composition. The LPMEOH ${ }^{\mathrm{TM}}$ Process can be used with an IGCC power plant to provide the once-through methanol production as depicted in Figure 7.1-1. The process can be designed to operate in a continuous, baseload manner, converting syngas from oversized gasifiers or from a spare gasifier. The process can also be designed to operate only during periods of off-peak electric power demand to consume a portion of the excess syngas and allow the electricity output from the combined-cycle power unit to be reduced. In this latter circumstance, the gasifiers continue to operate at full baseload capacity, so the IGCC facility's major capital asset is fully utilized. In either baseload or cycling operation, partial conversion of between $20 \%$ and $40 \%$ of the volume of $\mathrm{H}_{2}$ and $\mathrm{CO}$ in the IGCC power plant's syngas is optimal on an economic basis, and conversion of up to $50 \%$ is feasible.

A simplified process flow diagram for the LPMEOH ${ }^{\mathrm{TM}}$ Process design options is shown in Figure 10.1-1. This shows several once-through LPMEOH ${ }^{\mathrm{TM}}$ Process design options, as described more fully in the Public Design Report (Final Report - Volume 1) and in a topical report on the economics of methanol coproduction as an add-on to an IGCC power plant.

In its simplest configuration, part or all of the CO-rich syngas at its maximum available pressure from the IGCC power plant (Stream 1) is passed once, without recycle, through the LPMEOH ${ }^{\mathrm{TM}}$ reactor. The unreacted syngas (Stream 3 ) is returned to the IGCC power plant's combustion turbines.

If greater amounts of syngas conversion are required, different design options are available:

a) Use of Gas Recycle;

b) Once-Through, with Feed Gas Compression;

c) Once-Through, with Water Addition;

d) Once-Through, with Water Addition and $\mathrm{CO}_{2}$ Removal; and

e) Staged Liquid Phase Reactors.

With any of these options, there is still no need for upstream stoichiometric adjustment of the feed gas by the water-gas shift reaction and $\mathrm{CO}_{2}$ removal, so the simplicity of once-through $\mathrm{CO}$ rich gas processing is retained.

The design configuration for the LPMEOH ${ }^{\mathrm{TM}}$ Process depends upon the degree of conversion of syngas (or the quantity of methanol produced relative to the power plant size). 


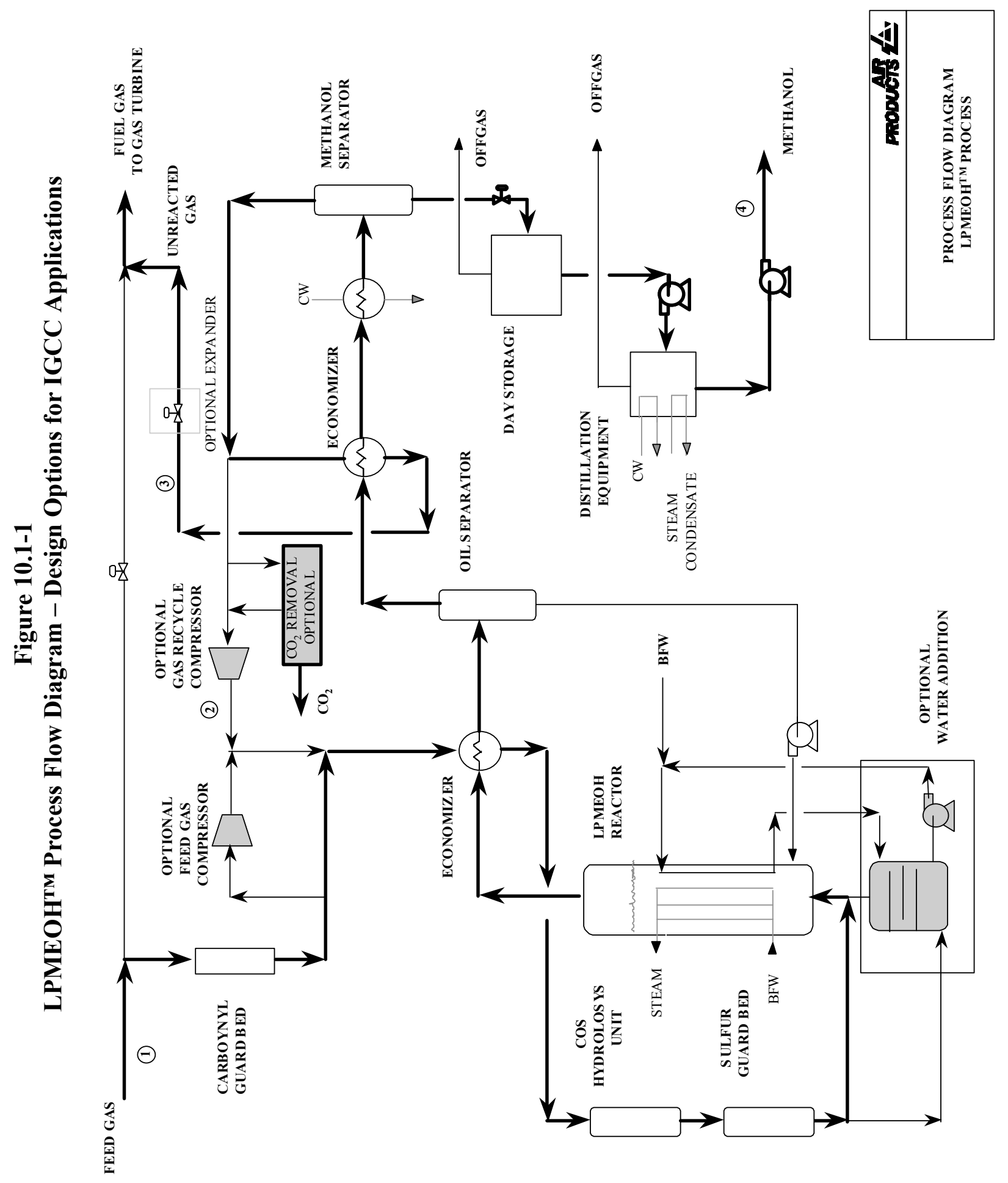

몰 
The features of the $\mathrm{LPMEOH}^{\mathrm{TM}}$ Process that satisfy the requirements in the coproduction application can also be applied to other carbon-rich feedstocks such as petroleum coke and other environmentally disadvantaged fuels. The LPMEOH ${ }^{\mathrm{TM}}$ Process has also shown the potential to meet the economic requirements for large, natural gas-based methanol production plants. ${ }^{\text {(a) }}$

\subsubsection{Market Size and Barriers}

Table 10.1.2-1 provides an assessment by the Methanol Institute of the forecast of the market for methanol through 2007. ${ }^{\text {(b) }}$ The decrease in demand for methanol to produce MTBE is expected to be offset by increases in other basic chemicals such as formaldehyde and methyl methacrylate. Beyond this analysis, the potential exists for future market growth for methanol as a source of $\mathrm{H}_{2}$ for fuel cell systems.

As noted in Section 10.1.1, a key market for the LPMEOH ${ }^{\mathrm{TM}}$ Process is the coproduction of methanol with electric power in an IGCC power plant. Using the DOE's High Fossil Electricity Technology Case that relates to the output of DOE's Fossil Energy program, the potential market for IGCC power plants in the United States could exceed $60 \mathrm{GW}$ by 2020. ${ }^{(\mathrm{c})}$ Assuming that coproduction could be a candidate for $10-20 \%$ of this total, the opportunity can exist for significant market participation for the $\mathrm{LPMEOH}^{\mathrm{TM}}$ Process.

The methanol marketplace is currently undergoing a period of transition due to the planned elimination of MTBE by several states in the United States as well as the development of large (greater that 5,000 metric tons per day), off-shore methanol plants utilizing low-cost natural gas as feedstock.

Future markets will depend on such factors as the rate of growth of the IGCC power generation

Table 10.1.2-1

Market Forecast for Methanol

(Thousands of Metric Tons; Source: Methanol Institute)

SUPPLY
Capacity Available
Production
Excess Capacity
Operating Rate
DEMAND
Formaldehyde
MTBE
Acetic Acid
Dimethyl Terephthalate
Methyl Methacrylate
Gas/Fuels
Solvents
Others
TOTAL DEMAND

$\begin{array}{ccccc}2003 & 2004 & 2005 & 2006 & 2007 \\ 35,680 & 38,617 & 40,692 & 39,944 & 40,910 \\ 30,427 & 31,016 & 31,774 & 31,885 & 32,196 \\ 5,253 & 7,601 & 8,918 & 8,059 & 8,714 \\ 85 \% & 80 \% & 78 \% & 80 \% & 79 \% \\ & & & & \\ 11,000 & 11,390 & 11,708 & 12,029 & 12,386 \\ 7,506 & 7,428 & 7,197 & 6,598 & 6,207 \\ 3,339 & 3,374 & 3,649 & 3,735 & 3,826 \\ 590 & 590 & 603 & 618 & 632 \\ 892 & 923 & 979 & 1,004 & 1,030 \\ 859 & 867 & 896 & 946 & 988 \\ 1,285 & 1,313 & 1,342 & 1,379 & 1,411 \\ 4,956 & 5,131 & 5,401 & 5,577 & 5,716 \\ 30,427 & 31,016 & 31,774 & 31,885 & 32,196\end{array}$


business, global methanol market prices, and government incentives aimed at encouraging IGCC and/or IGCC coproduction projects, consistent with DOE's Vision 21. Methanol coproduction with IGCC power generation, using the LPMEOH ${ }^{\mathrm{TM}}$ Process, will continue to benefit from the economies of scale provided by the gasification plant, and result in lower methanol costs than for a standalone methanol plant with the same methanol production capacity. Methanol transport economies, compared with imported methanol based on low cost stranded natural gas, can also be achieved by serving local inland markets. Outside the United States, most of the current interest in LPMEOH ${ }^{\mathrm{TM}}$ technology has come from China, because of China's abundance of coal, historic dependence on domestic chemical production, and the amenability of the LPMEOH ${ }^{\mathrm{TM}}$ Process to coal-based syngas. In the longer term, the development of clean coal projects in China utilizing IGCC technology would provide a platform for additional interest in the LPMEOH ${ }^{\mathrm{TM}}$ Process. In the U.S., interest in LPMEOH ${ }^{\mathrm{TM}}$ technology will also depend on the development and timing of the IGCC industry, which in turn will depend on a number of factors, notably, natural gas price and availability, further improvement in IGCC economics, new environmental regulations further affecting coal-based power generation, and government incentives.

\subsubsection{Economic Comparison with Competing Technologies}

As noted in Section 9, a topical report was written during the performance period that compared the cost of methanol as produced from the LPMEOH ${ }^{\text {TM }}$ Process and from a conventional gasphase process as applied to a generic 500 sT/D methanol plant as part of an IGCC coproduction facility. The cost of methanol was calculated as the sum of three terms: the methanol conversion cost (which includes the fixed and operating costs for the methanol unit), the distillation cost, and the syngas cost from the IGCC facility. A proprietary cost estimation screening program was used to calculate the methanol conversion cost and the distillation cost from the LPMEOH ${ }^{\mathrm{TM}}$ Process and the gas-phase process for various syngas supply pressures and on-stream factors. The methanol conversion cost from the LPMEOH ${ }^{\mathrm{TM}}$ Process was $\$ 0.02$ to $\$ 0.07$ per gallon lower than from the gas-phase methanol process.

A major component of the methanol conversion cost in an IGCC complex is the cost to distill the as-produced methanol product in order to meet the final specification. It is typical for methanol to be stabilized (either by distillation or by deep flashing) to remove volatile components (such as $\mathrm{CO}_{2}$ ) and permit shipment and transport in atmospheric vessels. Beyond stabilization, other distillation may be necessary so that the final methanol product meets the specification for the designated end-use. There are two grades of methanol product (Chemical-Grade AA and FuelGrade) that could be used in downstream chemical or power applications. These grades of methanol differ in the amounts of water and higher alcohols that are present in the final product. In particular, the Fuel-Grade product has a water specification of $1 \mathrm{wt} \%$, while the ChemicalGrade AA methanol has a maximum water content of $0.1 \mathrm{wt} \%$.

The LPMEOH ${ }^{\mathrm{TM}}$ Process, which can directly process coal-derived syngas which is rich in $\mathrm{CO}$, produces a methanol product with nominally about $1 \mathrm{wt} \%$ water. Whereas, gas-phase methanol synthesis results in as-produced methanol stream with $2-20 \mathrm{wt} \%$ water, depending on the amount of $\mathrm{CO}_{2}$ in the syngas which is converted to methanol and water. This resulted in lower purification cost for the LPMEOH ${ }^{\mathrm{TM}}$ Process for the Fuel-Grade product. By applying the same 
cost estimation screening program, the distillation cost to produce Fuel-Grade methanol from the LPMEOH $^{\mathrm{TM}}$ Process which directly utilizes CO-rich syngas was about $\$ 0.02$ per gallon less than from the gas-phase methanol process.

Sensitivity studies performed as part of this Report indicated that the magnitude of the advantage in the methanol conversion cost for the LPMEOH ${ }^{\mathrm{TM}}$ Process when compared with the conventional gas-phase process is increased when:

a) the syngas is rich in $\mathrm{CO}$,

b) syngas is available at higher pressures,

c) only modest syngas conversion to methanol is required,

d) syngas is available with low $\mathrm{H}_{2} \mathrm{~S}$ and $\mathrm{COS}$ content,

e) inerts in the syngas (such as $\mathrm{N}_{2}$ in the $\mathrm{O}_{2}$ from the air separation unit feeding the gasifier) are relatively high, and

f) Fuel-Grade Methanol is required.

Table 10.1.3-1 summarizes several operating scenarios for a baseload 500 sT/D LPMEOH ${ }^{\mathrm{TM}}$ Facility, when compared with the more complex 500 sT/D gas-phase methanol facility. As in the prior discussion, the baseload coproduction assumes that the syngas is normally available $90 \%$ of the time and syngas is charged at $\$ 4.50$ per MMBtu. Cost advantages of $\$ 0.04$ to $\$ 0.11$ per gallon of methanol can be realized by utilizing the LPMEOH ${ }^{\mathrm{TM}}$ Process.

\subsection{COMMERCIALIZATION PLAN}

During the development phase for the LPMEOH ${ }^{\mathrm{TM}}$ technology, a team within Air Products was assembled to manage the various programs needed to achieve commercial readiness. With the conclusion of the LPMEOH ${ }^{\mathrm{TM}}$ Demonstration Project, these efforts have achieved this goal. Future commercial activities will be managed from the Worldwide Hydrocarbon Equipment business unit.

Any future offerings will be based on the results from both the 4-month proof-of-concept run at the LaPorte AFDU and the operation at the LPMEOH ${ }^{\mathrm{TM}}$ demonstration unit. Future process flow

Table 10.1.3-1

Baseload Coproduction, 500 sT/D, Fuel Grade Methanol CO-rich Syngas $\left(\mathrm{H}_{2}: \mathrm{CO}=0.68\right) @ \$ 4.50$ per MMBtu

$\begin{array}{lcccc}\text { Syngas Feed Pressure, psig } & \underline{500} & \underline{500} & \underline{1,000} & \underline{1,000} \\ & & & & \\ \text { Flow Scheme } & \text { Once-Through } & 1: 1 \text { Recycle } & \text { Once-Through } & 1: 1 \text { Recycle } \\ \text { Syngas Conversion, \% } & 34 & 46 & 34 & 46 \\ \text { Methanol Cost, } \$ / \text { Gal } & 0.548 & 0.567 & 0.483 & 0.529 \\ \text { LPMEOH Advantage } & 0.055 & 0.036 & 0.109 & 0.063 \\ \text { over gas-phase, } \$ / \text { Gal } & & & & \end{array}$


diagrams will derive from the as-built flowsheet from the LPMEOH ${ }^{\mathrm{TM}}$ demonstration unit. Catalyst performance has improved since the completion of the second in-situ catalyst activation in June of 2002, and provides an indication of the potential for improved economics for the LPMEOH $^{\mathrm{TM}}$ Process. Future project opportunities will likely be based on coal-derived syngas in either IGCC facilities or standalone coal-to-chemicals complexes, or syngas that is produced from environmentally disadvantaged feedstocks (such as petroleum coke). Facility availability at the LPMEOH ${ }^{\mathrm{TM}}$ demonstration unit has been excellent since initial startup, and consistent with the high demands that accompany these capital-intensive projects.

\subsection{SECTION 10 BIBLIOGRAPHY}

a. D. E. Benedict, E. C. Heydorn, and T. R. Tsao (Air Products and Chemicals, Inc.), "Economics of Methanol Production from Natural Gas Using Liquid Phase Methanol Synthesis", Paper Presented at 2001 World Methanol Conference, 05-07 November 2001.

b. "World Methanol Supply and Demand", Methanol Institute Fact Sheet, published at www.methanol.org.

c. "Forecasting the Benefits of DOE Programs for Advanced Fossil-Fuel Electricity Generating Technologies: The EIA High Fossil Electricity Technology Case", U.S. DOE Office of Fossil Energy, National Energy Technology Laboratory, Office of Systems and Policy Support, October 2002. 


\subsection{CONCLUSIONS AND RECOMMENDATIONS}

The LPMEOH ${ }^{\mathrm{TM}}$ Demonstration Project accomplished the objectives set out in the Cooperative Agreement with DOE for this Clean Coal Technology project. Methanol operation began on 02 April 1997, and startup was completed in two days. Nameplate production of 80,000 gallons per day (260 sT/D) was achieved within four days, and production rates exceeding $115 \%$ of design were achieved within six days. Overall availability of the LPMEOH ${ }^{\mathrm{TM}}$ demonstration unit was $97.5 \%$, and the longest operating period without interruption of any kind was 94 days. Over 103.9 million gallons of methanol was produced, including a one-month maximum of 2.5 million gallons. Eastman accepted all of the available methanol for use in the production of methyl acetate, and ultimately cellulose acetate and acetic acid.

The slurry bubble column reactor was successfully scaled from the $10 \mathrm{sT} / \mathrm{D}$ LaPorte AFDU to the $260 \mathrm{sT} / \mathrm{D} \mathrm{LPMEOH}^{\mathrm{TM}}$ demonstration unit. The LPMEOH ${ }^{\mathrm{TM}}$ reactor did not exhibit any hydrodynamic instability, and the maximum catalyst loading of $151 \%$ of the design value of about 40,000 pounds (corresponding to a slurry concentration of greater than $49 \mathrm{wt} \%$ ) was achieved. The gas sparger at the inlet to the $\mathrm{LPMEOH}^{\mathrm{TM}}$ reactor was replaced with two modified units (using the same design principles as the original device), and stable performance was realized when a continuous flush of condensed process oil (in this case, by gravity) was utilized.

Catalyst performance (as determined by the rate of catalyst deactivation using an in-house kinetic model) improved during the demonstration test period. Initially high deactivation rates using Balanced Gas (greater than 1\% per day vs. the design basis of $0.4 \%$ per day from a 4month proof-of-concept run on CO-rich syngas derived from natural gas at the LaPorte AFDU [1988/89]) at the design operating temperature of $250^{\circ} \mathrm{C}$ were attributed to the presence of postconstruction debris in the reactor system. During the second catalyst campaign that began in December of 1997 , the rate of catalyst deactivation was calculated to be 0.6 to $0.7 \%$ per day at a reactor temperature of $235^{\circ} \mathrm{C}$. The practice of catalyst withdrawal and addition (removing a portion of the spent catalyst from the LPMEOH ${ }^{\mathrm{TM}}$ reactor and adding fresh catalyst in 2,000 pound batches) to maintain the desired methanol production rate was successfully demonstrated.

In determining the reasons for the higher rate of catalyst deactivation, the presence of certain elements (in particular, arsenic and sulfur) was identified from samples of spent catalyst, spent adsorbent materials from catalyst guard beds, and syngas entering the LPMEOH ${ }^{\mathrm{TM}}$ demonstration unit. A commercially available copper oxide-impregnated activated carbon was identified as having capacity to remove arsenic (in the form of arsine) within the existing carbonyl guard bed that was originally designed for removal of metal carbonyls at ambient temperature.

In parallel, laboratory testing was performed to develop a procedure to activate (or reduce) a full charge of methanol synthesis catalyst within the LPMEOH ${ }^{\mathrm{TM}}$ reactor (so-called in-situ activation). During the operating program, this feature was identified as having significant commercial interest, as capital cost savings of about $10 \%$ could be realized by elimination of the separate processing equipment for the catalyst withdrawal/addition procedure. Also, operating the LPMEOH ${ }^{\mathrm{TM}}$ reactor at low temperatures at the outset and slowly increasing temperature with 
time to maintain a constant production of methanol (called temperature programming) was believed to have the potential to extend the life of the methanol synthesis catalyst. Following the first in-situ activation of methanol synthesis catalyst in August of 2001 (during which initial performance of the catalyst was about $70 \%$ of the value expected from the laboratory testing), the concept of temperature programming was demonstrated (temperature was gradually raised from $216^{\circ} \mathrm{C}$ to $250^{\circ} \mathrm{C}$ in order to maintain the desired methanol production rate). Following changes to the storage conditions of the catalyst slurry prior to reduction, the in-situ activation procedure was successfully practiced in June of 2002, resulting in the catalyst meeting the initial performance targets.

During the final six months of operation under the demonstration test plan, the average rate of catalyst deactivation was calculated to be $0.17 \%$ per day, which was $1 / 2$ of the design basis for the $\mathrm{LPMEOH}^{\mathrm{TM}}$ demonstration unit. The reactor was maintained at a constant low temperature of $215^{\circ} \mathrm{C}$ during this period, and the carbonyl guard bed adsorbent (copper oxide-impregnated activated carbon) was replaced with fresh material after 3 months of operation (including a novel thermal treatment that was applied after two months to extend the useful life of the adsorbent). Because the impact of catalyst cost on the economics of methanol production is significant (reducing the rate of catalyst deactivation by up to $1 / 2$ of the current basis can realize a 25 percent reduction in variable cost), this performance demonstrated the potential of the LPMEOH ${ }^{\mathrm{TM}}$ process to meet the targets for catalyst consumption utilizing coal-derived syngas.

Although the host site for the LPMEOH ${ }^{\mathrm{TM}}$ demonstration unit was a chemical production facility, testing was able to be performed to simulate the performance of the $\mathrm{LPMEOH}^{\mathrm{TM}}$ Process in an IGCC power plant. A total of 78 days of testing at a variety of $\mathrm{H}_{2}: \mathrm{CO}$ ratios were performed to evaluate the effect of syngas compositions expected from coal-based IGCC units on the performance of the LPMEOH ${ }^{\mathrm{TM}}$ Process. All of the results met the expectations for methanol production rate based upon earlier studies in the laboratory. Catalyst performance for the $\mathrm{LPMEOH}^{\mathrm{TM}}$ reactor with lower $\mathrm{H}_{2}$ : $\mathrm{CO}$ ratios were not significantly impacted based on the calculated rate of catalyst deactivation. On/off and ramping studies were also completed, and the $\mathrm{LPMEOH}^{\mathrm{TM}}$ demonstration unit was capable of meeting the ramping requirements for an IGCC system by achieving the goal of a minimum 5\% change in design flow per minute. Tests of the ability of the LPMEOH ${ }^{\mathrm{TM}}$ reactor to operate in an electrical load-following environment were also successful.

An off-site, fuel-use test program was conducted to demonstrate the suitability of stabilized (degassed) methanol product as a transportation fuel and as a fuel for stationary applications for small modular electric power generators for distributed power. Stabilized (degassed) methanol produced from CO-rich syngas in the LPMEOH ${ }^{\mathrm{TM}}$ Process can have less than $1 \mathrm{wt} \%$ water, and has the potential to be used directly in these applications. Stabilized methanol from the LPMEOH $^{\text {TM }}$ Demonstration Project was made available to seven test locations. Successful demonstration of the use of stabilized methanol in these applications can enhance the flexibility of and revenue from IGCC plants. In bus and FFV trials, stabilized methanol provided the same environmental benefits as chemical-grade methanol with no penalty on performance or fuel economy. Tests in a gas turbine and a diesel generator showed that levels of $\mathrm{NO}_{\mathrm{x}}$ in the exhaust air were lowered when stabilized methanol or methanol emulsions are used instead of conventional oil fuels. As with chemical-grade methanol, lubrication additives will likely be 
required when stabilized methanol is fed to a gas turbine. Testing of stabilized methanol as the source of $\mathrm{H}_{2}$ to a phosphoric acid fuel cell has shown that conventional steam reforming catalysts are not compatible with the trace mineral oil present in the stabilized methanol; when auto-thermal reforming or partial oxidation reforming are used, the stabilized methanol would possibly be acceptable as a fuel. Methanol from the LPMEOH ${ }^{\mathrm{TM}}$ Process that is purified to chemical-grade specifications should be suitable for use in this application.

As a secondary objective to the LPMEOH ${ }^{\mathrm{TM}}$ Demonstration Project, design verification testing was completed to evaluate capability of the slurry bubble column reactor to produce DME as a mixed coproduct with methanol using the LPDMETM Process. In addition to its current uses, DME has potential applications as a chemical building block. Also, since the physical properties of DME are similar to those of LPG, it has been speculated that DME could be used in large scale power production, in home heating, in replacement of LPG for automobiles, and as a diesel fuel substitute or combustion supplement. Economic targets on the production cost of DME from the LPDMETM Process were established, and a 25-day design verification test was performed at the LaPorte AFDU in 1999. The rate of catalyst deactivation for both the methanol synthesis and dehydration catalysts was calculated to be $0.7 \%$ per day, which was a large improvement over the $4 \%$ per day rate of deactivation which was calculated from autoclave studies prior to the initial test of the LPDMETM Process at the LaPorte AFDU in 1991; these results were slightly higher than the results $\left(0.5 \%\right.$ per day) for the $\mathrm{LPMEOH}^{\mathrm{TM}}$ Process from the first 3 weeks of the 4-month proof-of-concept run at the LaPorte AFDU in 1988/89. Follow-up economic analysis showed that the target DME cost of $\$ 7$ to $\$ 8$ per MMBtu (equivalent to costs for LPG in China) can likely be achieved at plant sizes approaching 1,100 sT/D. The program participants agreed that additional work on DME should be deferred so that all resources could be directed toward improving the catalyst performance for the LPMEOH ${ }^{\mathrm{TM}}$ Process during the remaining time within the operating program.

The commercial application of the $\mathrm{LPMEOH}^{\mathrm{TM}}$ technology with the greatest long-term potential continues to be the coproduction of methanol within an IGCC power plant. The ability of the slurry reactor to ramp rapidly and to start/stop easily makes it amenable to peak shaving scenarios in an IGCC power plant. Of significant interest is that relatively small quantities (30,000 gallons per day) of methanol can be coproduced from coal at world scale (greater than 600,000 gallons per day) economics. Parametric studies were performed to determine the production cost of methanol from the LPMEOH ${ }^{\mathrm{TM}}$ Process in an IGCC power plant. The process can be designed to operate in a continuous, baseload manner, converting syngas from oversized gasifiers or from a spare gasifier. The process can also be designed to operate only during periods of off-peak electric power demand to consume a portion of the excess syngas and allow the electricity output from the combined-cycle power unit to be reduced. In this latter circumstance, the gasifiers continue to operate at full baseload capacity, so the IGCC facility's major capital asset is fully utilized. In either baseload or cycling operation, partial conversion of between $20 \%$ and $40 \%$ of the volume of $\mathrm{H}_{2}$ and $\mathrm{CO}$ in the IGCC power plant's syngas is optimal on an economic basis, and conversion of up to $50 \%$ is feasible. Methanol conversion costs of about $\$ 0.15$ per gallon were determined for a coal-based IGCC plant using the once-through configuration; when the cost of syngas is added, the price of methanol is less than $\$ 0.50$ per gallon. As the economics for IGCC systems improve, the economics for coproduction of 
methanol will continue to look attractive in local markets when compared with methanol that is produced in off-shore locations from natural gas.

Further reductions to the cost of syngas from a modern coal gasification system will increase the market opportunities for coproduction of chemicals such as methanol from the LPMEOH ${ }^{\mathrm{TM}}$ Process. Developments of and advancements in the processes for the removal of trace contaminants in coal-derived syngas will extend catalyst life and lead to lower methanol conversion costs. Continued studies of the hydrodynamics of slurry bubble column reactors would facilitate the use of larger diameter reactors, which will improve the economies of scale for all potential feedstocks (coal, natural gas, environmentally disadvantaged fuels). 


\subsection{OTHER PROJECT REPORTS AND PUBLICATIONS}

(since the Public Design Report [Final Report - Volume 1])

Note: Reports or publications on specific topics are included in individual chapters where appropriate.

1. Technical Progress Report No. 34, October - December 2002.

2. Technical Progress Report No. 33, July - September 2002.

3. Technical Progress Report No. 32, April - June 2002.

4. Technical Progress Report No. 31, January - March 2002.

5. Technical Progress Report No. 30, October - December 2001.

6. Technical Progress Report No. 29, July - September 2001.

7. Technical Progress Report No. 28, April - June 2001.

8. Technical Progress Report No. 27, January - March 2001.

9. Technical Progress Report No. 26, October - December 2000.

10. Technical Progress Report No. 25, July - September 2000.

11. Technical Progress Report No. 24, April - June 2000.

12. Technical Progress Report No. 23, January - March 2000.

13. Technical Progress Report No. 22, October - December 1999.

14. Technical Progress Report No. 21, July - September 1999.

15. Technical Progress Report No. 20, April - June 1999.

16. Technical Progress Report No. 19, January - March 1999.

17. Technical Progress Report No. 18, October - December 1998.

18. Technical Progress Report No. 17, July - September 1998.

19. Technical Progress Report No. 16, April - June 1998.

20. Technical Progress Report No. 15, January - March 1998.

21. Technical Progress Report No. 14, October - December 1997.

22. Technical Progress Report No. 13, July - September 1997.

23. Technical Progress Report No. 12, April - June 1997.

24. Technical Progress Report No. 11, January - March 1997.

25. Technical Progress Report No. 10, October - December 1996.

26. Technical Progress Report No. 9, July - September 1996.

27. Technical Progress Report No. 8, April - June 1996.

28. Technical Progress Report No. 7, January - March 1996.

29. Technical Progress Report No. 6, October - December 1995.

30. Technical Progress Report No. 5, July - September 1995.

31. Technical Progress Report No. 4, April - June 1995.

32. Technical Progress Report No. 3, October 1994 - March 1995.

33. Technical Progress Report No. 2, July - September 1994.

34. Technical Progress Report No. 1, October 1993 - June 1994.

35. Environmental Monitoring Report No. 23, October - December 2002.

36. Environmental Monitoring Report No. 22, July - September 2002.

37. Environmental Monitoring Report No. 21, April - June 2002.

38. Environmental Monitoring Report No. 20, January - March 2002.

39. Environmental Monitoring Report No. 19, October - December 2001.

40. Environmental Monitoring Report No. 18, July - September 2001.

41. Environmental Monitoring Report No. 17, April - June 2001.

42. Environmental Monitoring Report No. 16, January - March 2001.

43. Environmental Monitoring Report No. 15, October - December 2000.

44. Environmental Monitoring Report No. 14, July - September 2000. 
45. Environmental Monitoring Report No. 13, April - June 2000.

46. Environmental Monitoring Report No. 12, January - March 2000.

47. Environmental Monitoring Report No. 11, October - December 1999.

48. Environmental Monitoring Report No. 10, July - September 1999.

49. Environmental Monitoring Report No. 9, April - June 1999.

50. Environmental Monitoring Report No. 8, January - March 1999.

51. Environmental Monitoring Report No. 7, October - December 1998.

52. Environmental Monitoring Report No. 6, July - September 1998.

53. Environmental Monitoring Report No. 5, April - June 1998.

54. Environmental Monitoring Report No. 4, January - March 1998.

55. Environmental Monitoring Report No. 3, October - December 1997.

56. Environmental Monitoring Report No. 2, July - September 1997.

57. Environmental Monitoring Report No. 1, April - June 1997.

58. "Commercial-Scale Demonstration of the Liquid Phase Methanol (LPMEOH ${ }^{\mathrm{TM}}$ ) Process", Public Design Report (Final Design Report, Volume 1: Public Design)", Prepared by Air Products Liquid Phase Conversion Co., L.P., DOE Cooperative Agreement No. DE-FC22-92PC90543, January 2000.

59. "Commercial-Scale Demonstration of the Liquid Phase Methanol (LPMEOH ${ }^{\mathrm{TM}}$ ) Process", Demonstration Technology Startup Report", Prepared by Air Products Liquid Phase Conversion Co., L.P., DOE Cooperative Agreement No. DE-FC22-92PC90543, September 1998.

60. "Peroxide Formation of Dimethyl Ether in Methanol Mixtures", Topical Report Prepared by Air Products Liquid Phase Conversion Co., L.P., DOE Cooperative Agreement No. DE-FC2292PC90543, November 1997.

61. "Liquid Phase Methanol (LPMEOH ${ }^{\mathrm{TM}}$ ) Process Development", E. C. Heydorn, B. W. Diamond (Air Products and Chemicals, Inc.), R. D. Lilly (Eastman Chemical Co.), and R. M. Kornosky (U.S. Department of Energy), 2001 Pittsburgh Coal Conference, 04-07 December 2001.

62. "Liquid Phase Methanol (LPMEOH ${ }^{\mathrm{TM}}$ ) Process Development Demonstration Plant Availability", D. E. Benedict, E. C. Heydorn (Air Products and Chemicals, Inc.), R. D. Lilly (Eastman Chemical Co.), and R. M. Kornosky (U.S. Department of Energy), 2001 Gasification Technologies Conference, 0710 October 2001.

63. "Lubricity Problems and Solutions in a Methanol Fueled Gas Turbine", R. E. Bond, J. L. Loth, R. W. Guiler, N. N. Clark (West Virginia University), E. C. Heydorn, P. J. A. Tijm (Air Products and Chemicals, Inc), 2000 International Mechanical Engineering Congress and Exposition, 05-10 November 2000.

64. "Liquid Phase Methanol (LPMEOH ${ }^{\mathrm{TM}}$ ) Process Development", E. C. Heydorn, P. J. A. Tijm, B. L. Bhatt (Air Products and Chemicals, Inc.), B. T. Smith (Eastman Chemical Co.), and R. M. Kornosky (U.S. Department of Energy), Energex 2000 - The $8^{\text {th }}$ International Energy Forum, 23-28 July 2000.

65. "Catalyst and Process Development for Liquid Phase DME Synthesis", B. L. Bhatt, B. A. Toseland, X. D. Peng, E. C. Heydorn, (Air Products and Chemicals, Inc.), 2000 Pittsburgh Coal Conference, 1115 September 2000.

66. "Liquid Phase Methanol (LPMEOH ${ }^{\mathrm{TM}}$ ) Project: Operating Experience Update", P. J. A. Tijm, E. C. Heydorn, B. W. Diamond (Air Products and Chemicals, Inc.), B. T. Street (Eastman Chemical Co.), and R. M. Kornosky (U.S. Department of Energy), 1999 Gasification Technologies Conference, 1720 October 1999.

67. "Commercial-Scale Demonstration of the Liquid Phase Methanol (LPMEOH'M) Process, Clean Coal Technology Topical Report No. 11, April 1999.

68. "Commercial-Scale Demonstration of the Liquid Phase Methanol (LPMEOH ${ }^{\mathrm{TM}}$ ) Process: Initial Operating Experience", E. C. Heydorn, V. E. Stein, P. J. A. Tijm (Air Products and Chemicals Inc.), B. T. Street (Eastman Chemical Co.), and R. M. Kornosky (U.S. Department of Energy), Sixth Clean Coal Technology Conference, May 1998. 
APPENDIX A

ANALYTICAL MEASUREMENTS FOR LPMEOHTM DEMONSTRATION UNIT 


\section{Table A-1 \\ Summary of Streams to be Analyzed for Material Balance Calculations}

Stream No.

Description

PFD Material Balance Point No.

Gas Chromatograph Point No.

Reported in:

EMRs (Compliance)

EMRs (Supplemental)

Technical Progress Reports

Test Series Report (one time)

Temperature

Pressure

Flow Rate

Composition

LPMEOH $^{\mathrm{TM}}$ Gas Analysis (vol\%)

Hydrogen

Carbon Monoxide

Nitrogen

Carbon Dioxide

Methanol

Dimethyl Ether

Methane

Oxygen (Argon)

Trace (by difference)

Analysis Frequency

Sampling Technique

Analytical Method
10

CO Gas to LPMEOHTM

Demonstration Unit

10

2

X (Summary Data)

$\mathrm{X}$

$\mathrm{X}$

$\mathrm{X}$

$\mathrm{X}$

X
19

Distillation Fuel Gas

$-$

8

X

$\mathrm{X}$

$\mathrm{X}$

$\mathrm{X}$

$\mathrm{X}$

Continuous

Continuous

Piped to GC

GC
Piped to GC

GC 


\section{Table A-1}

\section{Summary of Streams to be Analyzed for Material Balance Calculations (cont'd)}

Stream No.

Description

PFD Material Balance Point No.

Gas Chromatograph Point No.

Reported in:

EMRs (Compliance)

EMRs (Supplemental)

Technical Progress Reports

Test Series Report (one time)

Temperature

Pressure

Flow Rate

Composition

LPMEOH ${ }^{\mathrm{TM}}$ Gas Analysis (vol\%)

Hydrogen

Carbon Monoxide

Nitrogen

Carbon Dioxide

Methanol

Dimethyl Ether

Methane

Oxygen (Argon)

Trace (by difference)

Analysis Frequency

Sampling Technique

Analytical Method

Notes:

a. Stream 20 was not available during operation of the $\mathrm{LPMEOH}^{\mathrm{TM}}$ demonstration unit (refer to Section 3.1.3).
20

$\mathrm{H}_{2}$ Gas to LPMEOH ${ }^{\mathrm{TM}}$

Demonstration Unit

20

3

X (Summary Data)

$\mathrm{X}$

$\mathrm{X}$

$\mathrm{X}$

$\mathrm{X}$

$\mathrm{X}$

$\mathrm{X}$

30

30

1

$\mathrm{X}$

$\mathrm{X}$

$\mathrm{X}$

$\mathrm{X}$
Balanced Gas to LPMEOH ${ }^{\mathrm{TM}}$

Demonstration Unit

X (Summary Data)

Continuous Continuous

Piped to GC Piped to GC

GC GC 


\section{Table A-1}

Summary of Streams to be Analyzed for Material Balance Calculations (cont'd)

Stream No.

Description

PFD Material Balance Point No.

Gas Chromatograph Point No.

Reported in:

EMRs (Compliance)

EMRs (Supplemental)

Technical Progress Reports

Test Series Report (one time)

Temperature

Pressure

Flow Rate

Composition

LPMEOH $^{\mathrm{TM}}$ Gas Analysis (vol\%)

Hydrogen

Carbon Monoxide

Nitrogen

Carbon Dioxide

Methanol

Dimethyl Ether

Methane

Oxygen (Argon)

"Other" (by difference)

Analysis Frequency

Sampling Technique

Analytical Method
109

Reactor Feed Gas

109

5

X (Summary Data)

$\mathrm{X}$

$\mathrm{X}$

$\mathrm{X}$

$\mathrm{X}$

X
120

Reactor Section Effluent Gas

120

6

$\mathrm{X}$

$\mathrm{X}$

$\mathrm{X}$

$\mathrm{X}$

X

Continuous

Continuous

Piped to GC

GC
Piped to GC

GC 
Table A-1

Summary of Streams to be Analyzed for Material Balance Calculations (cont'd)

Stream No.

Description

PFD Material Balance Point No.

Gas Chromatograph Point No.

Reported in:

EMRs (Compliance)

EMRs (Supplemental)

Technical Progress Reports

Test Series Report (one time)

Temperature

Pressure

Flow Rate

Composition

LPMEOH $^{\mathrm{TM}}$ Gas Analysis (vol\%)

Hydrogen

Carbon Monoxide

Nitrogen

Carbon Dioxide

Methanol

Dimethyl Ether

Methane

Oxygen (Argon)

"Other" (by difference)

Analysis Frequency

Sampling Technique

Analytical Method

$\begin{array}{cc}148 & 149 \\ \text { Main (Plant) Purge } & \text { Recycle Gas } \\ 148 & 149 \\ 7 & 7 \\ & \\ \text { X (Summary Data) } & \text { X } \\ \text { X } & \text { X } \\ \text { X } & \text { X } \\ \text { X } & \text { X } \\ \text { X } & \text { X } \\ \text { X } & \\ & \\ & \\ & \\ & \\ \text { Continuous } & \\ \text { Piped to GC } & \\ \text { GC } & \text { Continuous } \\ & \\ & \\ & \\ & \\ & \\ & \\ & \\ & \\ & \\ & \end{array}$




\section{Table A-1 \\ Summary of Streams to be Analyzed for Material Balance Calculations (cont'd)}

Stream No.

Description

PFD Material Balance Point No.

Gas Chromatograph Point No.

Reported in:

EMRs (Compliance)

EMRs (Supplemental)

Technical Progress Reports

Test Series Report (one time)

Temperature

Pressure

Flow Rate

Composition

Methanol Analysis (wt\%)

Acetic Acid

Water

Decane

Methanol

Acetone

Ethanol

Analysis Frequency

Sampling Technique

Analytical Method
204

Methanol to Distillation

204

N/A

X

$\mathrm{X}$

$\mathrm{X}$

$\mathrm{X}$

X

X (Summary Data)

$\mathrm{X}$

$X$

$X$

$\mathrm{X}$

X
Daily

Grab

GC/IR/TC 


\section{Table A-1 \\ Summary of Streams to be Analyzed for Material Balance Calculations (cont'd)}

Stream No.

Description

PFD Material Balance Point No.

Gas Chromatograph Point No.

Reported in:

EMRs (Compliance)

EMRs (Supplemental)

Technical Progress Reports

Test Series Report (one time)

Temperature

Pressure

Flow Rate

Composition

Methanol Analysis (wt\%)

Acetic Acid

Water

Decane

Methanol

Acetone

Ethanol

Analysis Frequency

Sampling Technique

Analytical Method
242

Crude-Grade Methanol to

Lurgi (Methanol) Unit

242

N/A

X (Summary Data)

$\mathrm{X}$

$\mathrm{X}$

$\mathrm{X}$

$\mathrm{X}$

$\mathrm{X}$

Weekly

Grab

GC/IR/TC 


\section{Test Methods for Sampling of Syngas}

Test methods were developed to determine the average concentration of arsenic (reported as arsine), iron, and nickel in syngas streams; these techniques were typically applied to the fresh feed gas entering the LPMEOH ${ }^{\mathrm{TM}}$ demonstration unit.

Gas-phase arsenic concentrations in a syngas feed were determined using a modified version of the National Institute for Occupational Safety and Health (NIOSH) Method 6001 for "Arsine" in which arsenic was trapped on a column of activated carbon. A diagram of the sampling set-up is given in Figure A.1. Sample gas was purged through a charcoal packed into a stainless steel tube for a predetermined length of time and flow. The sampling flow was set with the fine metering valve as illustrated. The charcoal was then washed with dilute nitric acid and arsenic was determined by Inductively Coupled Plasma Atomic Emission Spectroscopy (ICP-AES). The limit of detection was 1-5 ppbv arsenic (as arsine).

Gas-phase iron carbonyl concentrations in a syngas feed were determined using a modified NIOSH method 6007 for "Nickel Carbonyl," which is similar to the method for arsine previously described. Sample gas was purged through a packed bed of charcoal in a stainless steel tube for a predetermined length of time and flow. The charcoal was then washed with dilute nitric acid and the iron content was determined by ICP-AES. The limit of detection was relatively high due to the baseline presence of iron in charcoal, with a typical limit of $10 \mathrm{ppbv}$ iron (as iron carbonyl).

Figure A-1

\section{Syngas Sampling Apparatus}

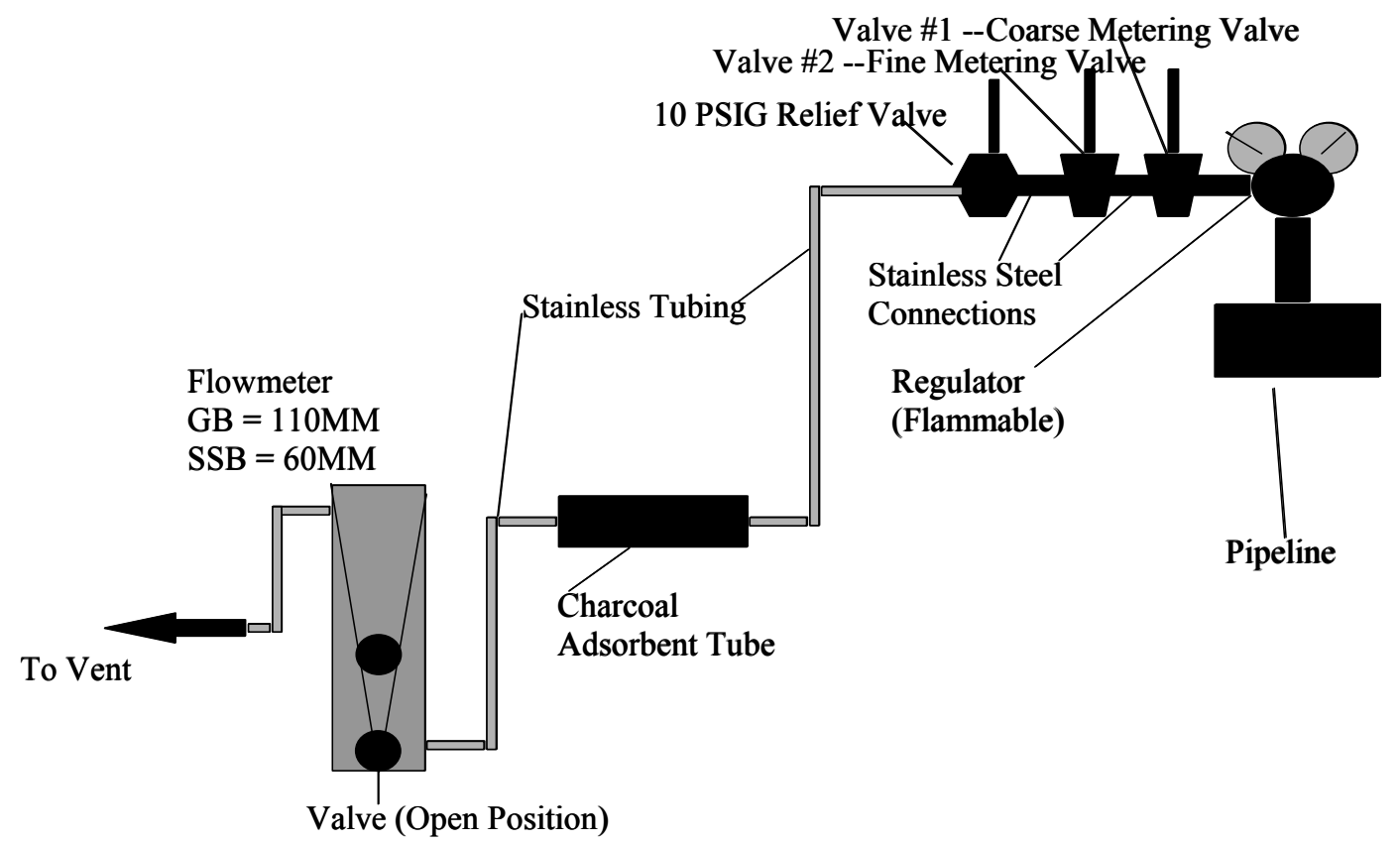


A gas scrubbing technique, using concentrated nitric acid as the scrubbing solution, was also utilized for determination of the concentration of iron carbonyl. Sample gas was purged through a set of bubbling impingers containing nitric acid scrubbing solutions for a predetermined length of time and flow. The nitric acid solution was then analyzed and the iron content was determined by ICP-AES. The limit of detection was generally in the range of 3-5 ppbv iron (as iron carbonyl). 
APPENDIX B

SAMPLE MATERIAL BALANCES FROM LPMEOH'M DEMONSTRATION UNIT 


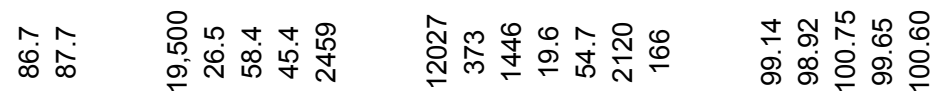

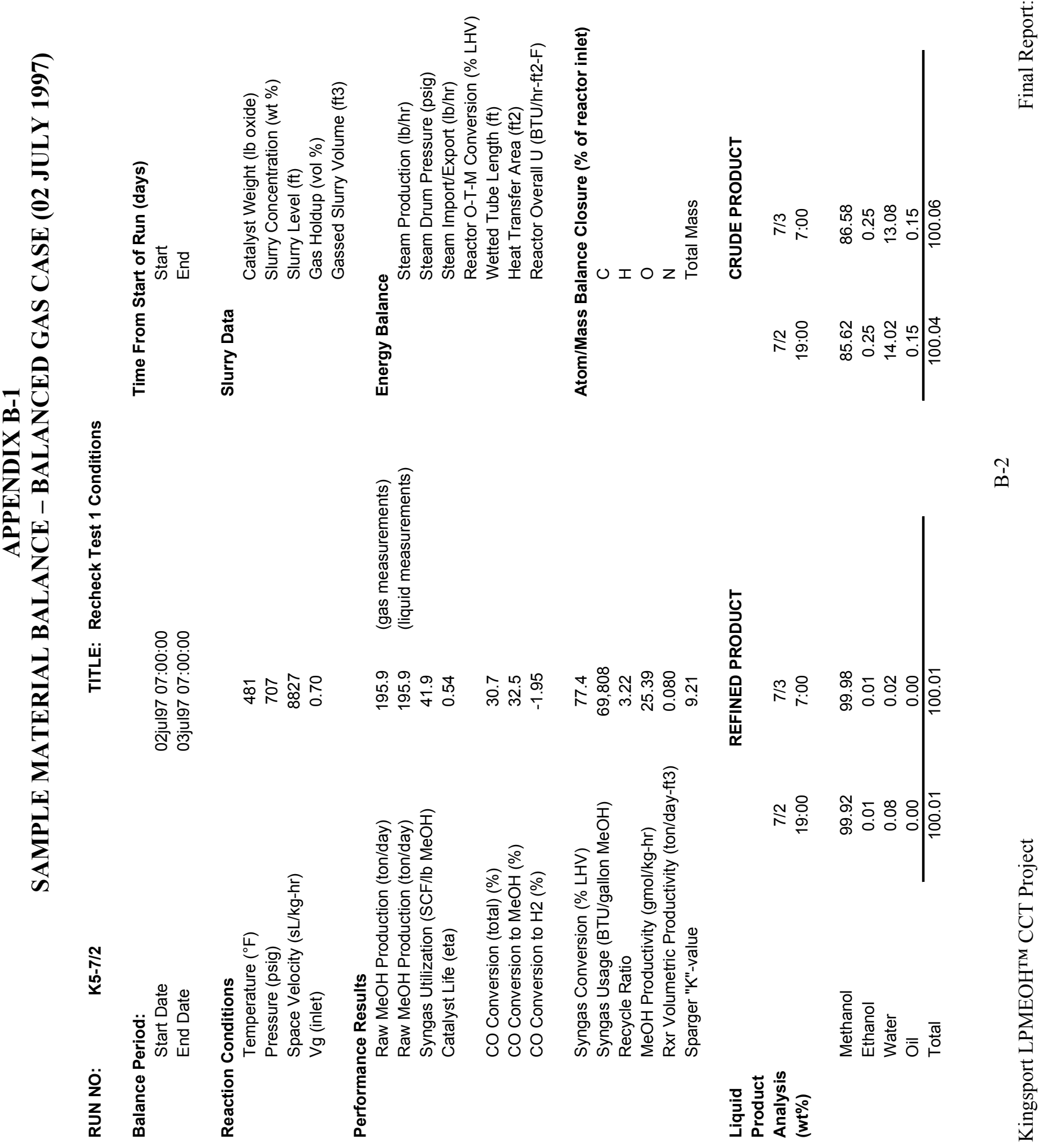




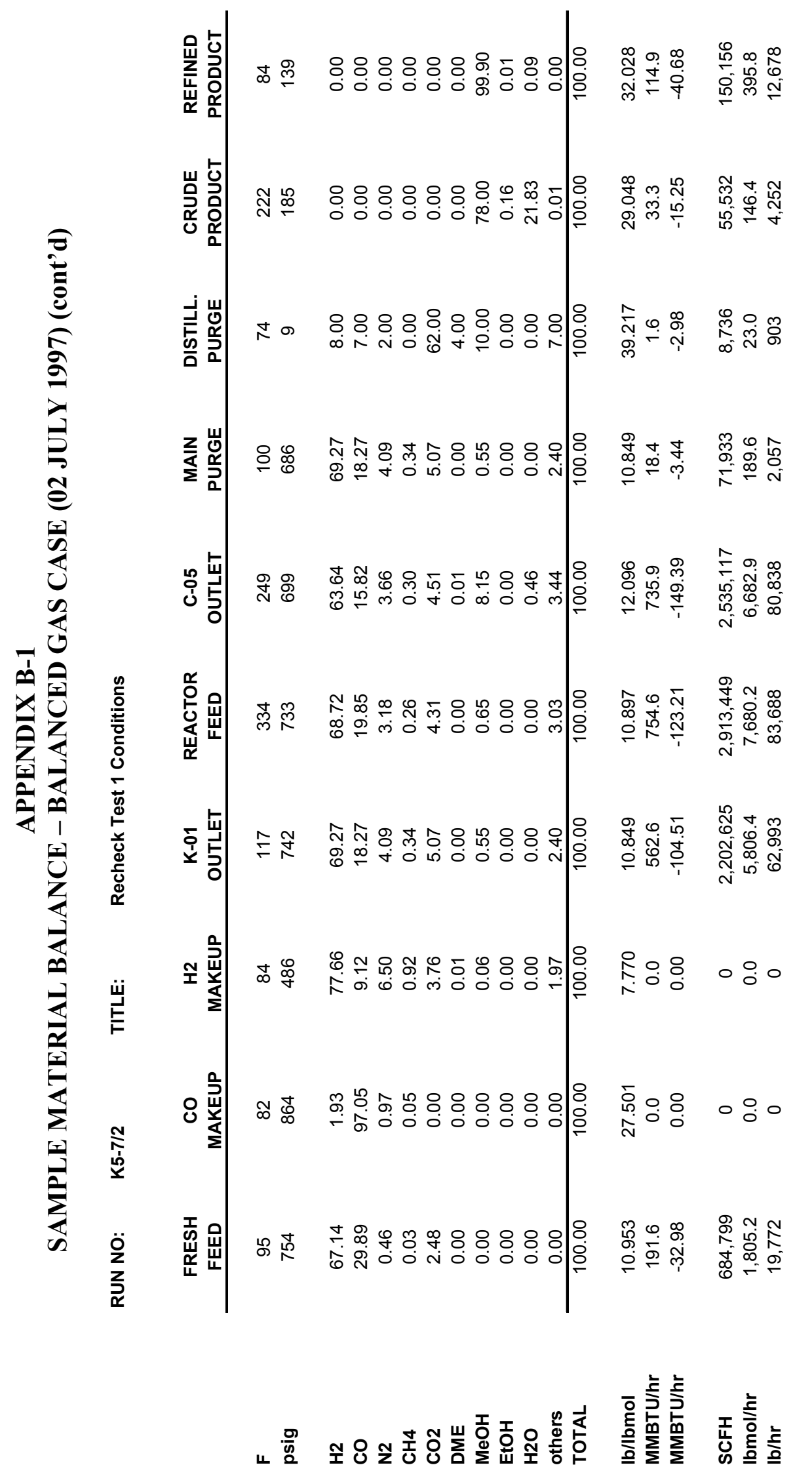




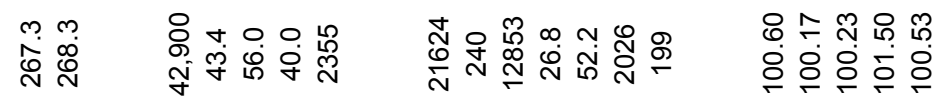






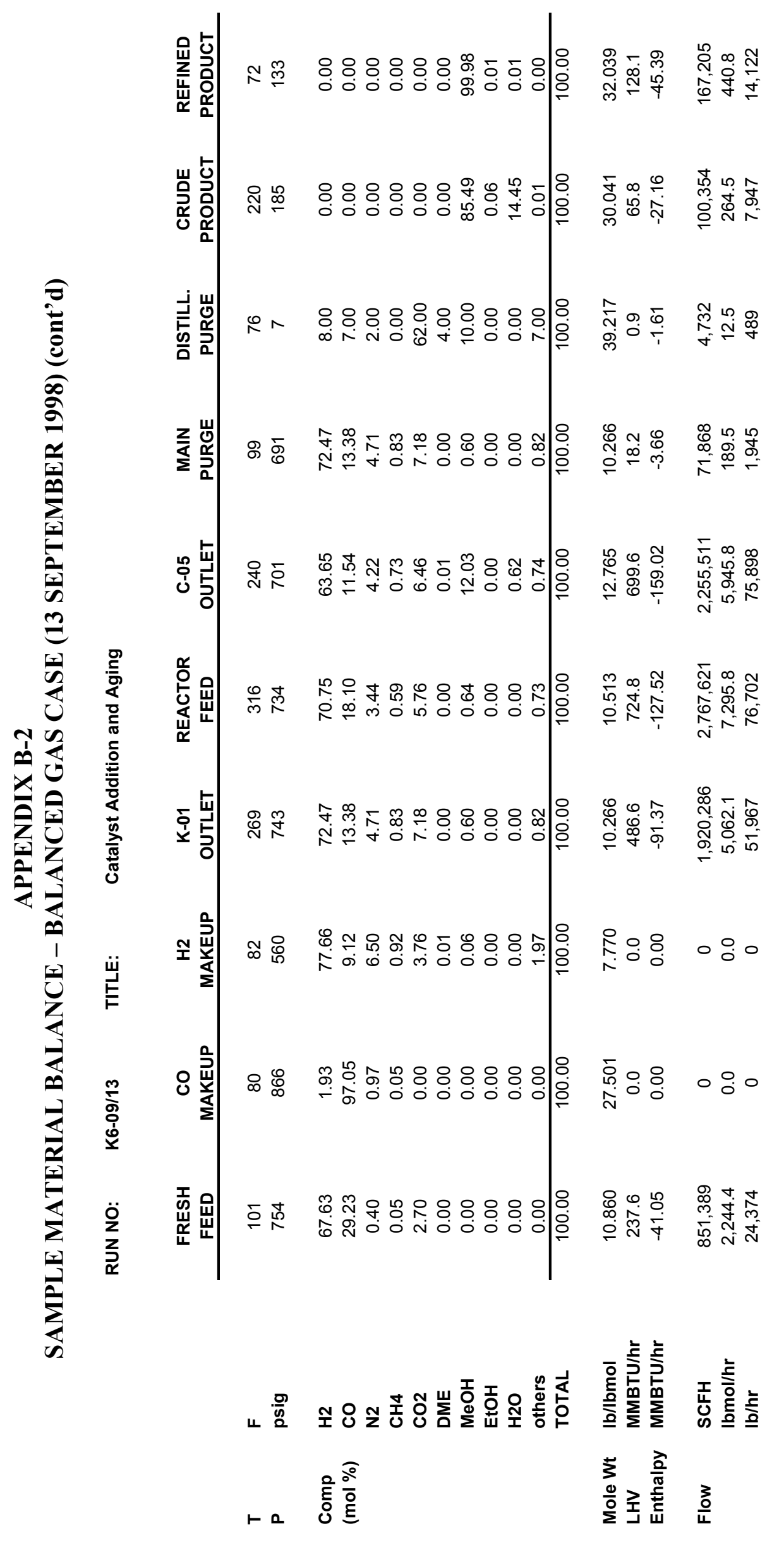




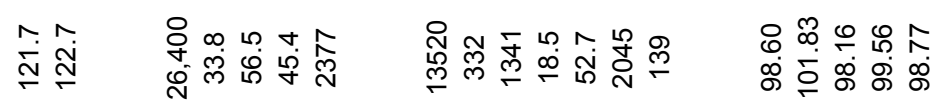

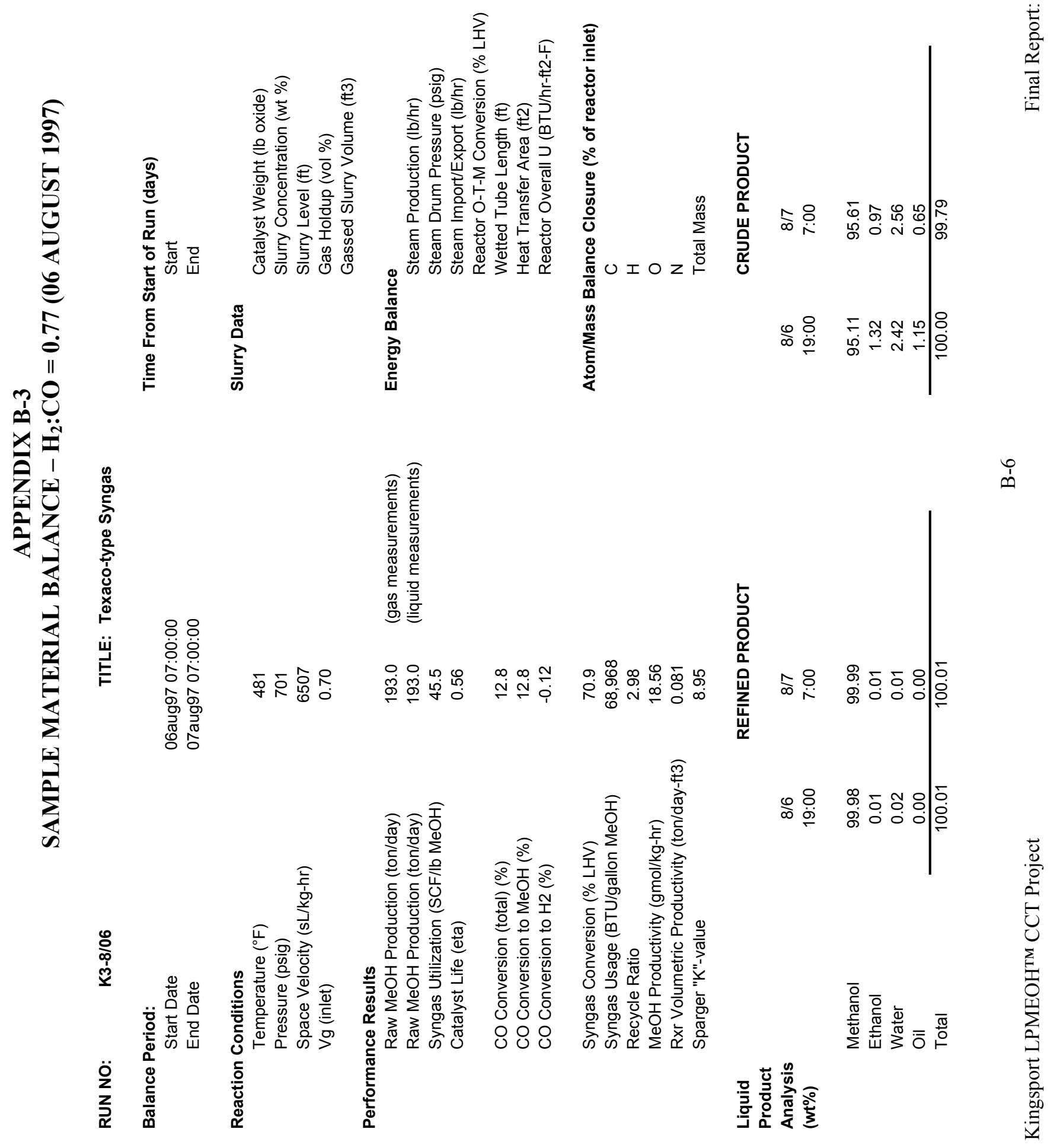




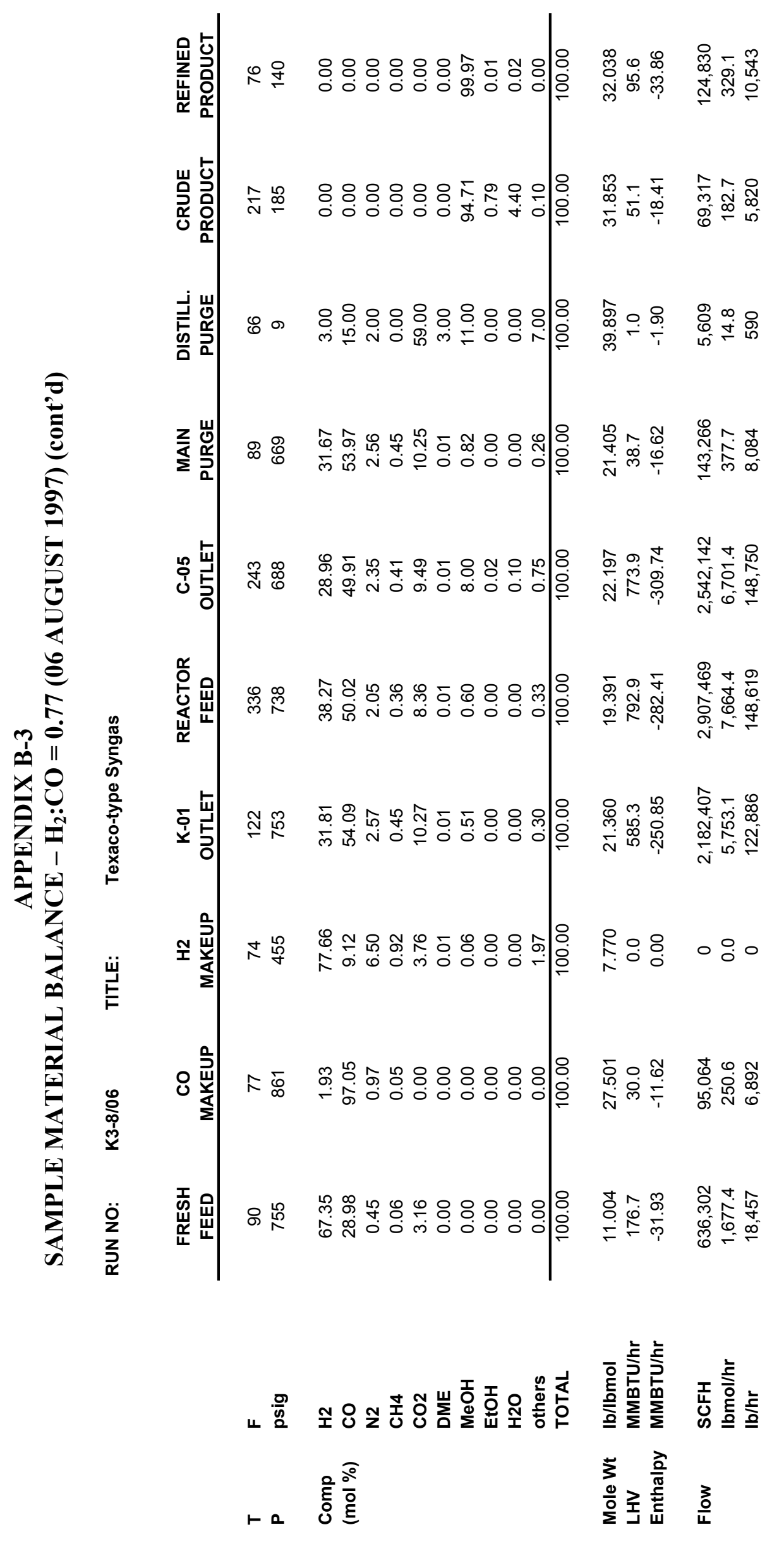

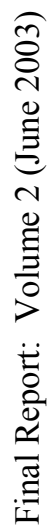




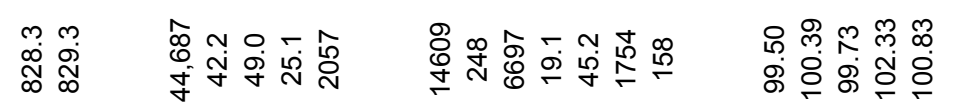

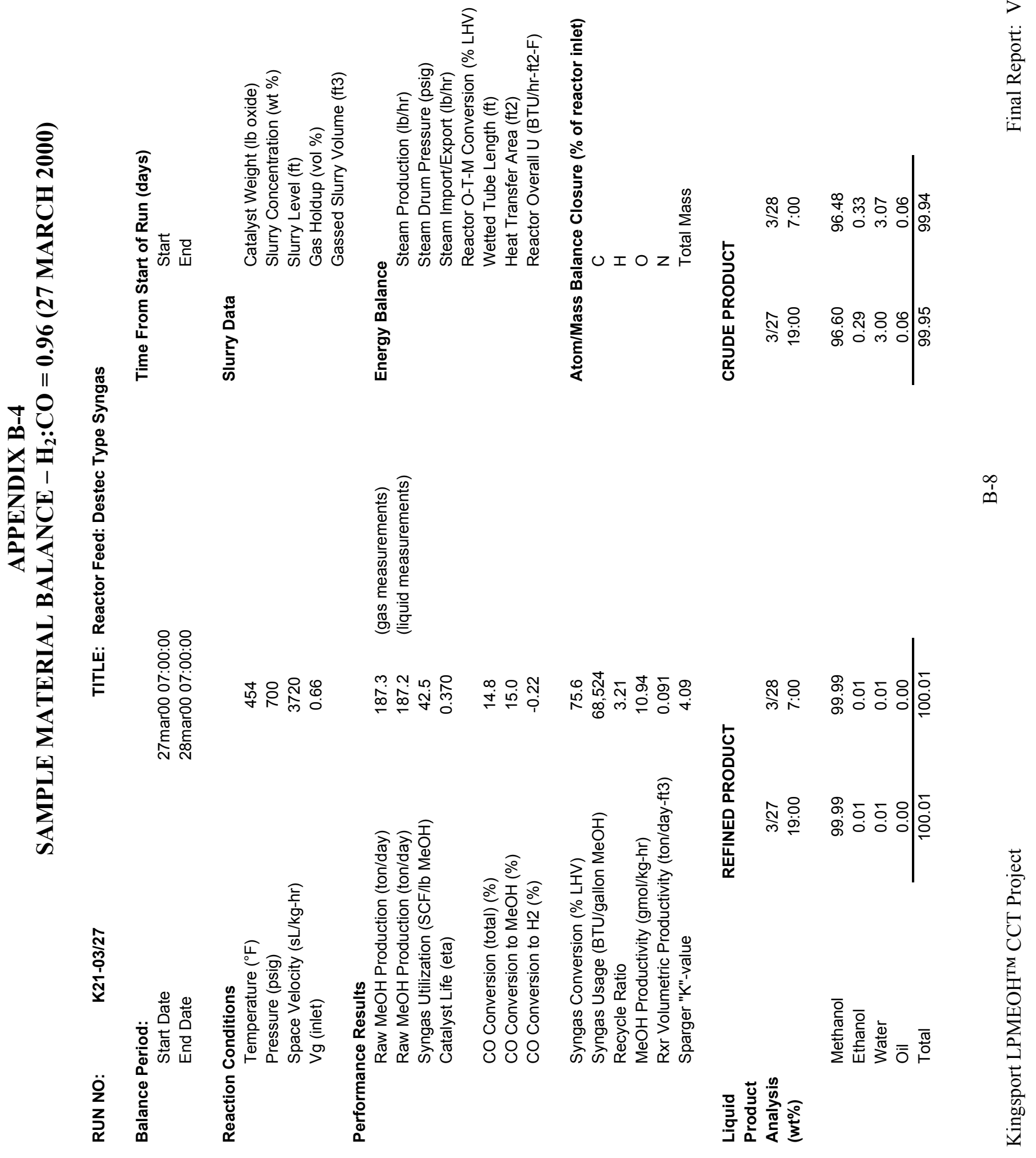




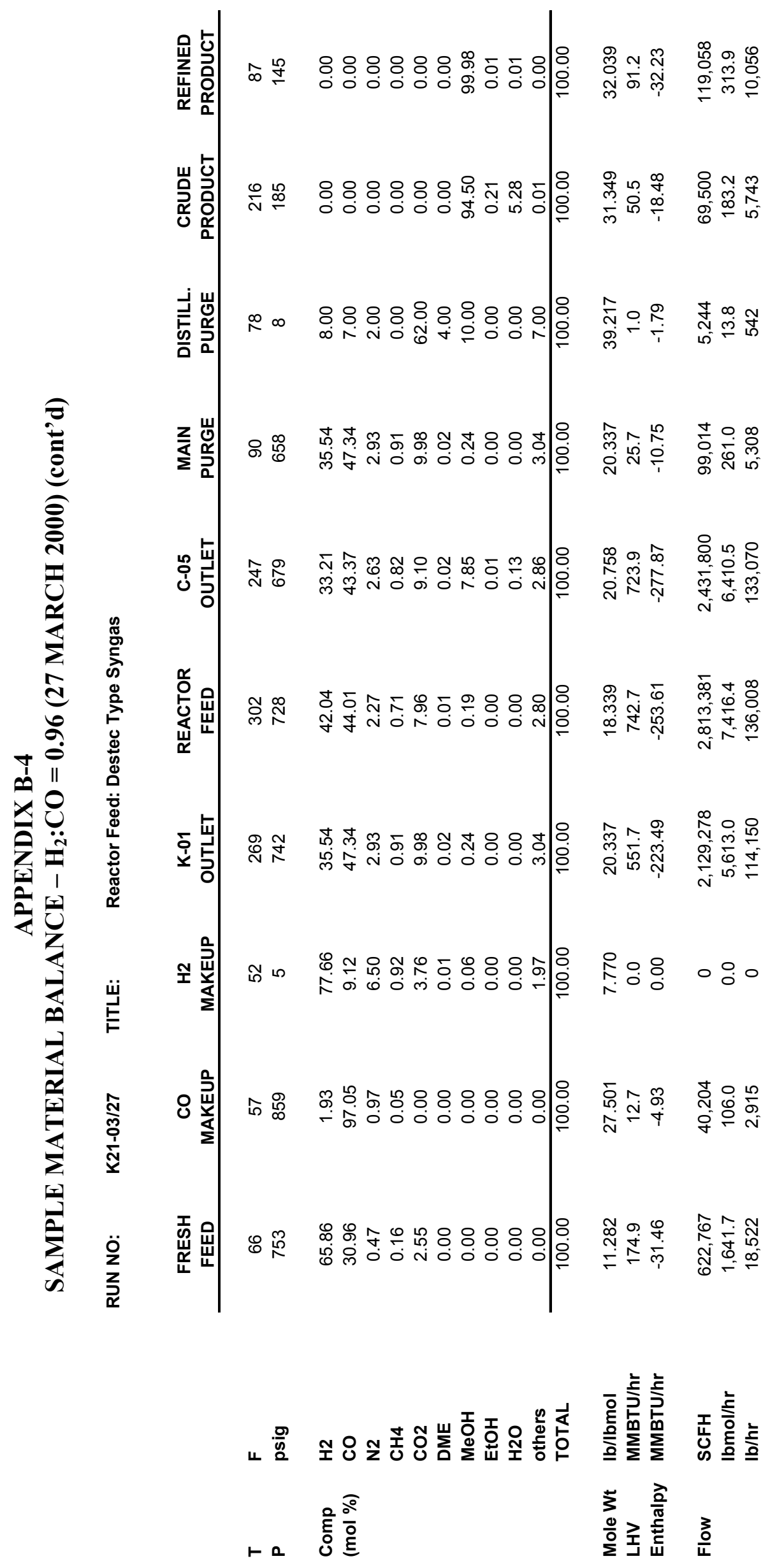


APPENDIX C

\section{DETAILS ON DATA ANALYSIS METHODOLOGY}

C-1 


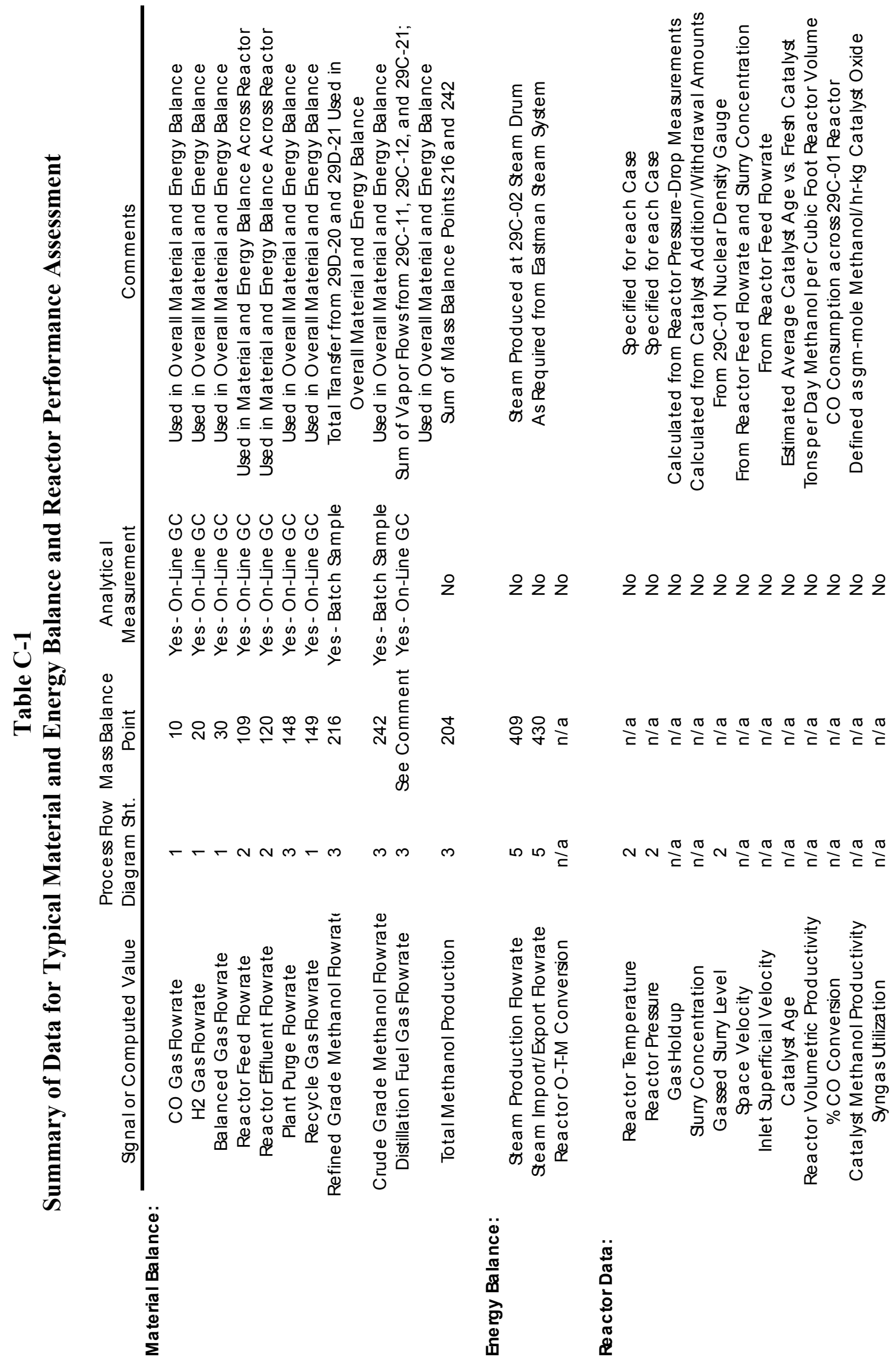

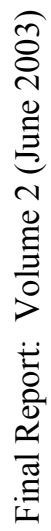

U 


\section{APPENDIX C-2 \\ METHODS OF CALCULATION FOR KEY PROCESS PARAMETERS}

Catalyst Age $(\eta)=\mathrm{k}_{0} / \mathrm{k}_{0}(\mathrm{t}=0)$

where: $\mathrm{k}_{0}=$ the pre-exponential kinetic rate constant for the methanol synthesis reaction at any time

$\mathrm{k}_{0}(\mathrm{t}=0)=$ the pre-exponential kinetic rate constant for the methanol synthesis reaction for fresh catalyst

The rate constants are determined using a proprietary model which computes the kinetic rate constant for the methanol synthesis reaction.

CO Conversion to Methanol [\%] =

(Raw Methanol Flow + Methanol in Main Plant Purge + Methanol in Distillation Purge [all lbmol/hr])

Carbon Monoxide in Reactor Feed $[\mathrm{lbmol} / \mathrm{hr}] * 0.01$

where: Methanol in Main Plant Purge $[1 \mathrm{bmol} / \mathrm{hr}]=$ Main Plant Purge Flow $[1 \mathrm{bmol} / \mathrm{hr}]$ *

Methanol Concentration in Main Plant Purge [mol\%]

Methanol in Distillation Purge $[\mathrm{lbmol} / \mathrm{hr}]=$ Distillation Purge Flow $[\mathrm{lbmol} / \mathrm{hr}]$ *

Methanol Concentration in Distillation Purge [mol\%]

Carbon Monoxide in Reactor Feed [lbmol/hr] = Reactor Feed Flow $[1 \mathrm{bmol} / \mathrm{hr}]$ *

Carbon Monoxide Concentration in Reactor Feed [mol\%]

Gas Holdup $\left(\right.$ vol\%) $=\frac{\left(\text { Liquid-Solid Density }\left[1 \mathrm{~b} / \mathrm{ft}^{3}\right]-3 \text {-Phase Density }\left[\mathrm{lb} / \mathrm{ft}^{3}\right]\right) * 100}{\left(\text { Liquid-Solid Density }\left[\mathrm{lb} / \mathrm{ft}^{3}\right]-\text { Vapor Density }\left[\mathrm{lb} / \mathrm{ft}^{3}\right]\right)}$

(Liquid-Solid Density $\left[\mathrm{lb} / \mathrm{ft}^{3}\right]$ - Vapor Density $\left[1 \mathrm{~b} / \mathrm{ft}^{3}\right]$ )

where: Vapor Density $\left[\mathrm{lb} / \mathrm{ft}^{3}\right]$ is calculated using the composition at the Reactor

Effluent, and at the measured temperature and pressure of the Reactor

3-Phase Density $\left[\mathrm{lb} / \mathrm{ft}^{3}\right]=\quad$ Pressure Drop $[\mathrm{psi}] * 144\left[\mathrm{in}^{2} / \mathrm{ft}^{2}\right]$

Span between Taps of Pressure Drop Measurement [ft]

Liquid-Solid Phase Density $\left[\mathrm{lb} / \mathrm{ft}^{3}\right]$ is a function of the catalyst concentration [wt\%], which is iterated until the calculated weight of catalyst matches the catalyst weight in the Reactor.

General Notes:

a. All terms in Italics refer to measured variables, either by field instruments or gas chromatographs. 


\section{APPENDIX C-2}

\section{METHODS OF CALCULATION FOR KEY PROCESS PARAMETERS (cont'd)}

Gassed Slurry Volume $\left[\mathrm{ft}^{3}\right]=$ Reactor Cylindrical Volume $\left[\mathrm{ft}^{3}\right]+$ Reactor Head Volume $\left[\mathrm{ft}^{3}\right]$

where: Reactor Cylindrical Volume $\left[\mathrm{ft}^{3}\right]=\mathrm{A}\left[\mathrm{ft}^{2}\right]^{*}$ Cylindrical Height $[\mathrm{ft}]$

$\mathrm{A}\left[\mathrm{ft}^{2}\right]=\frac{\Pi}{4} *(\text { Reactor ID }[\mathrm{ft}])^{2} *($ Fraction Open Area $)$

Reactor ID $=$ Reactor Inside Diameter $=7.5 \mathrm{ft}$

Fraction Open Area $=0.9652$ (3.48\% of the cross-sectional area of the Reactor is occupied by the tubes of the internal heat exchanger)

Cylindrical Height $[\mathrm{ft}]=$ Gassed Slurry Height $[\mathrm{ft}]-($ Reactor ID [ft] $)$

Note: The term "(Reactor ID)/4" is the depth of the bottom head of the Reactor.

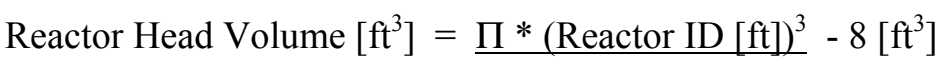
24

Note: 8 cubic feet is subtracted from the Reactor Head Volume to account for the displacement of the gas sparger and the header piping for the internal heat exchanger.

Inlet Superficial Velocity $[\mathbf{f t} / \mathbf{s}]=\underline{\text { Reactor Feed Flow }[\mathrm{lbmol} / \mathrm{hr}] * \mathrm{~V}\left[\mathrm{ft}^{3} / \mathrm{lbmol}\right]}$

$$
3,600[\mathrm{~s} / \mathrm{hr}] * \mathrm{~A}\left[\mathrm{ft}^{2}\right]
$$

where: $\mathrm{V}\left[\mathrm{ft}^{3} / \mathrm{lbmol}\right]=\underline{10.73 *\left(\text { Reactor Temperature }\left[{ }^{\circ} \mathrm{F}\right]+459.67\right)}$

(Reactor Pressure $[\mathrm{psig}]+14.1)$

$\mathrm{A}\left[\mathrm{ft}^{2}\right]=\frac{\Pi}{4} *(\text { Reactor ID }[\mathrm{ft}])^{2} *($ Fraction Open Area $)$

Reactor ID $=$ Reactor Inside Diameter $=7.5 \mathrm{ft}$

Fraction Open Area $=0.9652(3.48 \%$ of the cross-sectional area of the Reactor is occupied by the tubes of the internal heat exchanger)

General Notes:

a. All terms in Italics refer to measured variables, either by field instruments or gas chromatographs. 


\title{
APPENDIX C-2
}

\section{METHODS OF CALCULATION FOR KEY PROCESS PARAMETERS (cont'd)}

\author{
Methanol Productivity [gmol/kg-hr] = \\ (Methanol in Reactor Effluent $[1 \mathrm{bmol} / \mathrm{hr}]$ - Methanol in Reactor Feed [1bmol/hr]) * 1,000 [g/kg] \\ Catalyst Weight (lb oxide) \\ where: Methanol in Reactor Effluent $[\mathrm{lbmol} / \mathrm{hr}]=$ Reactor Effluent Flow $[\mathrm{lbmol} / \mathrm{hr}]$ * \\ Methanol Concentration in Reactor Effluent Stream [mol\%] \\ Methanol in Reactor Feed [lbmol/hr] = Reactor Feed Flow $[1 \mathrm{bmol} / \mathrm{hr}] *$ \\ Methanol Concentration in Reactor Feed Stream [mol\%]
}

\begin{abstract}
Reactor O-T-M Conversion [\%] = LHV of Raw Methanol * 100
LHV of Reactor Feed

Note: Lower heating values (LHV's) for Raw Methanol and Reactor Feed are calculated from compositions of each stream, in units of million Btu per hour.
\end{abstract}
Reactor Volumetric Productivity [TPD $\left./ \mathbf{f t}^{3}\right]=$ Raw Methanol Flow [TPD]
Gassed Slurry Volume [ $\left.\mathrm{ft}^{3}\right]$

Space Velocity [sL/kg-hr] $=\underline{\text { Reactor Feed Flow }[\mathrm{lbmol} / \mathrm{hr}] * 10,175\left[\mathrm{sL} / \mathrm{lbmol} @, 0^{\circ} \mathrm{C}\right]}$

Catalyst Weight [lb oxide] $* 0.454[\mathrm{~kg} / \mathrm{lb}]$

Sparger Resistance Coefficient " $K$ " =

Sparger Pressure Drop $[\mathrm{psi}] *$ Reactor Feed Density $\left[\mathrm{lb} / \mathrm{ft}^{3}\right] *$ constant

$(\text { Reactor Feed Flow [KSCFH] * Reactor Feed Molecular Weight [lb/lbmol] })^{2}$

\section{Syngas Usage [Btu/gallon Methanol] = \\ Syngas LHV to Methanol [Btu/hr] *24 [hr/day] * 6.642 [lb/gallon Methanol] \\ Raw Methanol Flow [TPD] * 2,000 [lb/ton]}

where: Syngas LHV to Methanol $[\mathrm{Btu} / \mathrm{hr}]=$ the difference between the Lower Heating Value of the three feed gas streams (Balanced Gas, $\mathrm{CO}$ Gas, $\mathrm{H}_{2} \mathrm{Gas}$ ) and the two purge gas streams (Main Plant Purge, Distillation Purge). Lower heating values are calculated from the compositions of each stream.

General Notes:

a. All terms in Italics refer to measured variables, either by field instruments or gas chromatographs. 


\title{
APPENDIX C-2
}

\section{METHODS OF CALCULATION FOR KEY PROCESS PARAMETERS (cont'd)}

\author{
Syngas Utilization [SCF/lb Methanol] = \\ (Balanced Gas Flow [SCFH] + CO Gas Flow [SCFH]) * 24 [hr/day] \\ Raw Methanol Flow [TPD] * 2,000 [1b/ton]
}

General Notes:

a. All terms in Italics refer to measured variables, either by field instruments or gas chromatographs. 
APPENDIX D

DATA SUMMARY TABLES

D-1 


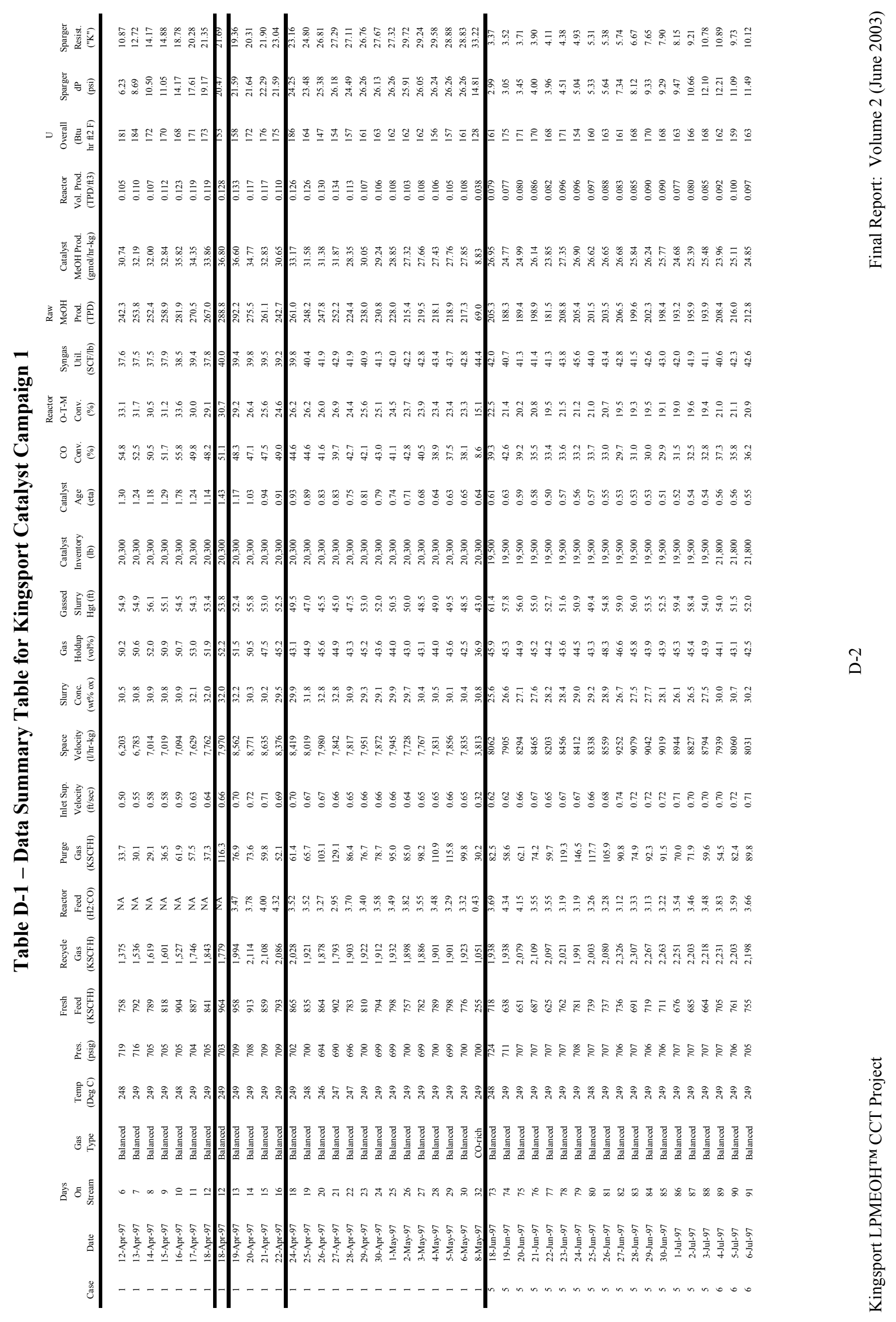




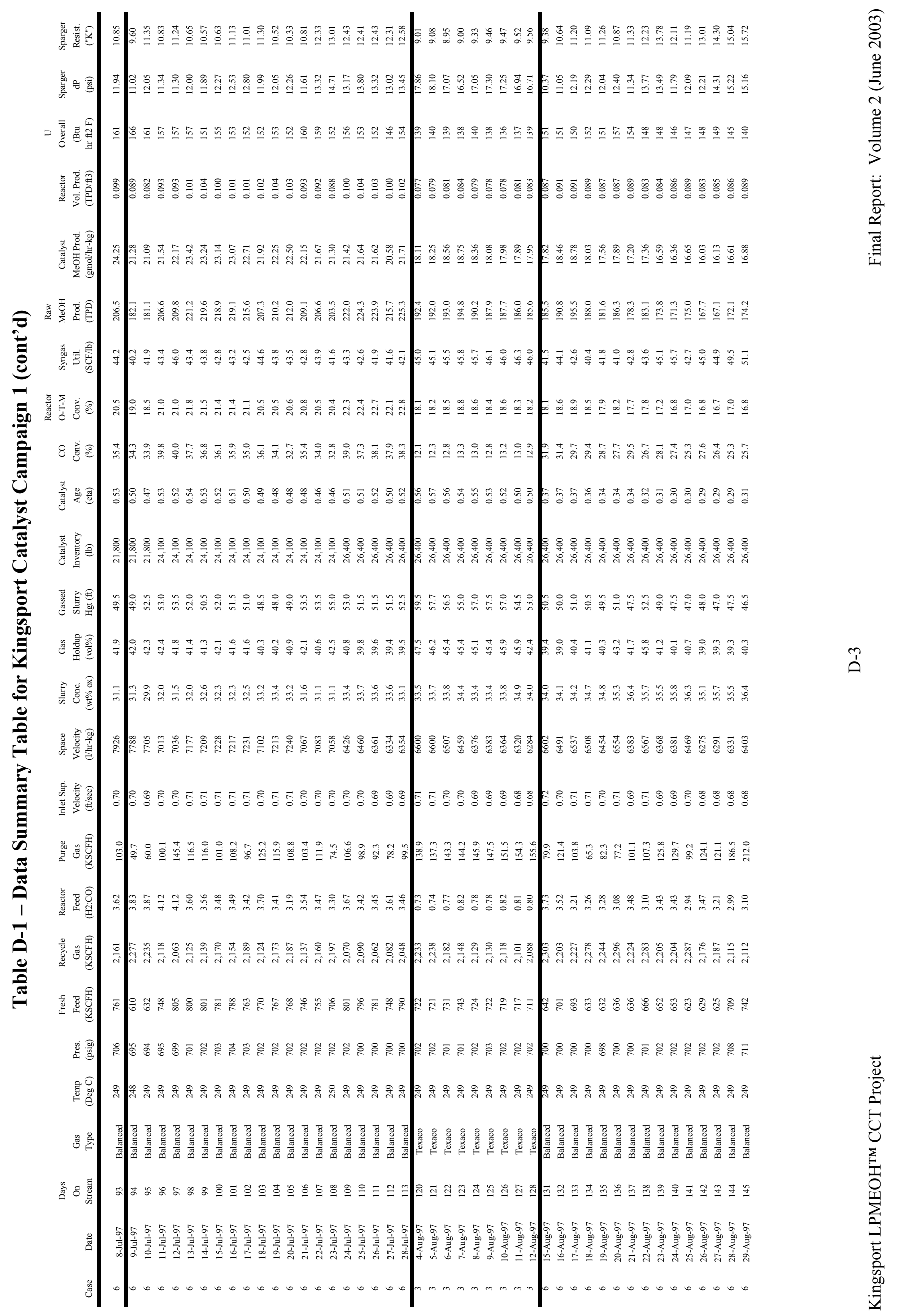




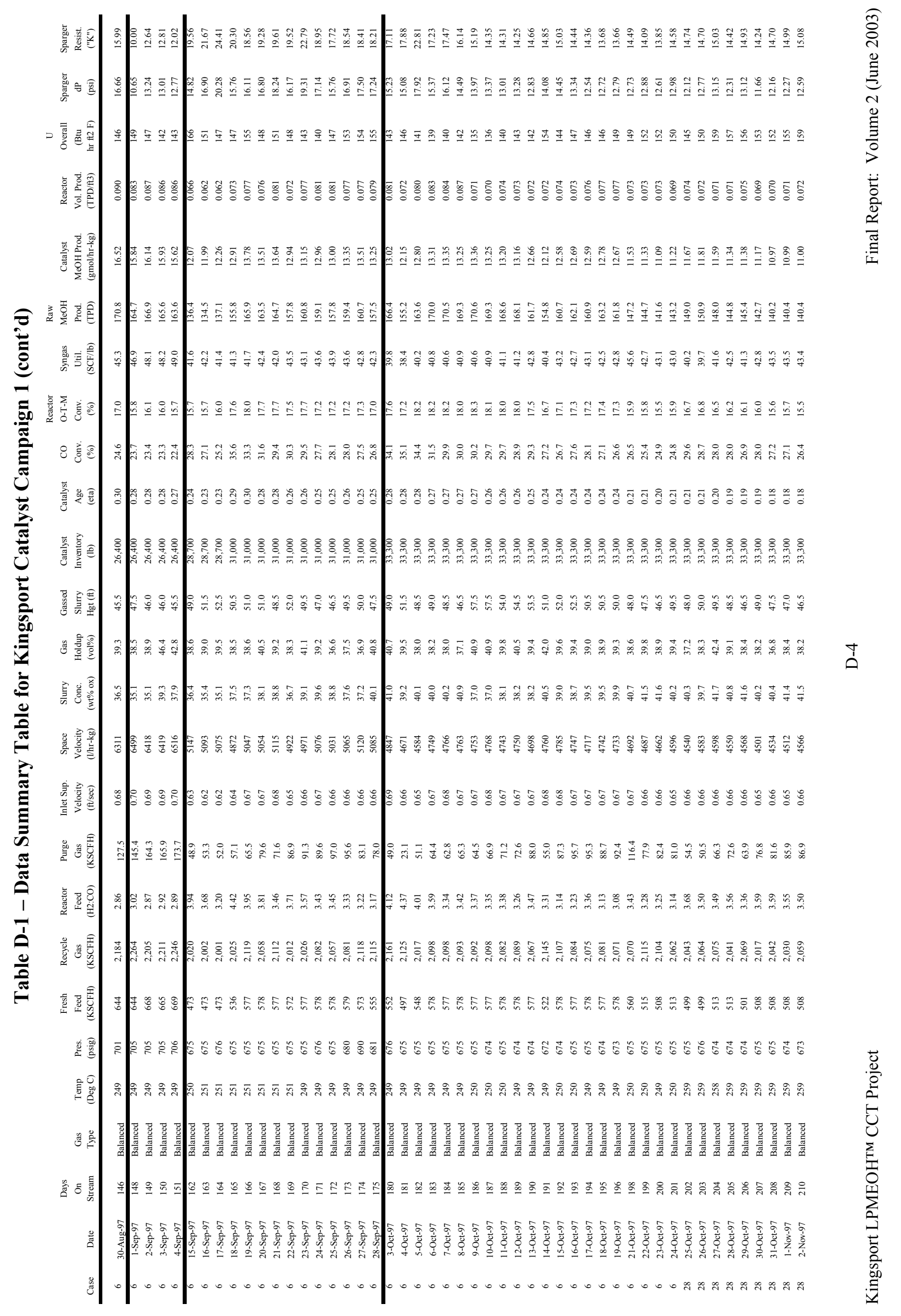




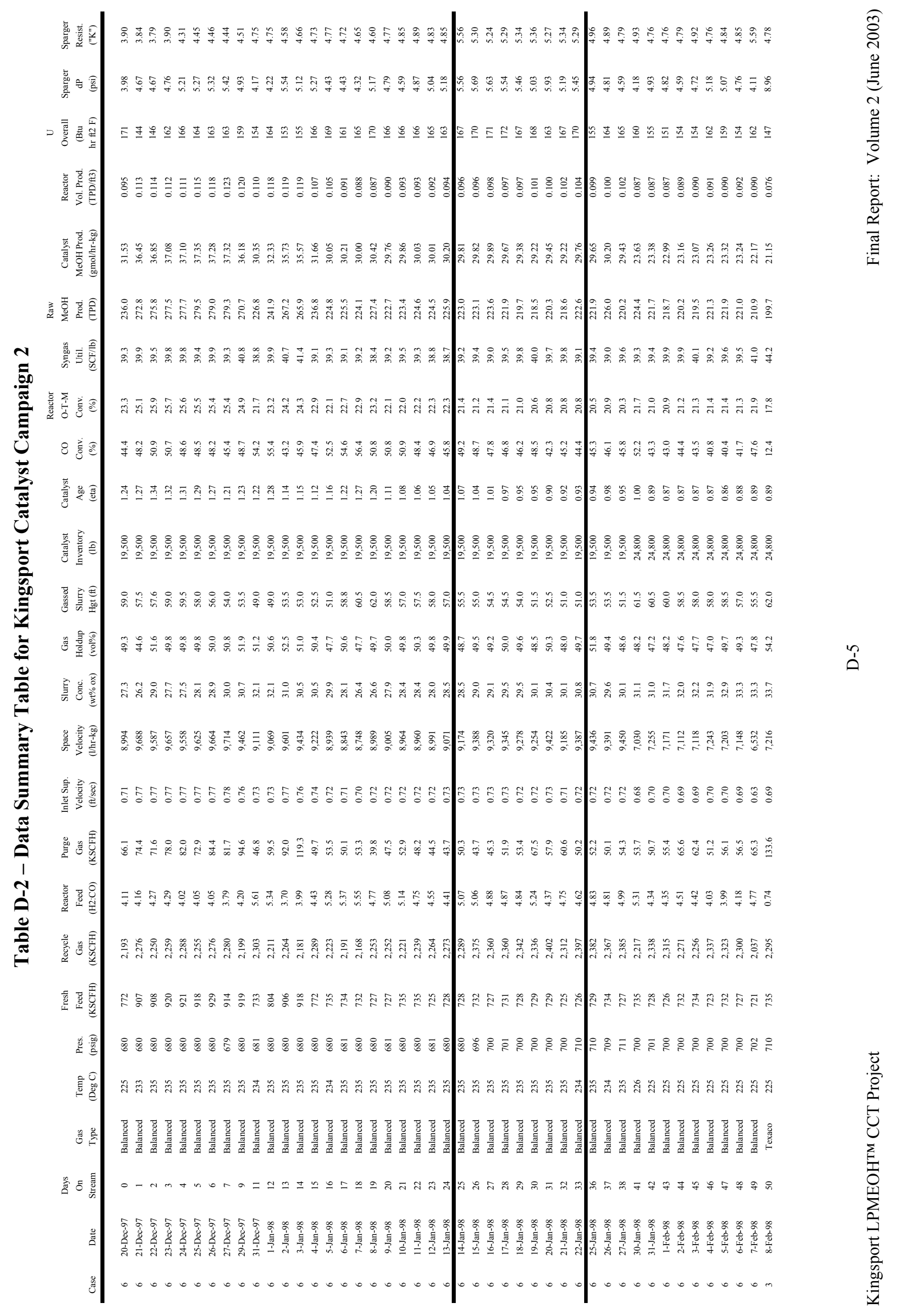




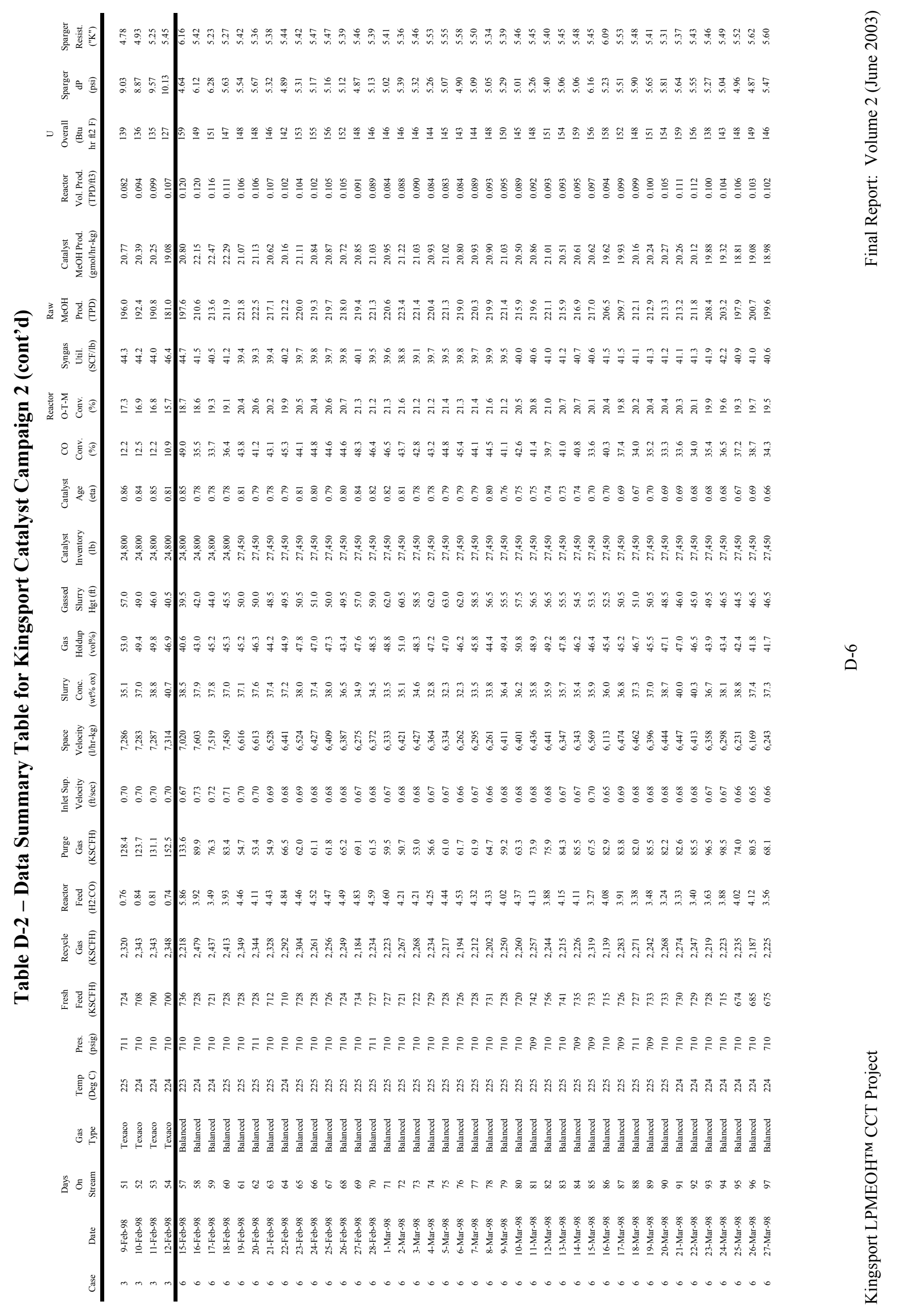




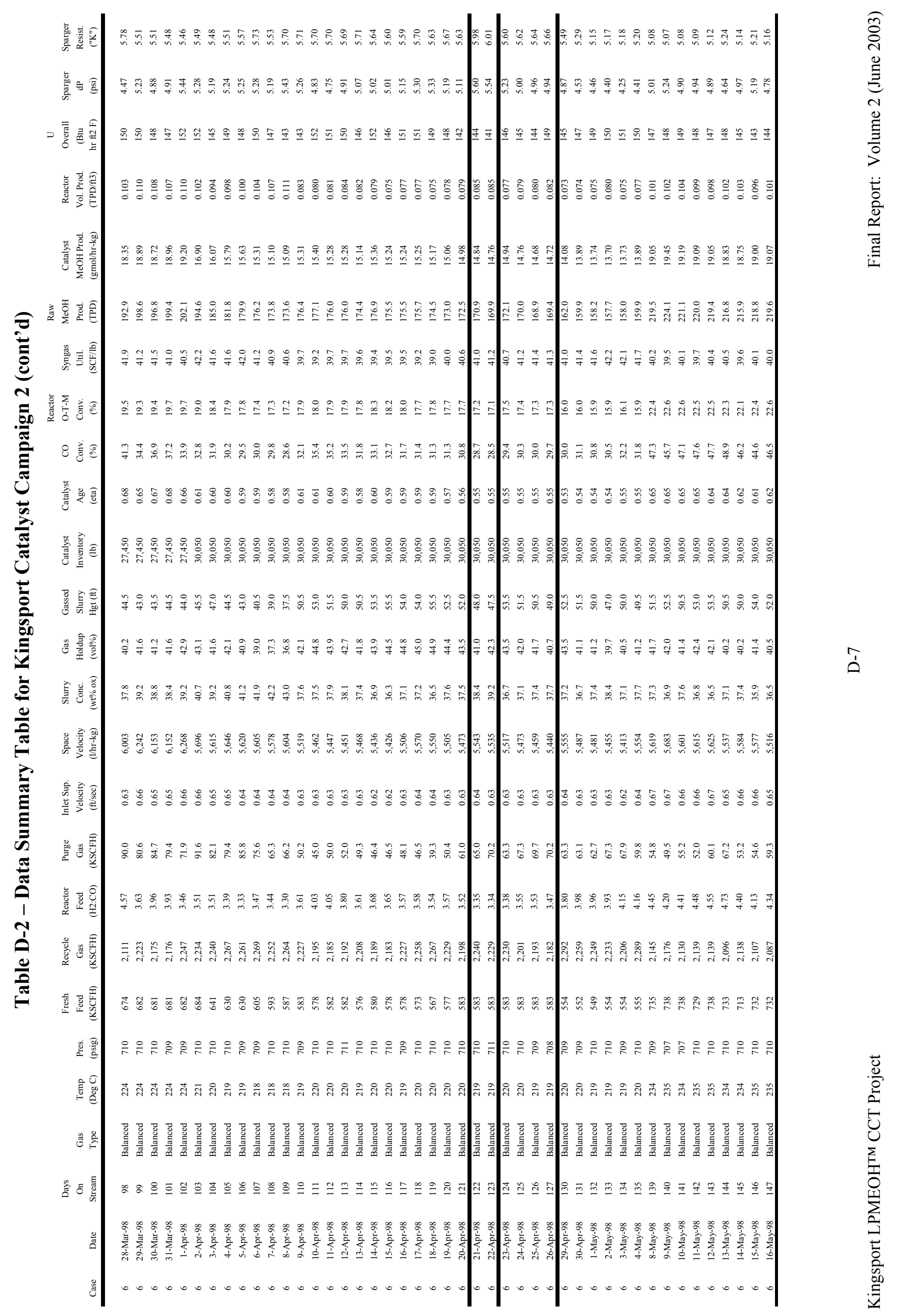




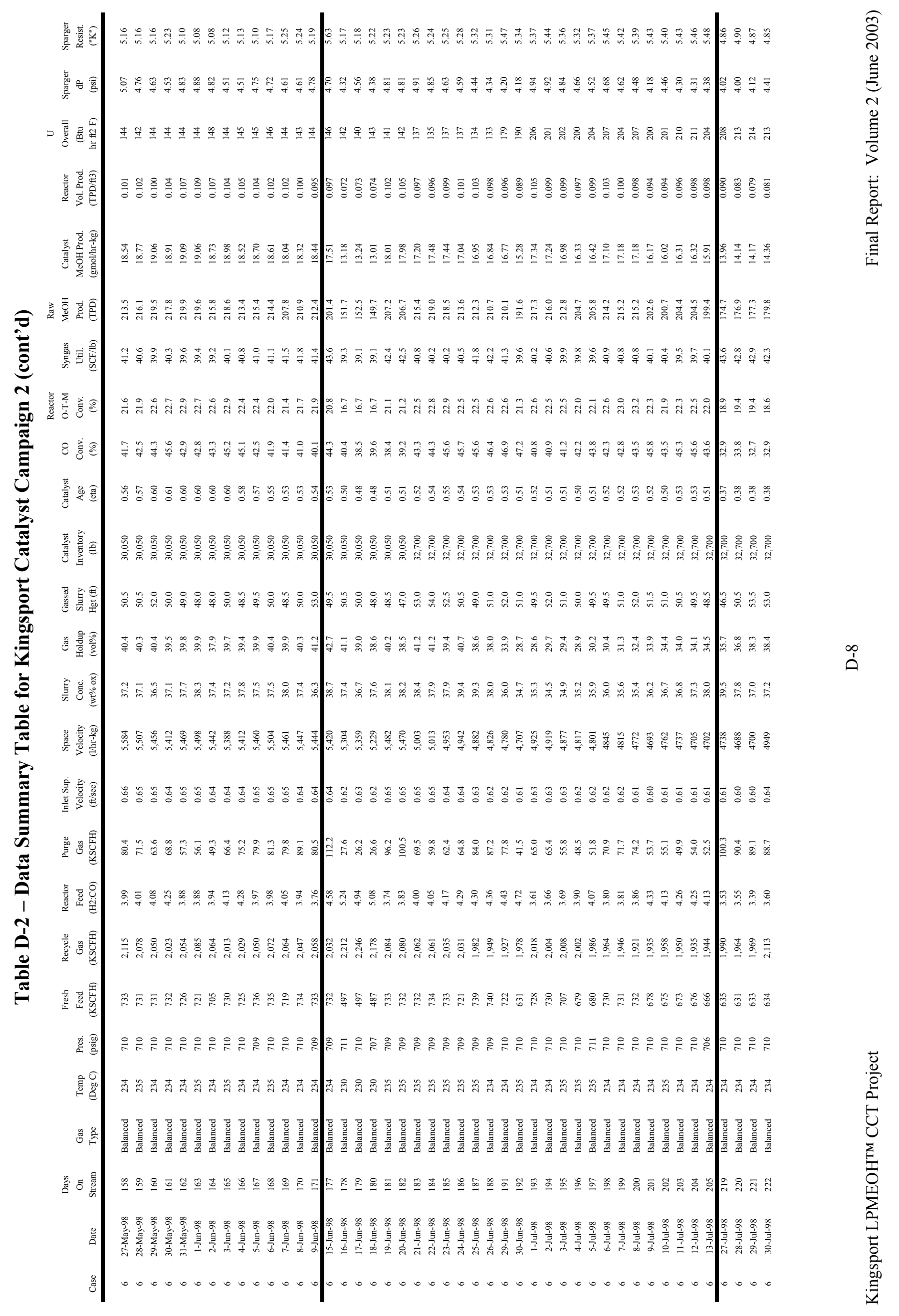




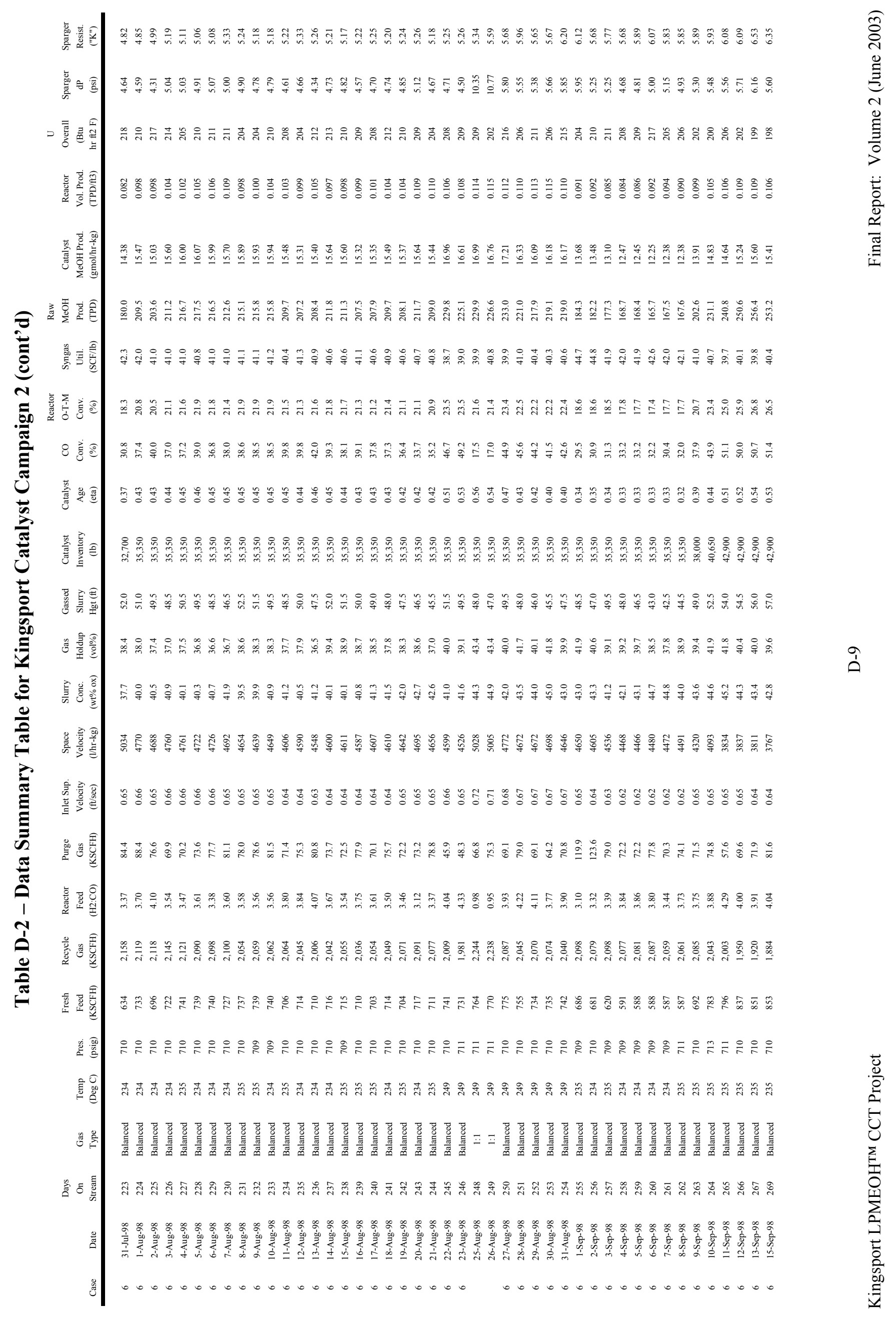




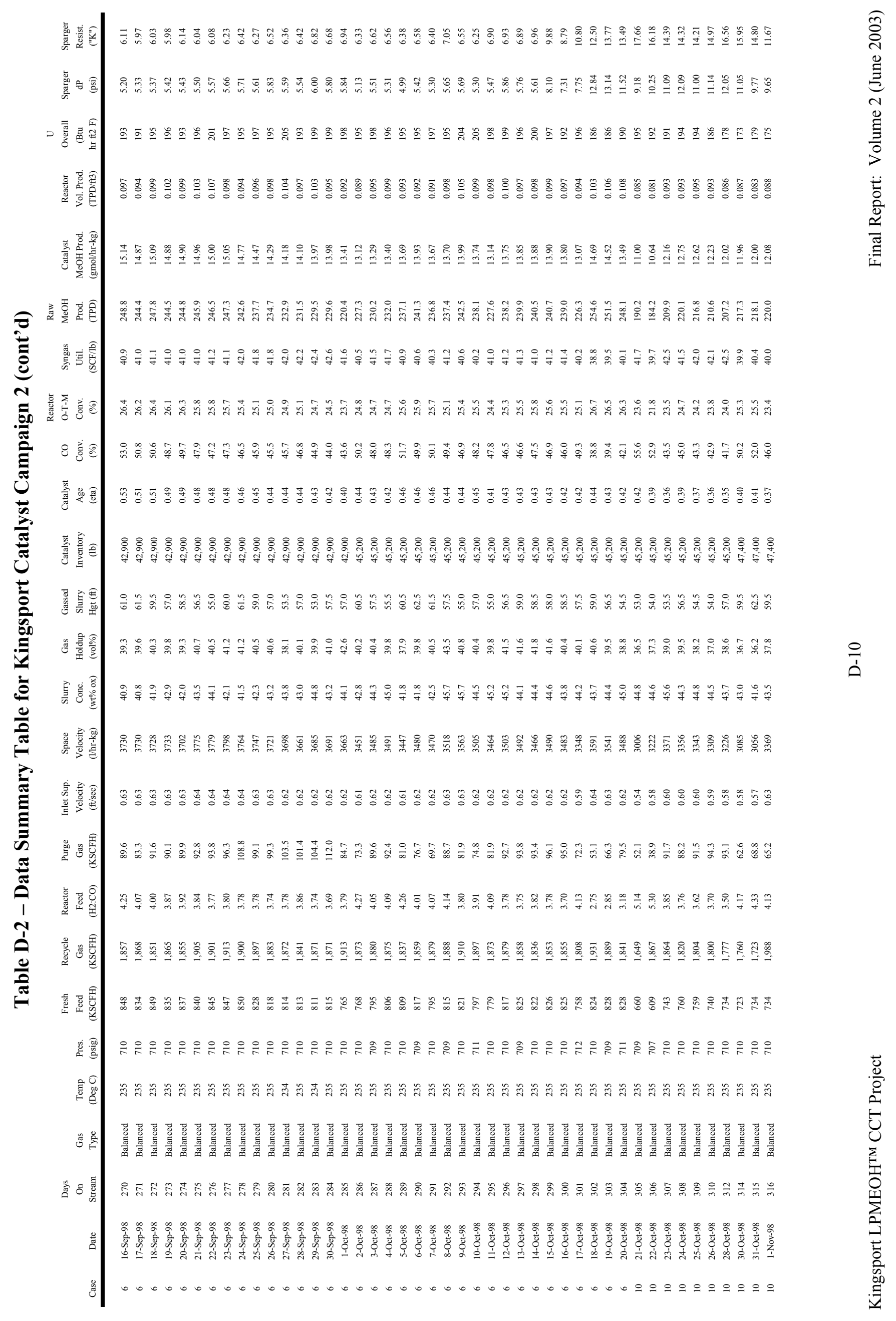




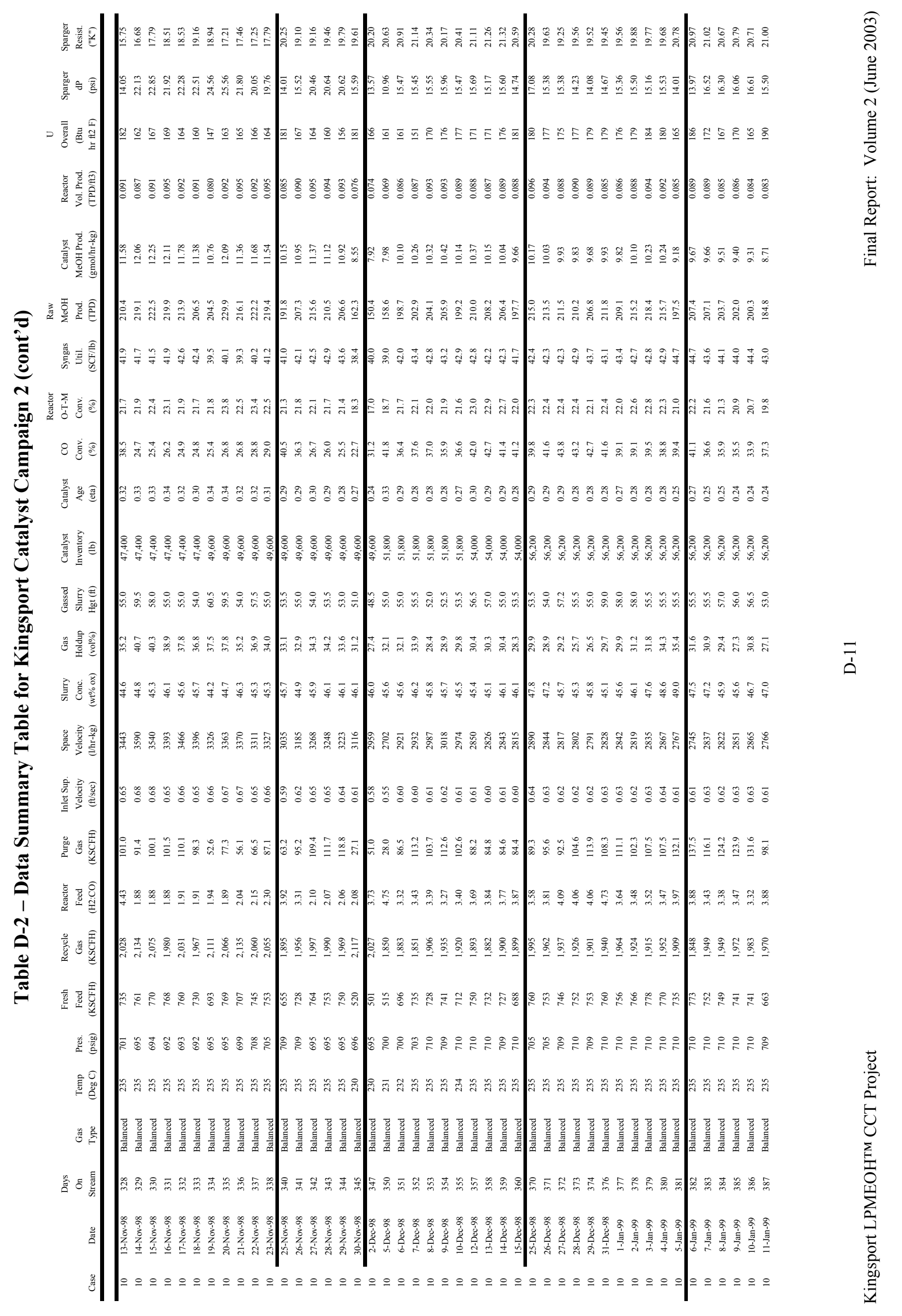




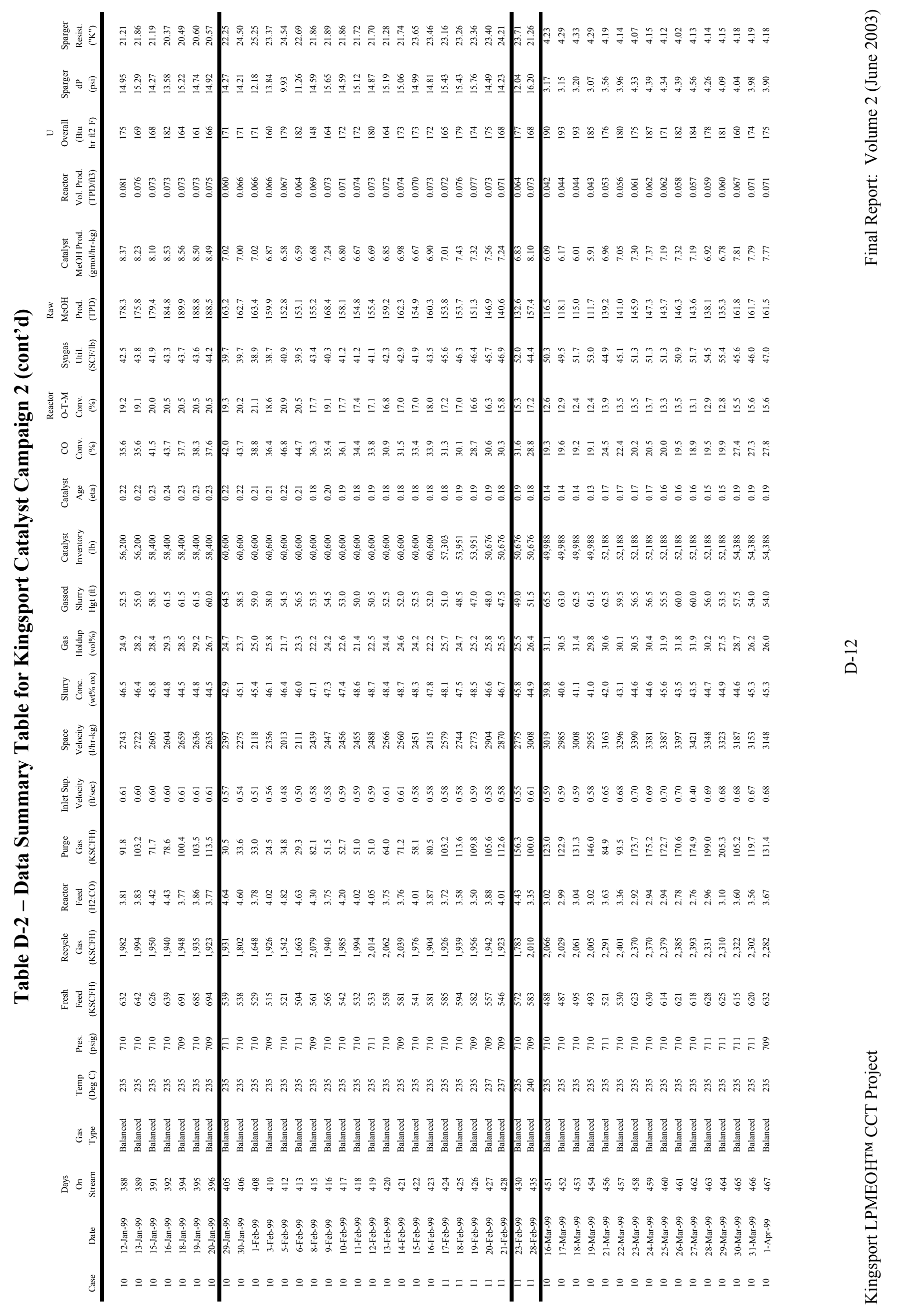




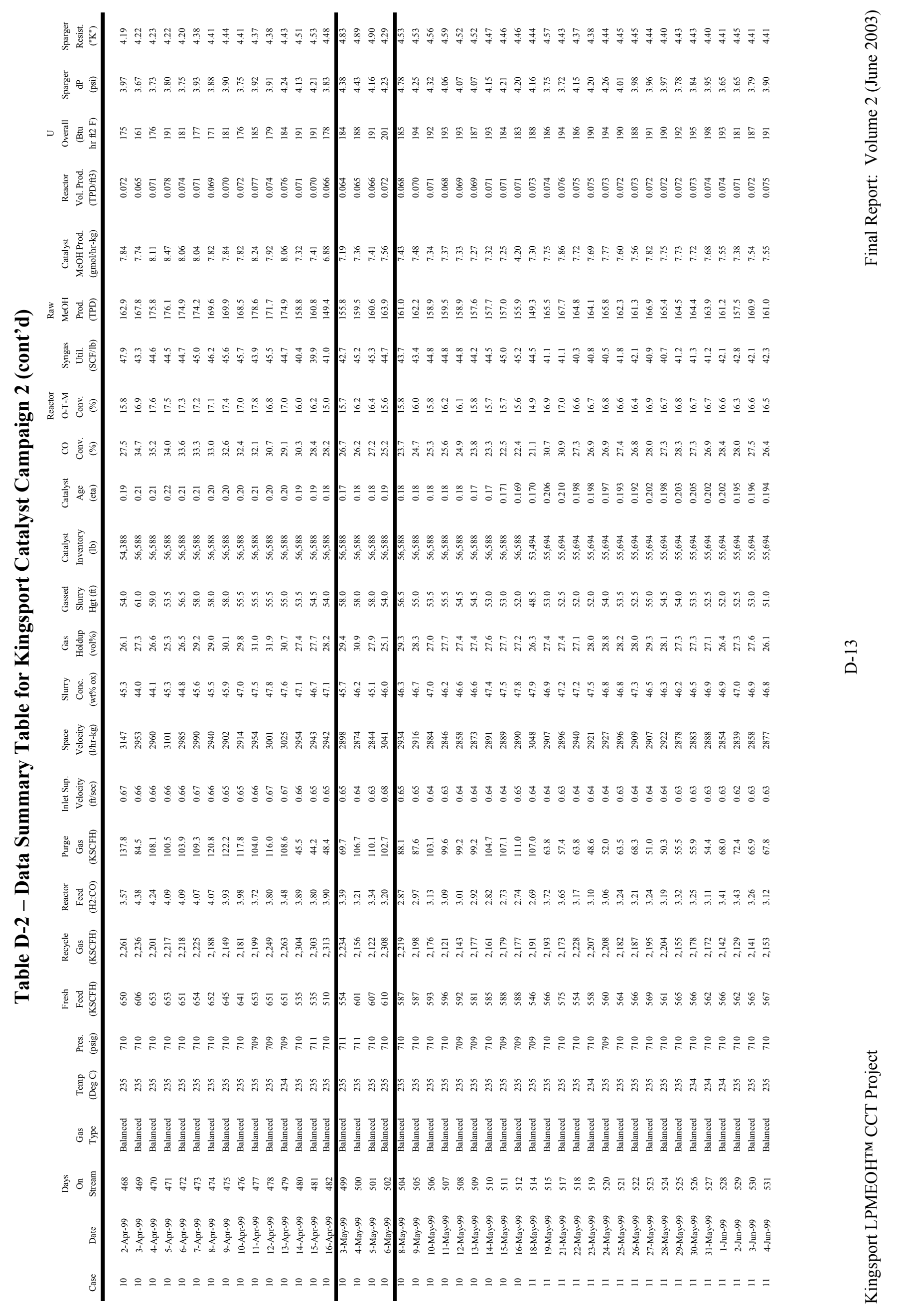




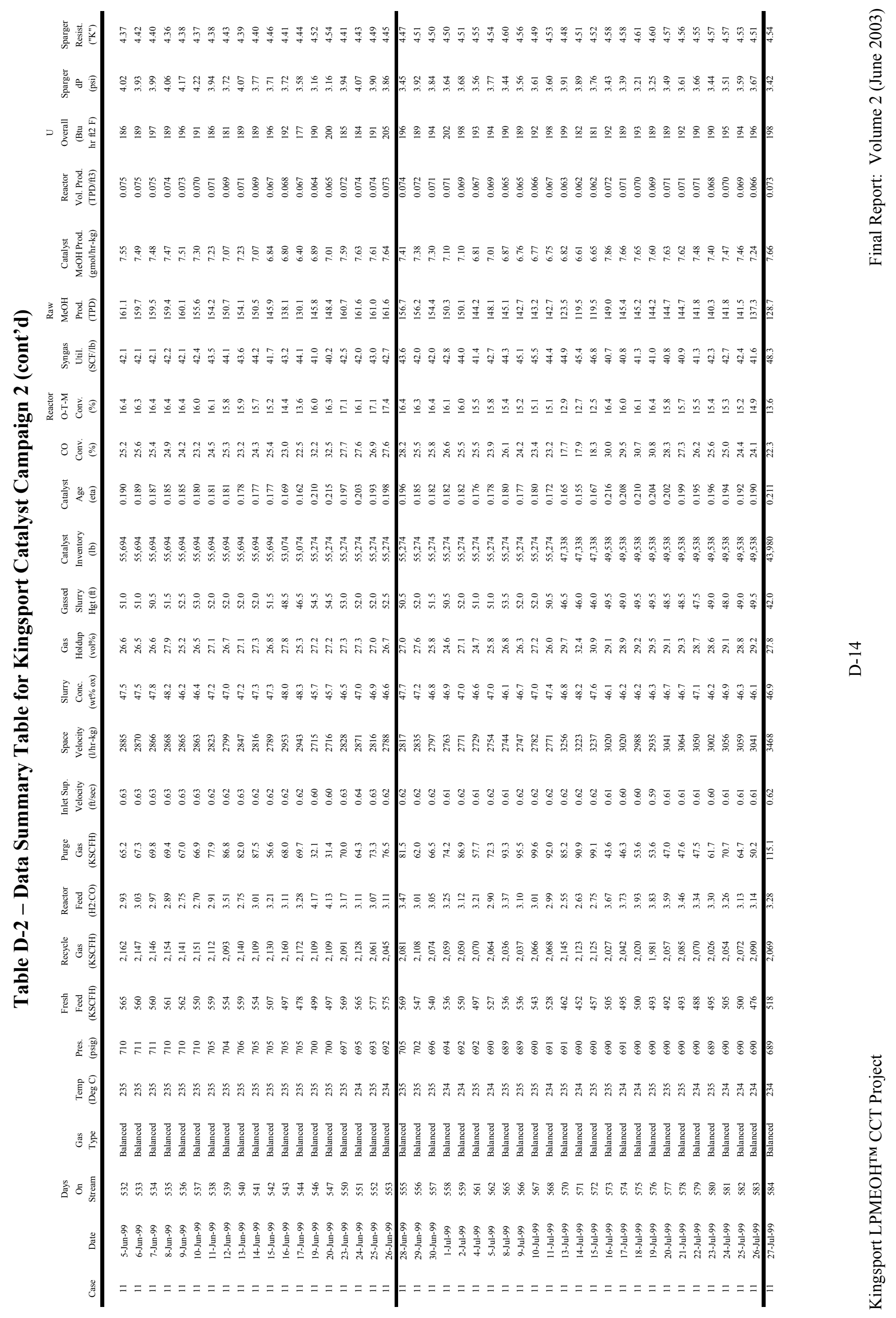




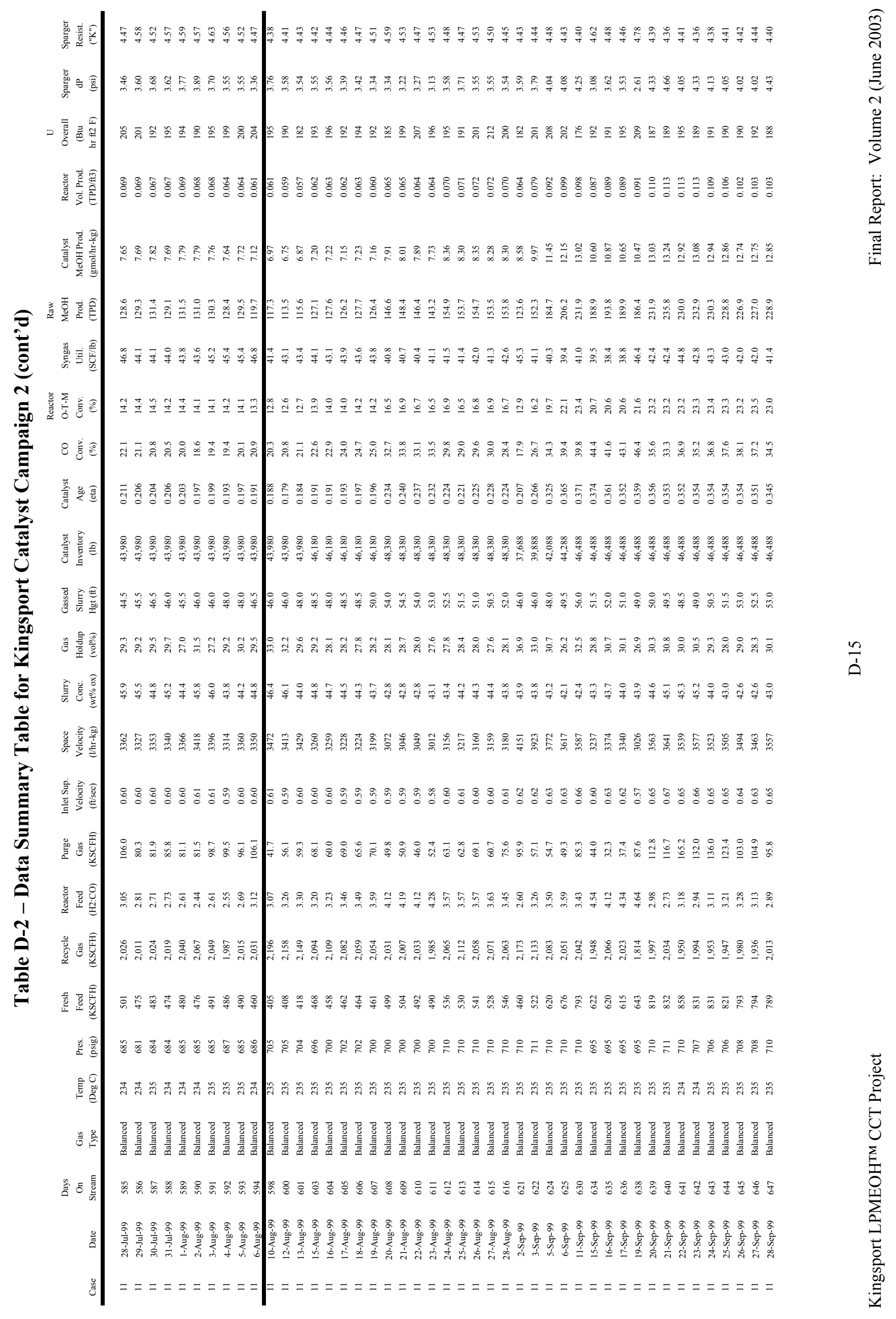




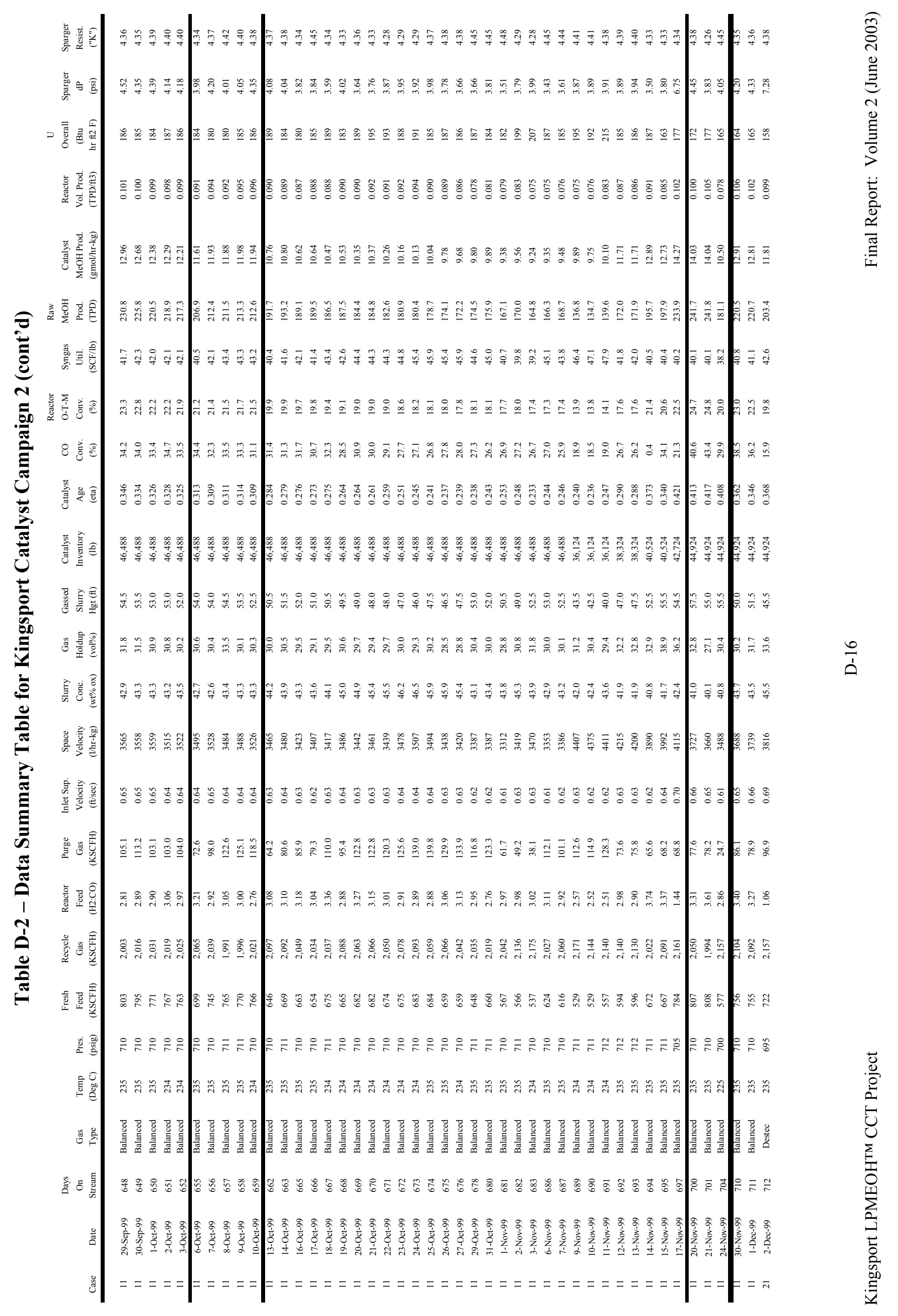




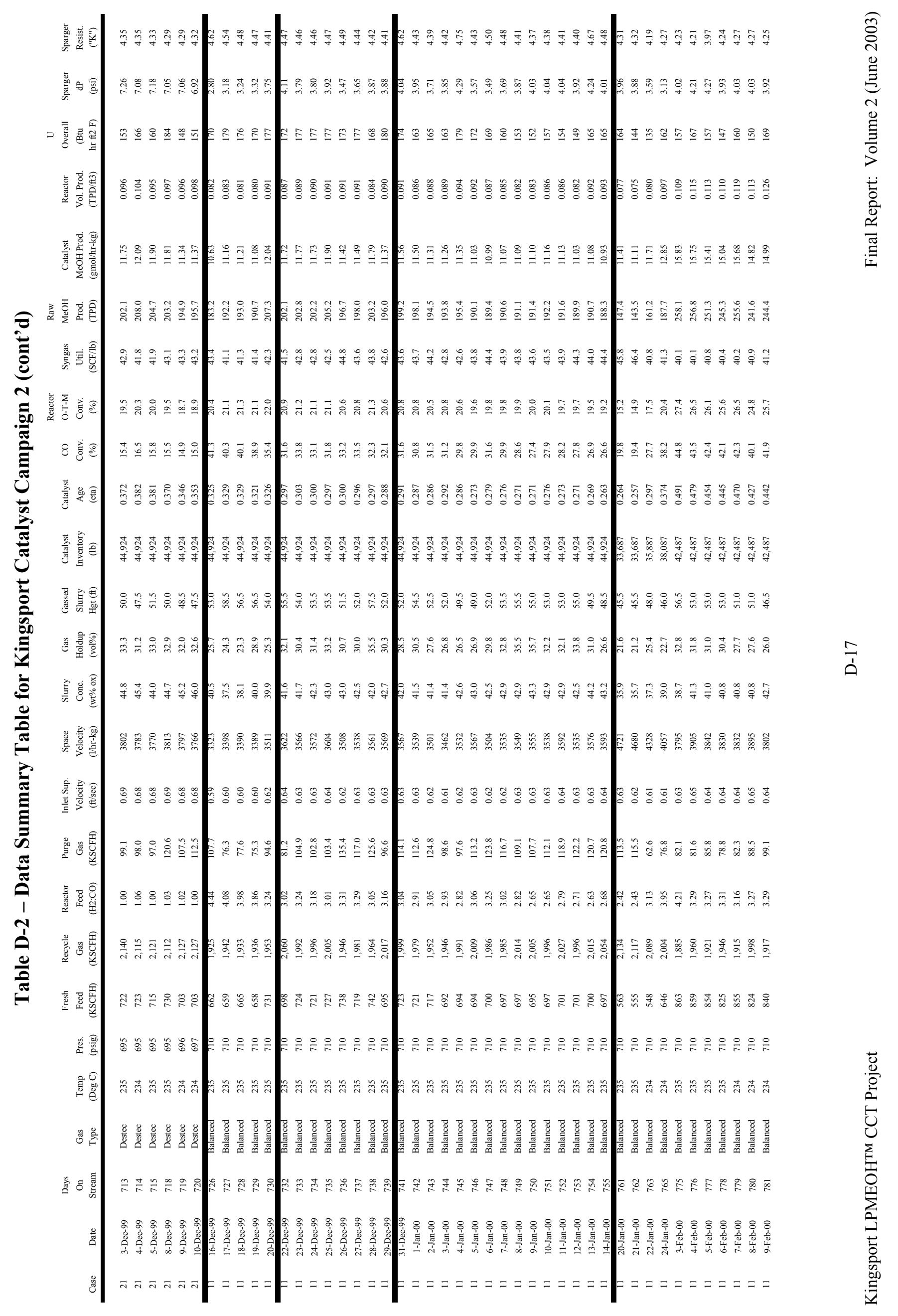




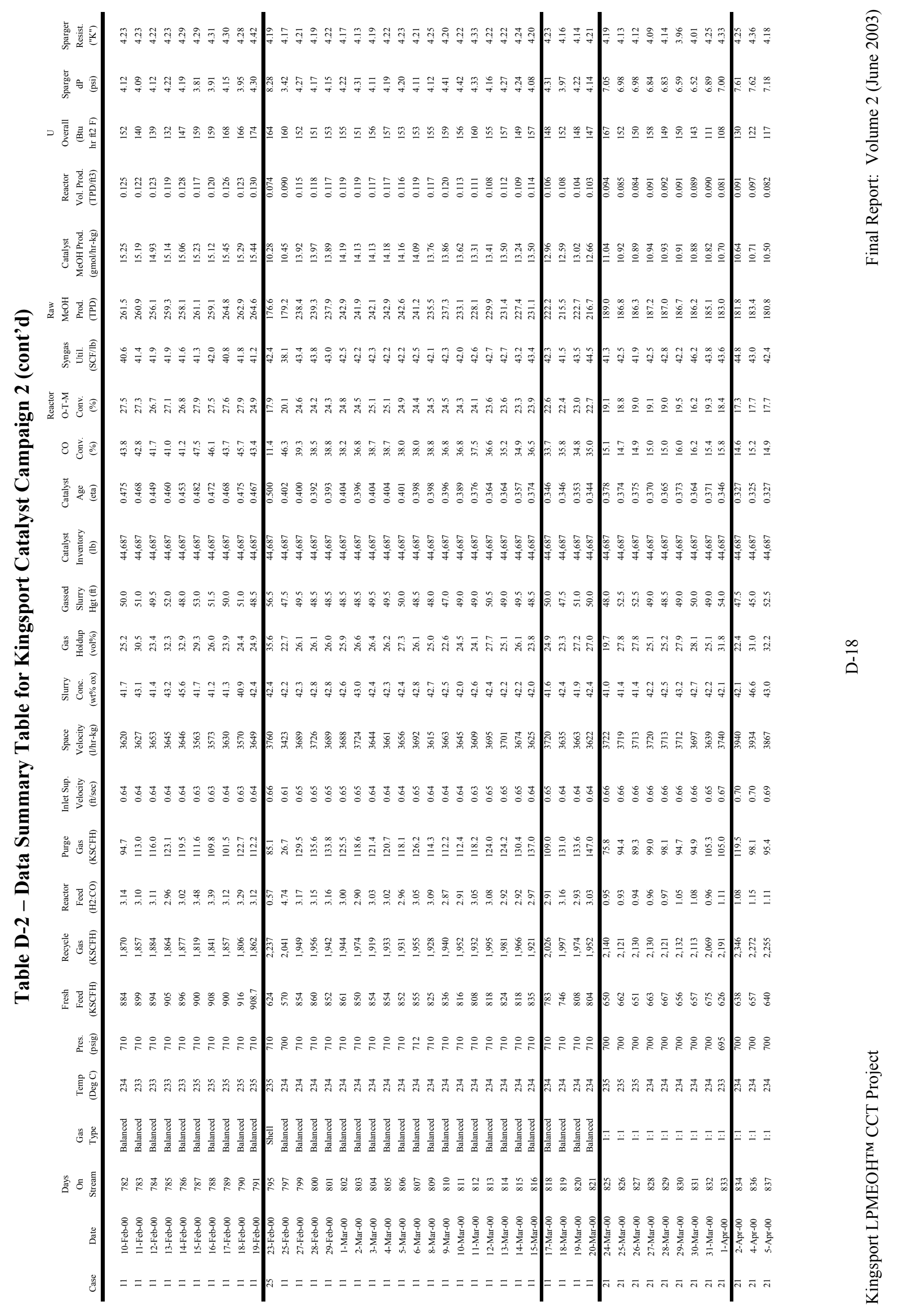




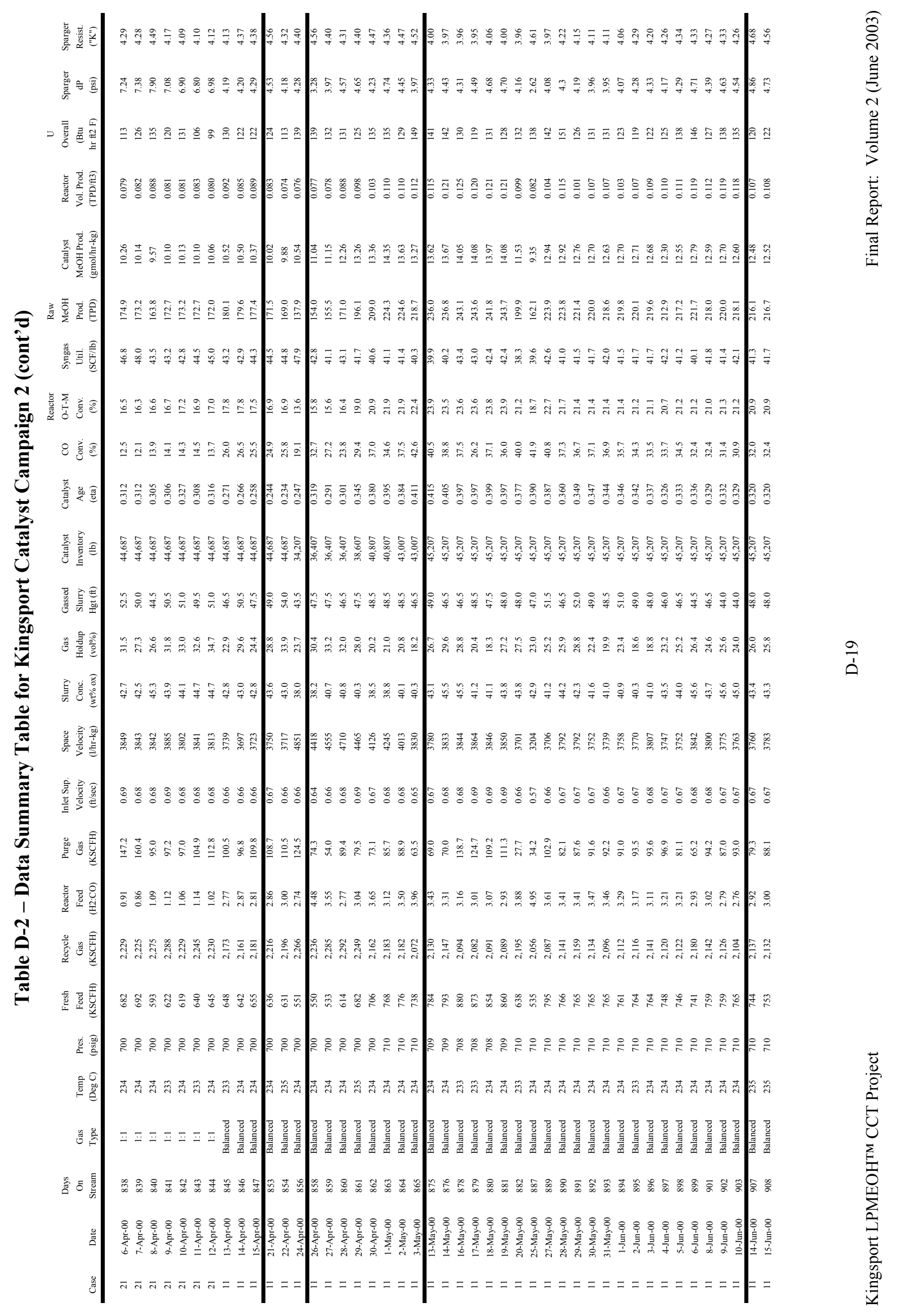




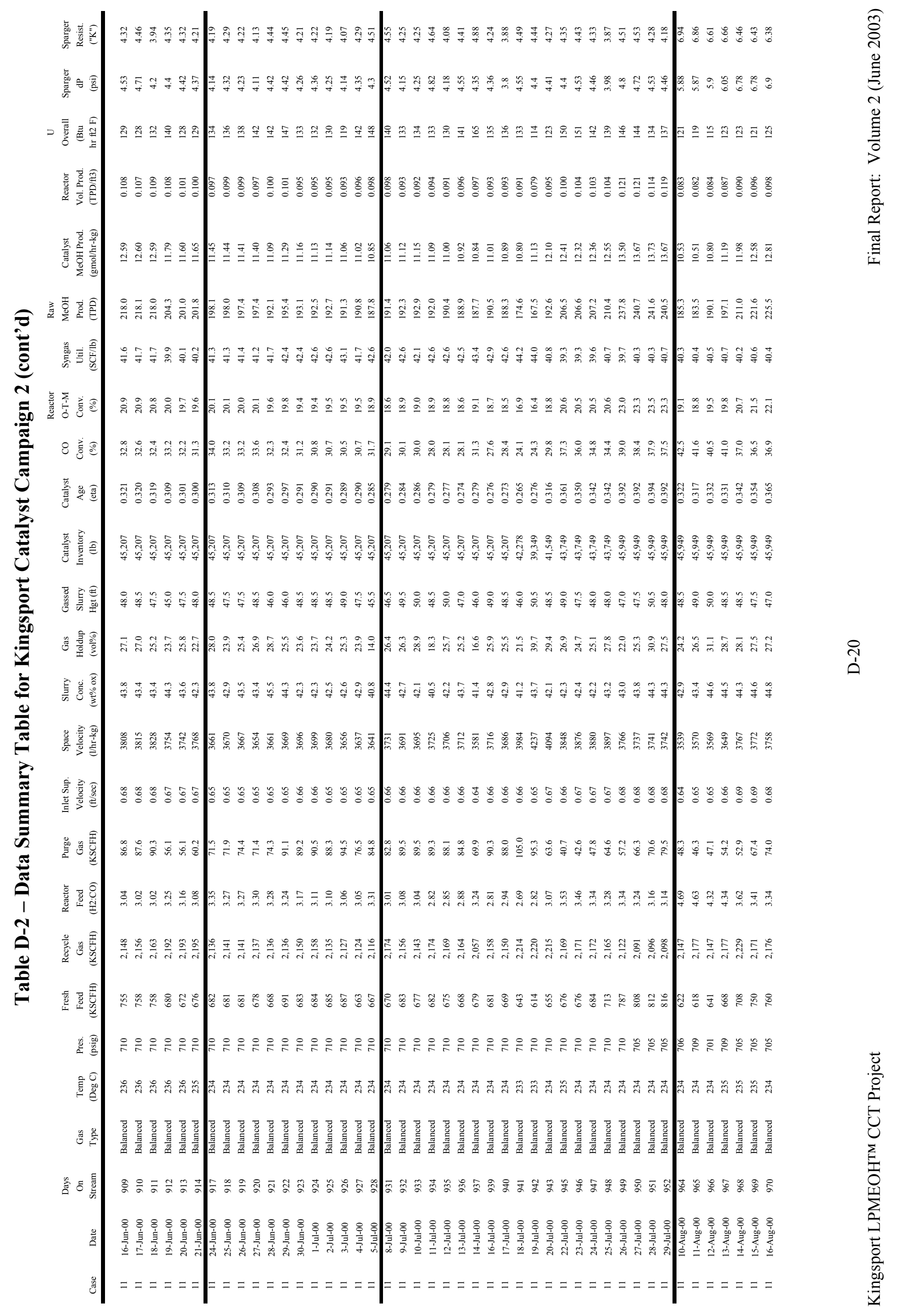




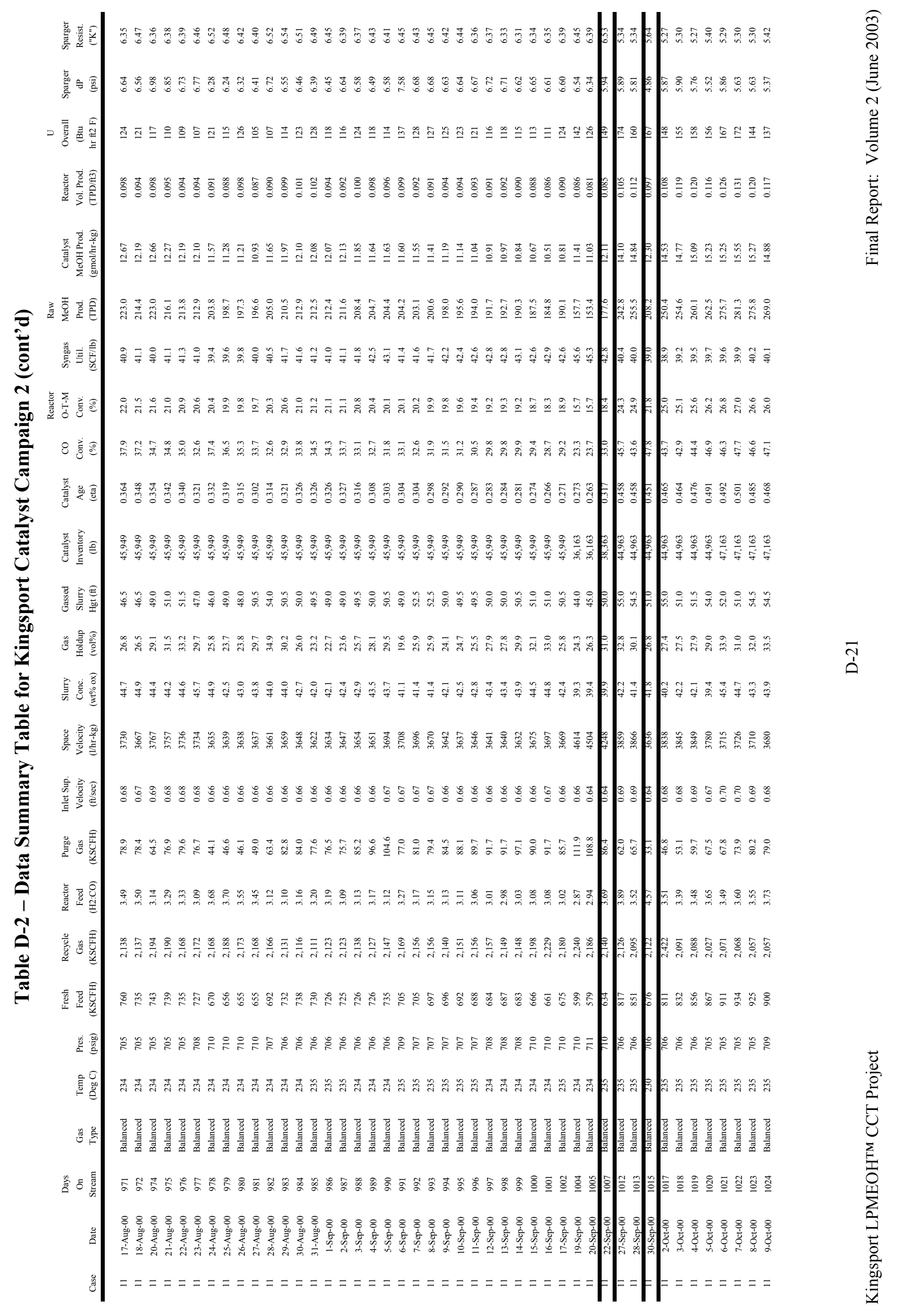




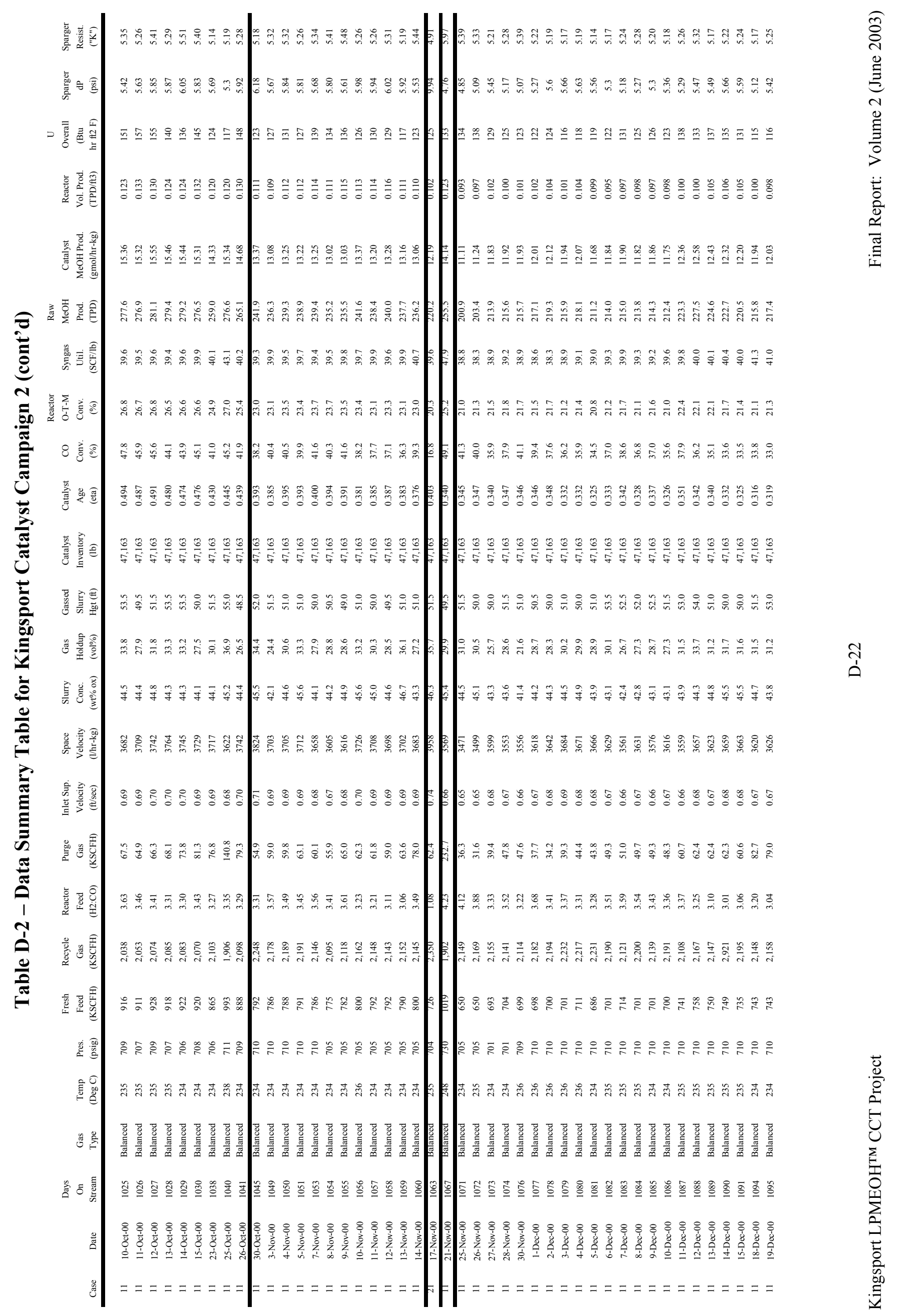




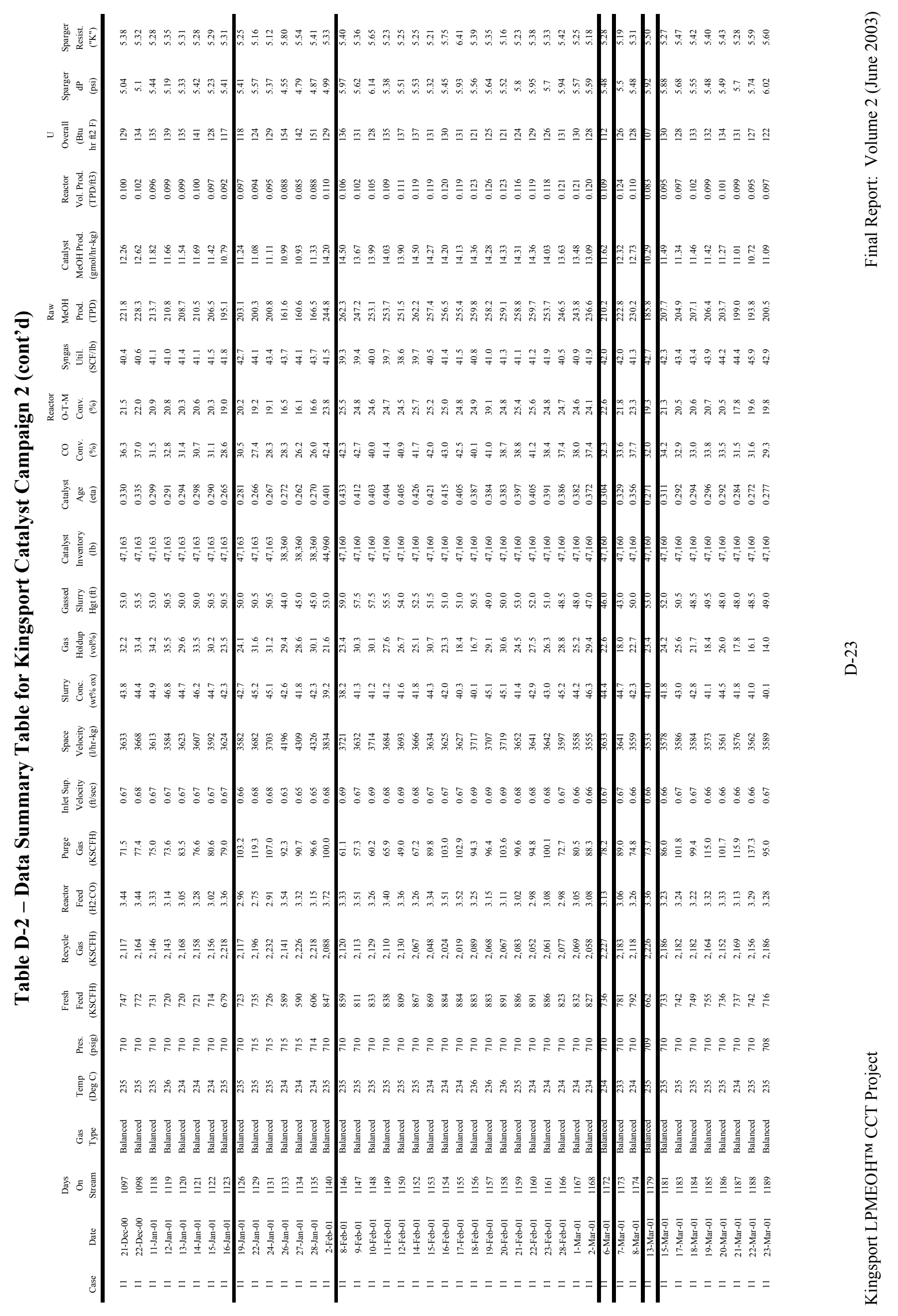




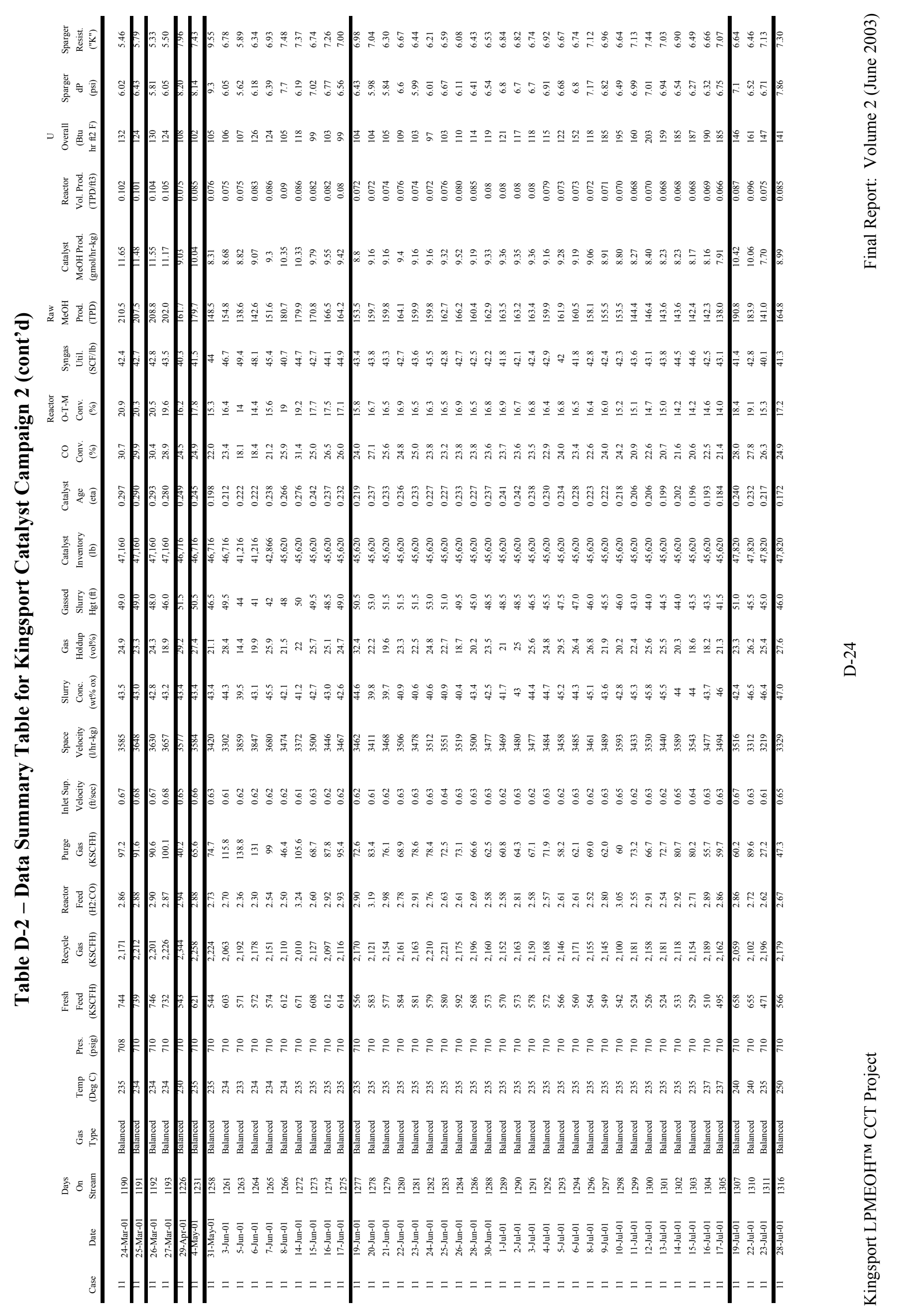




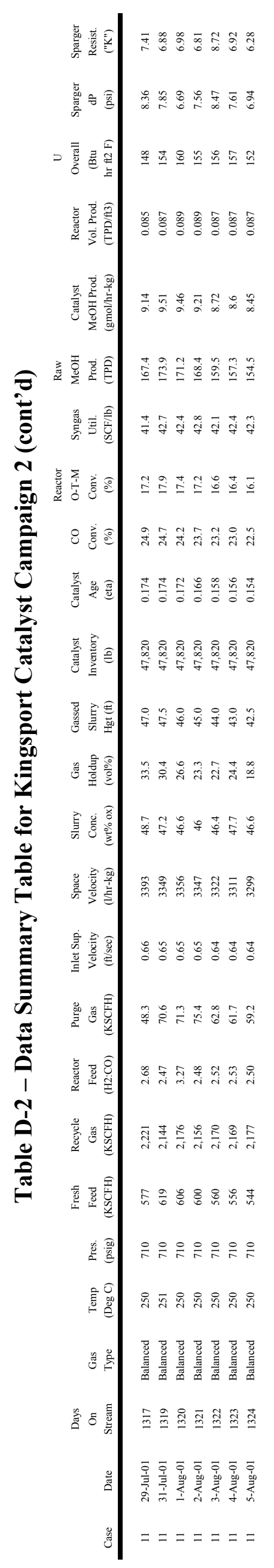




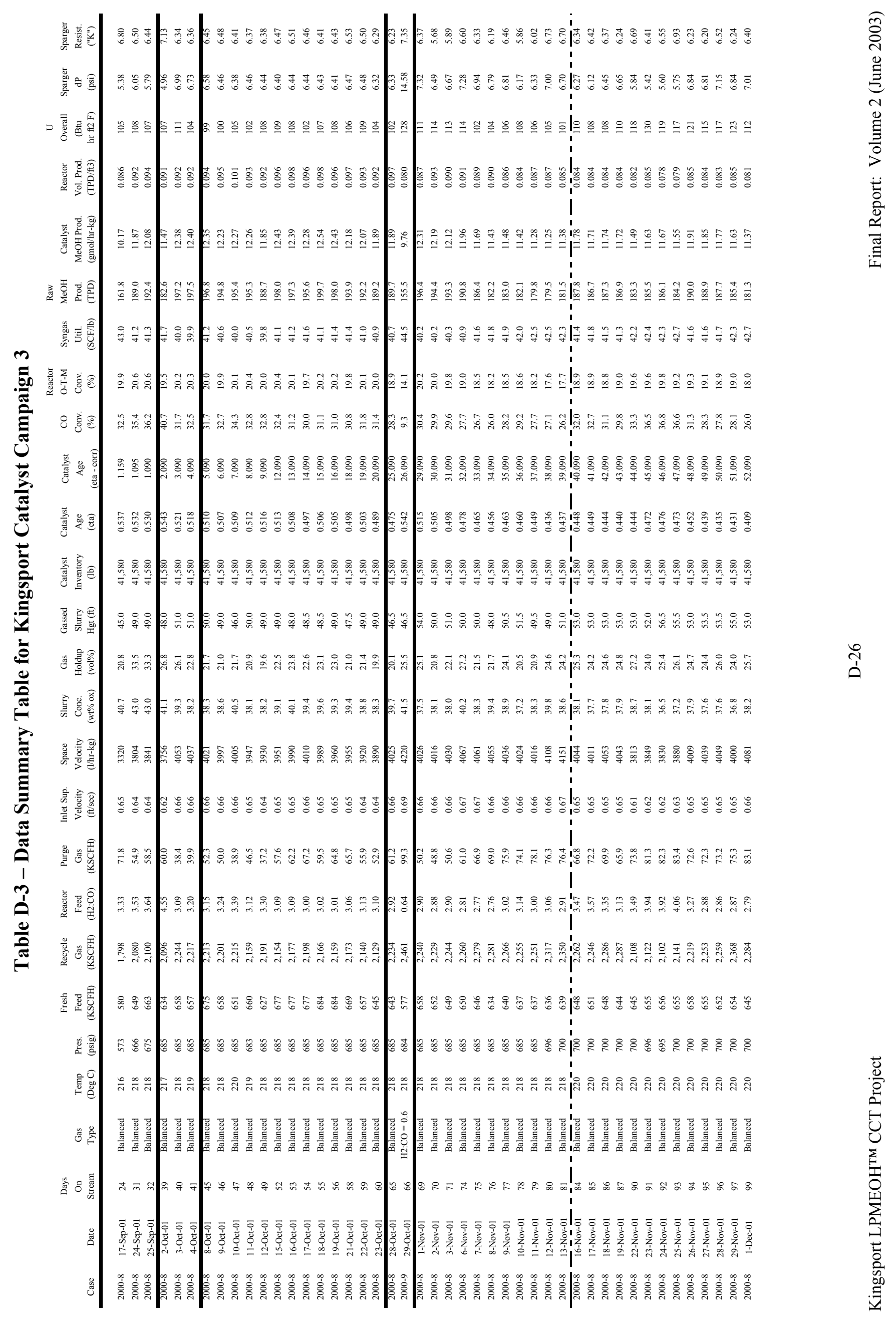




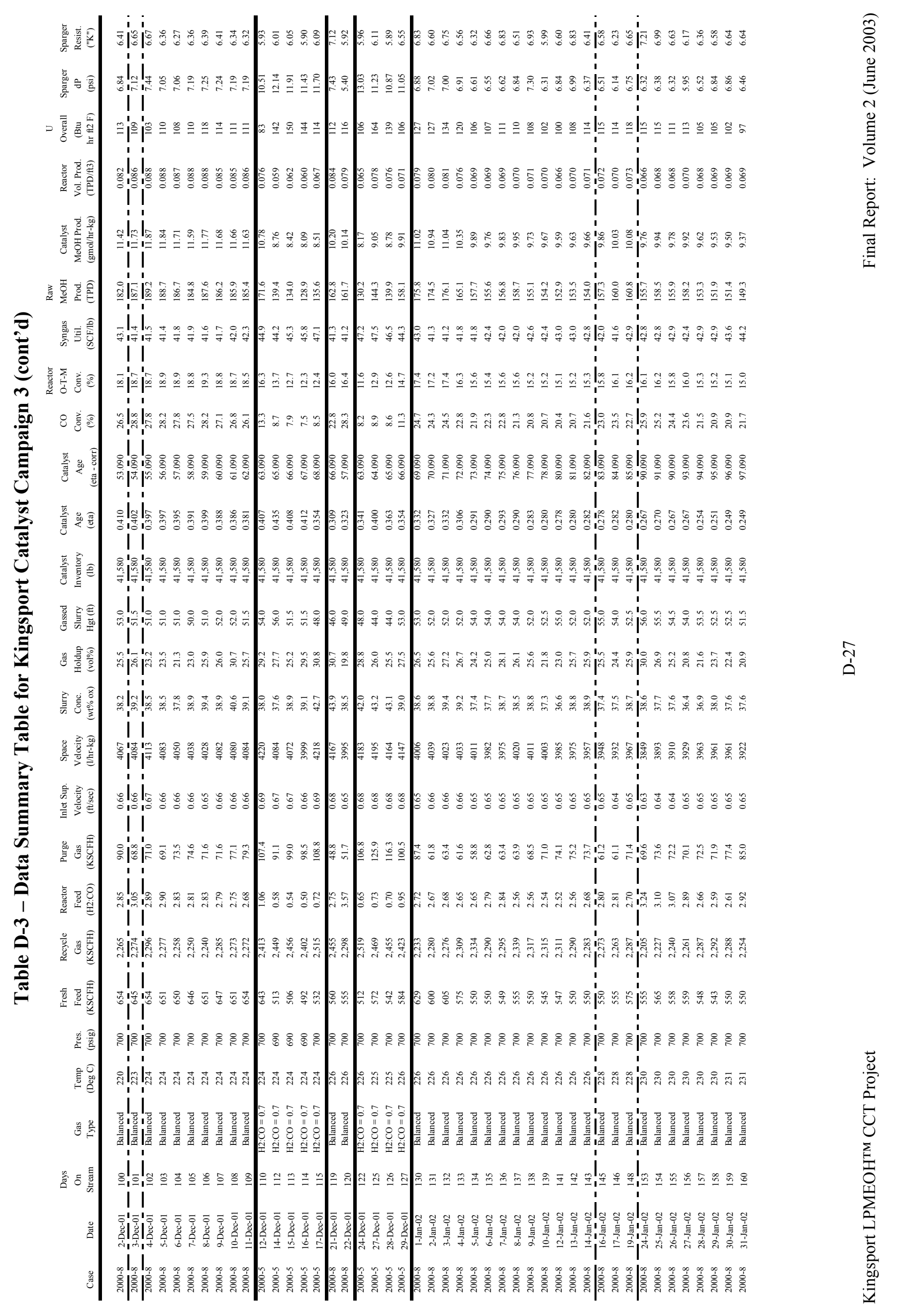




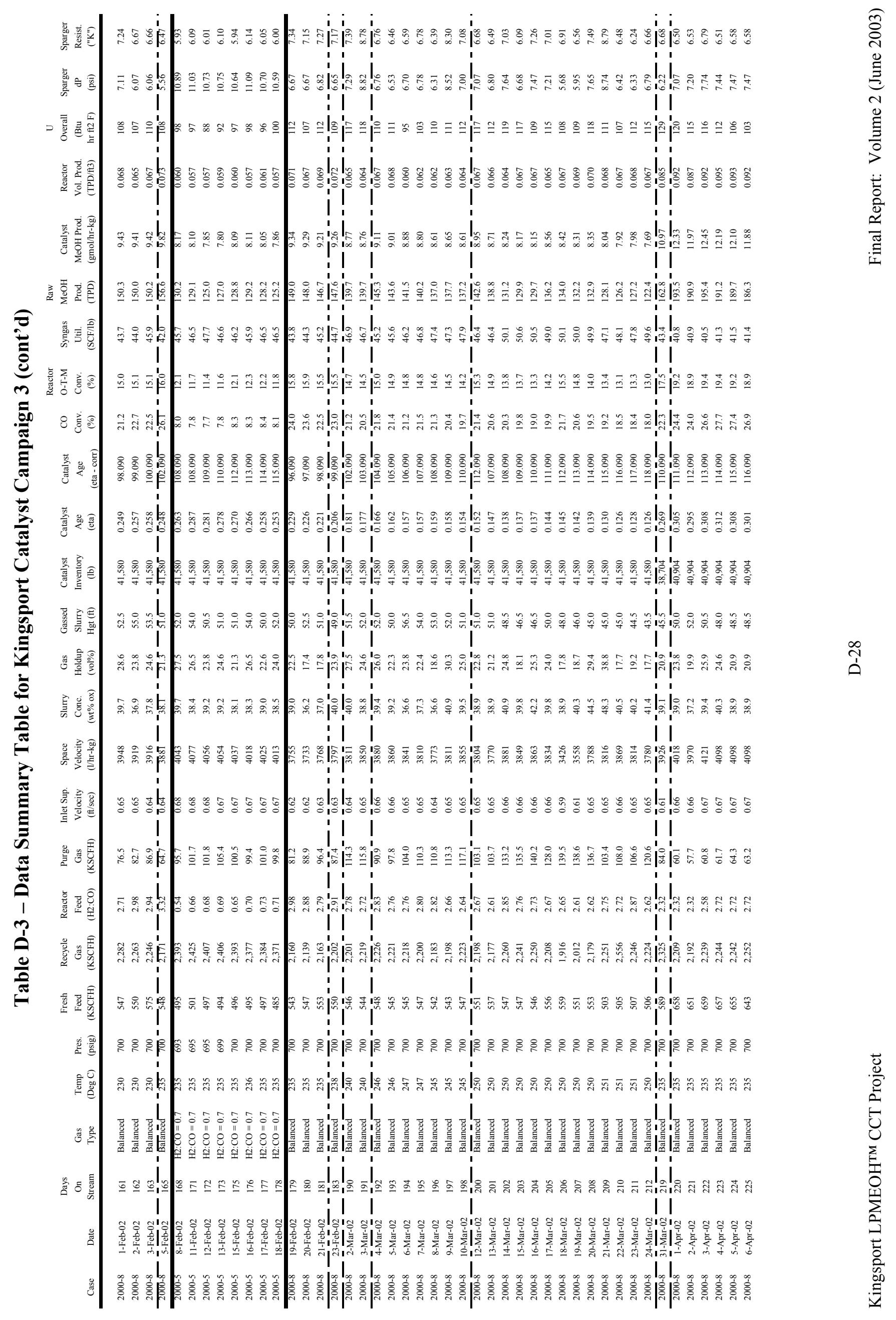




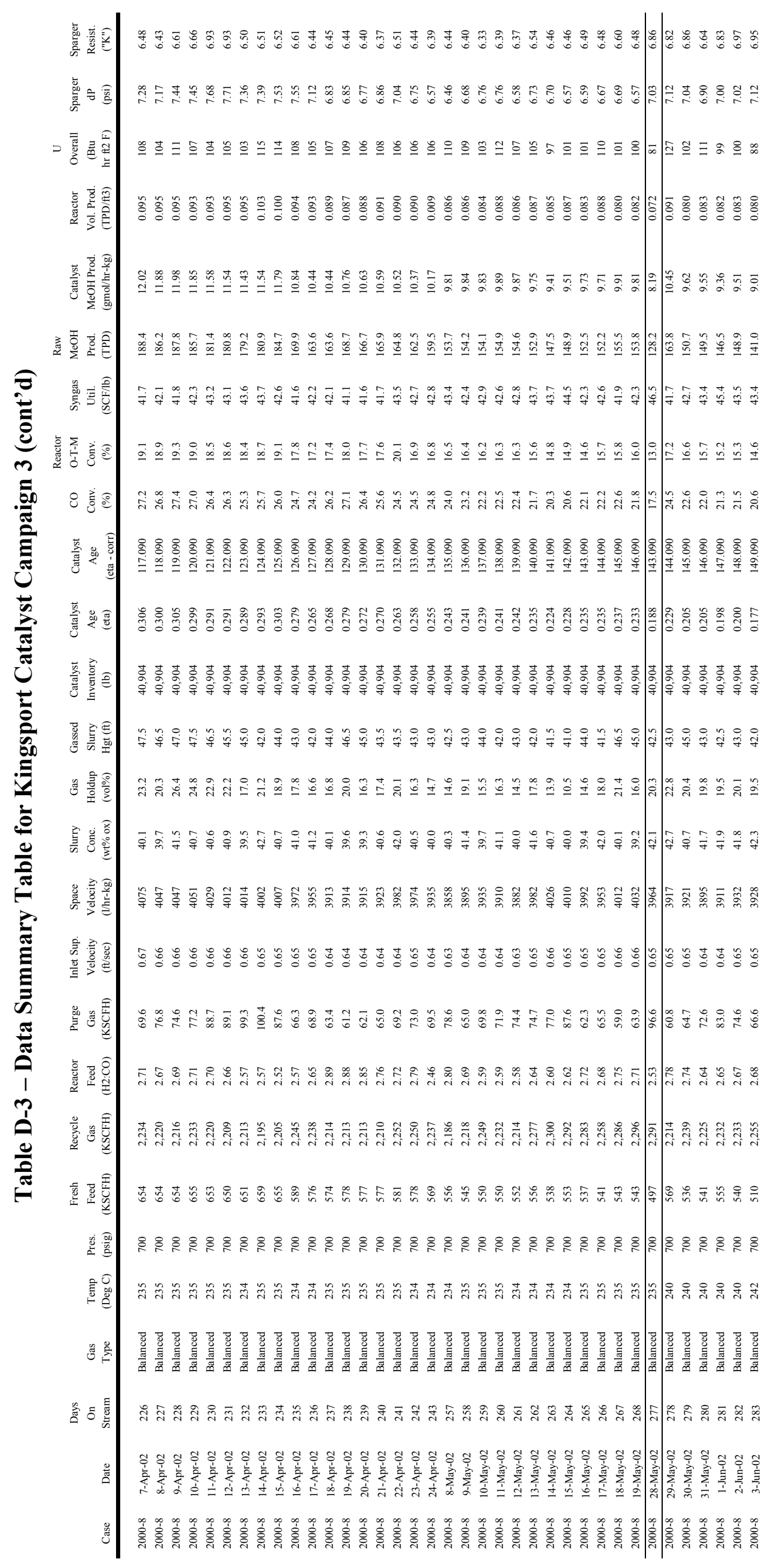




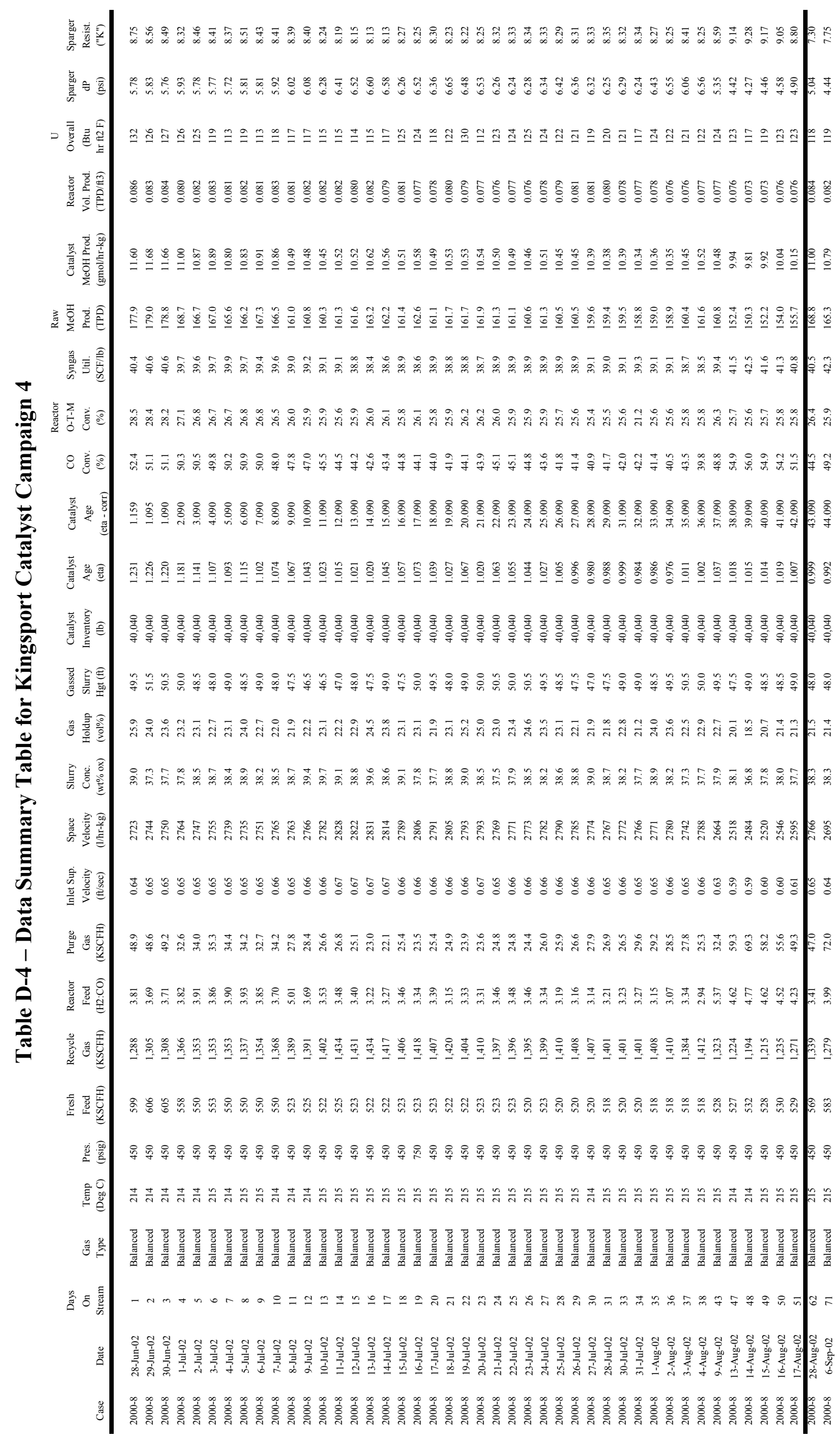




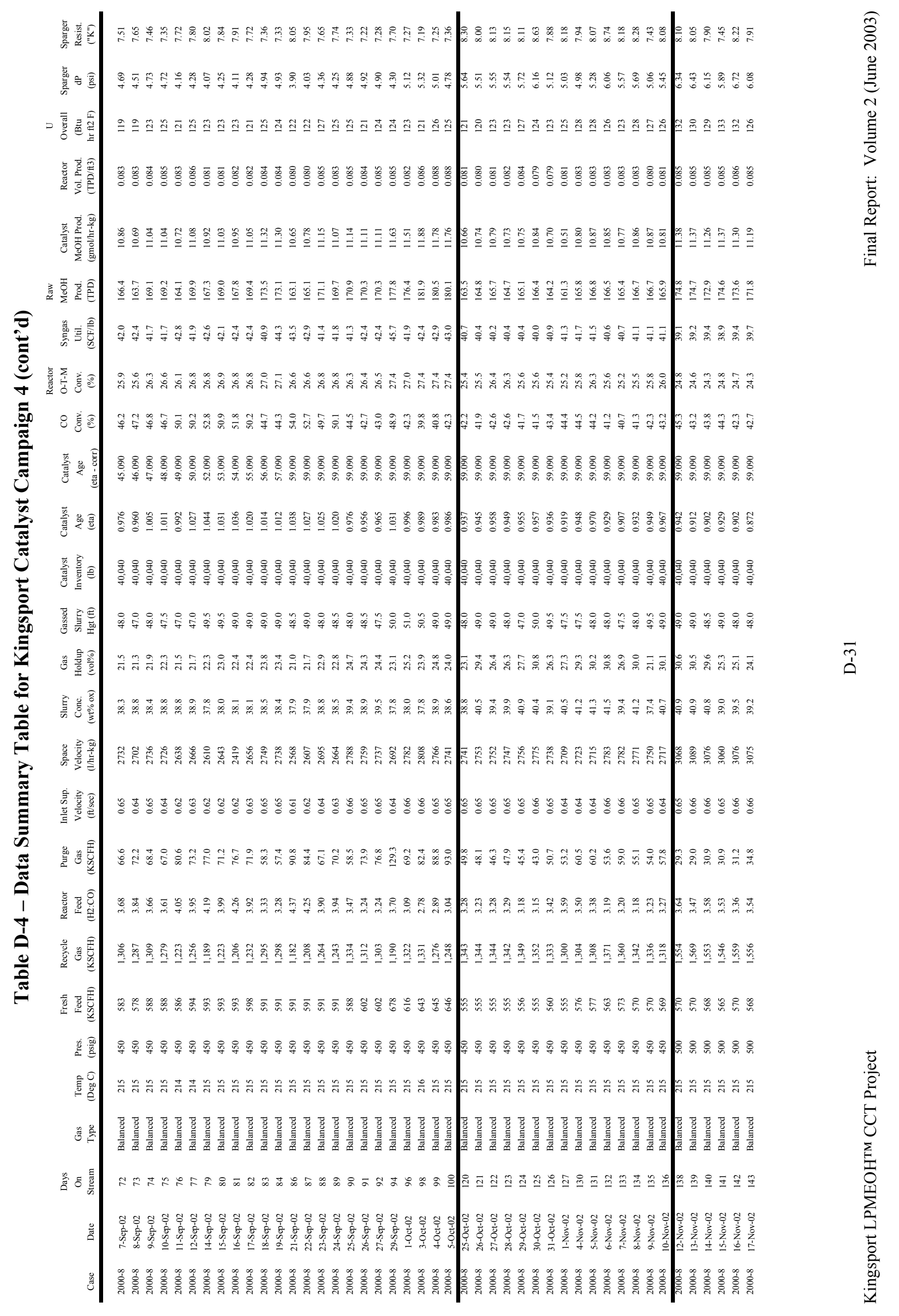




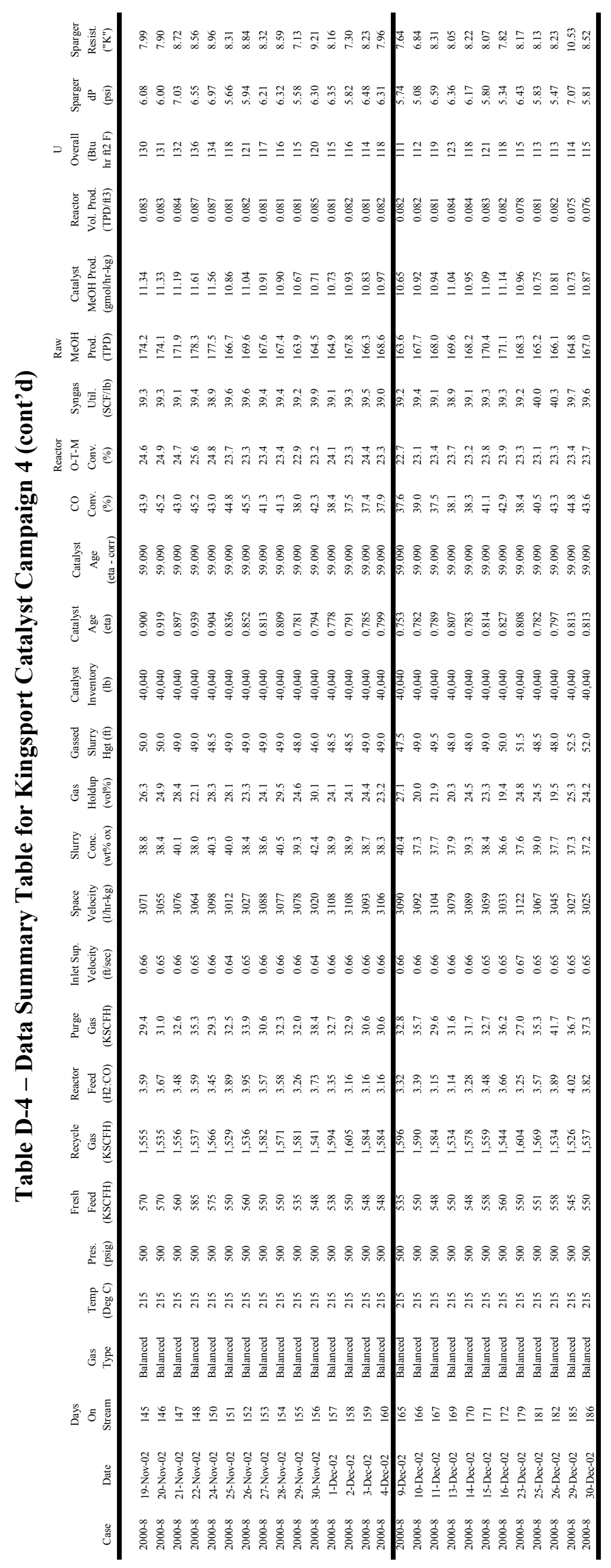

